\title{
TROPICAL PACIFIC RELATIONSHIPS WITH SOUTHERN HEMISPHERE ATMOSPHERIC CIRCULATION AND ANTARCTIC CLIMATE
}

BY

KYLE ROBERT CHRISTOPHER CLEM

\author{
A thesis \\ submitted to the Victoria University of Wellington \\ in partial fulfilment of the requirements for the degree of \\ Doctor of Philosophy
}

Victoria University of Wellington

2017 
Significant trends in high-latitude Southern Hemisphere atmospheric circulation and surface climate have been observed over recent decades, which are likely linked to teleconnections from the tropics. This study investigates how a recent shift in tropical Pacific climate toward increased La Niña conditions has influenced the atmospheric circulation and surface climate across the high southern latitudes, and how variations in the El Niño-Southern Oscillation (ENSO) and Southern Annular Mode (SAM) influence the surface climate of Antarctica.

Over 1979-2014, significant cooling of eastern tropical Pacific sea surface temperatures (SSTs) is detected in all seasons. The eastern tropical Pacific cooling is associated with: (1) an intensified Walker Circulation during austral summer and autumn; (2) a weakened South Pacific Hadley cell and sub-tropical jet during autumn; and (3) a strengthening of the circumpolar westerlies between 50 and $60^{\circ} \mathrm{S}$ during both summer and autumn. Observed cooling in the eastern tropical Pacific is linearly congruent with $60-80 \%$ of the observed positive zonal-mean zonal wind trend between 50 and $60^{\circ} \mathrm{S}$ during summer ( $\sim 35 \%$ of the interannual variability), and around half of the positive zonal-mean zonal wind trend during autumn ( $\sim 15 \%$ of the interannual variability), the latter being most marked over the South Pacific. Although previous studies have linked the strengthening of the tropospheric westerlies during summer and autumn to ozone depletion, results from this study indicate poleward momentum fluxes and strengthened lowertropospheric baroclinicity associated with eastern tropical Pacific cooling also help to maintain a strengthened mid-latitude jet through the $21^{\text {st }}$ century, especially across the South Pacific.

The La Niña shift in tropical Pacific SSTs is also significantly related to several changes in Antarctic surface climate. During autumn, a regional pattern of cooling occurred along coastal East Antarctica after 1979, with the rate of cooling increasing at Novolazarevskaya, Syowa, Casey, and Dumont d'Urville stations, while the rate of cooling decreased at Mawson and Davis stations. It is shown that regional circulation changes associated with tropical Pacific teleconnections project strongly onto the regional nature of the cooling trends, with $40 \%$ of the cooling at Novolazarevskaya and Syowa linearly congruent with the increased La Niña conditions, and more than $60 \%$ of the cooling at Casey and Dumont d'Urville linearly congruent with increased SSTs over the western tropical Pacific. The autumn La Niña pattern is associated 
with an anomalous anticyclone over the high-latitude South Atlantic that strengthens southwesterly winds and cold air advection across Novolazarevskaya and Syowa. Meanwhile, warming over the western tropical Pacific is associated with a meridional wavetrain stretching from southwest Australia to eastern East Antarctica and anomalous poleward momentum fluxes that locally strengthen westerly / southwesterly winds along and offshore of Casey and Dumont d'Urville, amplifying the cooling seen there.

During spring, a physical mechanism linking the West Antarctic warming to the tropical Pacific is identified. Spring warming of West Antarctica and the Antarctic Peninsula is associated with a significant increase in tropical deep convection on the poleward side of the South Pacific Convergence Zone. The increase in deep convection is strongest during September, during which a meridional wavetrain is seen over the western South Pacific with anomalous cyclonic circulation over the Ross Sea and warm, northerly flow to western West Antarctica. During October, the wavetrain propagates east toward the Antarctic Peninsula as the climatological background westerlies strengthen, which leads to increased warm, northerly flow to the western Antarctic Peninsula. Observed increases in deep convection along the South Pacific Convergence Zone during September are linearly congruent with over half of the observed circulation and surface warming trends seen across the West Antarctic region during September and October.

Lastly, this study finds a spatial dependency of the ENSO and SAM impact on Antarctic Peninsula climate. Variability in ENSO has a persistent and statistically significant relationship with western Peninsula climate only, which is strongest during the winter and spring seasons. Meanwhile, variability in the SAM dominates climate across the northeastern Peninsula during all seasons through the Föhn effect, and northeast Peninsula relationships with the tropics are relatively weak. In autumn, when widespread warming of the Antarctic Peninsula has been linked to the tropics, this study finds the tropical connection to be weak and statistically insignificant on interannual timescales, and regional circulation associated with the SAM dominates climate variability across the Peninsula during autumn. 


\section{ACKNOWLEDGEMENTS}

I would like to acknowledge the financial support of Victoria University of Wellington for a Victoria Scholarship, without which this $\mathrm{PhD}$ would not have been possible. I would like to thank my supervisors, Dr. James Renwick and Dr. Jim McGregor, for helpful discussions and feedback throughout my $\mathrm{PhD}$ and for providing me with financial support for publications. I would also like to acknowledge the American Meteorological Society, the Antarctic Research Centre, the International Conference on Southern Hemisphere Meteorology and Oceanography, the World Climate Research Programme-Climate and Cryosphere, and the West Antarctic Ice Sheet Initiative team for their financial support to attend conferences, which has helped me to grow as a scientist and provided me with opportunities to build collaborative networks.

I would like to take this opportunity to also thank my friends and family for their love and support over the past three years which has truly inspired and motivated me to persevere through the difficult times. This $\mathrm{PhD}$ would not have been possible without the loving support of my wife, Natalie, and my family: Rhonda, Bryan, Kelly, Doris, Ronald, Tom, Laura, and Michael; they are all role models in my life, and without their prayers, guidance, and encouragement this $\mathrm{PhD}$ would not have been possible. I would also like to thank my friend and colleague Ryan for his support, encouragement, and helpful discussions throughout my $\mathrm{PhD}$. I would like to especially thank my grandparents, Doris and Ronald, for believing in me and supporting me throughout my entire academic career. It is in this vein that I would like to dedicate this thesis to my grandparents, who never gave up on me and inspired and supported me throughout my academic career. 


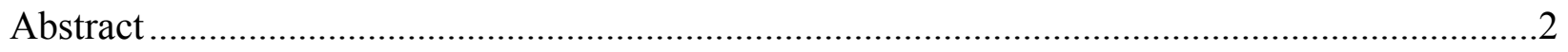

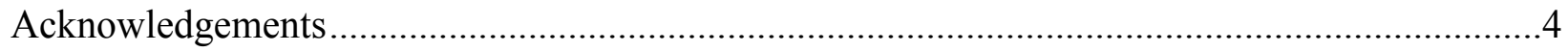

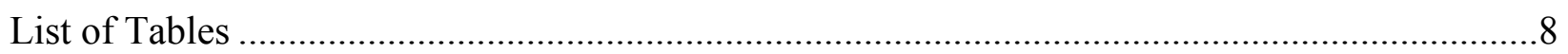

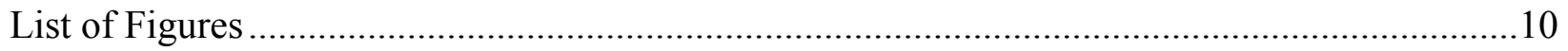

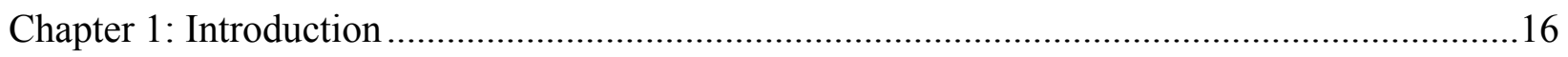

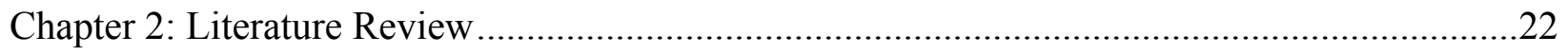

2.1 The El Niño-Southern Oscillation: Teleconnections and Trends .....................................22

2.2 The Southern Annular Mode: Dynamics and Trends ..................................................25

2.3 Antarctic Climate and Mass Balance: Variability and Trends.........................................29

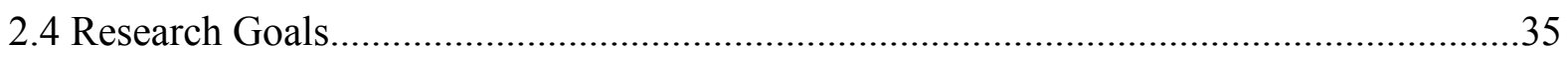

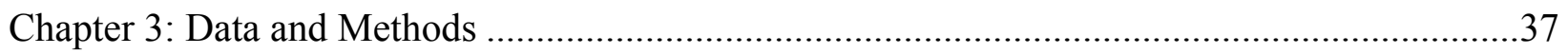

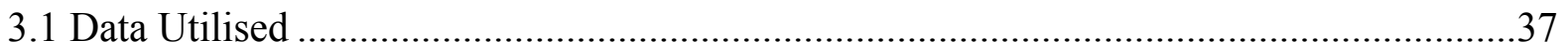

3.2 Analysis Techniques ................................................................................................

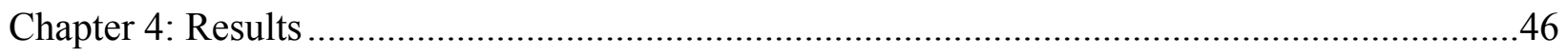

4.1 Tropical Pacific Relationships with Recent Trends in the SH Zonal-Mean Circulation ...46

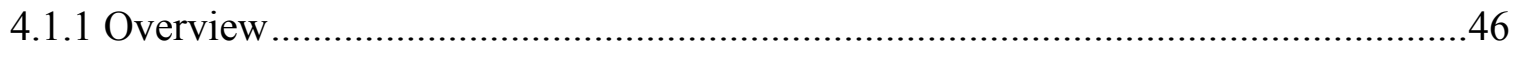

4.1.2 Seasonal Trends and Correlations.....................................................................

4.1.3 Spatial Trends in the SAM and SH Zonal-Mean Circulation during DJF and

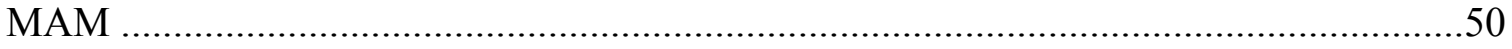

4.1.4 Zonal-Mean Zonal Wind Relationship with the Tropical Pacific.............................54

4.1.5 Eddy Momentum Forcing associated with Eastern Tropical Pacific SSTs ...............60

4.1.6 Thermal Forcing Associated with Eastern Tropical Pacific SSTs...........................67 
4.2 Tropical Pacific Relationship with East Antarctic Cooling during Austral Autumn.........70

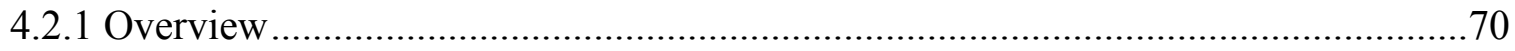

4.2.2 Seasonal Trends in East Antarctic Surface Temperatures ...................................71

4.2.3 Atmospheric Circulation Trends and Their Connection to East Antarctic Cooling and Large-Scale Climate Forcing ................................................................73

4.2.4 Tropical Pacific Composites and Relationships with East Antarctic Cooling..........84

4.3 Increased Deep Convection in the SPCZ and Relationship with West Antarctic

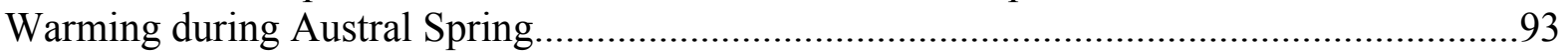

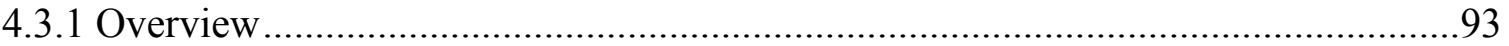

4.3.2 SON Seasonal and Monthly Trends...................................................................94

4.3.3 September and October Circulation Trends and Linear Relationships with the

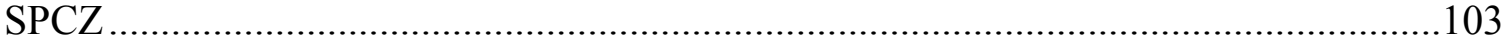

4.3.4 Atmospheric Composites and Correlations for September SPCZ OLR ................108

4.3.5 The SPCZ Teleconnection to the Southern Hemisphere .....................................111

4.4 The Relative Influence of ENSO and SAM on Antarctic Peninsula Climate.................115

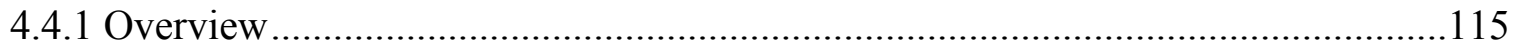

4.4.2 Seasonal and Spatial Influence of ENSO and SAM on Antarctic Peninsula

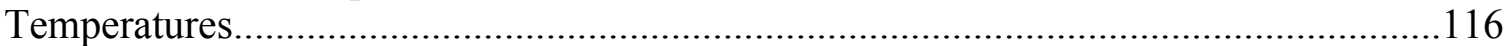

4.4.3 Regional Circulation Characteristics across the Peninsula and their Connection

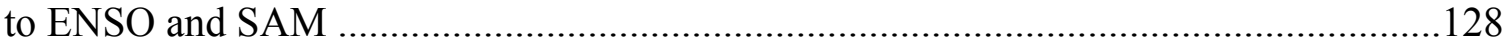

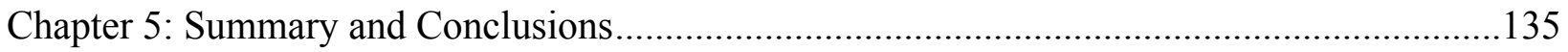

5.1 Tropical Pacific Relationships with Recent Trends in the SAM during Austral Summer and Autumn 135

5.2 Tropical Pacific Relationships with East Antarctic Cooling during Austral Autumn .....137

5.3 SPCZ Relationship with West Antarctic Warming during Austral Spring.....................138

5.4 Spatial Impacts of ENSO and SAM on Antarctic Peninsula Climate 139 
5.5 Concluding Remarks and Future Work ……………..................................................141

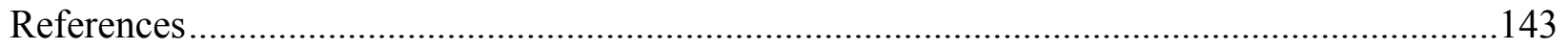




\section{LIST OF TABLES}

PAGE

Table 3.1: Antarctic meteorological stations used in the study, listed from west to east. Percent complete refers to percentage of monthly-mean values available following the inclusion rate of $90 \%$ or more of the routine daily observations being available for each month.

Table 4.1: Seasonal trends and 95\% confidence intervals, 1979-2014, for SOI, Niño 3.4 and eastern tropical Pacific (denoted by box in Fig. 4.1) SST, Marshall SAM index, Indian sector $\left(0^{\circ}-130.5^{\circ} \mathrm{E}\right) \mathrm{SAM}$ index, and Pacific sector $\left(150^{\circ} \mathrm{E}-85.5^{\circ} \mathrm{W}\right) \mathrm{SAM}$ index. Units for SOI and SAM index trends are standardised index decade ${ }^{-1}$, and units for SST trends are ${ }^{\circ} \mathrm{C}$ decade $^{-1}$. Trends significant at $p<0.10$ are boldface, trends significant at $p<0.05$ are boldface and underlined, and trends significant at $p<0.01$ are denoted with an asterisk.

Table 4.2: Seasonal detrended correlations, 1979-2014, of Marshall SAM index, Indian sector SAM index, and Pacific sector SAM index with the SOI and eastern tropical Pacific SSTs. Statistical significance of correlation coefficients is as denoted in Table 4.1.

Table 4.3: Top six positive Marshall SAM index years and bottom six cold eastern tropical Pacific SST years (rank order; $85^{\text {th }}$ and $15^{\text {th }}$ percentiles, respectively) used for compositing in Figs. 4.9-4.14. Years are selected for each season individually over the period 1979-2014. The standardised eastern tropical Pacific SST anomaly observed during each positive SAM year and the Marshall SAM index observed during each cold eastern tropical Pacific SST year is given in brackets.

Table 4.4: Seasonal trends and $95 \%$ confidence intervals for Antarctic station temperatures (units are ${ }^{\circ} \mathrm{C}$ decade $^{-1}$ ). Trends are calculated from the start of the record (see Table 3.1 for starting years) ending in 2014, and for 1979-2014. Trends significant at $p<0.10$ are boldface, $p<0.05$ are boldface and underlined, and $p<0.01$ are denoted with an asterisk.

Table 4.5: MAM detrended correlations, 1957-2014 or the start of the record, of coastal East Antarctic station temperatures (those exhibiting an increased rate of cooling after 1979) with the SOI and tropical SSTs in the Niño 3.4 , ATL3 $\left(4^{\circ} \mathrm{S}-2^{\circ} \mathrm{N}, 20^{\circ} \mathrm{W}-0^{\circ}\right)$, and equatorial Indian Ocean $\left(6^{\circ} \mathrm{S}-6^{\circ} \mathrm{N}, 60-88^{\circ} \mathrm{E}\right)$ regions, and Marshall (2003) SAM index. Statistical significance of correlations is denoted as in Table 4.4.

Table 4.6: The 1979-2014 MAM trends and 95\% confidence intervals for East Antarctic station temperatures (as in Table 4.4), the SOI, western tropical Pacific residual SST, and the Marshall (2003) SAM index (units of standardised index decade ${ }^{-1}$ for SOI and SAM index and ${ }^{\circ} \mathrm{C}_{\text {decade }}{ }^{-1}$ for station temperature and SST), and the portion / percentage (units of ${ }^{\circ} \mathrm{C}$ decade $^{-1}$ ) of the station temperature trends that is linearly congruent with the climate index trends. The western tropical Pacific region $\left(4^{\circ} \mathrm{S}-14^{\circ} \mathrm{N}, 122-144^{\circ} \mathrm{E}\right)$ is indicated by a black box in Figs. $4.15 \mathrm{c}$ and $4.17 \mathrm{a}$, and the residual is the SST time series remaining after linearly removing the SOI. Statistical significance of trends is denoted as in Tables 4.4-4.5. 
Table 4.7: Top six coldest MAM years (rank order; $15^{\text {th }}$ percentile) over 1979-2014 for Novo, Syowa, Casey, and Dumont, and top six highest SOI and warmest western tropical Pacific residual SST years (rank order, $85^{\text {th }}$ percentile). Also given for the station years are the ENSO / SAM phases based on when the climate index (SAM index and either the SOI or Niño 3.4 SST anomaly) is above or below the $70^{\text {th }}$ or $30^{\text {th }}$ percentile, respectively. EN=El Niño (negative SOI or positive Niño 3.4 SST anomaly) and LN=La Niña (positive SOI or negative Niño 3.4 SST anomaly)

Table 4.8: September and October temperature trends and 95\% confidence intervals, 1979-2014, for Byrd, Faraday, and Rothera stations (first column, units of ${ }^{\circ} \mathrm{C} \operatorname{decade}^{-1}$ ), and portion (second column, in units of ${ }^{\circ} \mathrm{C}$ decade ${ }^{-1}$ ) and percentage (third column) of these temperature trends linearly congruent with September OLR in the $25-32.5^{\circ} \mathrm{S}, 180-165^{\circ} \mathrm{W}$ region. Temperature trends (first column) significant at $p<0.10$ are boldface, and trends significant at $p<0.05$ are boldface and underlined.

Table 4.9: Seasonal detrended correlations of Antarctic Peninsula temperatures with the SOI, Niño 3.4 SST anomalies, and Marshall (2003) SAM index over 1979-2015. All Peninsula temperatures are the average of the five stations shown in Fig. 3.1: Rothera, Faraday, Bellingshausen, Marambio, and Esperanza. Western Peninsula temperature is the average of Rothera and Faraday, and northeast Peninsula temperature is the average of Esperanza and Marambio. Also given are detrended correlations with ASL magnitude, which is the minimum sea level pressure value in the region $55-75^{\circ} \mathrm{S}, 180-60^{\circ} \mathrm{W}$. Boldface correlations are significant at $\mathrm{p}<0.10$, boldface and underlined correlations are significant at $\mathrm{p}<0.05$, and correlations significant at $\mathrm{p}<0.01$ are denoted with an asterisk.

Table 4.10: Seasonal detrended partial correlations over 1979-2015 of Antarctic Peninsula temperatures with the SOI (after removing the SAM index) and the SAM index (after removing the SOI). Also given are detrended partial correlations with ASL magnitude, as in Table 4.9. Statistical significance of partial correlations is denoted as in Table 4.9.

Table 4.11: Top six warmest and coldest years (rank order; $85^{\text {th }}$ and $15^{\text {th }}$ percentiles, respectively) by season for western and northeast Peninsula temperatures used for compositing in Figs. 4.38-4.40. Also given is the observed average temperature $\left({ }^{\circ} \mathrm{C}\right)$ for each year and the ENSO / SAM phase. Phases are based on when the climate index (SAM index and either the SOI or Niño $3.4 \mathrm{SST}$ ) is above or below the $70^{\text {th }}$ or $30^{\text {th }}$ percentile, respectively. EN=El Niño (negative SOI or positive SST anomaly) and LN=La Niña (positive SOI or negative SST anomaly). Neutral implies that both ENSO and SAM were weak (their indices were between the $30^{\text {th }}$ and $70^{\text {th }}$ percentiles). 


\section{LIST OF FIGURES}

PAGE

Figure 1.1: Map of Antarctica and surrounding seas. .17

Figure 3.1: Map of the study area showing stations used and the ASL region. .38

Figure 4.1: Seasonal linear trends in HadISST tropical Pacific SST over 1979-2014 for (a) DJF, (b) MAM, (c) JJA, and (d) SON. Shading (from lightest to darkest) indicates regions where trends are statistically different from zero at $p<0.10, p<0.05$, and $p<0.01$, respectively, as indicated by color bar. Contour interval is $0.1^{\circ} \mathrm{C}$ decade $^{-1}$.

Figure 4.2: Linear trends in (a) DJF and (b) MAM ERA-Interim $500 \mathrm{hPa}$ geopotential height over 1979-2014. Statistical significance of trends is shaded as in Fig. 4.1. Contour interval is 4.0 m decade ${ }^{-1}$......

Figure 4.3: DJF linear trends in ERA-Interim zonal-mean zonal wind (contours) and zonal-mean vertical circulation (vectors) over 1979-2014 for (a) the full SH, (b) Pacific Ocean sector $\left(150^{\circ} \mathrm{E}-\right.$ $\left.85.5^{\circ} \mathrm{W}\right)$, and $(\mathrm{c})$ Indian Ocean sector $\left(0^{\circ}-130.5^{\circ} \mathrm{E}\right)$. Shading indicates statistical significance of zonal-mean zonal wind trends, and is drawn as in Figs. 4.1-4.2. Vectors are comprised of the zonal-mean meridional wind trend $\left(\mathrm{ms}^{-1}\right.$ decade $\left.^{-1}\right)$ and zonal-mean vertical velocity trend (hPa decade $^{-1}$; scaled by a factor of $-10^{2}$ ), and are drawn only if at least one vector component has a significant trend different from zero at $p<0.10$. Contour interval is $0.3 \mathrm{~ms}^{-1}$ decade $^{-1}$

Figure 4.4: As in Fig. 4.3, except for MAM.

Figure 4.5: Linear trends of DJF ERA-Interim zonal-mean zonal wind for (a) SH and (b) Pacific sector, as in Fig. 4.3a-b, and linear congruency of the trends with the DJF (c-d) SOI and (e-f) eastern tropical Pacific SST trends. Contours in (c-f) indicate the expected zonal-mean zonal wind trends $\left(\mathrm{ms}^{-1}\right.$ decade $\left.^{-1}\right)$ from the SOI and eastern tropical Pacific SST trends, and shading indicates the percentage of the statistically significant trends in (a-b) that is linearly congruent with the SOI and eastern tropical Pacific SST trends. Contour interval is $0.3 \mathrm{~ms}^{-1} \mathrm{decade}^{-1}$ for (ab) and $0.2 \mathrm{~ms}^{-1}$ decade $^{-1}$ with an additional contour at $\pm 0.1 \mathrm{~ms}^{-1}$ decade $^{-1}$ for (c-f). Zero contours

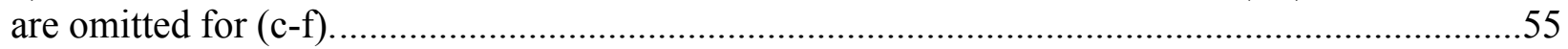

Figure 4.6: As in Fig. 4.5, except for MAM.................................................................56

Figure 4.7: DJF detrended partial correlation of eastern tropical Pacific SSTs (after removing the Marshall SAM index, left column, multiplied by -1) and Marshall SAM index (after removing eastern tropical SSTs, right column) with zonal-mean zonal wind, 1979-2014, for (a-b) full SH, (c-d) Pacific sector, and (e-f) Indian sector. Shading indicates statistical significance of correlations and is drawn as in Figs. 4.1-4.4. Contour interval is 0.1...

Figure 4.8: As in Fig. 4.7, except for MAM. 
Figure 4.9: Anomaly composite mean for the top six highest Marshall SAM index years during DJF over 1979-2014 for (a) SH, (b) Pacific sector, and (c) Indian sector. Shading indicates zonalmean zonal wind anomalies ( $\mathrm{ms}^{-1}$; contour interval provided in color bar). Zonal-mean total eddy momentum flux anomalies are drawn as thin contours (solid for positive, dashed for negative) and have a contour interval of $2.0 \mathrm{~m}^{2} \mathrm{~s}^{-2}$. Zonal-mean total eddy momentum flux meridional divergence anomalies are drawn as thick contours (solid for positive, dashed for negative) and have a contour interval of $0.2 \mathrm{~ms}^{-2}$. Zero contours are omitted for momentum flux and momentum flux divergence anomalies.

Figure 4.10: As in Fig. 4.9, but for the top six coldest SST years in the eastern tropical Pacific during DJF.

Figure 4.11: As in Figs. 4.9-4.10, except for the top six highest Marshall SAM index years during MAM.

Figure 4.12. As in Figs. 4.9-4.11, except for the top six coldest SST years in the eastern tropical Pacific during MAM.

Figure 4.13: Anomaly composite mean for the top six coldest SST years in the eastern tropical Pacific during DJF over 1979-2014 for (a) $850 \mathrm{hPa}$ zonal-mean temperature anomalies $\left({ }^{\circ} \mathrm{C}\right)$, (b) $850 \mathrm{hPa}$ zonal-mean meridional temperature gradient anomalies $\left({ }^{\circ} \mathrm{C} \mathrm{m}^{-1}\right.$; scaled by a factor of $10^{7}$ ), and (c) $300 \mathrm{hPa}$ zonal-mean zonal wind anomalies $\left(\mathrm{ms}^{-1}\right)$. Correlations between $850 \mathrm{hPa}$ zonal-mean meridional temperature gradient anomalies and $300 \mathrm{hPa}$ zonal-mean zonal wind anomalies by sector are shown in bottom left of (c).

Figure 4.14: As in Fig. 4.13, except for MAM.

Figure 4.15: MAM linear trend, 1979-2014, in (a) $500 \mathrm{hPa}$ geopotential height and $300 \mathrm{hPa}$ wind, (b) 2-m temperature, (c) tropical SST, and (d) $300 \mathrm{hPa}$ velocity potential. Wind vector trends ( $\mathrm{ms}^{-1}$ decade $^{-1}$; indicated by reference vector) are shown only if at least one component is significant at $p<0.10$. Contour interval for (a) is $3 \mathrm{~m} \mathrm{decade}^{-1}$, (b) is $0.3^{\circ} \mathrm{C} \mathrm{decade}^{-1}$, (c) is $0.1^{\circ} \mathrm{C}$ decade $^{-1}$, and (d) is $1 \times 10^{5} \mathrm{~m}^{2} \mathrm{~s}^{-1}$ decade $^{-1}$. Shading, from lightest to darkest, indicates trends that are statistically significant at $p<0.10, p<0.05$, and $p<0.01$, respectively, as referenced by the color bar. Station sites are shown as black circles. From left to right, station sites are: Halley, Neumayer, Novolazarevskaya, Syowa, Mawson, Davis, Mirny, Casey, and Dumont d'Urville..74

Figure 4.16: MAM linear trend, 1979-2014, in (a) sea ice concentration and 10-m wind, and (b) $500 \mathrm{hPa}$ meridional temperature advection $\left(-v^{\prime} \partial \mathrm{T} / \partial \mathrm{y}\right)$ and $500 \mathrm{hPa}$ wind. Wind vector trends $\left(\mathrm{ms}^{-1}\right.$ decade $^{-1}$; indicated by reference vector) are shown only if at least one component is significant at $p<0.10$. Contour interval for (a) is $4 \%$ decade $^{-1}$ and (b) is $1^{\circ} \mathrm{Cs}^{-1}$ decade $^{-1}$ (scaled by $10^{6}$ ) with zero contours omitted in (b). Shading indicates statistical significance of trends as in Fig. 4.15. Station sites are plotted as in Fig. 4.15.

Figure 4.17: MAM detrended correlations, 1979-2014, of Novo-Syowa (left column) and CaseyDumont (right column) mean temperatures with (a-b) tropical SST, (c-d) $500 \mathrm{hPa}$ streamfunction, (e-f) $300 \mathrm{hPa}$ zonal wind, and (g-h) $300 \mathrm{hPa}$ meridional wind. Correlation 
coefficients are multiplied by -1 except for (c-d) to show correct anomalies associated with negative East Antarctic temperature anomalies. Shading indicates statistical significance of correlations and is drawn as in Figs. 4.15-4.16. Contour interval is 0.2. Station sites are plotted as in Fig. 4.15.

Figure 4.18: Time series of MAM western tropical Pacific SST raw (red) and residual (blue) after removing the SOI. Also plotted are the respective trend lines.

Figure 4.19: (a) Linear trend in MAM $500 \mathrm{hPa}$ geopotential height (and significance), 19792014, as in Fig. 4.15c, and spatial linear congruency with (b) the SOI, (c) the western tropical Pacific residual SST, and (d) the SAM index trends. Contours in (b-d) show the $500 \mathrm{hPa}$ height trend pattern that is associated with the linear trend in the (b) SOI, (c) western tropical Pacific residual SST, and (d) SAM index, while shading in (b-d) indicates the percentage of the $500 \mathrm{hPa}$ height trends that is linearly congruent with the SOI, western tropical Pacific residual SST, and SAM index trends. Shading is drawn only where $500 \mathrm{hPa}$ height trends are significant at $p<0.10$. Contour interval for (b-d) is $2 \mathrm{~m}_{\text {decade }}{ }^{-1}$. Black dots denote the locations of surface observing stations.

Figure 4.20: As in Fig. 4.19, except for East Antarctic 2-m temperature. Contour interval for (bd) is $0.1^{\circ} \mathrm{C}$ decade $^{-1}$.

Figure 4.21: MAM anomaly composite mean for the six coldest years at Novo (left column) and the six highest SOI years (right column) during 1979-2014. (a-b) Tropical SST, (c-d) $300 \mathrm{hPa}$ velocity potential, (e-f) $500 \mathrm{hPa}$ streamfunction (multiplied by -1, contour labels omitted) and $300 \mathrm{hPa} \mathbf{E u}$, and (g-h) $500 \mathrm{hPa}$ geopotential height and $300 \mathrm{hPa}$ wind. The MAM years used for compositing are given in Table 4.7. Shading indicates significance of anomalies and is drawn as in Figs. 4.15-4.17. Contour interval for (a-b) is $0.2^{\circ} \mathrm{C}$, (c-d) is $2 \times 10^{5} \mathrm{~m}^{2} \mathrm{~s}^{-1}$, (e-f) is $1 \times 10^{6} \mathrm{~m}^{2} \mathrm{~s}^{-1}$, and $(\mathrm{g}-\mathrm{h})$ is $20 \mathrm{~m}$. Eu vector and $300 \mathrm{hPa}$ wind vector anomalies are shown only if at least one component is significant at $p<0.10$.

Figure 4.22: As in Fig. 4.21, except for the six coldest MAM years at Dumont (left column) and the six warmest western tropical Pacific residual SST years during MAM (right column)..........86

Figure 4.23: MAM detrended correlation, 1979-2014, of western tropical Pacific OLR (115$155^{\circ} \mathrm{E}, 20^{\circ} \mathrm{S}-7.5^{\circ} \mathrm{N}$ ) with (a) $500 \mathrm{hPa}$ geopotential height and (b) 2-m temperature. (c) The detrended, standardised time series of western tropical Pacific OLR and Novo-Syowa mean temperature. The correlation of the two time series is given in the bottom left of (c). Contour interval for (a-b) is 0.1 , and the zero and \pm 0.1 contours are omitted in (b). Shading in (a-b) indicates statistical significance of correlations as in Figs. 4.15-4.17. Only Novo and Syowa station sites are plotted.

Figure 4.24: As in Fig. 4.23, except for OLR over the eastern Indian Ocean $\left(90-122.5^{\circ} \mathrm{E}, 15^{\circ} \mathrm{S}-\right.$ $5^{\circ} \mathrm{N}$ ) and for Casey-Dumont mean temperature. Only Casey and Dumont station sites are plotted. 
Figure 4.25: 1979-2014 MSLP and 10-m wind trends for a) SON-average, b) September, c) October, and d) November. Shading (from lightest to darkest) indicates trends that are statistically different from zero at $p<0.10, p<0.05$, and $p<0.01$, respectively. Wind trends ( $\mathrm{ms}^{-1}$ decade $^{-1}$; indicated by reference vector) are only displayed if at least one component is significant at $p<0.10$. Contour interval is $0.4 \mathrm{hPa}$ decade $^{-1}$.

Figure 4.26: As in Fig. 4.25, except for 2-m temperature across the West Antarctic and Antarctic Peninsula region. Contour interval is $0.4^{\circ} \mathrm{C}$ decade $^{-1}$.

Figure 4.27: As in Figs. 4.25-4.26, except for HadISST sea ice concentrations across the West Antarctic and Antarctic Peninsula region. Contour interval is $5 \%$ decade $^{-1}$

Figure 4.28: As in Figs. 4.25-4.27, except for $500 \mathrm{hPa}$ meridional temperature advection ( $-v^{\prime}$ $\partial \mathrm{T} / \partial \mathrm{y}$ ) and $500 \mathrm{hPa}$ wind (vectors). Contour interval is $2.0^{\circ} \mathrm{C} \mathrm{s}^{-1}$ decade $^{-1}$ (scaled $10^{6}$ ) and zero contours are omitted.

Figure 4.29: As in Figs. 4.25-4.28, except for OLR over the tropical Pacific region. The annualaverage SPCZ region is drawn as a black line in all panels, and the September OLR region used for area-averaging is drawn as a red box in panel b). Contour interval is $1.0 \mathrm{~W} \mathrm{~m}^{-2} \mathrm{decade}^{-1}$, and zero contours are omitted.

Figure 4.30: Spatial linear congruency of the a) September and b) October MSLP trends with September OLR area-averaged over the $25-32.5^{\circ} \mathrm{S}, 180-165^{\circ} \mathrm{W}$ region (red box in Fig. $4.29 \mathrm{~b}$ ). Contours indicate the MSLP trend that is linearly congruent with the September OLR trend $\left(\mathrm{hPa}\right.$ decade $\left.^{-1}\right)$. Shading indicates the percentage of the statistically significant MSLP trends that is linearly congruent with the September OLR. Shading is only shown where trends are statistically significant at $p<0.10$. Contour interval is $0.3 \mathrm{hPa}$ decade $^{-1}$

Figure 4.31: As in Fig. 4.30, but for 2-m temperature trends $\left({ }^{\circ} \mathrm{C}\right.$ decade $\left.{ }^{-1}\right)$ across the West Antarctic and Antarctic Peninsula region. Contour interval is $0.2^{\circ} \mathrm{C}$ decade ${ }^{-1}$........

Figure 4.32: Anomaly composite mean for the six years of lowest September OLR averaged over the $25-32.5^{\circ} \mathrm{S}, 180-165^{\circ} \mathrm{W}$ region over the period $1979-2014$. The six years of lowest September OLR used for compositing include: $2007\left(231.5 \mathrm{~W} \mathrm{~m}^{-2}\right), 2008\left(222.1 \mathrm{~W} \mathrm{~m}^{-2}\right), 2009$ $\left(231.6 \mathrm{~W} \mathrm{~m}^{-2}\right), 2010\left(231.9 \mathrm{~W} \mathrm{~m}^{-2}\right), 2012\left(227.6 \mathrm{~W} \mathrm{~m}^{-2}\right)$, and $2014\left(230.4 \mathrm{~W} \mathrm{~m}^{-2}\right)$. The a) September and b) October MSLP and 10-m wind anomalies for the six years are calculated from the respective 1981-2010 September and October climatological means. Shading (from lightest to darkest) indicates MSLP anomalies (hPa) that are statistically different than zero at $p<0.10$, $p<0.05$, and $p<0.01$, respectively, and $10-\mathrm{m}$ wind anomalies $\left(\mathrm{ms}^{-1}\right.$; indicated by reference vector) are only plotted if at least one of the wind components is significant at the $p<0.10$ level. Contour interval is $1.0 \mathrm{hPa}$.

Figure 4.33: Detrended correlation of September OLR with a) September and b) October MSLP. Correlation coefficients (contours) are multiplied by negative one to reflect pressure anomalies associated with anomalous deep convection. Shading (from lightest to darkest) indicates 
correlation coefficients that are statistically different from zero at $p<0.10, p<0.05$, and $p<0.01$,

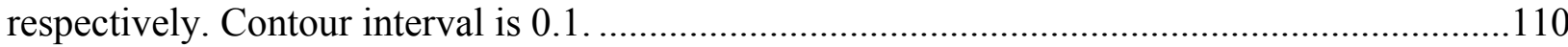

Figure 4.34: Detrended correlation, 1979-2014, of OLR in the September region (25-32.5 $5^{\circ}$, $180-165^{\circ} \mathrm{W}$ ) with MSLP for a) DJF, b) MAM, c) JJA, and d) SON. Correlation coefficients and statistical significance are drawn as in Fig. 4.33. Contour interval is 0.2 .

Figure 4.35: Detrended correlation, 1979-2014, of SON OLR in the a) northwest SPCZ region $\left.\left(10-20^{\circ} \mathrm{S}, 155^{\circ} \mathrm{E}-180^{\circ} \mathrm{E}\right), \mathrm{b}\right)$ middle SPCZ region $\left(15-25^{\circ} \mathrm{S}, 165^{\circ} \mathrm{E}-170^{\circ} \mathrm{W}\right)$, and c) southeast SPCZ region $\left(25-35^{\circ} \mathrm{S}, 170^{\circ} \mathrm{E}-165^{\circ} \mathrm{W}\right)$ with SON MSLP. OLR regions used for area-averaging are drawn as a red box in each panel. Correlation coefficients and statistical significance are plotted as in Fig. 4.33-34. Contour interval is 0.2.

Figure 4.36: Detrended seasonal correlations of western (left column) and northeast (right column) Antarctic Peninsula temperatures with HadISST tropical SST (top panels) and ERAInterim $500 \mathrm{hPa}$ geopotential height (bottom panels) for (a-b) DJF, (c-d) MAM. Correlation coefficients are contoured (contour interval is 0.2 and zero contours are omitted for SST correlations), and statistical significance of correlations at the $p<0.10, p<0.05$, and $p<0.01$ is shaded (indicated by reference color bar at bottom).

Figure 4.37: As in Fig. 4.36, except for (a-b) JJA and (c-d) SON seasons.

Figure 4.38: Anomaly composite mean for the six warmest years on the western (left column) and northeast (right column) Peninsula during MAM over 1979-2015. (a-b) $300 \mathrm{hPa}$ velocity potential anomalies (contour interval is $2 \times 10^{5} \mathrm{~m}^{2} \mathrm{~s}^{-1}$ ), (c-d) inverted $500 \mathrm{hPa}$ streamfunction anomalies (contour interval is $1 \times 10^{6} \mathrm{~m}^{2} \mathrm{~s}^{-1}$ ), (e-f) $500 \mathrm{hPa}$ geopotential height and $300 \mathrm{hPa}$ wind anomalies (contour interval is 20 metres and wind anomalies are indicated by reference vector in $\mathrm{ms}^{-1}$ ), and (g-h) $925 \mathrm{hPa}$ meridional temperature advection (-v $\left.\partial \mathrm{T} / \partial \mathrm{y}\right)$ and $925 \mathrm{hPa}$ wind anomalies (contour interval is $0.5 \times 10^{5}{ }^{\circ} \mathrm{C} \mathrm{s}^{-1}$ and wind anomalies are indicated by reference vector in $\mathrm{ms}^{-1}$ ). Statistical significance of anomalies is shaded as in Figs. 4.36-4.37. Vectors are plotted only if at least one component of the wind anomaly is significant at the $\mathrm{p}<0.10$ level...125

Figure 4.39: As in Fig. 4.38, except for the six warmest years during JJA

Figure 4.40: Anomaly composite mean of northern Peninsula (meridionally averaged over 64.5$67.5^{\circ} \mathrm{S}$ ) meridional wind (contours) and zonal vertical circulation (vectors) for the six warmest years on the western (left column) and northeast (right column) Peninsula for (a-b) DJF, (c-d) MAM, (e-f) JJA, and (g-h) SON. Contour interval for meridional wind anomalies is $0.5 \mathrm{~ms}^{-1}$, and statistical significance of meridional wind anomalies is shaded as in Figs. 4.38-4.39. Vectors are comprised of the zonal wind and omega anomalies (scaled $-10^{2}$ ), and vectors are only plotted if at least component is significant at $p<0.10$. Wind and omega data are from ERA-Interim employed at $0.75^{\circ}$ latitude-longitude resolution. Anomalies and significance are calculated after data are meridionally averaged.

Figure 4.41: Detrended partial correlations of SOI (after removing the SAM index, left column) and SAM index (after removing the SOI, right column) with $700 \mathrm{hPa}$ zonal wind for (a-b) DJF, 
(c-d) MAM, (e-f) JJA, and (g-h) SON. Contour interval is 0.1 and statistical significance of correlations is plotted as in Figs. 4.36-4.37 ..............................................................................131

Figure 4.42: As in Fig. 4.41, except for 700 hPa meridional wind.........................................132 


\section{CHAPTER 1: INTRODUCTION}

Antarctica and the Southern Ocean are a critical component of the global climate system. Antarctica consists of a massive grounded ice sheet that comprises the region poleward of $\sim 65^{\circ} \mathrm{S}$. The Antarctic ice sheet is the greatest potential source of global sea level rise on the planet, and portions of the ice sheet are rapidly retreating and raising global sea levels on the order of 10-20 $\mathrm{mm}_{\text {year }}{ }^{-1}$, and the retreat may only intensify in coming decades (e.g., DeConto and Pollard 2016; Joughin et al. 2014; Shepherd et al. 2012). The Southern Ocean also plays a crucial role in the global climate system, particularly through the uptake of carbon dioxide due to strong and persistent upwelling of deep ocean water that effectively absorbs atmospheric carbon dioxide (e.g., Landschützer et al. 2015). Therefore, future global sea levels and atmospheric carbon dioxide concentrations are highly dependent on variability in the high-latitude Southern Hemisphere climate system and feedback mechanisms, and understanding current and past climate variability in this region is paramount to accurately predicting future changes.

Significant trends in high-latitude Southern Hemisphere atmospheric circulation and surface climate have been observed since the 1950s which marks the beginning of many instrumental records in the Antarctic. Trends include a significant strengthening of the circumpolar westerlies, significant warming of West Antarctica and the Antarctic Peninsula, and slight cooling over East Antarctica (e.g., Jones et al. 2016a). A map of the Antarctic continent and its surrounding seas is given in Fig. 1.1.

The strengthening of the circumpolar westerlies is seen during the austral summer and autumn seasons (Kidson 1999; Thompson et al. 2000; Thompson and Solomon 2002; Marshall 2003). It is primarily linked to decreases in stratospheric ozone concentration over Antarctica during austral spring, which cools the polar stratosphere and increases the upper-tropospheric temperature gradient between the middle and high latitudes, in turn strengthening the polar vortex during spring (Thompson and Solomon 2002; Gillett and Thompson 2003). The positive zonal wind anomalies in the stratosphere propagate downward into the troposphere during the following summer months, which has caused summer warming of the northeast Peninsula through the Föhn effect (Marshall et al. 2006; Orr et al. 2008). The surface warming on the northeast Peninsula has caused dramatic changes in the cryosphere, with portions of the Larsen Ice Shelf collapsing in the early 2000s and a rapid acceleration and thinning of outlet glaciers 


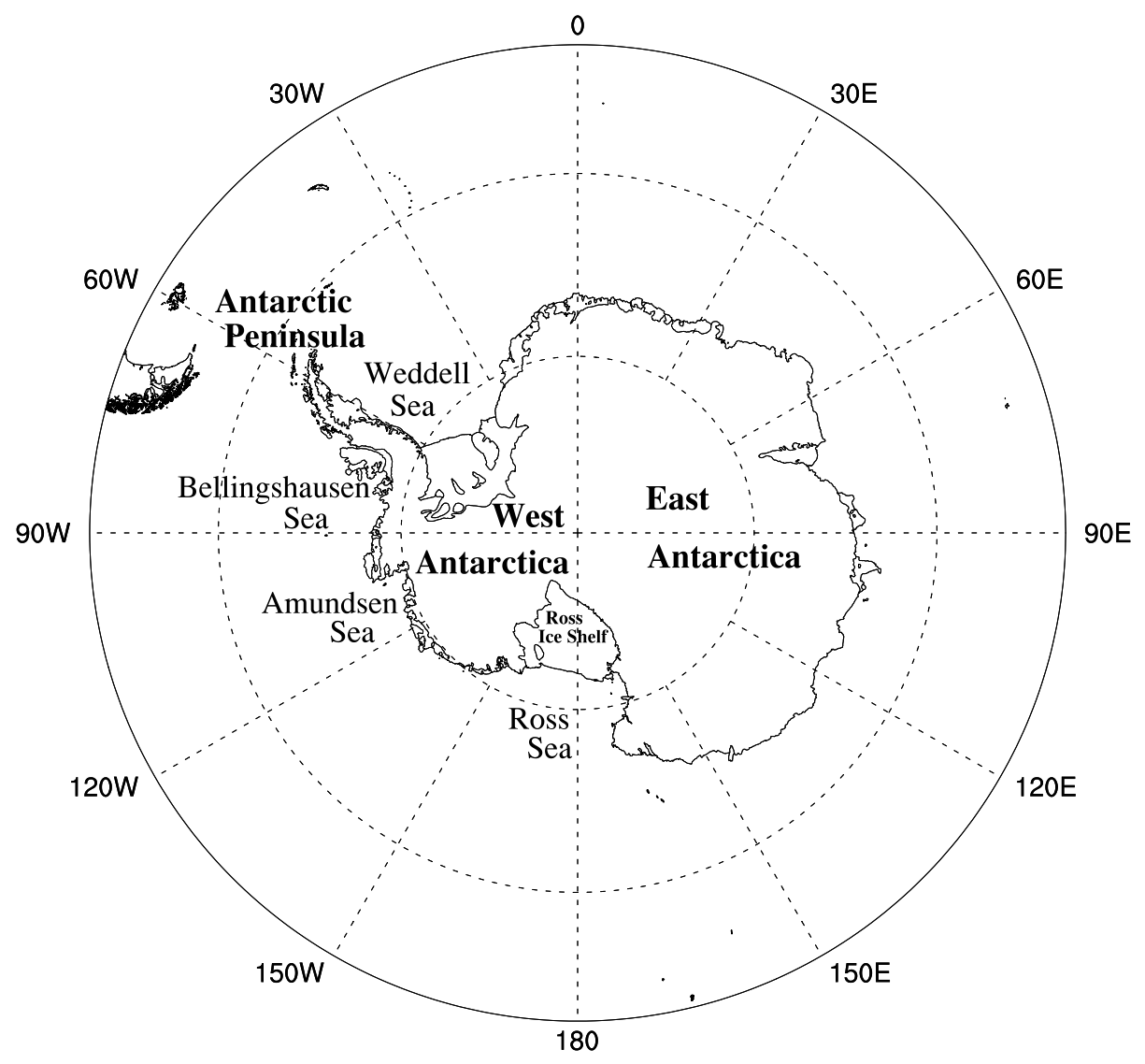

Figure 1.1: Map of Antarctica and surrounding seas.

across much of northeastern Peninsula (Fahnestock et al. 2002; Scambos et al. 2000, 2004; Rignot et al. 2004).

The western Antarctic Peninsula has also warmed significantly since the 1950s, which is most marked during austral autumn, winter, and spring (King 1994; Meredith and King 2005; Turner et al. 2005; Ding and Steig 2013; Clem and Fogt 2015), although a recent study by Turner et al. (2016) demonstrated the warming stopped after the late 1990s. The most widespread warming across the Peninsula is seen during autumn (Ding and Steig 2013), while the strongest warming rates are observed during winter but are confined to the western Peninsula only (Turner et al. 2005). Warming of the western Peninsula is closely tied to strong reductions in sea ice concentration in the Bellingshausen Sea and associated increases in heat flux from the ocean to the surrounding atmosphere (Meredith and King 2005; Turner et al. 2013b). Both the 
warming and local reductions in sea ice are linked to regional circulation changes that have increased warm, northerly flow to the Peninsula (Ding and Steig 2013; Clem and Fogt 2015). Unlike the northeast Peninsula warming, which is linked to a strengthening of the westerlies, the warming of the western Peninsula as well as the more recent Peninsula-wide cooling are tied to regional circulation changes forced by the tropical Pacific and Atlantic (Schneider et al. 2012; Ding and Steig 2013; Li et al. 2014; Clem and Fogt 2015), highlighting the important role of tropical teleconnections in Antarctic climate variability.

Significant warming has also been seen across West Antarctica, primarily during the winter and spring seasons (Steig et al. 2009; Bromwich et al. 2013; Nicolas and Bromwich 2014). Like the Peninsula, both the winter and spring warming are linked to regional circulation changes associated with tropical teleconnections, which have increased warm, northerly flow toward the continent and reduced sea ice concentrations in the adjacent Amundsen and Bellingshausen Seas (Ding et al. 2011; Schneider et al. 2012; Clem and Fogt 2015). A recent study by Nicolas and Bromwich (2014) showed that recent warming of West Antarctica (i.e., after 1979) is strongest and most widespread during the spring season, and Clem and Fogt (2015) found spring warming on the western Peninsula to have increased in magnitude after 1979 while the autumn and winter warming rates across the Peninsula weakened in recent decades. Therefore, the strongest and most widespread warming in the West Antarctic region over recent decades has been during the spring season. If surface warming continues across West Antarctica, especially along the coast where buttressing ice shelves are exposed to the warmest surface air temperatures, there could be irreversible retreat of portions of the West Antarctic Ice Sheet leading to rapid global sea level rises of up to one metre by the end of the $21^{\text {st }}$ century (Joughin et al. 2014; DeConto and Pollard 2016).

In contrast to the West Antarctic region, East Antarctica has exhibited weak cooling trends and slight gains in mass over recent decades (Turner et al. 2005; Steig et al. 2009; Nicolas and Bromwich 2014; Shepherd et al. 2012). The cooling is most marked during summer and autumn and has been linked primarily to the strengthening of the circumpolar westerlies associated with springtime stratospheric ozone depletion (Thompson and Solomon 2002; Gillett and Thompson 2003; Marshall 2007). Despite strong tropical connections documented across the West Antarctic, little is known regarding how the tropics impact East Antarctic climate including the recent cooling seen there. 
Recent studies have also documented significant trends in tropical sea surface temperatures (SSTs) over the past three decades which are suggested to be linked to the regional warming across the West Antarctic. Since the late 1990s, there has been a La Niña-like shift in tropical Pacific SSTs with significant cooling over the eastern tropical Pacific and warming throughout much of the western tropical Pacific (Zhang et al. 2010; Trenberth et al. 2014; England et al. 2014). During spring, these increased La Niña conditions and warming of the western tropical Pacific forced a Rossby wavetrain to the South Pacific and South Atlantic that brings warm, northerly flow to portions of West Antarctica and the Antarctic Peninsula that is consistent with the warming observed there (Schneider et al. 2012; Clem and Fogt 2015). However, a physical mechanism by which the tropics have forced the high-latitude regional circulation changes that in turn have warmed West Antarctica has yet to be established. Results from Schneider et al. (2012) were based on an SST-forced modeling experiment, while Clem and Fogt (2015) identified statistical relationships with tropical Pacific climate indices; neither study identified a physical mechanism (i.e., changes in tropical deep convection) driving the poleward Rossby wave propagation to the high southern latitudes linking them to the observed Antarctic climate changes. Given that the most robust and widespread warming including some of the strongest warming rates observed on the planet have been across the West Antarctic during the spring season (e.g., Bromwich et al. 2013), more work is needed in identifying the mechanism(s) explaining the West Antarctic warming to more fully understand how the West Antarctic surface climate and cryosphere will change in the coming decades.

Drivers of recent climate change across the Antarctic Peninsula are even less understood. As mentioned previously, Turner et al. (2016) recently showed that warming across the Peninsula stopped after the late 1990s, which is suggested to be linked to a Rossby wavetrain emanating from the western tropical Pacific. However, Clem and Fogt (2015) and Ding and Steig (2013) recently reported significant warming on the Peninsula continued through the first decade of the $21^{\text {st }}$ century during some seasons, the cause for which was also linked to wavetrains emanating from the tropical Pacific. A possible explanation for these conflicting reports may be that Ding and Steig (2013) and Turner et al. (2016) examined mean temperatures averaged across the entire Peninsula (i.e., western and northeast temperatures together), while previous studies have shown strong differences in local circulation and climate variability between the western and eastern Peninsula (Orr et al. 2004, 2008; Clem and Fogt 2013). In particular, tropical 
variability has been shown to strongly impact the western Peninsula climate (Clem and Fogt 2013; Kwok and Comiso 2002), while the impact of tropical variability on the northeast Peninsula climate are less clear. Therefore, the representation and interpretation of Antarctic Peninsula climate presented by Ding and Steig (2013) and Turner et al. (2016) by examining temperatures averaged across the entire Peninsula may be misleading and may be overlooking important spatial differences between the western and eastern Peninsula climate. A better understanding of the spatial impacts of tropical variability across this region of very strong topographic relief is needed to resolve these conflicting reports and better assess and interpret Antarctic Peninsula climate variability both in the past and in future climate projections.

Finally, although many recent studies having focused on how the tropics impact the climate of West Antarctica and the Antarctic Peninsula, the influence of the tropics on East Antarctica is relatively unexplored. Despite strong connections between springtime stratospheric ozone depletion and trends in the summertime tropospheric westerlies / Antarctic surface climate, the stratosphere-troposphere-surface climate relationship is much less clear for the autumn season (e.g., Gillet and Thompson 2003). Therefore, it is possible that other mechanisms, such as tropical forcing, may be linked to the strengthened westerlies / East Antarctic cooling during autumn. This question is particularly relevant given the recent shift in tropical Pacific climate toward more La Niña events, as studies have shown La Niña events are associated with a strengthening of the circumpolar westerlies by increasing poleward momentum fluxes, similar to the thermal forcing exerted by ozone depletion (L'Heureux and Thompson 2006; Fogt et al. 2011). Given that the ozone hole has shown signs of recovery during the $21^{\text {st }}$ century (Solomon et al. 2016) while the circumpolar westerlies have remained anomalously strong during both summer and autumn, and given the strongest shift in tropical Pacific SSTs occurred after 2000 (Meehl et al. 2013; Purich et al. 2016), more work is needed in teasing out the relative influences of ozone depletion and tropical forcing on recent high-latitude circulation and surface climate changes during summer and autumn.

There are three primary goals of this study, all of which build on previous literature to more fully understand how the tropics influence atmospheric circulation and surface climate variability across the high-latitude Southern Hemisphere. First, this study will investigate what role the recent La Niña-shift in tropical Pacific climate has had on the recent intensification of the Southern Hemisphere westerlies and East Antarctic cooling during summer and autumn. 
Second, this study will seek to identify a physical mechanism forcing the circulation and climate changes across the West Antarctic region during spring. Third, this study will investigate the spatial impacts of tropical Pacific teleconnections on Antarctic Peninsula climate to more fully understand how the tropics influence this unique region of the planet that has exhibited extreme climate fluctuations over the past 60 years. 


\section{CHAPTER 2: LITERATURE REVIEW}

\subsection{The El Niño-Southern Oscillation: Teleconnections and Trends}

The El Niño-Southern Oscillation (ENSO) is a naturally occurring oscillation of SST and surface pressure anomalies between the western and eastern tropical Pacific. It was first studied by Sir Gilbert T. Walker and E. W. Bliss (Walker and Bliss 1932, 1937) who identified a surface pressure see-saw between the western and eastern tropical Pacific, which they termed the Southern Oscillation due to the strongest pressure anomalies occurring over the Southern Hemisphere (SH). El Niño is the oceanic component of ENSO, originally identified by fishermen who observed strong interannual changes in SST anomalies off the coast of Peru (Trenberth 1997). The ENSO phenomenon is maintained by positive feedbacks in the tropical atmosphereocean coupled system through modification of the trade winds / Walker circulation and associated variations in the slope and depth of the equatorial Pacific thermocline, known as the Bjerknes feedback (Bjerknes 1969; Lau and Yang 2002). The La Niña phase is an amplification of the climatological oceanic and atmospheric state of the tropical Pacific, with positive SST anomalies / deepened thermocline observed over the western tropical Pacific, negative SST anomalies / shoaled thermocline over the eastern tropical Pacific, and a strengthened Walker Circulation (Oort and Yienger 1996). El Niño is associated with a weakening of the Walker circulation and increased surface westerly wind bursts along the equatorial Pacific (Verbickas 1998; Chen et al. 2015), leading to negative SST anomalies / shoaled thermocline over the western tropical Pacific and positive SST anomalies / deepened thermocline over the eastern tropical Pacific.

Variations in ENSO have a significant impact on global climate via atmospheric teleconnections. The primary mechanism by which ENSO remotely influences regional climates is through the production of poleward propagating Rossby waves associated with anomalous SST and tropical deep convection patterns. Using a theoretical model framework, Hoskins and Karoly (1981) and Held et al. (1989) were among the first to demonstrate that anomalous surface heating and deep convection over the equator can generate poleward propagating Rossby waves, which in turn can influence atmospheric circulation and storm tracks across the middle and high latitudes. Regions where Rossby waves develop and propagate out of the tropics are known as Rossby wave source regions, where there is advection of absolute vorticity by the divergent wind 
(Trenberth et al. 1998; Renwick and Revell 1999; Lachlan-Cope and Connolley 2006). In the tropics, anomalous divergent wind occurs in the upper troposphere above regions of surface heating anomalies and associated deep convection / ascent, and absolute vorticity gradients are maximised along the sub-tropical jet stream. As the strong rising air within deep convection reaches the tropopause, it turns poleward toward the sub-tropical jet streams, where it can then advect anomalous vorticity gradients poleward. Because regions of anomalous deep convection tend to follow surface heating / positive SST anomalies, La Niña events favor enhanced convection / divergent winds over the western tropical Pacific, while El Niño events are associated with an eastward migration of enhanced convection / divergent winds to the central and eastern tropical Pacific (Trenberth 1997; Lachlan-Cope and Connolley 2006). It is through these various configurations of tropical deep convection / Rossby wave source patterns that allow ENSO to influence atmospheric circulation and climate variability in remote locations around the globe.

A key source region of Rossby wave development and propagation into the $\mathrm{SH}$ is along the South Pacific Convergence Zone (SPCZ). The SPCZ is a region of persistent surface convergence and tropical deep convection that lies in a northwest-southeast oriented band stretching from the western equatorial Pacific to approximately $30^{\circ} \mathrm{S}, 120^{\circ} \mathrm{W}$ (Kiladis et al. 1989; Vincent 1994; Widlansky et al. 2011). The SPCZ position is modulated by variability in ENSO and associated fluctuations in the strength of the South Pacific sub-tropical anticyclone: the SPCZ shifts equatorward and becomes less diagonal during El Niño conditions, and it migrates poleward and becomes more diagonal during La Niña conditions (Trenberth 1997; Folland et al. 2002; Vincent et al. 2011). Due to the strong and persistent convective activity along the SPCZ and its climatological position near the sub-tropical jet (where vorticity gradients are maximised), the SPCZ is a key genesis region for Rossby waves that develop and propagate into the high southern latitudes.

In the SH, the leading Rossby wave / teleconnection pattern associated with ENSO is the Pacific-South American (PSA) pattern, which consists of a standing wave of alternating highlow pressure anomalies that extends poleward from the tropical Pacific following a great circle (Wallace and Gutzler 1981; Ghil and Mo 1991; Lau et al. 1994; Mo and Higgins 1998; Mo and Paegle 2001). This standing wave pattern, known as a wavetrain, tends to be most defined during the austral winter season when the background circulation is strongest, with the same being true 
for the Northern Hemisphere counterpart, the Pacific-North American pattern (Wallace and Gutzler 1981; Karoly 1989; Lachlan-Cope and Connolley 2006). There are two primary PSA patterns, which emerge as the second and third EOFs of monthly-mean sea level pressure, upper troposphere geopotential height, and streamfunction anomalies across the extratropical SH (Kidson 1988; Mo and Paegle 2001). The first and second PSA patterns explain approximately $13 \%$ and $11 \%$, respectively, of the total geopotential height variance over the SH (Mo and Paegle 2001) on monthly and longer timescales. As alluded to previously, there is strong seasonality in the ENSO teleconnection / PSA patterns. The austral summer ENSO teleconnection pattern consists of a zonally-symmetric circulation anomaly over the South Pacific, while in the winter the teleconnection is defined by stronger regional circulation anomalies (Karoly 1989; Mo and Higgins 1998; L'Heureux and Thompson 2006). Despite the varying spatial structure of the ENSO teleconnection pattern, the teleconnection itself is strong over the SH during all seasons (Fogt et al. 2011).

Recent studies have identified significant trends in ENSO and tropical Pacific SSTs since 1979, which marks the beginning of the modern satellite era when continuous global SST measurements began. Tropical Pacific SSTs have exhibited a La Niña-like trend since 1979, with significant warming over the western tropical Pacific and cooling in the eastern tropical Pacific (Zhang et al. 2010; Trenberth et al. 2014; Kosaka and Xie 2013; Trenberth and Fasullo 2013; England et al. 2014; McGregor et al. 2014). The La Niña-like trend has been attributed to a strengthening of the surface easterly winds over the tropical Pacific, which is linked to the Pacific Decadal Oscillation (PDO; Mantua et al. 1997; Garreaud and Battisti 1999; Mantua and Hare 2002) shift toward its negative phase after the late 1990s (Meehl et al. 2013; Trenberth et al. 2014; Trenberth and Fasullo 2013), and to increasing SSTs over the equatorial Atlantic (Kucharski et al. 2016; McGregor et al. 2014; Li et al. 2015).

The PDO represents the naturally occurring decadal variability in ENSO, and therefore both ENSO and the PDO describe similar SST patterns over the tropical Pacific (negative PDO similar to La Niña, and positive PDO similar to El Niño) but on different timescales (Garreaud and Battisti 1999; Zhang et al. 1997). The negative phase of the PDO, which has dominated since the late 1990s, is associated with cooling over the eastern tropical Pacific, which promotes an increase in La Niña frequency and intensity (Purich et al. 2016). The observed cooling over the eastern tropical Pacific has been suggested to have caused the recent "hiatus" period where 
the overall rate of global warming weakened after the late-1990s (England et al. 2014; McGregor et al. 2014; Trenberth and Fasullo 2013; Kosaka and Xie 2013). Increasing equatorial Atlantic SSTs have also been shown to cool the eastern tropical Pacific in two different fashions. First, warming of the equatorial Atlantic modifies the Walker circulation over South America by strengthening the ascending branch over the tropical Atlantic and the descending branch over the central tropical Pacific, which strengthens the surface easterlies in the west-central tropical Pacific and excites La Niña events through the Bjerknes feedback (Kucharski et al. 2011, 2016; Ding et al. 2012a; McGregor et al. 2014). Second, positive SST anomalies in the equatorial Atlantic can warm the equatorial Indian / western Pacific basin through wind-evaporation effect, which also acts to the strengthen the surface easterlies and produce cooling over the eastern tropical Pacific (Li et al. 2015).

\subsection{The Southern Annular Mode: Dynamics and Trends}

The Southern Annular Mode (SAM) is the leading mode of extra-tropical SH atmospheric circulation, and explains $20-30 \%$ of monthly sea level pressure and geopotential height variability poleward of $20^{\circ} \mathrm{S}$ (Kidson 1988; Thompson and Wallace 2000). The SAM is characterised by an equivalent barotropic, zonally symmetric see-saw in atmospheric mass between the SH middle latitudes $\left(\sim 40^{\circ} \mathrm{S}\right)$ and polar cap (poleward of $\sim 65^{\circ} \mathrm{S}$; Rogers and van Loon 1982; Limpasuvan and Hartmann 1999; Thompson and Wallace 2000; Marshall 2003). During its positive phase, positive pressure anomalies are generally seen across the middle latitudes and negative pressure anomalies are found over Antarctica. The positive phase of the SAM is commonly characterised by a strengthening and poleward contraction of the SH midlatitude jet (Thompson et al. 2000; Lorenz and Hartmann 2001; Fyfe and Lorenz 2005), although a recent study by Swart et al. (2015) concluded that the SAM pattern may not directly describe the jet strength or position, at least in terms of surface winds. Opposite conditions are observed during the negative phase of the SAM.

The SAM pattern exists due to a positive feedback between zonal wind anomalies in the mid-latitude jet and eddy momentum fluxes associated with poleward propagating baroclinic waves (Feldstein 1998; Lorenz and Hartmann 2001; Barnes and Hartmann 2010). Through thermal wind balance, regions of anomalous meridional temperature gradients in the lower 
troposphere are associated with zonal wind anomalies in the mid-latitude jet. As baroclinic waves propagate away from the jet, they feed momentum fluxes into the jet, exciting additional positive zonal wind anomalies, hence the positive feedback. On the other hand, barotropic waves tend to have a negative feedback on the mid-latitude jet by taking momentum out of the jet (Lorenz and Hartmann 2001). Due to the positive feedbacks between zonal wind anomalies and eddy momentum fluxes, the SAM pattern is a persistent feature that exists year-round and its phase and magnitude explains much of the variability in the mid-latitude jet.

The SAM exhibits strong seasonal variability in its structure primarily due to feedback mechanisms between the mid-latitude jet and transient eddies. During the austral summer, the SAM exhibits strong zonal symmetry across the entire $\mathrm{SH}$, while during winter the $\mathrm{SAM}$ is comprised of a zonally symmetric component over the Indian Ocean and a zonally asymmetric component over the Pacific sector (Rogers and van Loon 1982; Szeredi and Karoly 1987; Jones et al. 2009; Fogt et al. 2012a). Similarly, the mid-latitude jet is present year-round in the Indian Ocean near $50^{\circ} \mathrm{S}$ maintained by positive eddy feedbacks, while over the Pacific it is present primarily during the summer season only with a stronger sub-tropical jet seen over the Pacific during winter (Bals-Elsholz et al. 2001; Nakamura and Shimpo 2004; Hoskins and Hodges 2005). The reason for the seasonality is primarily due to eddy variability being strongest over the South Pacific during summer and weakest during winter, hence stronger feedbacks and an eddy driven mid-latitude jet over the Pacific during summer (Barnes and Hartmann 2010). During winter, the Pacific consists of a split jet structure with a strong sub-tropical jet and weaker midlatitude jet (due to weaker eddy feedbacks), giving rise to less zonal symmetry in the overall SAM pattern during winter, particularly over the Pacific.

Many studies have noted a significant positive trend in the SAM since the mid-1950s during the austral summer and autumn seasons (Kidson 1999; Thompson et al. 2000; Thompson and Solomon 2002; Marshall 2003). The positive SAM trend is attributed primarily to stratospheric ozone depletion over Antarctica, and to a lesser extent increases in greenhouse gas concentrations (Thompson and Solomon 2002; Gillett and Thompson 2003; Marshall et al. 2004; Arblaster and Meehl 2006; Miller et al. 2006; Son et al. 2010; Polvani et al. 2011). Ozone depletion acts to cool the stratosphere over Antarctica by reducing the amount of heat radiated to the surrounding environment, and increasing greenhouse gases warm the lower and middle latitudes by increasing the amount of heat radiated back to the Earth's surface. Therefore, both 
stratospheric ozone depletion and increasing greenhouse gases increase the meridional temperature gradient between the middle and high southern latitudes, which strengthens the midlatitude jet through thermal wind balance and excites the positive phase of the SAM.

The cause for Antarctic ozone depletion during the second half of the $20^{\text {th }}$ century is due to the anthropogenic release of industrial chlorofluorocarbons used as refrigerants and aerosols. These chemicals become trapped in the stratosphere, especially over Antarctica where they are often trapped within the polar vortex, and release chlorine and bromine when exposed to ultraviolet radiation from the sun which reacts with and destroys ozone (Farman et al. 1985; WMO 2014; Solomon et al. 2016). Therefore, the strongest impacts of ozone depletion on the stratosphere are during the austral spring when insolation and ultraviolet radiation returns to Antarctica. The release of industrial chlorofluorocarbons was globally phased out in 1989 after the signing of the Montreal Protocol, and since about 2000 there have been signs that the Antarctic ozone hole is slowly recovering (Solomon et al. 2016).

Early observational and modeling studies by Thompson and Solomon (2002) and Gillett and Thompson (2003) showed that ozone depletion during spring produces a negative temperature and geopotential height anomaly in the stratosphere over Antarctica that strengthens the spring stratospheric polar vortex (by increasing the meridional temperature and pressure gradient). The positive zonal wind anomalies then propagate down from the stratosphere into the troposphere during the following summer months, which strengthens the mid-latitude jet and excites the positive polarity of the SAM. The zonal wind anomalies in the troposphere are strongest during summer, but can persist into autumn. Hence, the positive SAM trend / strengthening of the tropospheric westerlies is strongest during summer, with weaker but significant trends also seen during autumn. Nearly all the observed atmospheric circulation and surface climate changes over the middle and high-latitude SH during summer and autumn are accounted for by the observed decreases in spring ozone over Antarctica (Thompson et al. 2000; Thompson and Solomon 2002; Gillett and Thompson 2003). More recent modeling studies confirm that ozone depletion is the undoubtedly the dominant mechanism driving observed summertime $\mathrm{SH}$ atmospheric circulation changes over the second half of the $20^{\text {th }}$ century, with radiative forcing associated with greenhouse gases playing a similar but weaker role (Arblaster and Meehl 2006; Miller et al. 2006; Son et al. 2010; Polvani et al. 2011). 
Ozone forcing is not the only mechanism known to influence the SAM. Many studies have also found tropical variability associated with ENSO can drive changes in the SAM through eddy feedbacks (Fogt and Bromwich 2006; L'Heureux and Thompson 2006; Fogt et al. 2011; Ding et al. 2012b; Schneider et al. 2015). During La Niña events, anomalous eddy momentum fluxes out of the tropics and into the middle latitudes of the SH project strongly onto the zonally symmetric portion of the SAM pattern, which can trigger and maintain positive SAM events by feeding anomalous momentum fluxes into the mid-latitude jet (Seager et al. 2003; Codron 2005; L'Heureux and Thompson 2006; Gong et al. 2010, 2013). Conversely, El Niño events weaken the momentum fluxes to the SH extra-tropics which tends to favor negative SAM conditions. This relationship is strongest during late spring and summer when ENSO events reach their peak intensity and the SAM / mid-latitude jet is most zonally symmetric (Seager et al. 2003; L'Heureux and Thompson 2006; Gong et al. 2010; Fogt et al. 2012a). Fogt and Bromwich (2006) and Fogt et al. (2011) further demonstrated that ENSO and SAM combinations also modulate the respective ENSO and SAM momentum fluxes observed throughout the $\mathrm{SH}$. The anomalous eddy momentum fluxes associated with La Niña / positive SAM events and El Niño / negative SAM events reinforce each other, which reinforces the SAM pattern and also strengthens the ENSO teleconnection to the high-latitude SH. In contrast, when La Niña events occur with negative SAM or El Niño with positive SAM, the anomalous eddy momentum fluxes oppose each other, and the ENSO teleconnection to the high-latitude SH is weakened or altogether absent (Clem and Fogt 2013).

A recent study by Ding et al. (2012b) suggests the SAM is actually comprised of two separate patterns driven by separate mechanisms: a persistent, tropically forced wavetrain over the Pacific sector, and an internally generated eddy driven jet over the Indian and Atlantic (IndoAtlantic) sector. The two SAM patterns described by Ding et al. (2012b) are consistent with other studies discussed previously that detail the different structures of the mid-latitude jet over the Indian and Pacific sectors outside of summer, but Ding et al. (2012b) further suggest that the Pacific portion of the SAM is comprised of a frequently-occurring PSA pattern resulting from ubiquitous Rossby wave propagation from the western tropical Pacific near the exit region of the sub-tropical jet. This suggests changes in ENSO may have a direct influence of the SAM pattern in addition to altering poleward momentum fluxes and associated mid-latitude jet feedbacks. 
Given this novel approach in describing the SAM along with many other studies showing ENSO events can trigger and maintain SAM events, it is possible that recent trends in the SAM may be related to the recent changes in ENSO. More specifically, the post-1979 La Niña-like trend, which would favor positive SAM events, may also have influenced the positive SAM trend in addition to forcing from ozone depletion and increasing greenhouse gases, especially since the ozone hole has shown signs of recovering after 2000. However, the influence of the recent La Niña-trend on the observed positive trend in the SAM during summer and autumn has not been quantified. Furthermore, the relationship between spring ozone depletion and the autumn SAM trend is less clear than for the summer season, suggesting the autumn circulation changes (in addition to the summer changes) may not be entirely caused by ozone depletion.

\subsection{Antarctic Climate and Mass Balance: Variability and Trends}

Antarctica consists of a massive sheet of grounded ice that occupies the high-latitudes of the SH poleward of $65^{\circ} \mathrm{S}$ (see Fig. 1.1 for map). Its climate is dominated by circulation variability associated with ENSO and the SAM, but in different fashions. Circulation variability associated with ENSO primarily affects Antarctic climate through teleconnections associated with the PSA patterns (Turner 2004; Marshall and Thompson 2016), which alters meridional circulation primarily across the West Antarctic region. Circulation variability associated with the SAM influences climate variability primarily over East Antarctica and the eastern Antarctic Peninsula through variability in the strength and position of the mid-latitude jet (Lefebvre et al. 2004; Marshall 2007; Marshall and Thompson 2016).

The most prominent meridional circulation feature near the Antarctic continent is the Amundsen Sea Low (ASL), which is a semi-permanent cyclone that is centered on-average over the Amundsen Sea in the high-latitude South Pacific (Fogt et al. 2012b; Turner et al. 2013a; Raphael et al. 2016). The ASL is found primarily over the domain $45-75^{\circ} \mathrm{S}, 180-60^{\circ} \mathrm{W}$, and located farthest east during summer and farthest west during winter following the maximum cyclone density (Fogt et al. 2012b; Turner et al. 2013). It exists due to a combination of local topography and persistent cyclonic activity in the region (Fogt et al. 2012b). As shown in Fig. 1.1 , to the south of the ASL the West Antarctic Ice Sheet lies more poleward $\left(\sim 75^{\circ} \mathrm{S}\right)$ than the upstream East Antarctic Ice Sheet $\left(\sim 65^{\circ} \mathrm{S}\right)$, and the ASL is bounded on its eastern flank by the 
Antarctic Peninsula that protrudes equatorward from the West Antarctic Ice Sheet and consists of steep mountains that exceed 2000 metres in elevation. The topography promotes strong cyclogenesis to occur downwind of East Antarctica (Baines and Fraedrich 1989; Walsh et al. 2000; Lachlan-Cope et al. 2001). Cyclones then track poleward and eastward into the Amundsen Sea following lower tropospheric baroclinicity and upper tropospheric vorticity gradients (Simmonds et al. 2003), and cyclones are rarely able to propagate over the steep topography of the West Antarctic Ice Sheet to their south and the Antarctic Peninsula to their east (Simmonds et al. 2003; Uotila et al. 2009, 2011). As a result, the high-latitude South Pacific / Amundsen Sea is a region of persistent cyclogenesis and cyclolysis, with many cyclones unable to propagate out of the region.

The ASL accounts for the zonal asymmetry in the SAM (i.e., the Pacific sector; Fogt et al. 2012a), and its position and intensity significantly influences climate variability over West Antarctica and the Antarctic Peninsula through modification of the local meridional winds (Clem and Fogt 2013; Hosking et al. 2013). Both ENSO and SAM have a significant impact on the depth and latitudinal position of the ASL, and thus it is the ENSO and SAM-related impacts on the ASL by which ENSO and SAM primarily influence the West Antarctic and Antarctic Peninsula climate. La Niña and positive SAM phases tend to deepen and broaden the ASL and shift it poleward toward the West Antarctic continent. A deeper than normal ASL is associated with anomalous warm northerly surface winds / reductions in sea ice concentration over the Antarctic Peninsula and adjacent Bellingshausen Sea, and cold southerly surface winds / increased sea ice concentration over the Ross Ice Shelf and adjacent Ross Sea (Kwok and Comiso 2002; Turner 2004; Lefebvre et al. 2004; Stammerjohn et al. 2008, 2012; Holland and Kwok 2012; Hosking et al. 2013; Ding and Steig 2013). Opposite circulation anomalies and associated climate and sea ice conditions are seen when the ASL is weaker than normal, which commonly occurs during El Niño and negative SAM phases (Turner 2004; Turner et al. 2013a). Recent studies have shown positive SST anomalies over the tropical North Atlantic can also deepen the ASL during the winter and spring seasons, impacting the Antarctic Peninsula climate (Li et al. 2014; Simpkins et al. 2014).

Across central West Antarctica, the longitudinal position of the ASL, rather than its depth, plays a more important role at impacting interior West Antarctic climate (Nicolas and 
Bromwich 2011; Hosking et al. 2013). However, the longitudinal position of the ASL shows no significant correlation with ENSO or SAM variability (Hosking et al. 2013).

East Antarctic climate is dominated by fluctuations in the strength and position of the zonal circulation associated with variability in the SAM / mid-latitude jet, with a weaker influence from ENSO and the associated PSA patterns (Thompson and Solomon 2002; Marshall and Thompson 2016). During positive phases of the SAM, the mid-latitude jet over the IndoAtlantic sector / along the East Antarctic coast is strengthened and exhibits higher zonal symmetry, which reduces poleward advection of heat and the occurrence of katabatic winds over the continent, which leads to cooling of interior East Antarctica (Thompson and Solomon 2002; Marshall 2007; van den Broeke and van Lipzig 2003). Opposite conditions are seen for the negative phase of the SAM. A unique topographic-induced SAM relationship also exists over the eastern Peninsula (Marshall 2007). During the summer season, when the SAM pattern is most zonally symmetric and the Pacific sector also exhibits a mid-latitude jet, positive zonal wind anomalies associated with the positive phase of the SAM flow over the Peninsula resulting in warm lee-side Föhn winds on the eastern side (Orr et al., 2004, 2008). Therefore, while positive SAM conditions are associated with cooling across East Antarctica, they tend to warm the eastern Peninsula through local topographic effects, especially during the summer season.

Significant trends in Antarctic climate since the 1957-58 International Geophysical Year have been reported in several studies (Turner et al. 2005; Chapman and Walsh 2007; Steig et al. 2009; O’Donnell et al. 2011; Bromwich et al. 2013; Nicolas and Bromwich 2014). Temperature changes have not been uniform across the continent. East Antarctica has exhibited weak, insignificant cooling during summer and autumn associated with the positive trend in the SAM / strengthened mid-latitude jet (Kwok and Comiso 2002; Thompson and Solomon 2002; Turner et al. 2005; Chapman and Walsh 2007; Marshall 2007; Monaghan et al. 2008; Steig et al. 2009; Nicolas and Bromwich 2014), and the overall East Antarctic mass balance has been near-zero to weakly positive (Rignot et al. 2008; Shepherd et al. 2012).

Meanwhile, West Antarctica and the Antarctic Peninsula have exhibited significant warming trends since the 1950s. The Peninsula warming is highly variable in space and time. Significant warming trends have been documented along the western Antarctic Peninsula that are strongest during the autumn and winter seasons, which has been linked to a deepening of the ASL and reductions in sea ice off the western Peninsula coast (King 1994; Vaughan et al. 2003; 
Meredith and King 2005; Turner et al. 2005, 2013b; Ding and Steig 2013). The deepened ASL is linked to increasing SSTs over the western tropical Pacific and a PSA-like wavetrain during autumn (Ding and Steig 2013), while increasing SSTs over the tropical North Atlantic have been shown to deepen the ASL during winter through a similar wavetrain structure (Li et al. 2014). Significant warming has also been noted along the western Peninsula during spring, which unlike the autumn and winter warming, has persisted and even intensified over recent decades (Clem and Fogt 2015). The spring warming on the western Peninsula has been linked to increased northerly flow from anticyclonic circulation conditions in the South Atlantic associated with the increased La Niña conditions / increasing SSTs over the western tropical Pacific since 1979 (Clem and Fogt 2015; Schneider et al. 2012). Persistent negative sea ice anomalies along the western Peninsula coast induced during the preceding autumn and winter seasons are also suggested to be related to the spring warming seen there (Ding and Steig 2013). The warming and reduced sea ice along the western Peninsula has had major biological impacts, including an increase in competition for krill-eating predators (Trivelpiece et al. 2011), and the ability for king crab populations to survive at unprecedented shallow depths along the outer shelf of the western Antarctic Peninsula due to increasing ocean temperatures (Aronson et al. 2015).

The northeast Peninsula has exhibited a significant warming trend during the summer season (Skvarca et al. 1998; Turner et al. 2005; Marshall 2007; Orr et al. 2008), which is linked to the summertime strengthening of the circumpolar westerlies associated with the positive trend in the SAM rather than changes in the ASL (Marshall et al. 2006; Orr et al. 2008). Closely linked to the northeast Peninsula surface warming has been the collapse of northern portions of the Larsen Ice Shelf located on the eastern Peninsula and the rapid acceleration and thinning of glaciers (Rott et al. 2002; Fahnestock et al. 2002; Scambos et al. 2004). Satellite images revealed surface melting in response to warm surface air temperatures was the dominant process leading to the disintegration and collapse of the ice shelves, indicating that the Peninsula's ice shelves and interior glaciers are highly sensitive to surface climate changes (Vaughan and Doake 1996; Scambos et al. 2000; Fahnestock et al. 2002).

More recently, it has been shown that the warming on the Antarctic Peninsula stopped after the late 1990s with significant cooling observed over 1999-2014 (Turner et al. 2016; Oliva et al. 2016). In contrast, other studies suggest warming of the Peninsula continued through the 2000s, especially on the western Peninsula (Ding and Steig 2013; Clem and Fogt 2015). The 
Peninsula-wide cooling is strongest during summer and is suggested to be a result of increased cold, easterly winds and compaction of sea ice along the eastern Peninsula associated with cyclonic circulation in the northern Weddell Sea and Drake Passage (Turner et al. 2016), which differs markedly from the enhanced anticyclonic circulation over the South Atlantic observed there during spring over 1979-2012 (Clem and Fogt 2015). The recent cooling on the Peninsula reflects the large range of internal climate variability in this region tied to natural decadal variability in the atmospheric circulation (Jones et al. 2016a; Turner et al. 2016).

Across West Antarctica, significant warming has been noted during the winter and spring seasons (Monaghan et al. 2008; Steig et al. 2009; Schneider et al. 2012; Bromwich et al. 2013; Nicolas and Bromwich 2014). Although associated with different mechanisms, both the winter and spring warming of West Antarctica are linked to teleconnections stemming from the tropical Pacific. A modeling study by Ding et al. (2011) concluded that the winter warming of West Antarctica is caused by an anticyclonic circulation over the Amundsen Sea associated with increasing SSTs over the central tropical Pacific. The anticyclone brings warm air advection to western and central West Antarctica; however, this circulation pattern would be associated with cooling over the Peninsula during winter, which is not seen in observations, and is inconsistent with the deepening of the ASL suggested by Li et al. (2014) during winter. In spring, an observed deepening of the ASL over the Ross Sea associated with the Pacific Decadal Oscillation shift to its negative phase brings increased warm air advection to western West Antarctica and the Ross Ice Shelf, which is consistent with the spring warming seen there and reductions in sea ice concentration along the Amundsen Sea Embayment (Schneider et al. 2012; Clem and Fogt 2015).

These tropically-forced circulation changes around West Antarctica are associated with influxes of warm circumpolar deep water to the Amundsen Sea Embayment (Steig et al. 2012), which is suggested my many studies to be driving the rapid retreat of the Thwaites and Pine Island glaciers in central West Antarctica (Rignot, 2006; Rignot et al. 2013; Joughin et al. 2003; Shepherd et al. 2001, 2004; Thomas et al. 2004; Wingham et al. 2009; Pritchard et al. 2009, 2012; Steig et al. 2012; Joughin et al. 2014). Mass loss from Thwaites and Pine Island Glaciers currently dominates Antarctica's contribution to global sea level rise, with secondary contributions from the Antarctic Peninsula (Shepherd and Wingham 2007; Shepherd et al. 2012). Because much of the interior bedrock of Thwaites and Pine Island Glaciers lies below sea level, 
the glaciers are dynamically unstable (i.e., they sit on downward sloping beds), and it is possible that the current retreat could be irreversible even without further oceanic or atmospheric warming (Wingham et al. 2009; Joughin et al. 2014).

Clearly, tropical Pacific teleconnections play an important role at modulating climate variability across the West Antarctic and Antarctic Peninsula region. Therefore, understanding these tropical connections is vitally import for accurately predicting future climate changes in the Antarctic. However, as alluded to earlier, there have been conflicting reports regarding mechanisms explaining warming in various regions and seasons of the West Antarctic sector, and observed physical mechanisms (rather than model simulations) linking the tropics to the observed high-latitude circulation changes is warranted.

During the spring season, Clem and Fogt (2015) showed that warming of West Antarctica and the Antarctic Peninsula is statistically related to the negative trend in the PDO index (associated with the shift of the PDO to its negative phase after the late 1990s) and a positive trend in the Southern Oscillation Index (SOI; associated with the increased La Niña conditions), but a physical mechanism was not provided. Schneider et al. (2012) suggested the spring warming of West Antarctica was linked to the SPCZ, but again a physical relationship between changes in tropical deep convection and the high-latitude circulation was not established. Given that the most widespread warming of both West Antarctica and the Antarctic Peninsula is occurring during spring (Nicolas and Bromwich 2014), more work is needed to understand causes for the observed climate changes during spring.

Another aspect of the literature needing additional work is on the relative influences of ENSO and SAM on the Antarctic Peninsula climate. Clem and Fogt (2013) showed that ENSO and SAM impact different aspects of climate variability on the Peninsula during spring, with ENSO having a persistent, significant relationship with climate variability on the western Peninsula, and SAM having a persistent, significant relationship with the northeast Peninsula climate. However, Ding and Steig (2013) showed warming of the entire Antarctic Peninsula during autumn, winter, and spring was related to tropical Pacific forcing during autumn that deepened the ASL and reduced sea ice along the western Peninsula coast. Therefore, Ding and Steig (2013) may have overlooked the important role of the SAM at modulating climate variability on the Peninsula by investigating western and northeast Peninsula temperatures as a single quantity. 
Lastly, despite strong connections between the tropics and West Antarctic / Antarctic Peninsula climate, little is known about the influence of the tropics on East Antarctic climate. In particular, if and how the recent La Niña-shift in tropical Pacific SSTs has impacted East Antarctic climate has not been explored. Although ENSO's influence on climate over the West Antarctic region through modification of the ASL is the most prominent feature of the ENSOAntarctic teleconnection, it would be useful for future research to understand the behavior of the La Niña wavetrain pattern outside of the South Pacific (following a great circle) and to investigate potential impacts on East Antarctic climate.

\subsection{Research Goals}

As stated previously, there are three main goals of this study. First, this study will investigate how the recent La Niña-like shift in tropical Pacific SSTs has impacted the SH westerlies and Antarctic climate during summer and autumn. As previously discussed, many studies have linked the summer and autumn strengthening of the westerlies to stratospheric ozone depletion during spring, while other studies have identified that poleward momentum fluxes associated with La Niña conditions are also associated with a strengthening of the SH westerlies. Given the recent observed shift of tropical Pacific SSTs toward increased La Niña conditions, this study will build on previous literature by investigating if forcing associated with the recent La Niña shift is also partly related to the recent intensification of the westerlies during summer and autumn in addition to ozone depletion, and what influence, if any, this has had on the cooling of East Antarctica. These research questions are investigated in Sections 1 and 2 of Chapter 4.

Second, this study will investigate the physical mechanism likely to have caused the regional circulation changes and associated warming of West Antarctica during spring.

While previous studies have linked the spring warming of West Antarctica to the tropics, these studies focused on relationships with climate indices and model simulations forced by tropical SSTs, neither of which fully describe a physical linkage between the tropics and observed changes in the high southern latitude climate. Given the strongest and most widespread warming of West Antarctica over recent decades has occurred during the spring seasons, more work is 
needed to fully understand this warming and to pinpoint where the tropical forcing originates. This research question is investigated in Section 3 of Chapter 4.

Finally, this study will investigate the spatial impact of ENSO and SAM variability on the Antarctic Peninsula climate. While many previous studies have shown remarkable changes in the climate and cryosphere across the Antarctic Peninsula since the 1950s, little is known on how ENSO and SAM impact the western and eastern Peninsula separately. This study will build on previous work by examining the relative influence of ENSO and SAM on the western and eastern Peninsula separately as well as the relative influence of thermal advection and Föhn winds at driving climate variability between these two topographically separated regions. This research question is investigated in Section 4 of Chapter 4. 


\section{CHAPTER 3: DATA AND METHODS}

\subsection{Data Utilised}

Surface climate variability over Antarctica is investigated using monthly-mean observed 2-metre temperature data from staffed weather stations across the continent. The data are obtained freely online from the Reference Antarctic Data for Environmental Research archive (READER; Turner et al. 2004) website hosted by the British Antarctic Survey (https://legacy.bas.ac.uk/met/READER/). The reconstructed temperature record for Byrd station is also used, which is a patched record for the Byrd automated weather station located in central West Antarctica (Bromwich et al. 2013). The reconstructed portion of the Byrd temperature record was downloaded from http://polarmet.osu.edu/datasets/Byrd recon/hosted by the Byrd Polar Research Center at The Ohio State University. A list of the stations used and a map of the study area are provided in Table 3.1 and Fig. 3.1.

Table 3.1: Antarctic meteorological stations used in the study, listed from west to east. Percent complete refers to percentage of monthly-mean values available following the inclusion rate of $90 \%$ or more of the routine daily observations being available for each month.

\begin{tabular}{|lcccc|}
\hline Station & Latitude & Longitude & Starting year & \% Complete \\
\hline \hline & \multicolumn{1}{c}{ Antarctic } & Peninsula / West & Antarctica & \\
Byrd & $80 \mathrm{~S}$ & $120 \mathrm{~W}$ & $1957^{*}$ & $100 \%^{*}$ \\
Rothera & $67.5 \mathrm{~S}$ & $68.1 \mathrm{~W}$ & 1977 & $98.9 \%$ \\
Faraday / Vernadsky & $64.5 \mathrm{~S}$ & $64.4 \mathrm{~W}$ & 1950 & $99.6 \%$ \\
Bellingshausen & $62.2 \mathrm{~S}$ & $58.9 \mathrm{~W}$ & 1968 & $99.6 \%$ \\
Esperanza & $63.4 \mathrm{~S}$ & $57 \mathrm{~W}$ & 1957 & $97.9 \%$ \\
Marambio & $64.2 \mathrm{~S}$ & $56.7 \mathrm{~W}$ & 1970 & $97 \%$ \\
& & East Antarctica & 1957 & $100 \%$ \\
Halley & $75.5 \mathrm{~S}$ & $26.4 \mathrm{~W}$ & 1981 & $99 \%$ \\
Neumayer & $70.7 \mathrm{~S}$ & $8.4 \mathrm{~W}$ & 1961 & $99.7 \%$ \\
Novolazarevskaya & $70.8 \mathrm{~S}$ & $11.8 \mathrm{E}$ & 1957 & $91.1 \%$ \\
Syowa & $69 \mathrm{~S}$ & $39.6 \mathrm{E}$ & 1954 & $99.7 \%$ \\
Mawson & $67.6 \mathrm{~S}$ & $62.9 \mathrm{E}$ & 1957 & $92.4 \%$ \\
Davis & $68.6 \mathrm{~S}$ & $78 \mathrm{E}$ & 1956 & $99.3 \%$ \\
Mirny & $66.5 \mathrm{~S}$ & $93 \mathrm{E}$ & 1959 & $99.9 \%$ \\
Casey & $66.3 \mathrm{~S}$ & $110.5 \mathrm{E}$ & 1956 & $99.9 \%$ \\
Dumont d'Urville & $66.7 \mathrm{~S}$ & $140 \mathrm{E}$ & \\
\hline
\end{tabular}

*Byrd station starting year and \% complete refers to the reconstructed temperature record of Bromwich et al. (2013), while all other stations refer to observed data only. 


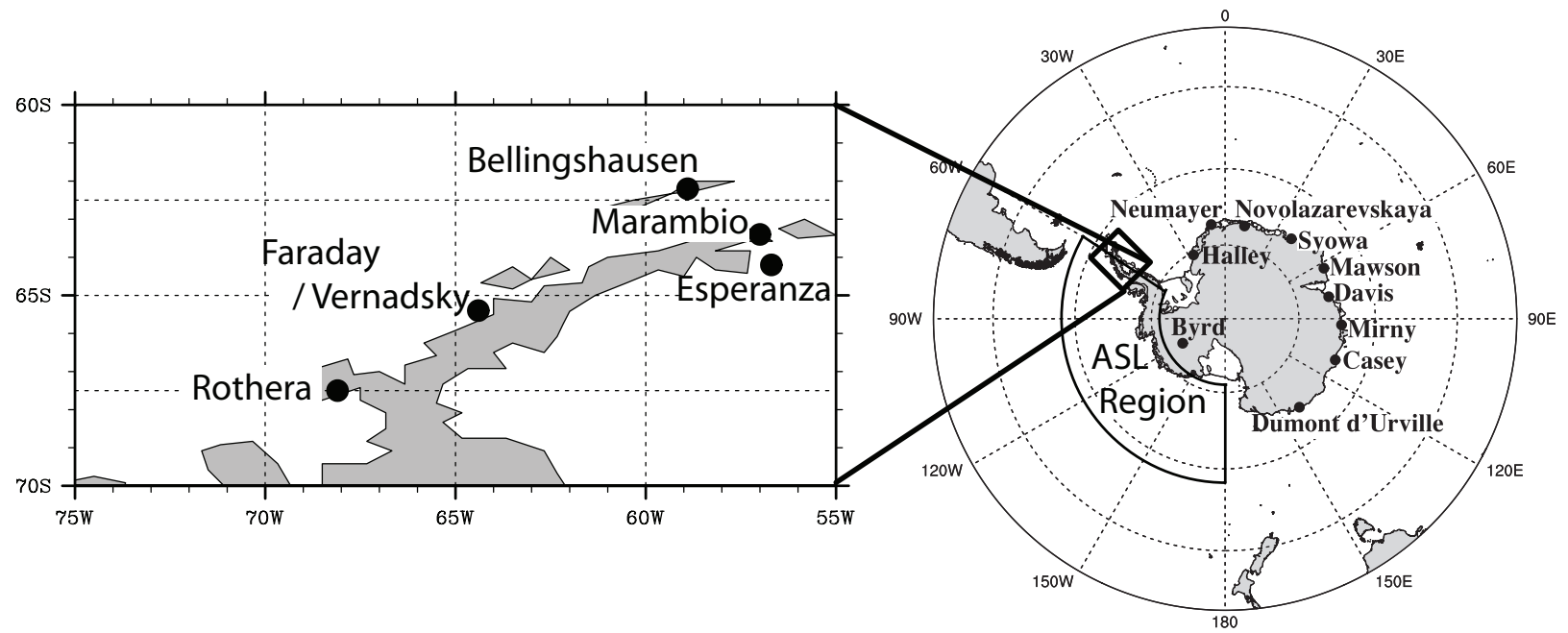

Figure 3.1: Map of the study area showing stations used and the ASL region.

To fill in gaps between the fixed station data and to investigate variability in the largescale atmospheric circulation, atmospheric reanalysis data are employed. Reanalysis data are generated by an atmospheric model at fixed times each day (every six hours) using a network of available surface, upper-air, and satellite observations (Kalnay et al. 1996). Reanalysis data are especially useful over the SH, especially in the Antarctic region, as they provide both spatial and time-continuous coverage of atmospheric conditions across remote regions where observations are sparse. Reanalysis data are not equivalent to observations, but they are constrained by global observations and their skill over the high southern latitudes improved significantly after 1979 once modern satellite observations were routinely incorporated into the data assimilation (Bromwich and Fogt 2004).

The primary reanalysis used in this study is the European Centre for Medium-Range Weather Forecasts Interim reanalysis (ERA-Interim; Dee et al. 2011), which was downloaded freely on the internet at http://apps.ecmwf.int/datasets/data/interim-full-daily/levtype $=\mathrm{sfc} /$. The atmospheric parameters are analyzed as monthly-means, and are employed at a $1.5^{\circ} \times 1.5^{\circ}$ latitude-longitude horizontal grid unless otherwise stated. As alluded to previously, reanalysis data are used only from 1979 onwards, which marks the beginning of the modern satellite era when satellite-derived temperature, winds, clouds, and sea ice concentrations were incorporated to fill in observation voids which significantly improved their skill over data sparse regions. Results using ERA-Interim were compared with other modern reanalyses, including the National 
Centers for Environmental Prediction Climate Forecast System Reanalysis (CFSR; Saha et al. 2010), the National Aeronautics and Space Administration's Modern-Era Retrospective Analysis for Research and Applications version 2 (MERRA-2; Rienecker et al. 2011), and the Japanese 55 year reanalysis (JRA-55; Kobayashi et al. 2015), and the key results presented in this study remain valid. Because ERA-Interim is considered superior over the high southern latitudes compared to other reanalyses (Bromwich et al. 2011; Bracegirdle and Marshall 2012), particularly in the Amundsen Sea / West Antarctic sector (Bracegirdle 2012; Jones et al. 2016b), ERA-Interim is preferred and only results from ERA-Interim are shown in this study.

Variability in the central pressure / magnitude of the ASL is investigated following Fogt et al. (2012b) using the minimum ERA-Interim mean sea level pressure value in the region 55$75^{\circ} \mathrm{S}, 180-60^{\circ} \mathrm{W}$. The ASL region is shown in Fig. 3.1.

Tropical SSTs and Antarctic sea ice concentrations are investigated using monthly-mean data from the Hadley Centre Sea Ice and Sea Surface Temperature data set (Rayner et al. 2003). The data are employed at $1^{\circ} \times 1^{\circ}$ latitude-longitude resolution starting in 1979 , and were accessed freely online from the UK Met Office Hadley Centre (http://www.metoffice.gov.uk/hadobs/hadisst/). Tropical SSTs are also examined using the National Oceanic and Atmospheric Administration Extended Reconstructed Sea Surface Temperature version 4 dataset (ERSSTv4; Huang et al. 2014; Liu et al. 2014) employed as monthly-means at $2^{\circ} \times 2^{\circ}$ latitude-longitude resolution and obtained online from the Earth System Research Laboratory (https://www.esrl.noaa.gov/psd/data/gridded/data.noaa.ersst.v4.html).

Variability in tropical deep convection is monitored using satellite-derived outgoing longwave radiation (OLR), which is a proxy to measure convective activity over the tropics. Negative OLR (cold temperature) anomalies in the tropics are associated with cold, high cloud tops, which reflect areas of deep convection in tropical regions. Monthly-mean OLR data are employed on an interpolated $2.5^{\circ} \times 2.5^{\circ}$ latitude-longitude horizontal grid, and are only assessed over the tropics (i.e., between $35^{\circ} \mathrm{S}$ and $35^{\circ} \mathrm{N}$ ); outside of the tropics, OLR data is less reliable at depicting convective activity due to colder surface and air temperatures surrounding the convection. The OLR data are downloaded online from the Earth System Research Laboratory's Physical Science Division (https://www.esrl.noaa.gov/psd/; Liebmann and Smith 1996).

Monthly ENSO activity is monitored using the Southern Oscillation Index (SOI) and SST anomalies averaged over the Niño 3.4 region of the central tropical Pacific $\left(5^{\circ} \mathrm{N}-5^{\circ} \mathrm{S}, 170\right.$ - 
$\left.120^{\circ} \mathrm{W}\right)$. The $\mathrm{SOI}$ is the calculated as the difference in observed sea level pressure anomalies between Tahiti (central tropical Pacific) and Darwin, Australia (western tropical Pacific). The SOI depicts the atmospheric (i.e., Southern Oscillation) component of ENSO events, and therefore is particularly useful for measuring the strength of the Walker circulation. Positive SOI values (i.e., a positive pressure anomaly at Tahiti and a negative pressure anomaly at Darwin) are associated with anomalously strong trade winds and an amplified Walker circulation, which is commonly seen for La Niña events. When the SOI is negative, negative surface pressure anomalies are seen farther east over the central tropical Pacific near Tahiti (following the region of warmest SSTs / deep convection), which is associated with a weakening of the trade winds / Walker circulation, which is commonly seen during El Niño events.

Sea surface temperature anomalies in the Niño 3.4 region reflect the oceanic component of ENSO. The Niño 3.4 region consists of the greatest interannual SST variance over the tropical Pacific, and therefore reflects the region where SST anomalies associated with ENSO tend to maximise and / or occur most frequently. Negative SST anomalies in the Niño 3.4 region are associated with La Niña conditions (and positive SOI values), while El Niño events are associated with positive SST anomalies in the Niño 3.4 region as the trade winds weaken and / or westerly winds episodes occur and the warm SSTs over the western tropical Pacific migrate east toward the central tropical Pacific. Because regions of deep convection / surface low pressure tend to follow the positive SST anomalies, negative surface pressure anomalies are often seen near the positive SST values, hence the strong connection between Niño 3.4 SST anomalies and the SOI. Both the SOI and Niño 3.4 SST anomalies were accessed online from the Climate Prediction Center (CPC; www.cpc.ncep.noaa.gov/data/indices).

Variability in the SAM is monitored using the observation-based index of Marshall (2003). The Marshall (2003) SAM index uses the difference in observed sea level pressure anomalies averaged across six stations located along $\sim 40^{\circ} \mathrm{S}$ and six stations located along $\sim 65^{\circ} \mathrm{S}$. Positive SAM index values reflect the positive polarity of the SAM in which positive pressure anomalies are seen across the middle latitudes and negative pressure anomalies are seen over Antarctica, which is commonly associated with a strengthening of the mid-latitude jet. Negative values of the SAM index reflect a weakened, more meridional mid-latitude jet with negative pressure anomalies seen across the middle latitude and positive pressure anomalies seen over 
Antarctica. The Marshall (2003) SAM index was obtained freely on the internet at https://legacy.bas.ac.uk/met/gjma/sam.html.

\subsection{Analysis Techniques}

Relationships between the tropics and SH climate are investigated using a range of linear statistical techniques. The data are assumed to be normally distributed (i.e., the data are most commonly located around the mean, and the probability of data occurring outside of the mean decreases moving farther away from the mean), which is a reasonable assumption for the meteorological / climate parameters analyzed in this study (i.e., temperature, pressure, and meridional / zonal components of the wind).

Linear trends in the data are investigated using the linear least squares regression approach, where the "trend" is the slope of the line that best fits the data. Linear trend analysis is used to investigate changes in meteorological parameters and climate indices over time. The line used to fit the data is defined as:

$$
y=b x+a
$$

where $y$ is the dependent variable (i.e., the meteorological parameter or climate index), $x$ is the independent variable (i.e., time), $b$ is the regression coefficient (i.e., slope or trend), and $a$ is the intercept. The regression coefficient $(b)$ is the covariance of $x$ and $y$ divided by the variance of $x$, written as:

$$
b=\frac{\sum_{i=1}^{n}\left(x_{i}-\bar{x}\right)\left(y_{i}-\bar{y}\right)}{\sum_{i=1}^{n}\left(x_{i}-\bar{x}\right)^{2}}
$$

where $x_{i}$ and $y_{i}$ are the data minus their respective time means, $\bar{x}$ and $\bar{y}$, over all time steps $n$ (i.e., number of years). A two-tailed Student's $t$ test is used to calculate the statistical significance of trends. The two-tailed $t$ test is used to calculate the probability of the 
hypothesised (i.e., null hypothesis) slope being zero while allowing for the actual slope to be either positive or negative, which is a more conservative approach than a one-tailed $t$ test as it makes no prior assumptions to the data. The $t$ test is calculated following the equation:

$$
t_{n-2} \approx \frac{b-b_{0}}{s_{b}}
$$

where $b_{o}$ is the hypothesised slope (zero), $b$ is the actual slope, and $S_{b}$ is the standard error of the slope:

$$
s_{b}=\frac{\sqrt{\left(\frac{1}{n(n-2)}\right)\left[n \sum_{i=1}^{n}\left(y_{i}\right)^{2}-\left(\sum_{i=1}^{n} y_{i}\right)^{2}-\frac{\left(n \sum_{i=1}^{n} x_{i} y_{i}-\left[\sum_{i=1}^{n} x_{i}\right]\left[\sum_{i=1}^{n} y_{i}\right]\right)^{2}}{n \sum_{i=1}^{n}\left(x_{i}\right)^{2}-\left(\sum_{i=1}^{n} x_{i}\right)^{2}}\right]}}{\sqrt{n \sum_{i=1}^{n}\left(x_{i}\right)^{2}-\left(\sum_{i=1}^{n} x_{i}\right)^{2}}}
$$

Because the data used in this study are monthly and seasonal means, which are assumed to be independent from year to year (i.e., autocorrelation in the data is weak), the degrees of freedom used throughout the study are $n-2$.

Linear relationships between data are calculated using linear correlation and linear congruency analysis. The linear correlation coefficient, $r$, also known as the Pearson productmoment correlation, is calculated as:

$$
r=\frac{\sum_{i=1}^{n}\left(x_{i}-\bar{x}\right)\left(y_{i}-\bar{y}\right)}{\sqrt{\sum_{i=1}^{n}\left(x_{i}-\bar{x}\right)^{2}} \sqrt{\sum_{i=1}^{n}\left(y_{i}-\bar{y}\right)^{2}}}
$$

which is the covariance of two variables, $x$ and $y$, divided by the product of their respective standard deviations. Defined in this fashion, the correlation coefficient varies between \pm 1 and reflects how well two variables vary together in time or space. The percent of variance explained in $x$ by $y$ or vice versa is calculated by squaring the correlation coefficient and multiplying by 100. Therefore, correlations of 1 and -1 indicate $x$ and $y$ vary perfectly together and variability in 
$x$ explains $100 \%$ of the variability in $y$. Linear correlation analysis is especially useful in climate studies for identifying teleconnection patterns, which often appear as alternating "centers" of maximum correlation, which is originally how the ENSO teleconnection patterns were identified (Walker and Bliss 1932, 1937).

Partial correlation analysis is also used in this study to investigate relative relationships between two variables that may be influenced by a common third variable, called the covariate. Give three variables that are correlated with one another, $x$ (i.e., ENSO), $y$ (i.e., SAM), and $z$ (i.e., temperature), partial correlation calculates the correlation of $x$ with $z$ after linearly removing the shared correlation that $x$ and $y$ have with the covariate, $y$. Partial correlation of $x$ with $z\left(p r_{x z}\right)$ is calculated following Cohen and Cohen (1983):

$$
p r_{x z}=\frac{r_{x z}-\left(r_{y z} r_{x y}\right)}{\sqrt{1-r_{y z}^{2}} \sqrt{1-r_{x y}^{2}}}
$$

where $r_{x z}$ is the correlation of $x$ with $z, r_{y z}$ is the correlation of $y$ with $z$, and $r_{x y}$ is the correlation of $x$ with $y$.

The statistical significance of correlations and partial correlations is calculated using a two-tailed Student's $t$ test against the null hypothesis of a zero correlation:

$$
t_{n-2}=\frac{r \sqrt{n-2}}{\sqrt{1-r^{2}}}
$$

where $r$ is the correlation coefficient and $n$ is the sample size. As with the trend / slope analysis, using two tails allows for the correlation to be positive or negative and makes no prior assumptions to the data. In all cases where correlation analysis is performed, the data are detrended prior to calculating the correlation so that trends in the data do not influence how much two variables vary together.

To statistically quantify the impact of linear trends in the data, linear congruency analysis is employed. Linear congruency is an algebraic manipulation of the linear regression techniques already discussed in this section, whereby the linear trend in a variable $x$ and its linear 
relationship with another variable $y$ is used to statistically quantify how linear changes in $x$ will produce linear responses in $y$. It is calculated as:

$$
\text { linear congruency }=b_{x} b_{x y}
$$

where $b_{x}$ is the slope of $x$ over time (i.e., the trend) and $b_{x y}$ is the slope of $y$ over $x$ (i.e., $y$ regressed onto $x$ ). In this study, $x$ will be some climate index exhibiting a statistically significant trend, such as the SOI, SAM index, tropical SSTs, or tropical deep convection (OLR), and $y$ will be some meteorological parameter, such as pressure, temperature, or wind. Linear congruency analysis has been proven useful in many previous climate studies (e.g., Thompson et al. 2000; Nicolas and Bromwich 2014; Clem and Fogt 2015), and will be particularly useful in this study to quantify linear atmospheric circulation and temperature responses associated with changes over the tropics.

Lastly, this study uses anomaly composite analysis to identify anomalous atmospheric patterns associated with unique groups of data. To define groups, the data of interest are sorted with respect to either standardised anomalies or percentiles. For example, groups may be selected based on months or seasons where the SOI value exceeds one standard deviation above the climatological mean or for SOI values that are in the top $85^{\text {th }}$ percentile. Anomaly composite analysis examines the mean anomalies associated with these exceptional events. In this study, groups are selected with respect to the available years of atmospheric reanalysis data (i.e., around 36 years), and so sample sizes of five or six are used to allow for the cleanest investigation of anomalies associated with exceptional events; sample sizes of four or less may not capture the "average" conditions of extreme cases that instead may be dominated by the top one or two events, while sample sizes of seven or more fall below the $85^{\text {th }}$ percentile and therefore may not capture the uniqueness of the upper / lower percentiles of the distribution.

The statistical significance of anomaly composites is again calculated using a two-tailed Student's $t$ test, allowing for anomalies to be either positive or negative, following:

$$
t_{n-2}=\frac{\mu_{x \sqrt{n}}}{S_{p}}
$$


where $\mu_{x}$ is the mean of the pooled sample anomalies, $n$ is the pooled sample size, and $S_{p}$ is the pooled sample standard deviation.

In all cases, anomalies are calculated based on the 1981-2010 climatological mean, which is the standard 30-year period defined by the World Meteorological Organization by which to investigate modern (i.e., $21^{\text {st }}$ century) climate anomalies (WMO 2011). Seasons are defined as three-month averages with respect to the SH: summer is December-January-February (DJF), autumn is March-April-May (MAM), winter is June-July-August (JJA), and spring is SeptemberOctober-November (SON). Summer refers to the December year in all cases. 


\section{CHAPTER 4: RESULTS}

\subsection{Tropical Pacific Relationships with Recent Trends in the SH Zonal-Mean Circulation}

\subsubsection{Overview}

This section presents results from Clem et al. (2016a) published in Climate Dynamics in August of 2016. It investigates how recent trends in tropical Pacific SSTs have impacted the SH zonal-mean circulation, particularly the SH westerlies / mid-latitude jet, during austral summer and autumn. In these seasons, there has been a marked increase in the strength of the westerlies, which has been linked primarily to stratospheric ozone depletion during the spring. Here, it is demonstrated that recent trends in tropical Pacific SSTs are also consistent with the strengthened westerlies during summer and autumn. The tropical Pacific impact is most marked during autumn when the westerlies are observed to have significantly strengthened over the Pacific only, which is consistent with tropical forcing, while ozone-related forcing consists of a hemisphere-wide strengthening of the westerlies, which is not seen in observations during autumn. These results suggest the strengthened summer and autumn westerlies, which has had a profound impact on Antarctic and mid-latitude SH climate, are a combined result of ozone forcing (which tightens the upper-tropospheric mid-to-high latitude temperature gradient) and tropical Pacific forcing (which increases poleward momentum fluxes and strengthens the lowertropospheric temperature gradient), and future variability and changes in the SH westerlies during summer and autumn will be dependent on a combination of both ozone recovery and tropical Pacific climate variability. These results significantly add to our understanding of how and why there have been such strong changes in the SH westerlies during summer and autumn by highlighting that it is a combination of ozone depletion and forcing from the tropical Pacific occurring simultaneously rather than just the former acting in isolation. 


\subsubsection{Seasonal Trends and Correlations}

Seasonal linear trends in tropical Pacific SSTs over 1979-2014 are shown in Fig. 4.1. Consistent with previous findings (e.g., Zhang et al. 2010; Trenberth et al. 2014), all seasons show a significant negative SST trend in the eastern tropical Pacific and significant positive SST trend across the western equatorial Pacific stretching southeastward along the South Pacific Convergence Zone. To place the eastern tropical Pacific cooling in context with ENSO and other SH climate trends, seasonal trends in the SOI, Niño 3.4 SSTs, and SAM are examined in Table 4.1. The eastern tropical Pacific cooling region is defined as the area-averaged (weighted by cosine of latitude) SST over the region $15-25^{\circ} \mathrm{S}, 110-80^{\circ} \mathrm{W}$ and is denoted by a black box in Fig. 4.1. Trends in the SAM are calculated for the Marshall SAM index and for the Indian $\left(0^{\circ}-\right.$ $\left.130.5^{\circ} \mathrm{E}\right)$ and Pacific $\left(150^{\circ} \mathrm{E}-85.5^{\circ} \mathrm{W}\right)$ Ocean sectors separately using the difference in standardised zonal-mean ERA-Interim $500 \mathrm{hPa}$ geopotential height anomalies between $40^{\circ} \mathrm{S}$ and $65^{\circ} \mathrm{S}$. The $500 \mathrm{hPa}$ level is used to define the regional SAM indices because extra-tropical circulation anomalies associated with tropical teleconnections are commonly more pronounced and easier to distinguish at middle to upper tropospheric levels (e.g., Karoly 1989; Mo and Higgins 1998; Ding and Steig 2013). It should be noted that although splitting the SAM index into Pacific and Indian sectors does not actually describe the SAM (as it is a hemispheric pattern), this study builds on the results of Ding et al. (2012b) and it is useful to examine the circulation over each region separately to more fully understand differences between the tropically-forced component of the SAM (i.e., the Pacific) and the eddy-driven component (i.e., the Indian).

A weakly significant $(p<0.10)$ positive trend in the SOI is found during all seasons except JJA, but no significant SST trends are observed in the Niño 3.4 region during any season. As shown in Fig. 4.1, the significant cooling in the eastern tropical Pacific is primarily off-equatorial and located southeastward of the equatorial regions where ENSO activity is commonly monitored. This suggests that the eastern tropical Pacific cooling is possibly a manifestation of 


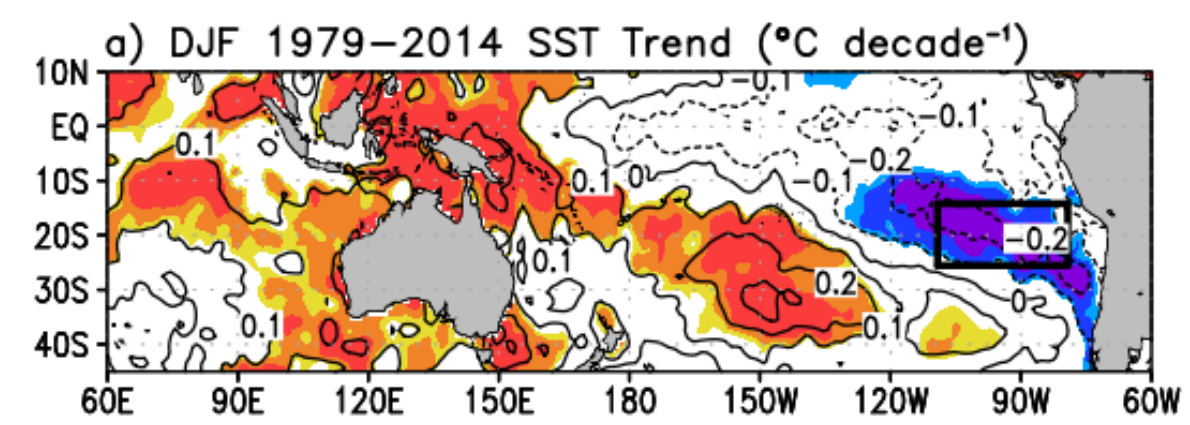

b) MAM SST Trend

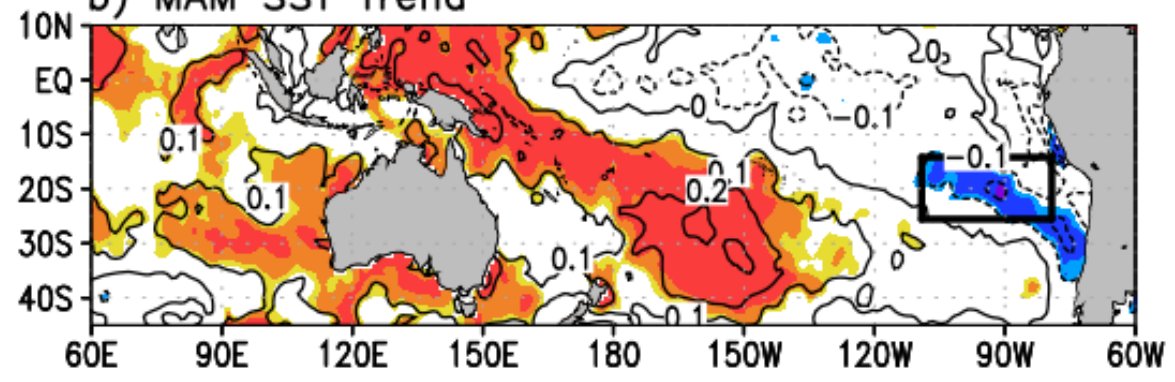

c) JJA SST Trend

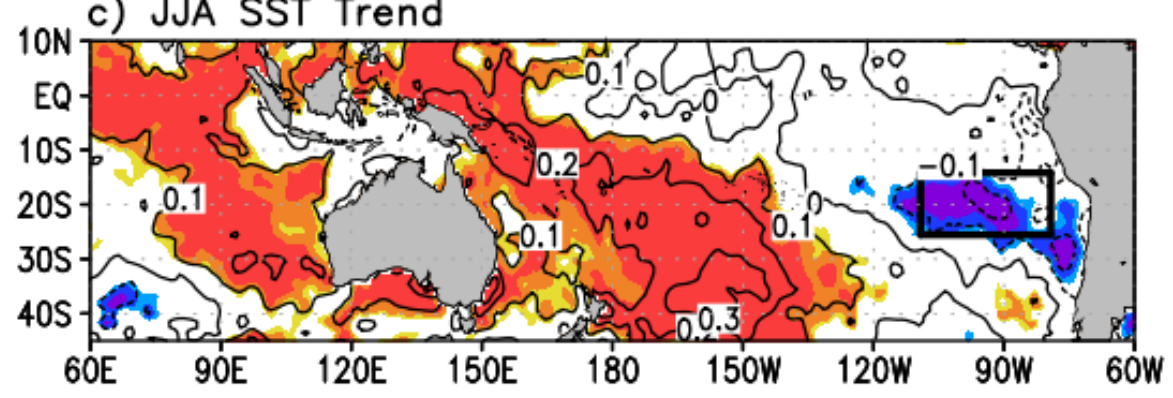

d) SON SST Trend

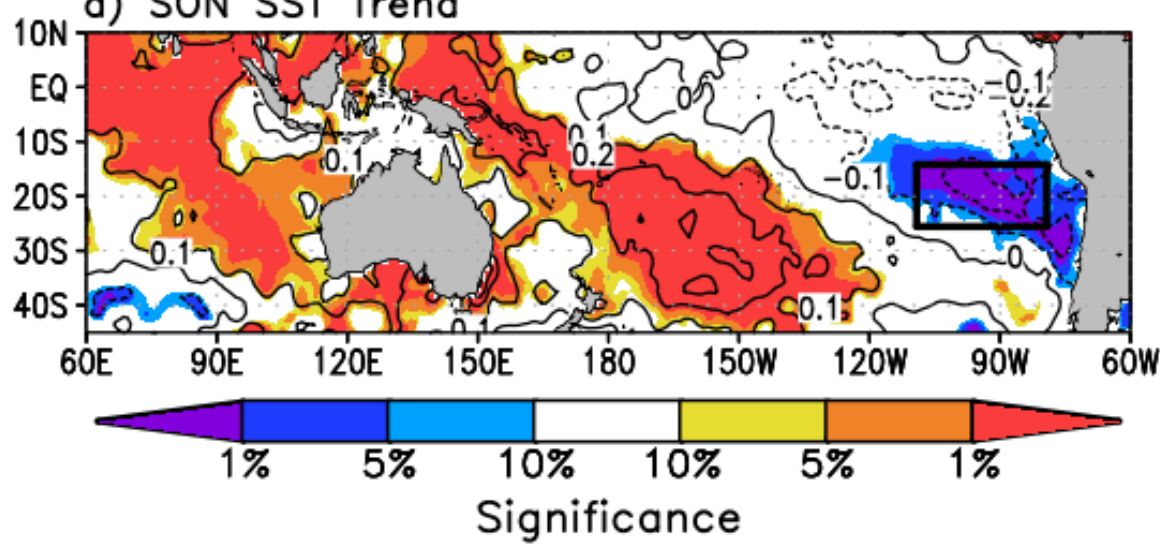

Figure 4.1: Seasonal linear trends in HadISST tropical Pacific SST over 1979-2014 for (a) DJF, (b) MAM, (c) JJA, and (d) SON. Shading (from lightest to darkest) indicates regions where trends are statistically different from zero at $p<0.10, p<0.05$, and $p<0.01$, respectively, as indicated by color bar. Contour interval is $0.1^{\circ} \mathrm{C}$ decade $^{-1}$. 
Table 4.1: Seasonal trends and 95\% confidence intervals, 1979-2014, for SOI, Niño 3.4 and eastern tropical Pacific (denoted by box in Fig. 4.1) SST, Marshall SAM index, Indian sector $\left(0^{\circ}-130.5^{\circ} \mathrm{E}\right) \mathrm{SAM}$ index, and Pacific sector $\left(150^{\circ} \mathrm{E}-85.5^{\circ} \mathrm{W}\right) \mathrm{SAM}$ index. Units for SOI and SAM index trends are standardised index decade ${ }^{-1}$, and units for SST trends are ${ }^{\circ} \mathrm{C}$ decade $^{-1}$. Trends significant at $p<0.10$ are boldface, trends significant at $p<0.05$ are boldface and underlined, and trends significant at $p<0.01$ are denoted with an asterisk.

\begin{tabular}{|c|c|c|c|c|}
\hline & DJF & MAM & JJA & SON \\
\hline \multicolumn{5}{|c|}{ Tropical Pacific } \\
\hline SOI & $0.53 \pm 0.61$ & $0.34 \pm 0.37$ & $0.11 \pm 0.36$ & $0.37 \pm 0.43$ \\
\hline Niño 3.4 SST & $-0.10 \pm 0.34$ & $-0.12 \pm 0.22$ & $-0.02 \pm 0.17$ & $-0.03 \pm 0.26$ \\
\hline \multirow[t]{2}{*}{ East Pacific SST } & $\underline{-0.17 \pm 0.11 *}$ & $-0.11 \pm 0.11$ & $\underline{-0.14 \pm 0.10 *}$ & $\underline{\mathbf{0}} .17 \pm 0.11^{*}$ \\
\hline & & $S A M$ & & \\
\hline Marshall Index & $\underline{0.52} \pm 0.37 *$ & $0.31 \pm 0.32$ & $0.08 \pm 0.37$ & $-0.01 \pm 0.39$ \\
\hline SAM Indian & $\underline{0.80} \pm \mathbf{0 . 5 2} *$ & $0.31 \pm 0.58$ & $-0.01 \pm 0.61$ & $-0.16 \pm 0.59$ \\
\hline SAM Pacific & $\underline{0.67 \pm 0.57}$ & $\underline{0.73 \pm 0.58}$ & $0.37 \pm 0.59$ & $0.36 \pm 0.54$ \\
\hline
\end{tabular}

mechanisms other than ENSO, while the western tropical Pacific warming is more consistent with the La Niña phase of ENSO (as reflected by the positive trends in the SOI).

The Marshall SAM index and Pacific SAM index both exhibit a significant positive trend during DJF and MAM, while the Indian SAM index shows a significant positive trend during DJF only. The positive trend in the Indian sector during DJF is significant at $p<0.01$ and is stronger than the Pacific sector trend, while the positive trend in the Pacific sector increases in magnitude during MAM. Although not statistically significant during JJA or SON, the Pacific sector SAM exhibits a positive trend during all seasons while the Indian sector SAM trend is near zero in JJA and weakly negative during SON.

Seasonal detrended correlations between the tropical Pacific and SAM indices are shown in Table 4.2. There is no significant correlation seen for the SOI or eastern tropical Pacific SSTs with the Marshall SAM index during any season. Correlations with the Marshall SAM index reverse sign during JJA, and in the Indian sector the correlations reverse sign during both JJA and SON. Seasonal correlations between the SOI and $500 \mathrm{hPa}$ geopotential height (not shown) show La Niña conditions are broadly associated with negative height anomalies across the middle latitudes of the Indian Ocean during JJA and SON, but the overall ENSO-related circulation pattern over the Indian Ocean does not project onto the JJA or SON Indian Ocean SAM pattern described by Fogt et al. (2012a). Therefore only during DJF and MAM would 
Table 4.2: Seasonal detrended correlations, 1979-2014, of Marshall SAM index, Indian sector SAM index, and Pacific sector SAM index with the SOI and eastern tropical Pacific SSTs. Statistical significance of correlation coefficients is as denoted in Table 4.1.

\begin{tabular}{|lcc|cc|cc|cc|}
\hline & \multicolumn{2}{c}{ DJF } & \multicolumn{2}{c|}{ MAM } & \multicolumn{2}{c|}{ JJA } & east & \multicolumn{2}{c|}{ east } \\
index & SOI & $\begin{array}{c}\text { east } \\
\text { Pacific }\end{array}$ & SOI & $\begin{array}{c}\text { east } \\
\text { Pacific }\end{array}$ & SOI & Pacific & SOI & Pacific \\
\hline Marshall & 0.27 & -0.23 & 0.18 & -0.20 & -0.13 & 0.21 & 0.21 & -0.20 \\
Indian & $\underline{\mathbf{0 . 3 5}}$ & $\mathbf{- 0 . 3 2}$ & 0.05 & -0.10 & -0.25 & 0.10 & -0.16 & 0.12 \\
Pacific & $\underline{\mathbf{0 . 5 6 *}}$ & $\underline{\mathbf{- 0 . 6 8 *}}$ & $\underline{\mathbf{0 . 5 6 *}}$ & $\underline{\mathbf{0 . 4 9 *}}$ & $\underline{\mathbf{0 . 4 3 *}}$ & -0.19 & $\underline{\mathbf{0 . 5 5 *}}$ & $\underline{\mathbf{0 . 4 9 *}}$ \\
\hline
\end{tabular}

positive SOI values / negative eastern tropical Pacific SST anomalies uniformly reinforce the full SH SAM pattern, although the ENSO-related circulation response is consistently strongest over the Pacific.

\subsubsection{Spatial Trends in the SAM and SH Zonal-Mean Circulation during DJF and MAM}

Statistically significant trends in the SAM are seen only during DJF and MAM, which have been linked to stratospheric ozone depletion. To quantify the influence of the tropical Pacific SST trends during these seasons, the remainder of this study will focus on DJF and MAM. The ENSO teleconnection to the SH also projects most strongly onto the full SH SAM pattern during DJF and MAM, and ENSO events tend to reach maturity during DJF and MAM further justifying a focus on DJF and MAM.

Linear trends in SH $500 \mathrm{hPa}$ geopotential height are shown in Fig. 4.2. During DJF, a positive SAM pattern is seen over the $\mathrm{SH}$ with positive height trends across the middle latitudes and a negative height trend poleward of $60^{\circ} \mathrm{S}$. The geopotential height trends during DJF are consistent with the significant positive trend in the Marshall SAM index and the significant positive SAM trends over both the Indian and Pacific sectors. During MAM, the $500 \mathrm{hPa}$ geopotential height trends are broadly consistent with the positive polarity of the SAM, but the significant trends are confined to the Pacific and reflect both a positive SAM phase and a tropically-forced wavetrain as discussed by Ding and Steig (2013). Outside of the Pacific, the positive SAM circulation trend is less apparent, consistent with the weaker, insignificant positive trend in the Indian sector SAM index and a weakened positive trend in the Marshall SAM index (Table 4.1). 

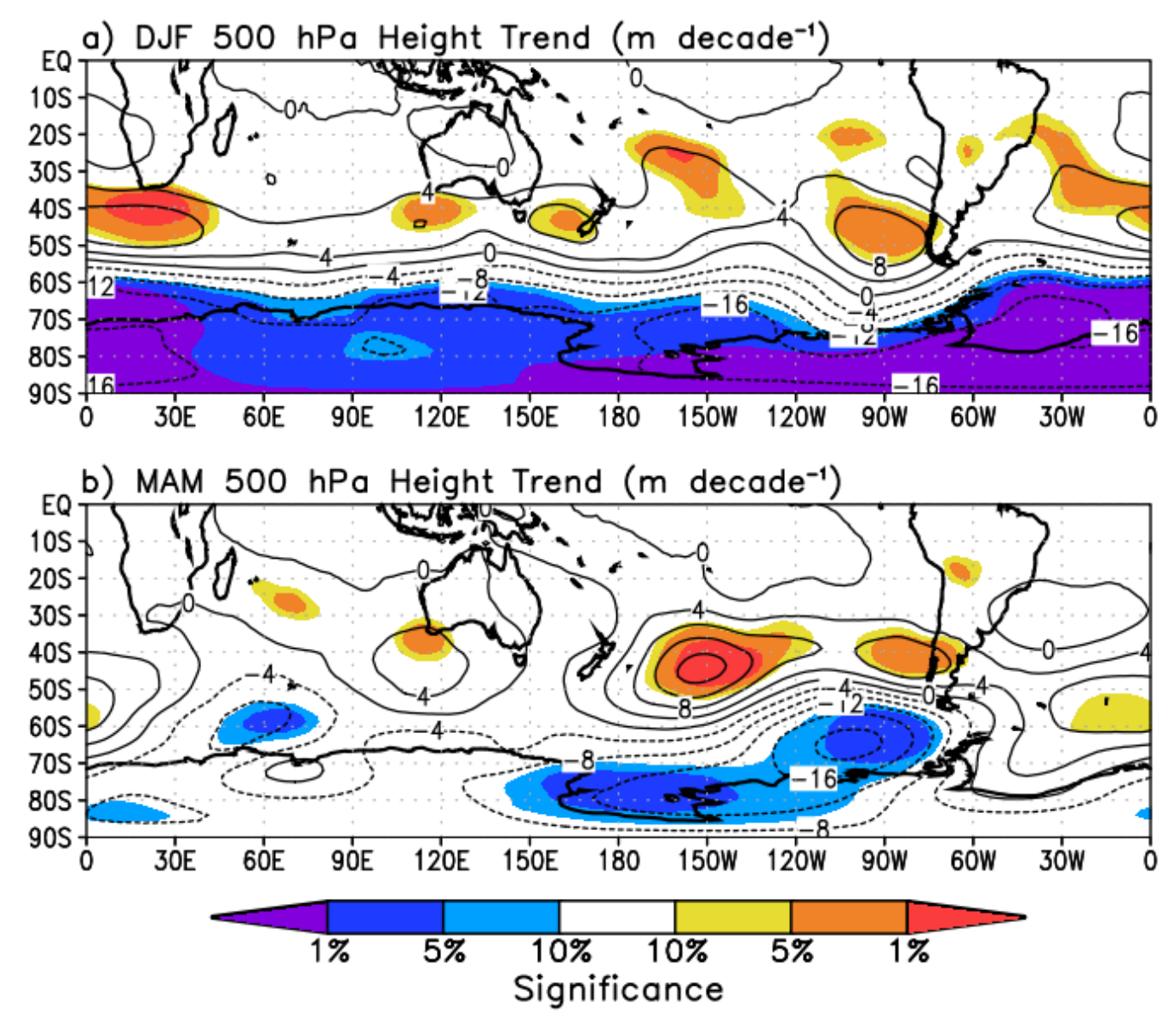

Figure 4.2: Linear trends in (a) DJF and (b) MAM ERA-Interim $500 \mathrm{hPa}$ geopotential height over 1979-2014. Statistical significance of trends is shaded as in Fig. 4.1. Contour interval is 4.0 m decade ${ }^{-1}$.

Linear trends in zonal-mean zonal wind and vertical overturning circulation are shown in Figs. 4.3 and 4.4 for the three separate regions: the full $\mathrm{SH}$, the Pacific sector $\left(150^{\circ} \mathrm{E}-85.5^{\circ} \mathrm{W}\right)$, and the Indian sector $\left(0^{\circ}-130.5^{\circ} \mathrm{E}\right)$ separately. The Atlantic Ocean sector from $75^{\circ} \mathrm{W}$ to the Greenwich Meridian is not included in the separate regions because this region is commonly comprised of circulation anomalies associated with the PSA pattern (which is captured well by the Pacific sector) yet is different from the Indian sector in that it does not always exhibit a strong eddy-driven jet.

During DJF (Fig. 4.3), significant positive zonal-mean zonal wind trends are observed between 50 and $60^{\circ} \mathrm{S}$ in all three cross-sections. The positive zonal wind trends extend from the troposphere into the lower stratosphere reflecting stratosphere-troposphere coupling that is commonly seen during DJF, and is also consistent with previous studies linking the 

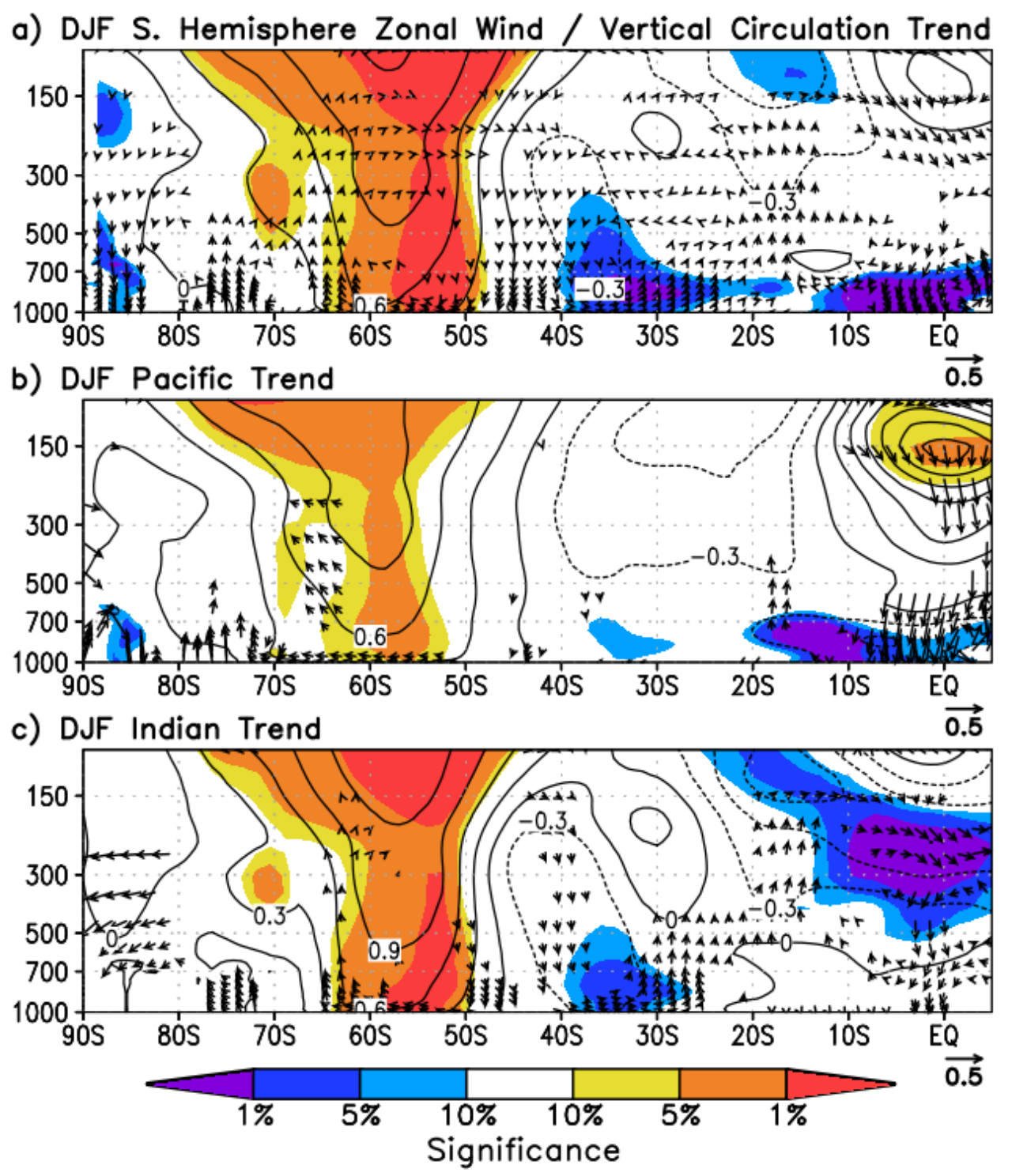

Figure 4.3: DJF linear trends in ERA-Interim zonal-mean zonal wind (contours) and zonal-mean vertical circulation (vectors) over 1979-2014 for (a) the full SH, (b) Pacific Ocean sector $\left(150^{\circ} \mathrm{E}-\right.$ $\left.85.5^{\circ} \mathrm{W}\right)$, and $(\mathrm{c})$ Indian Ocean sector $\left(0^{\circ}-130.5^{\circ} \mathrm{E}\right)$. Shading indicates statistical significance of zonal-mean zonal wind trends, and is drawn as in Figs. 4.1-4.2. Vectors are comprised of the zonal-mean meridional wind trend $\left(\mathrm{ms}^{-1}\right.$ decade $\left.^{-1}\right)$ and zonal-mean vertical velocity trend (hPa decade $^{-1}$; scaled by a factor of $-10^{2}$ ), and are drawn only if at least one vector component has a significant trend different from zero at $p<0.10$. Contour interval is $0.3 \mathrm{~ms}^{-1}$ decade $^{-1}$.

strengthening of the circumpolar westerlies during DJF to stratospheric ozone depletion (Thompson and Solomon 2002; Gillett and Thompson 2003; Son et al. 2010; Polvani et al. 2011). The positive zonal wind trend is strongest over the Indian sector compared to the Pacific sector, and is statistically significant at $p<0.01$ throughout the troposphere and lower stratosphere 


\section{a) MAM S. Hemisphere Zonal Wind / Vertical Circulation Trend}
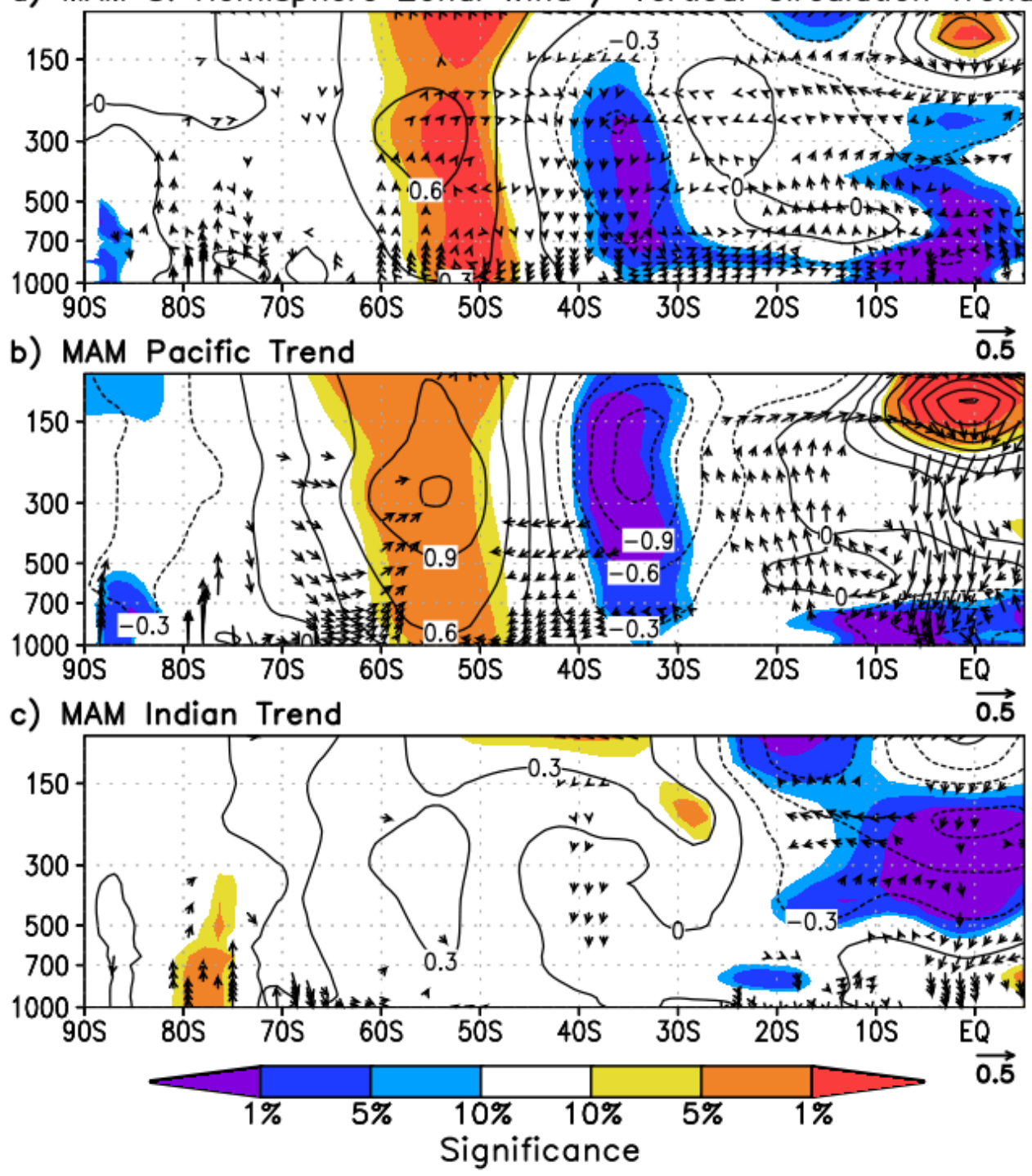

Figure 4.4: As in Fig. 4.3, except for MAM.

for the Indian sector and full SH zonal-mean. The lower significance values over the Pacific (compared to the SH and Indian) is likely due to higher interannual variability in the zonal circulation associated with the zonal asymmetry commonly seen over the South Pacific (Fogt et al. 2012a). Over the tropical Pacific during DJF (Fig. 4.3b), a significant negative trend in lowlevel zonal wind and a significant positive trend in upper tropospheric zonal wind indicate a strengthening of the Walker circulation, consistent with the SST trends toward increased La Niña conditions and in agreement with previous studies (e.g., McGregor et al. 2014). Across the tropical Indian sector (Fig. 4.3c), a significant negative trend in upper tropospheric zonal wind is 
seen which is likely related to changes in the Walker circulation associated with increased upward motion over the western tropical Pacific.

During MAM (Fig. 4.4), a significant positive trend in zonal-mean zonal wind is seen between 50 and $60 \cdot \mathrm{S}$ for the full $\mathrm{SH}$ cross-section, consistent with the continued positive trend in the Marshall SAM index during MAM. However, the positive zonal wind trends are only significant in the Pacific sector, which is consistent with the weakened, insignificant positive trend in the Indian sector SAM index while the positive trend in the Pacific sector SAM index increases in magnitude during MAM. The core of the strongest positive zonal wind trends is in the troposphere $(\sim 300 \mathrm{hPa})$ rather than the lower stratosphere, and is strongest over the Pacific. In the tropics, the full $\mathrm{SH}$ zonal mean shows a significant negative zonal wind trend between 30 and $40^{\circ} \mathrm{S}$, which is seen only over the Pacific. The weakened westerlies between 30 and $40^{\circ} \mathrm{S}$ over the Pacific resemble a weakening of the sub-tropical jet (STJ) as it develops over the Pacific during MAM. Closely tied to the weakened STJ is a weakening of the South Pacific Hadley cell during MAM (as indicated by increased subsidence / weakened ascent over the equatorial Pacific and weakened upper tropospheric poleward flow in the divergent branch of the Hadley cell) which is commonly associated with La Niña conditions (e.g., Oort and Yienger 1996). The weakened Hadley cell would be associated with a weakened Coriolis torque in the divergent branch which would in turn weaken the STJ. The Walker circulation over the Pacific also exhibits significant strengthening during MAM as indicated by strengthened low-level easterlies and upper tropospheric westerlies over the tropical Pacific (Fig. 4.4b).

\subsubsection{Zonal-Mean Zonal Wind Relationship with the Tropical Pacific}

The linear relationship between the positive SOI trend and eastern tropical Pacific cooling and trends in the SH zonal-mean zonal winds are examined using linear congruency in Figs. 4.5-4.6. The percentage of the expected zonal wind trends that is linearly congruent with the observed zonal wind trends is shaded and only shown where observed zonal wind trends are significant at $p<0.10$. To quantify the response in the Pacific relative to the full $\mathrm{SH}$, only results for the SH and Pacific are shown. The Indian sector is not included because the Indian sector trends during DJF are captured well by the SH trend, and the Pacific sector appears to dominate the $\mathrm{SH}$ trend during MAM. 
a) DJF S. Hemisphere Uwnd Trend
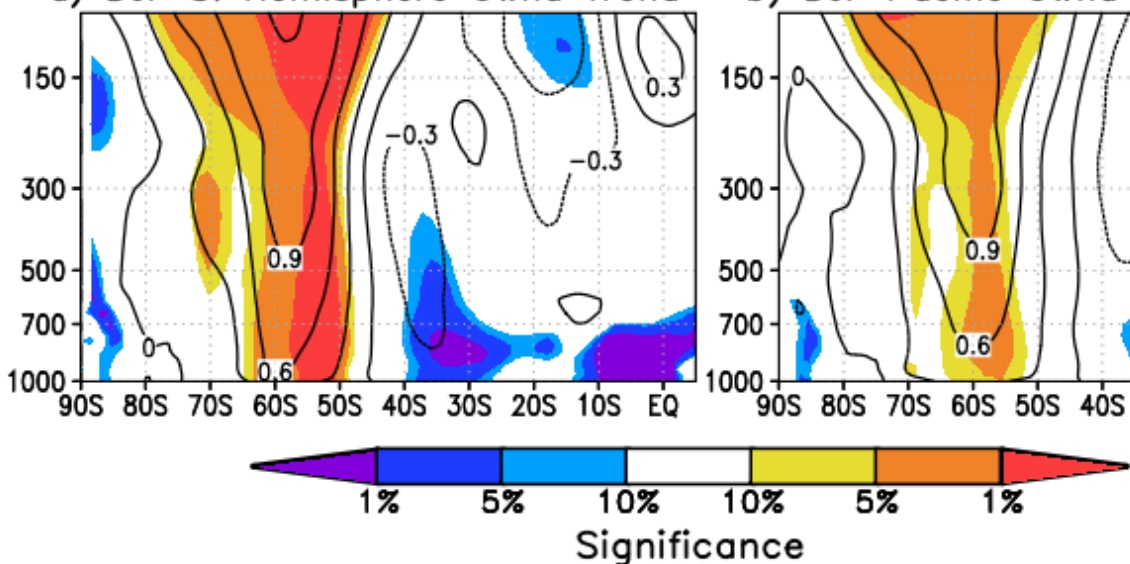

c) Congruent with SOI

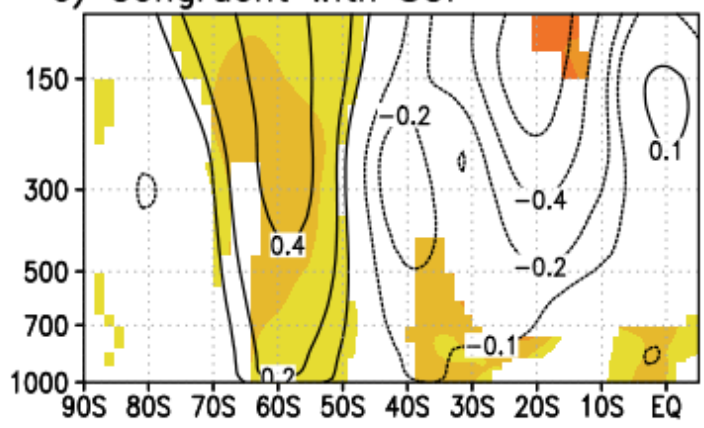

e) Congruent with east Pacific SST

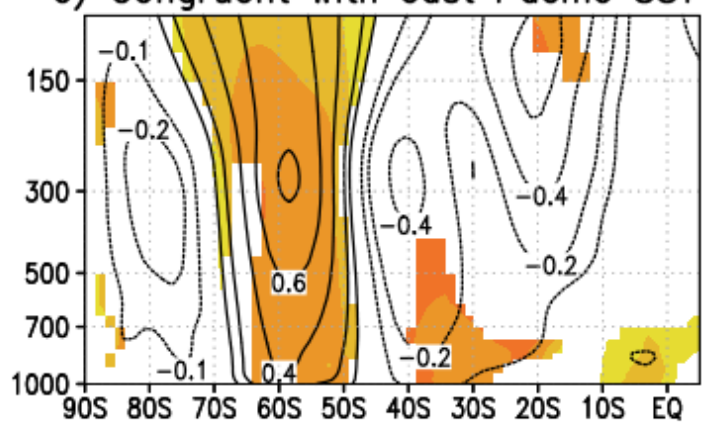

b) DJF Pacific Uwnd Trend

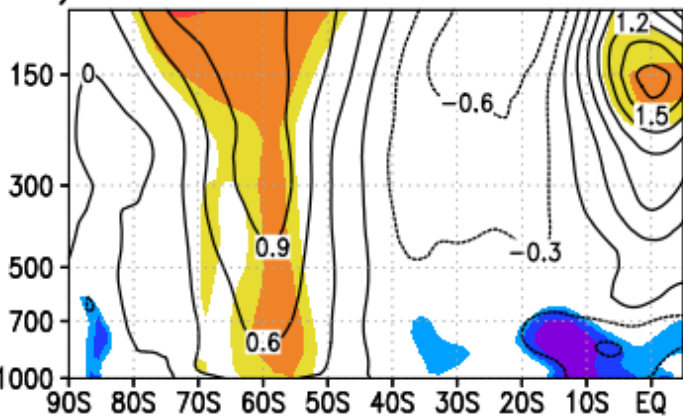

d) Congruent with SOI

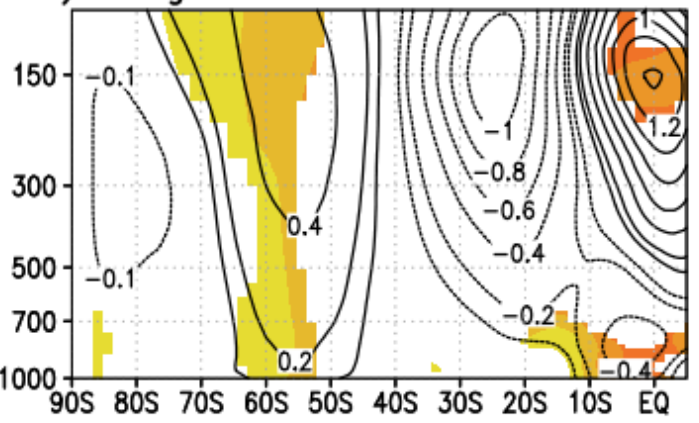

f) Congruent with east Pacific SST

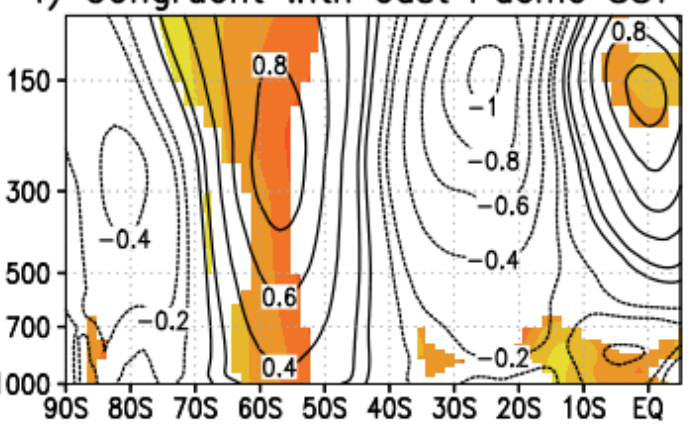

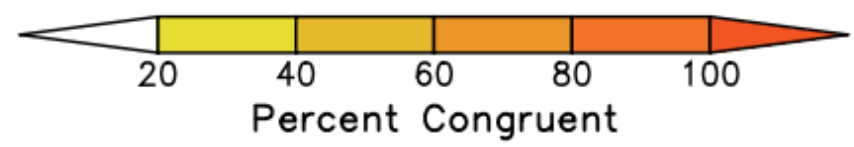

Figure 4.5: Linear trends of DJF ERA-Interim zonal-mean zonal wind for (a) SH and (b) Pacific sector, as in Fig. 4.3a-b, and linear congruency of the trends with the DJF (c-d) SOI and (e-f) eastern tropical Pacific SST trends. Contours in (c-f) indicate the expected zonal-mean zonal wind trends $\left(\mathrm{ms}^{-1}\right.$ decade $\left.^{-1}\right)$ from the SOI and eastern tropical Pacific SST trends, and shading indicates the percentage of the statistically significant trends in (a-b) that is linearly congruent with the SOI and eastern tropical Pacific SST trends. Contour interval is $0.3 \mathrm{~ms}^{-1}$ decade $^{-1}$ for (ab) and $0.2 \mathrm{~ms}^{-1}$ decade $^{-1}$ with an additional contour at $\pm 0.1 \mathrm{~ms}^{-1}$ decade $^{-1}$ for (c-f). Zero contours are omitted for (c-f). 
a) MAM S. Hemisphere Uwnd Trend
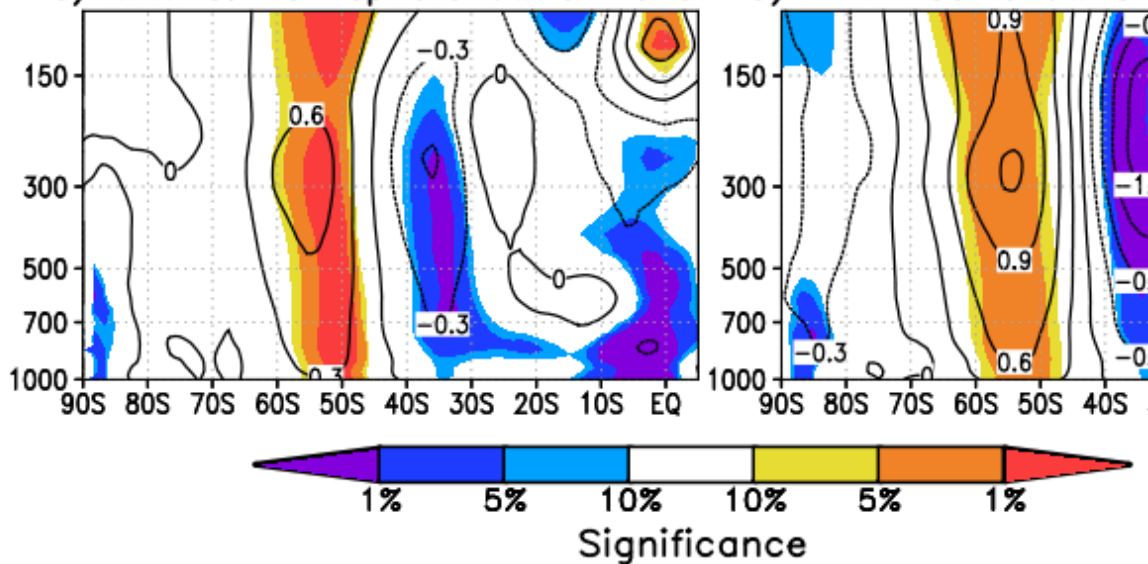

c) Congruent with SOI

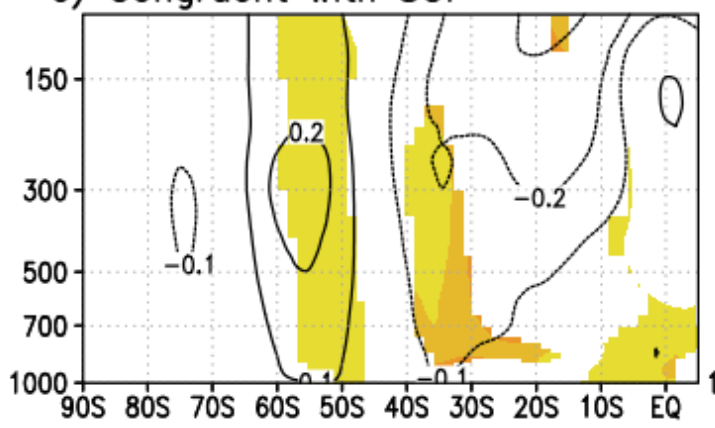

e) Congruent with east Pacific SST

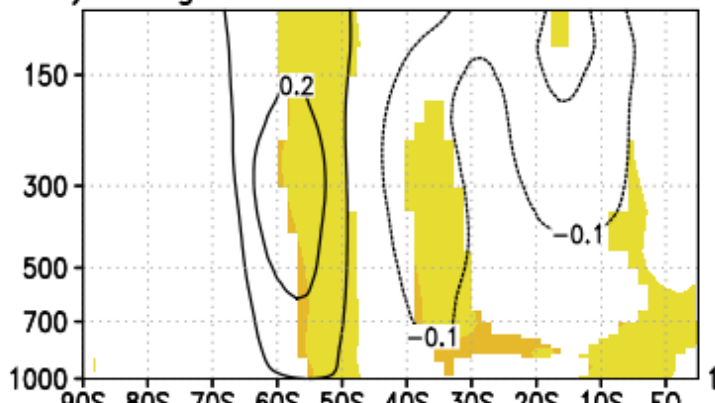

9OS $80 \mathrm{~S}$ TOS $60 \mathrm{~S}$ 5OS $40 \mathrm{~S}$ 3OS $20 \mathrm{~S}$ LOS EQ

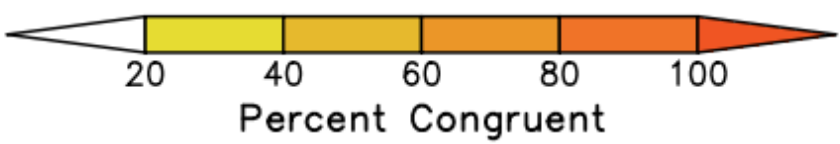

Figure 4.6: As in Fig. 4.5, except for MAM.

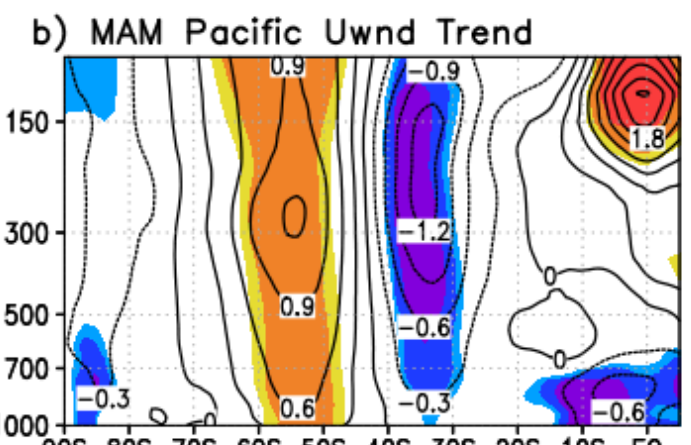

90S $80 \mathrm{~S} 70 \mathrm{~S}$ 6OS $50 \mathrm{~S} 40 \mathrm{~S} 30 \mathrm{~S} 20 \mathrm{~S} 10 \mathrm{~S}$ EQ

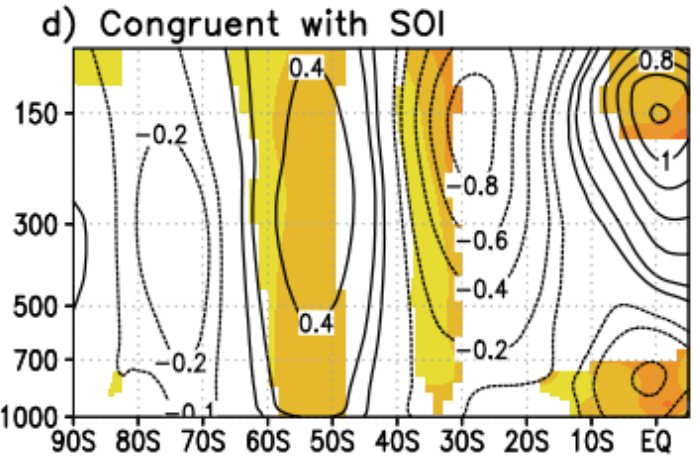

f) Congruent with east Pacific SST

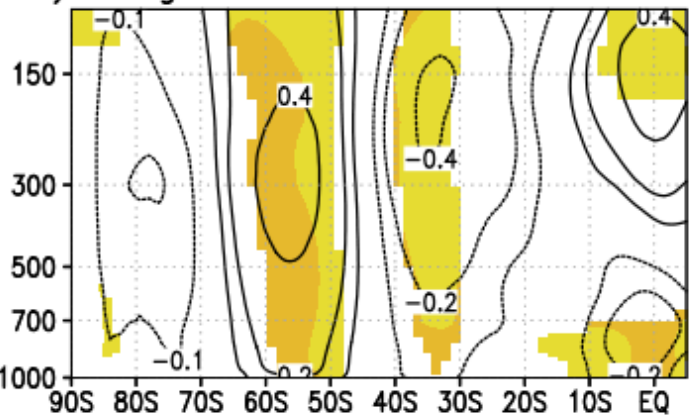

Linear congruency for DJF is shown in Fig. 4.5. The observed DJF zonal-mean zonal wind trends from Fig. 4.3 are given at the top for reference. The zonal-mean zonal wind response associated with the SOI and SST trends are spatially similar and both align well with the observed zonal wind trends. Both are associated with weakened upper tropospheric westerlies at $\sim 20^{\circ} \mathrm{S}$ and $\sim 40^{\circ} \mathrm{S}$ over the SH and strengthened westerlies between 50 and $60^{\circ} \mathrm{S}$ over both the 
SH and Pacific. The linear response associated with eastern tropical Pacific SST cooling is strongest, with $60-80 \%$ of the significant SH and Pacific tropospheric zonal wind trends poleward of $20^{\circ} \mathrm{S}$ linearly congruent with the observed eastern tropical Pacific cooling, including the tropospheric portion of the strengthened westerlies at $50-60^{\circ} \mathrm{S}$. Over the tropical Pacific (Fig. $4.5 \mathrm{~d}, \mathrm{f})$, the expected zonal wind trends are also nearly identical in sign and location and are consistent with a strengthened Walker circulation and weak, insignificant weakening of upper tropospheric westerlies between 15 and $30^{\circ} \mathrm{S}$.

During MAM (Fig. 4.6), the positive SOI trend and eastern tropical Pacific cooling are linearly congruent with $20-40 \%$ of the negative zonal wind trend between 30 and $40^{\circ} \mathrm{S}$ and the strengthened westerlies between 50 and $60^{\circ} \mathrm{S}$ for the $\mathrm{SH}$, and with around half (40-60\%) of the strengthened Pacific westerlies between 50 and $60^{\circ} \mathrm{S}$. The SOI trend is linearly congruent with more than half of the negative zonal wind trend at $30^{\circ} \mathrm{S}$ (Fig. 4.6d), but the maximum linear congruency values are located farther equatorward than the observed negative zonal wind trend (centered at $\sim 35^{\circ} \mathrm{S}$ ). Linear congruency associated with the eastern tropical Pacific cooling aligns more closely to the observed negative zonal wind trend despite being slightly weaker.

Detrended partial correlations for eastern tropical Pacific SSTs (after removing the Marshall SAM index) and the Marshall SAM index (after removing eastern tropical Pacific SSTs) with zonal-mean zonal wind are shown in Figs. 4.7-4.8. The eastern tropical Pacific SST partial correlation values are multiplied by -1 to represent the appropriate zonal wind anomaly associated with negative eastern tropical Pacific SST anomalies. Due to the higher statistical significance of eastern tropical Pacific SST trends (compared to the SOI), only results using eastern Pacific SSTs are shown for the remainder of the study.

The DJF eastern tropical Pacific SST partial correlation (Fig. 4.7, left column) confirms the strong eastern tropical Pacific SST relationship with zonal winds, even after trends covariability with the SAM index are removed. During DJF, negative eastern tropical Pacific SST anomalies are associated with a strengthened Walker circulation over the tropical Pacific, easterly wind anomalies throughout the troposphere over the sub-tropics of both the $\mathrm{SH}$ and Pacific sectors, and positive zonal wind anomalies between 50 and $60^{\circ} \mathrm{S}$ for the $\mathrm{SH}$ and Pacific sectors and farther poleward near $\sim 55$ to $65^{\circ} \mathrm{S}$ in the Indian sector. Eastern tropical Pacific SST variability during DJF accounts for more than $35 \%$ of the temporal variability in full $\mathrm{SH}$ 

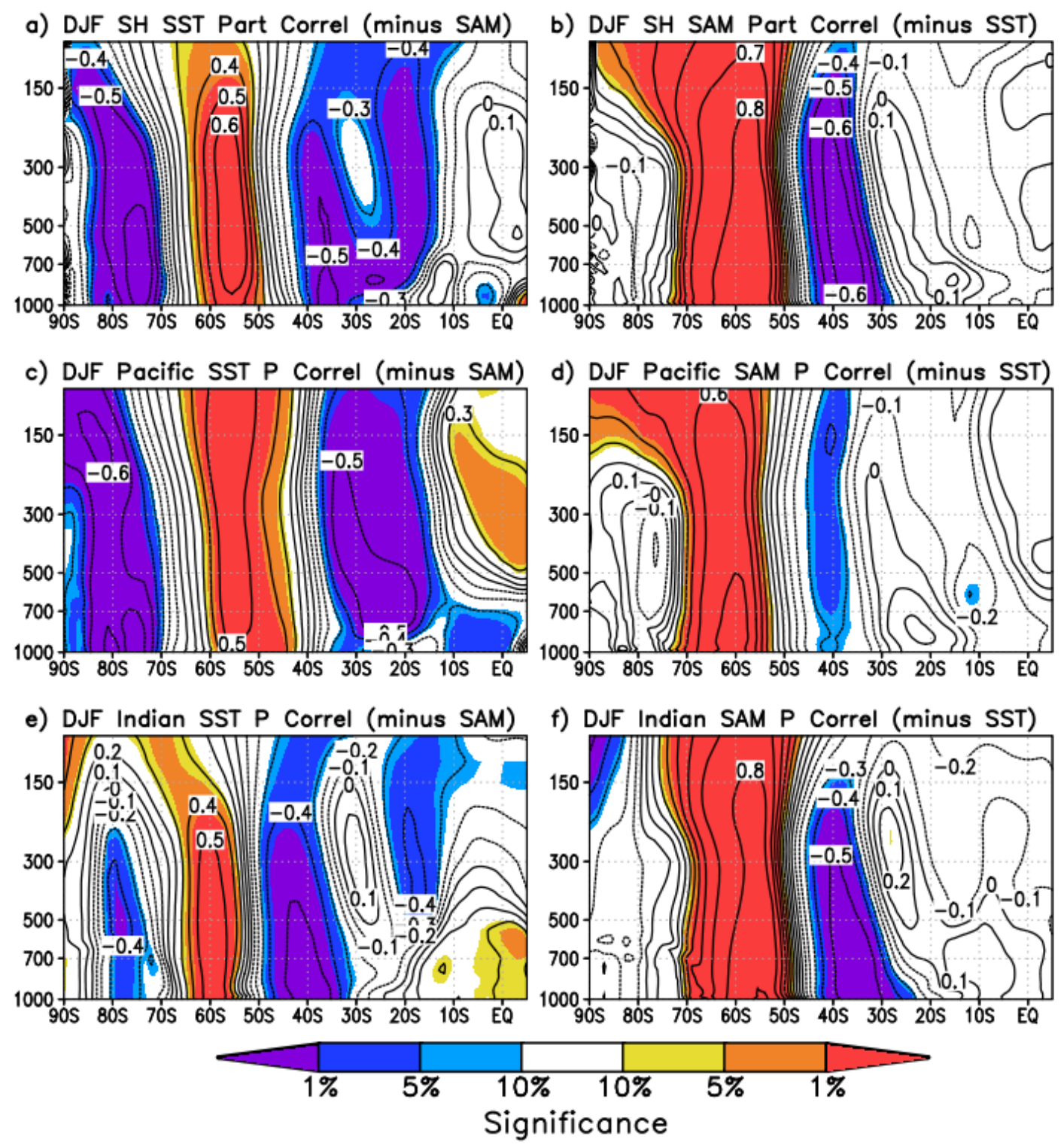

Figure 4.7: DJF detrended partial correlation of eastern tropical Pacific SSTs (after removing the Marshall SAM index, left column, multiplied by -1) and Marshall SAM index (after removing eastern tropical SSTs, right column) with zonal-mean zonal wind, 1979-2014, for (a-b) full SH, (c-d) Pacific sector, and (e-f) Indian sector. Shading indicates statistical significance of correlations and is drawn as in Figs. 4.1-4.4. Contour interval is 0.1.

tropospheric zonal-mean zonal wind between 50 and $60^{\circ} \mathrm{S}$, and more than $25 \%$ of the variability in the Pacific and Indian sectors. The DJF Marshall SAM index partial correlation after removing eastern tropical Pacific SSTs (right column) shows a stronger zonal wind relationship farther poleward at $55-70^{\circ} \mathrm{S}$. The significant SAM partial correlations also extend into the lower stratosphere reflecting the troposphere-stratosphere coupling that is commonly seen during DJF 


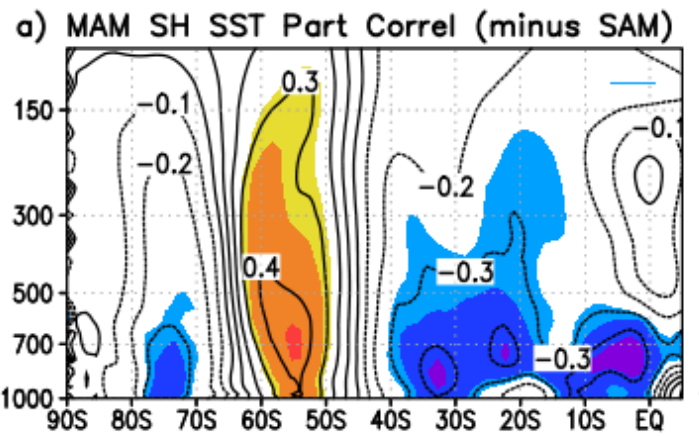

b) MAM SH SAM Part Correl (minus SST)

c) MAM Pacific SST P Correl (minus SAM)
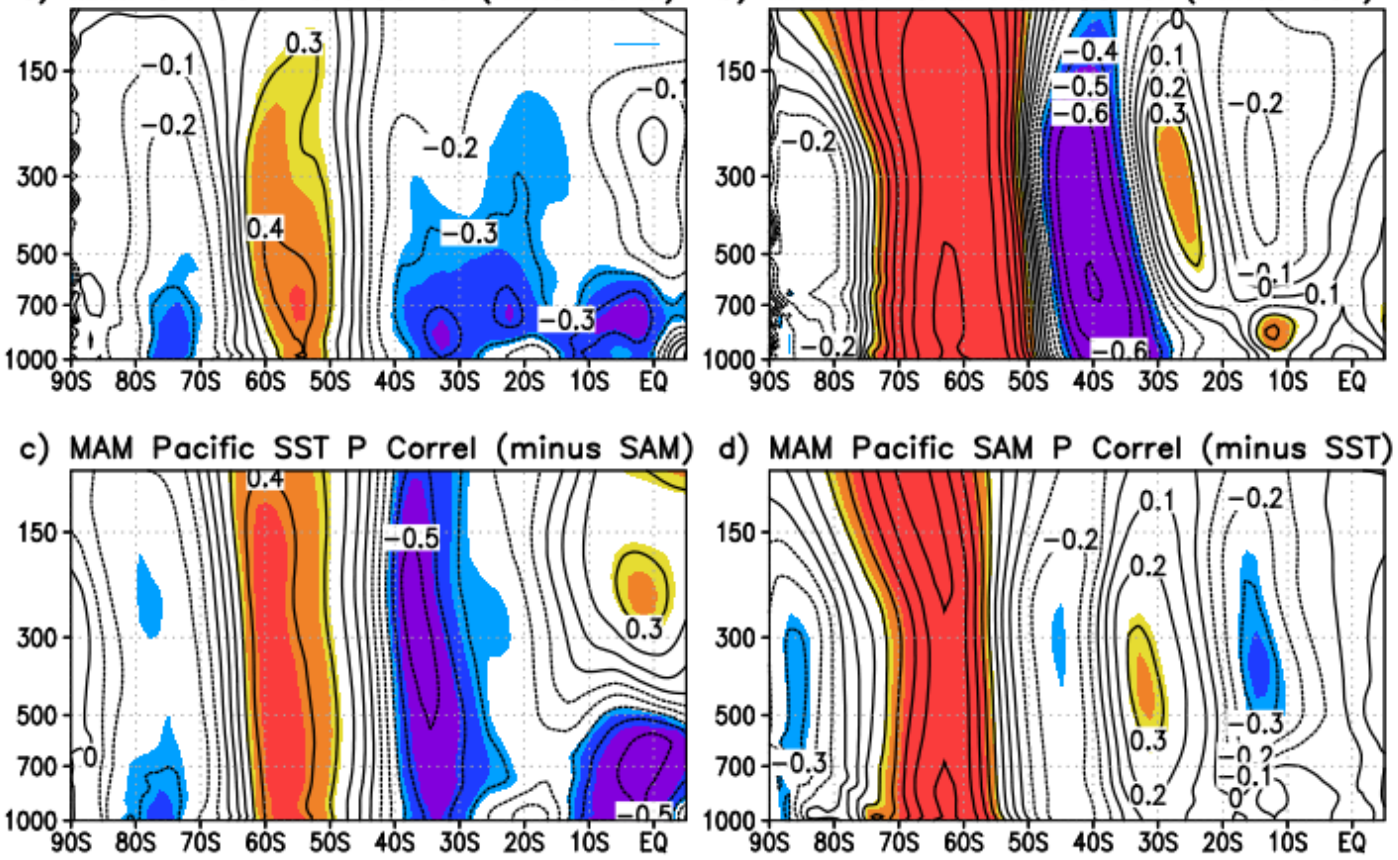

d) MAM Pacific SAM P Correl (minus SST)

e) MAM Indian SST P Correl (minus SAM)
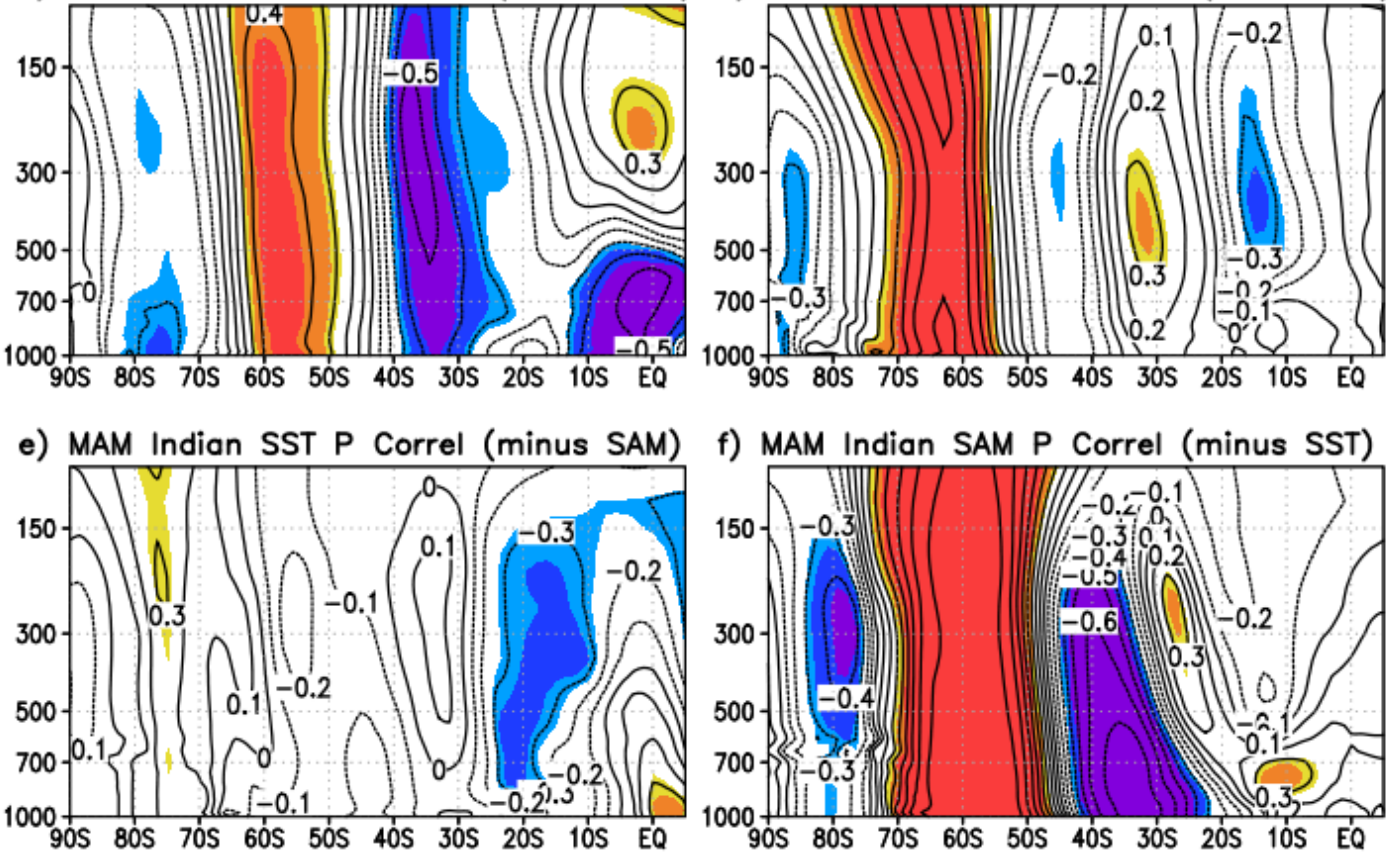

f) MAM Indian SAM P Correl (minus SST)
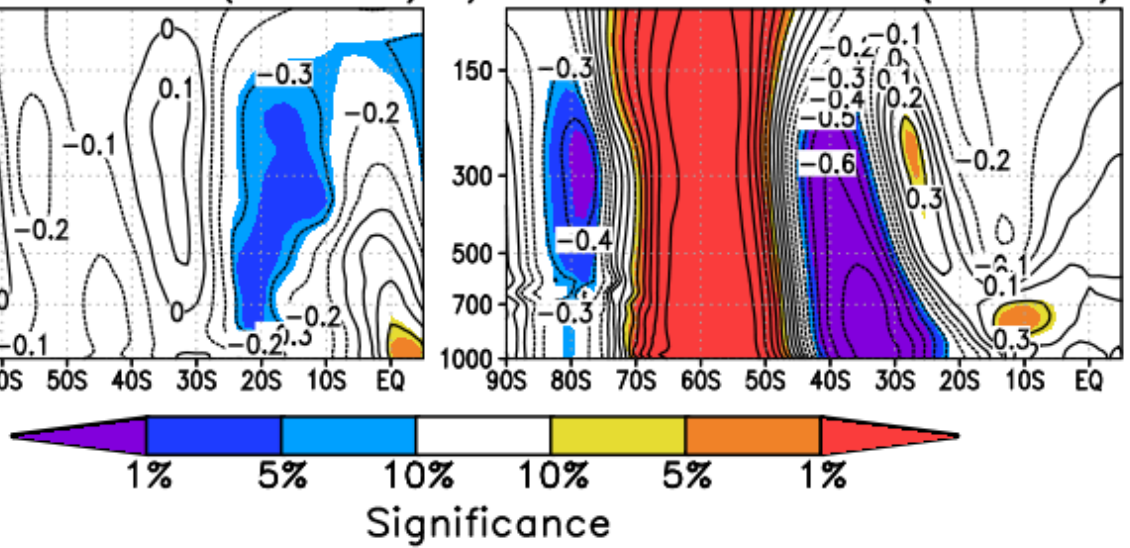

Figure 4.8: As in Fig. 4.7, except for MAM.

related to internal dynamics. It is inferred that eastern tropical Pacific SST variability during DJF is most strongly related to zonal-mean zonal wind variability on the equatorward side of the midlatitude jet, while internal SAM variability associated with stratospheric ozone variability dominates variability on the poleward side of the mid-latitude jet.

During MAM (Fig. 4.8), eastern tropical Pacific partial correlations are slightly weaker than those during DJF, and altogether absent over the Indian sector. However, the sign and location of the correlations are nearly identical to the observed MAM zonal wind trends (Fig. 4.4). Negative eastern tropical Pacific SST anomalies are associated with negative zonal wind anomalies 
between 30 and $40^{\circ} \mathrm{S}$ and positive zonal wind anomalies between 50 and $60^{\circ} \mathrm{S}$ in the $\mathrm{SH}$ and Pacific sectors, both of which are consistent with the observed MAM trends. The SAM partial correlation during MAM is strongest over the SH and Indian sectors and again continuous into the lower stratosphere. Over the Pacific, significant positive partial correlations are located primarily between 60 and $70^{\circ} \mathrm{S}$, which is again poleward of the eastern tropical Pacific SST significant correlation region, but more importantly, is poleward of the observed MAM trends over the Pacific. Also inconsistent with the trends are strong positive partial correlations over the Indian sector (where there is no significant trend) and positive correlations between 30 and $35^{\circ} \mathrm{S}$ over the Pacific sector (where the trend is negative). The partial correlations along with the linear congruency provide strong statistical evidence that the recent shift in tropical Pacific SSTs is associated with zonal-mean zonal wind anomalies that are consistent with observed DJF and MAM trends, especially during MAM.

\subsubsection{Eddy Momentum Forcing associated with Eastern Tropical Pacific SSTs}

Possible mechanisms for the zonal-mean zonal wind relationship with eastern tropical Pacific SSTs are explored using anomaly composites. To compare internal SAM forcing with remote forcing associated with eastern tropical Pacific SSTs, composites are shown separately for the six highest Marshall SAM index years and the six coldest eastern tropical Pacific SST years. The years used for compositing and the associated Marshall SAM index / eastern tropical Pacific SST anomaly are provided in Table 4.3. The top six positive SAM years and bottom six cold eastern tropical Pacific years represent the $85^{\text {th }}$ and $15^{\text {th }}$ percentile of the distribution, respectively, and are used to show average anomalies associated with extreme events.

Anomalous momentum fluxes are examined using the total eddy momentum flux (thin contours in Figs. 4.9-4.12) defined as the product of daily zonal and meridional wind deviations from the zonal-mean, or $\overline{u^{*} v^{*}}$. The total eddy momentum flux is nearly equivalent to the transient eddy momentum flux due to the lack of orographic standing waves in the SH (Peixoto and Oort 1992). Meridional divergence of the anomalous eddy momentum flux (thick contours in Figs. 4.9-4.12) and zonal wind anomalies are also investigated.

For positive SAM index years during DJF (Fig. 4.9), positive zonal wind anomalies are seen throughout the troposphere and lower stratosphere centered near $50^{\circ} \mathrm{S}$ over the $\mathrm{SH}$ and 
Table 4.3: Top six positive Marshall SAM index years and bottom six cold eastern tropical Pacific SST years (rank order; $85^{\text {th }}$ and $15^{\text {th }}$ percentiles, respectively) used for compositing in Figs. 4.9-4.14. Years are selected for each season individually over the period 1979-2014. The standardised eastern tropical Pacific SST anomaly observed during each positive SAM year and the Marshall SAM index observed during each cold eastern tropical Pacific SST year is given in brackets.

\begin{tabular}{|c|c|c|c|c|c|c|c|}
\hline \multicolumn{4}{|c|}{ Positive SAM Years } & \multicolumn{4}{|c|}{ Cold Eastern Tropical Pacific SST Years } \\
\hline \multicolumn{2}{|c|}{ DJF (SST anomaly) } & \multicolumn{2}{|c|}{ MAM (SST anomaly) } & \multicolumn{2}{|c|}{ DJF (SAM index) } & \multicolumn{2}{|c|}{$M A M(S A M$ index $)$} \\
\hline 1999 & $(0.13)$ & 1982 & $(-0.77)$ & 2010 & $(0.53)$ & 1991 & $(0.24)$ \\
\hline 2014 & $(-1.45)$ & 1998 & $(0.81)$ & 1990 & $(-0.13)$ & 2014 & $(0.30)$ \\
\hline 2007 & $(-1.42)$ & 1989 & $(-1.42)$ & 2014 & $(2.91)^{*}$ & 2011 & $(0.73)$ \\
\hline 2001 & $(-0.61)$ & 1993 & $(1.76)$ & 2007 & $(2.15)^{*}$ & 1985 & $(0.42)$ \\
\hline 1998 & $(-0.89)$ & 2000 & $(-0.42)$ & 1988 & $(1.00)$ & 1989 & $(1.31)^{*}$ \\
\hline 1994 & $(0.82)$ & 1999 & $(-1.37)$ & 2013 & $(0.33)$ & 2010 & $(0.54)$ \\
\hline
\end{tabular}

*Eastern tropical Pacific cold years that occurred with a positive SAM year.

Indian sectors. The strongest zonal wind anomalies are located over the Indian sector, and the core of the strongest positive zonal wind anomalies is located between 300 and $150 \mathrm{hPa}$ aligning with the region of strongest eddy momentum flux convergence. Over the Pacific sector, despite negative momentum flux anomalies throughout the upper troposphere poleward of $15^{\circ} \mathrm{S}$ (indicating anomalous poleward flow and a strengthened Coriolis torque that would favor westerly wind production), the zonal wind anomalies are weakest over the Pacific. This is likely because of the momentum flux divergence near the core of the mid-latitude jet (between 50 and $60^{\circ} \mathrm{S}$ ) with the region of momentum flux convergence displaced poleward from the jet (near $\sim 70^{\circ} \mathrm{S}$ ). The alignment of anomalous momentum flux convergence with the core of strongest westerly wind anomalies over the Indian ocean likely explains the more pronounced zonal wind anomalies over the Indian sector, and is consistent with previous findings of a strong positive feedback from transient eddies / baroclinic waves over the Indian Ocean (Feldstein and Lee 1998; Lorenz and Hartmann 2001; Codron 2005; Nakamura and Shimpo 2004).

Four of the six positive SAM index years during DJF occurred with negative SST anomalies in the eastern tropical Pacific (Table 4.3). Two of the six positive SAM index years overlap with the top six record coldest eastern tropical Pacific years, comprising the two most recent positive SAM events of 2007 and 2014, while the two positive SAM events that occurred without negative SST anomalies in the eastern tropical Pacific occurred before 2000 (1999 and 1994). 
a) DJF SAM+ S. Hemi Momentum Flux/Diverg Anomaly

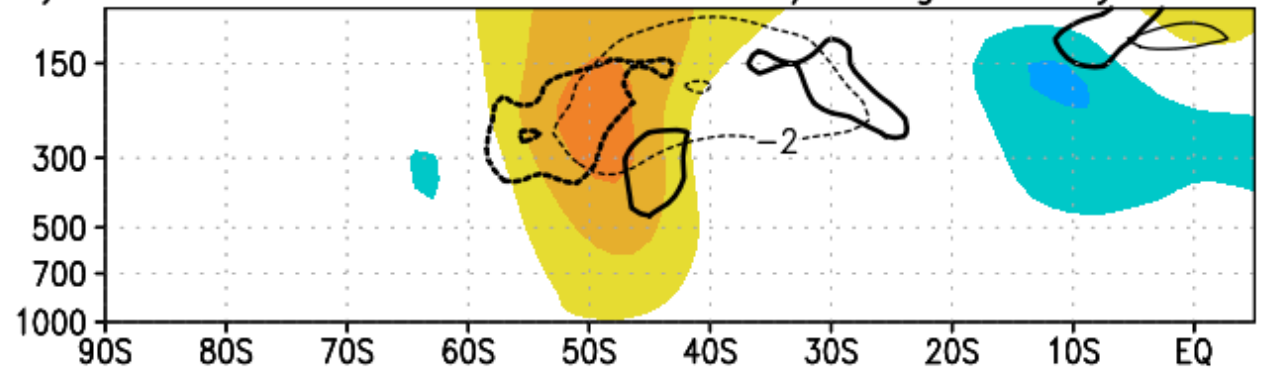

b) DJF SAM+ Pacific Momentum Flux/Diverg Anomaly

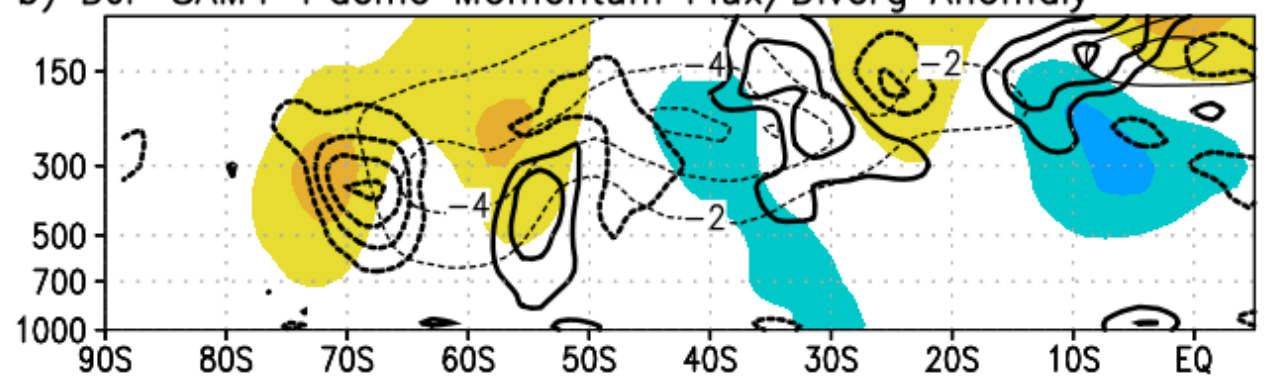

c) DJF SAM+ Indian Momentum Flux/Diverg Anomaly

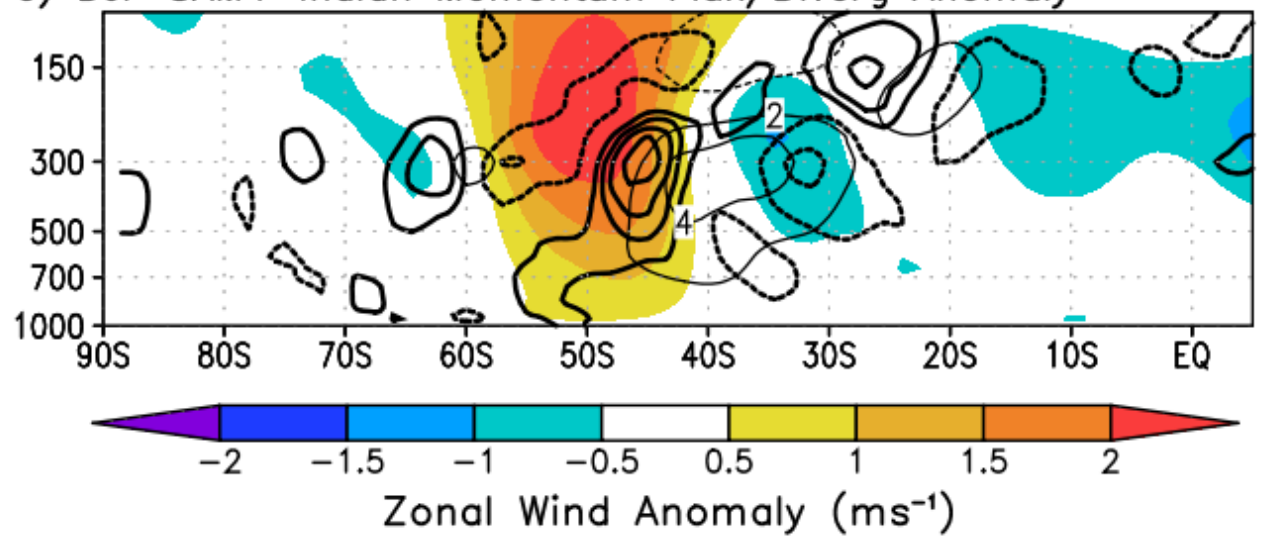

Figure 4.9: Anomaly composite mean for the top six highest Marshall SAM index years during DJF over 1979-2014 for (a) SH, (b) Pacific sector, and (c) Indian sector. Shading indicates zonalmean zonal wind anomalies ( $\mathrm{ms}^{-1}$; contour interval provided in color bar). Zonal-mean total eddy momentum flux anomalies are drawn as thin contours (solid for positive, dashed for negative) and have a contour interval of $2.0 \mathrm{~m}^{2} \mathrm{~s}^{-2}$. Zonal-mean total eddy momentum flux meridional divergence anomalies are drawn as thick contours (solid for positive, dashed for negative) and have a contour interval of $0.2 \mathrm{~ms}^{-2}$. Zero contours are omitted for momentum flux and momentum flux divergence anomalies.

For DJF cold eastern tropical Pacific SST years (Fig. 4.10), positive zonal wind anomalies are located between 40 and $45^{\circ} \mathrm{S}$, farther equatorward than SAM positive years, and they are overall much weaker and even weakly negative over the Pacific, which points to other mechanisms driving westerly wind anomalies across the SH middle latitudes during DJF. 
a) DJF eastPAC Cold S. Hemi Momentum Flux/Diverg Anomaly

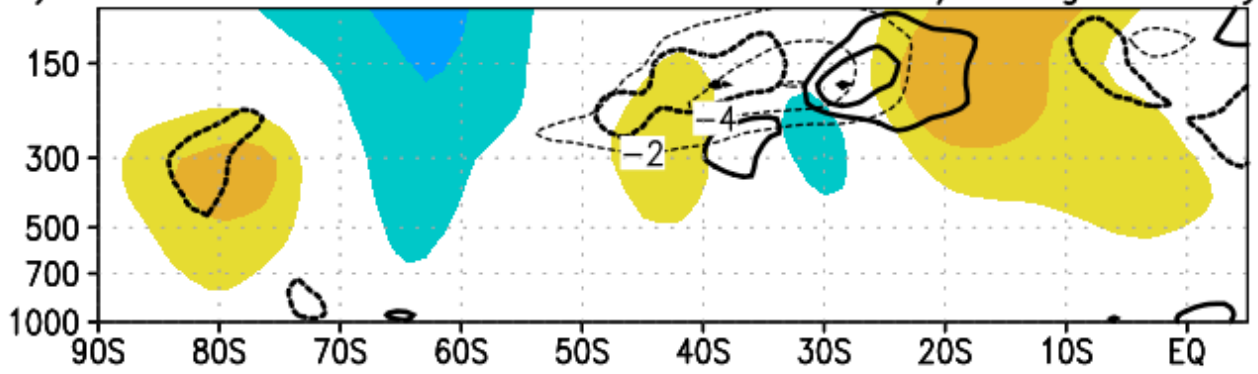

b) DJF eastPAC Cold Pacific Momentum Flux/Diverg Anomaly

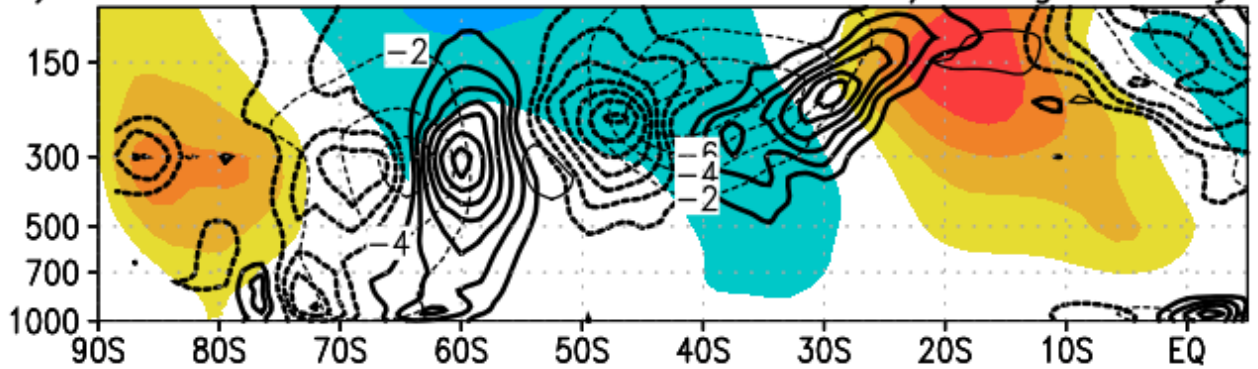

c) DJF eastPAC Cold Indian Momentum Flux/Diverg Anomaly

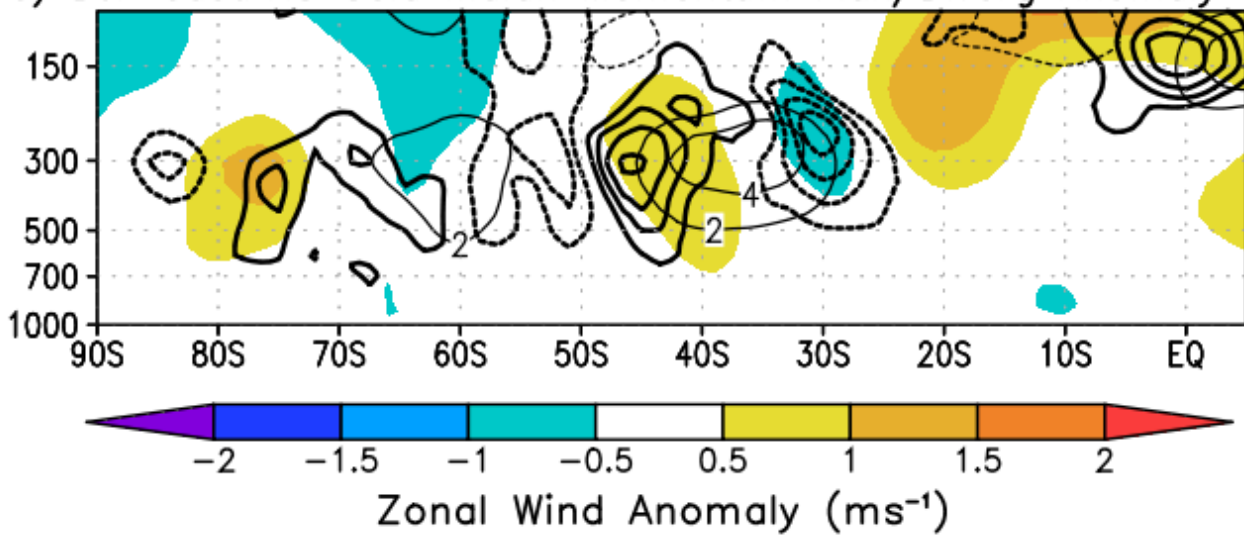

Figure 4.10: As in Fig. 4.9, but for the top six coldest SST years in the eastern tropical Pacific during DJF.

Nevertheless, strong negative eddy momentum flux anomalies and anomalous momentum flux convergence are seen across the SH and Pacific sectors between 30 and $50^{\circ} \mathrm{S}$ which projects onto the positive SAM pattern seen in Fig. 4.9. For the full SH, positive SAM years are associated with negative momentum fluxes and momentum flux convergence between 45 and $60^{\circ} \mathrm{S}$ and between 35 and $50^{\circ} \mathrm{S}$ for cold eastern tropical Pacific years (compare Fig. 4.9a with Fig. 4.10a), The weak / negative zonal wind anomalies, particularly over the Pacific where strong negative momentum fluxes and momentum flux convergence is seen, will be further investigated later. 
a) MAM SAM+ S. Hemi Momentum Flux/Diverg Anomaly

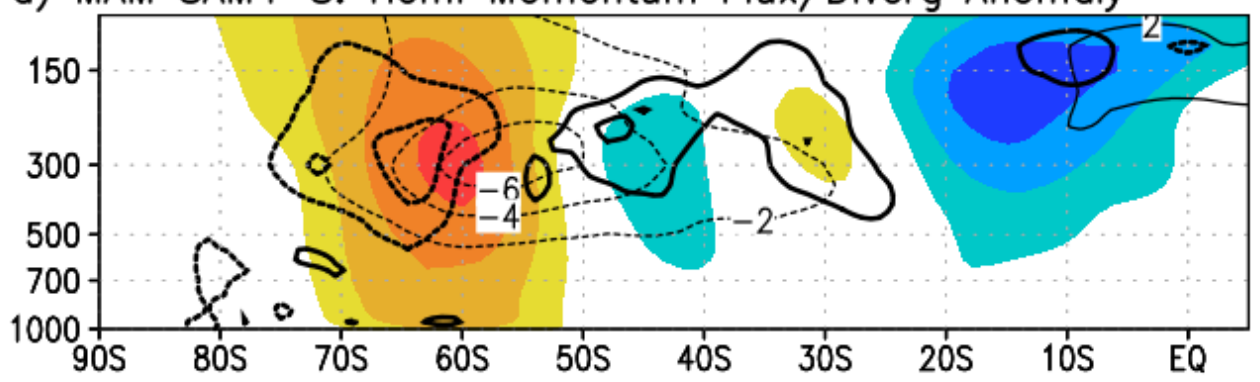

b) MAM SAM+ Pacific Momentum Flux/Diverg Anomaly

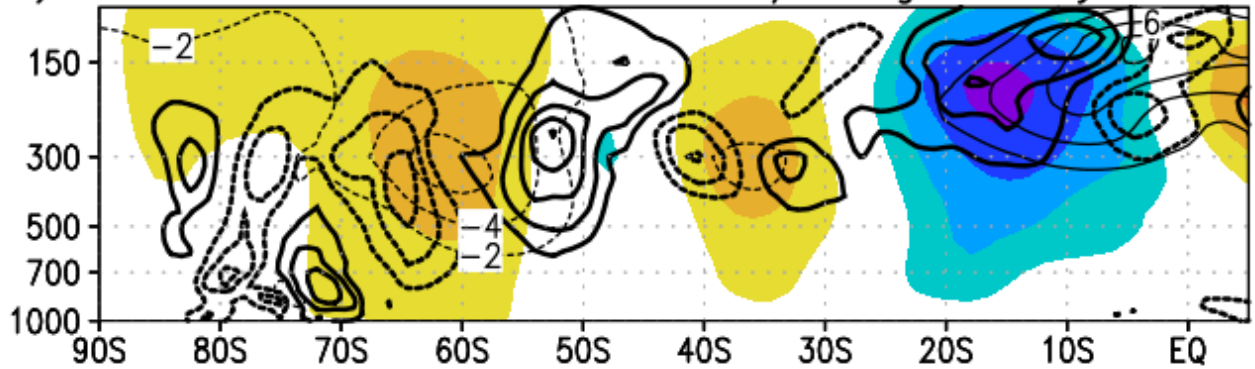

c) MAM SAM+ Indian Momentum Flux/Diverg Anomaly

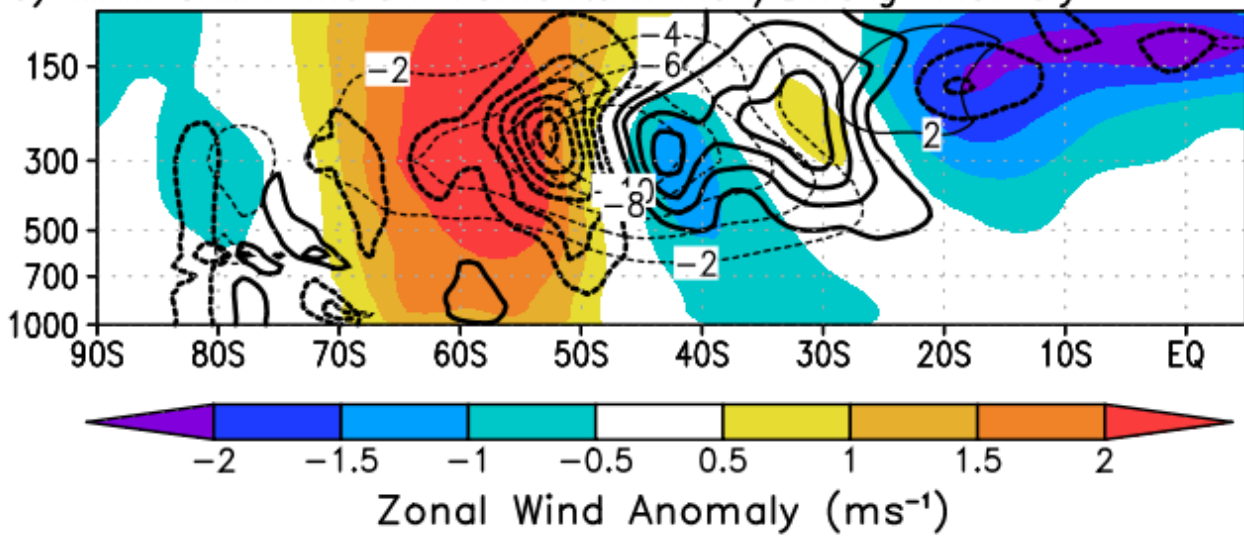

Figure 4.11: As in Figs. 4.9-4.10, except for the top six highest Marshall SAM index years during MAM.

Positive SAM index values are observed during all but one of the six eastern tropical Pacific years (a weak negative SAM index was seen during 1990), and the recent DJF positive SAM events of 2007, 2010, 2013, and 2014 all occurred in conjunction with cold eastern tropical Pacific SSTs. It is inferred that DJF positive SAM years are dominated by other mechanisms besides tropical Pacific SSTs, such as stratospheric ozone depletion and troposphere-stratosphere coupling, but eastern tropical Pacific cooling likely reinforced the positive SAM events during the 2000 s. 
a) MAM eastPAC Cold S. Hemi Momentum Flux/Diverg Anomaly

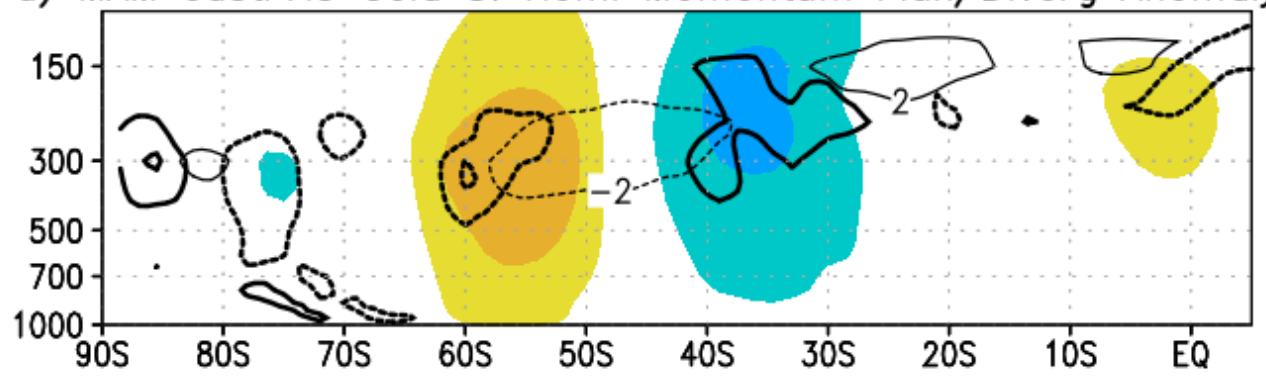

b) MAM eastPAC Cold Pacific Momentum Flux/Diverg Anomaly

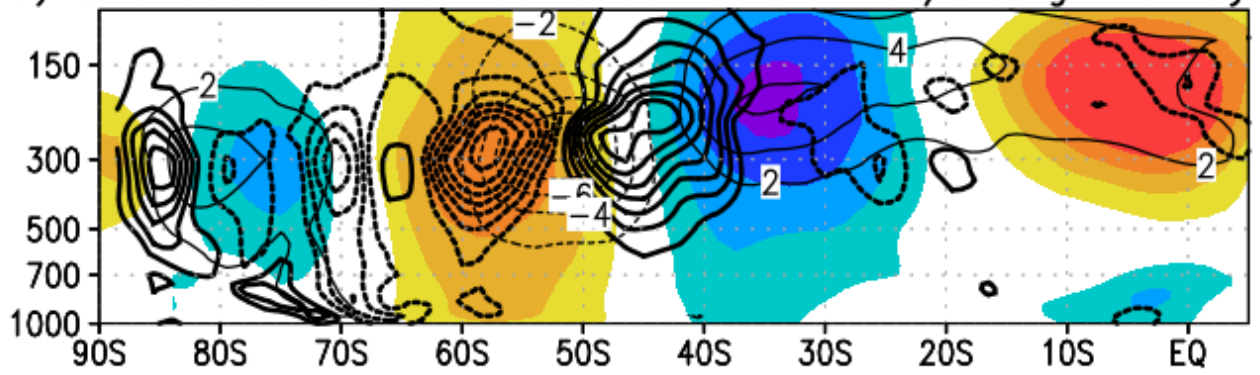

c) MAM eastPAC Cold Indian Momentum Flux/Diverg Anomaly

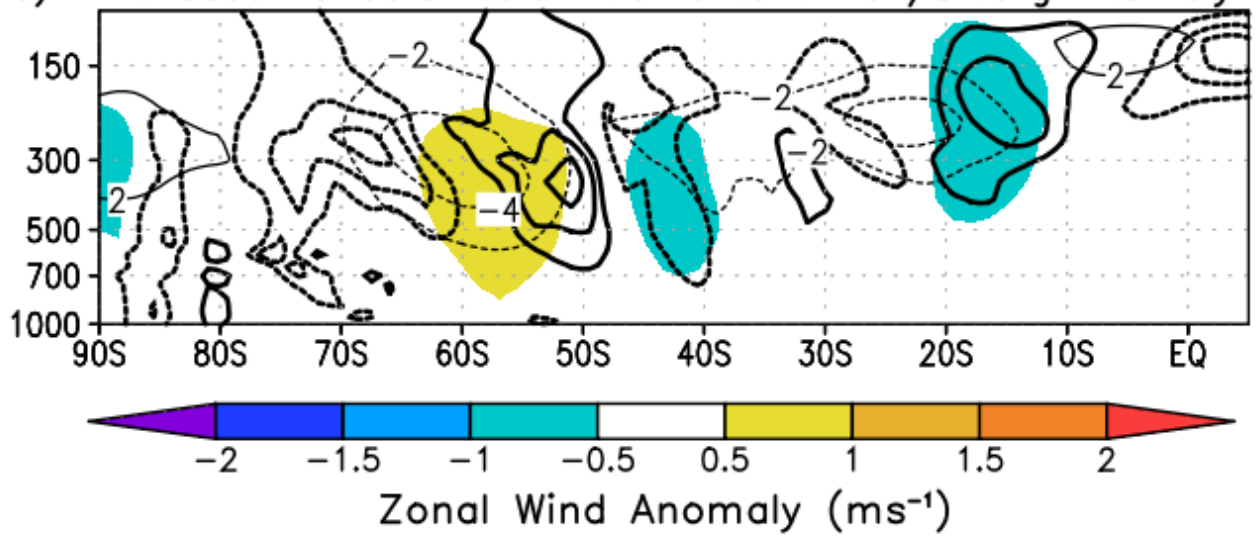

Figure 4.12. As in Figs. 4.9-4.11, except for the top six coldest SST years in the eastern tropical Pacific during MAM.

Positive SAM index years during MAM (Fig. 4.11) are associated with positive zonal wind anomalies between 55 and $\sim 70^{\circ} \mathrm{S}$ that extend from the troposphere to the lower stratosphere. The core of the strongest positive zonal wind anomalies again coincides with anomalous negative momentum fluxes and momentum flux convergence near $\sim 300 \mathrm{hPa}$. As with the partial correlations, the MAM zonal wind anomalies associated with SAM positive years are not consistent with the MAM trends. The MAM trends show significant strengthening of the westerlies between 50 and $60^{\circ} \mathrm{S}$ and significant weakening of the westerlies between 30 and 
$40^{\circ} \mathrm{S}$ in the Pacific and SH sectors, and no significant trends (outside of the tropics) over the Indian sector. In contrast, positive SAM years are associated with positive zonal wind anomalies farther poleward of where the westerlies have strengthened, the strongest positive zonal wind anomalies are seen over the Indian sector, and positive zonal wind anomalies are located over the Pacific between 30 and $40^{\circ} \mathrm{S}$.

The zonal wind anomalies associated with eastern tropical Pacific cold years during MAM (Fig. 4.12) are in much better agreement with the observed trends. The zonal wind anomalies in the Pacific sector reflect the full SH zonal wind anomalies, and zonal wind anomalies over the Indian Ocean are weaker than the full SH. Across the tropical Pacific (Fig. $4.12 \mathrm{~b}$ ), low-level easterly wind anomalies and upper tropospheric westerlies are seen between the Equator and $10^{\circ} \mathrm{S}$, which reflect a strengthened Walker circulation and are consistent with the MAM trends. Positive momentum fluxes, which indicate anomalous equatorward (decreased poleward) flow, are seen in the upper troposphere stretching out of the equatorial Pacific to $\sim 40^{\circ} \mathrm{S}$, consistent with the weakened divergent branch of the Pacific Hadley cell during MAM. Negative zonal wind anomalies are found over the STJ region between 30 and $40^{\circ} \mathrm{S}$ where the positive momentum flux anomalies maximise and momentum flux divergence occurs of the poleward side of the STJ. Between 50 and $60^{\circ} \mathrm{S}$ over the Pacific, strong negative momentum flux anomalies and momentum flux convergence align with positive zonal wind anomalies, which strongly projects onto the location of the strengthened westerlies observed during MAM.

All the cold eastern tropical Pacific SST years during MAM are associated with positive SAM index values, and only one year overlaps with the six most positive SAM index years (e.g., they occur primarily independent of SAM years). Three recent MAM positive SAM index years (2010, 2011, and 2014), although weak, occurred in association with negative SST anomalies in the eastern tropical Pacific, while the highest SAM index years (that occurred without eastern tropical Pacific years) primarily occurred prior to 2000. It appears likely that the recent positive SAM index trend during MAM, at least through the 2000s, is circulation anomalies associated with eastern tropical Pacific SST cooling, while the earlier trends were likely related to stratospheric ozone depletion or some other forcing mechanism. 


\subsubsection{Thermal Forcing Associated with Eastern Tropical Pacific SSTs}

Lower-tropospheric zonal-mean temperature anomalies and anomalous meridional temperature gradients associated with cold eastern tropical Pacific SST years are shown in Figs. 4.13-4.14. Temperature anomalies at $850 \mathrm{hPa}$ are used to depict the low-level temperature field. The $300 \mathrm{hPa}$ zonal wind anomalies (from Figs. 4.10 and 4.12) are also shown to better diagnose the relationship between low-level temperatures and upper tropospheric zonal wind anomalies. Meridional temperature gradients are calculated using the meridional derivative of the daily ERA-Interim temperature anomaly field (from the respective 1981-2010 daily climatology).

During DJF (Fig. 4.13), cold eastern tropical Pacific SST years are associated with a uniform response over the SH and Indian sectors (red and blue lines; Fig. 4.13a). Weak positive temperature anomalies are found throughout the low-to-middle latitudes of the SH and Indian sectors, and weak positive meridional temperature gradient anomalies (Fig. 4.13b) are found near $\sim 20^{\circ} \mathrm{S}$ and $\sim 40^{\circ} \mathrm{S}$ which would act to strengthen westerly winds above the $850 \mathrm{hPa}$ level through the thermal wind balance. For the Pacific (green lines), negative temperature anomalies are found between 20 and $40^{\circ} \mathrm{S}$ and positive temperature anomalies are found poleward of $40^{\circ} \mathrm{S}$. The meridional temperature gradient is weakened between 30 and $55^{\circ} \mathrm{S}$ over the Pacific, which would weaken westerly winds and oppose the negative momentum flux anomalies and momentum flux convergence seen over the Pacific between $\sim 35$ and $50^{\circ} \mathrm{S}$, helping to explain the absence of positive zonal wind anomalies over the Pacific during DJF cold eastern tropical Pacific years. Meanwhile, the slightly strengthened low-level temperature gradient in the SH and Indian sector, particularly at $\sim 40^{\circ} \mathrm{S}$, would reinforce the eddy momentum forcing for westerly wind production on the equatorward side of the mid-latitude jet.

During MAM (Fig. 4.14), all sectors show a similar response to cold eastern tropical Pacific SST years. Negative temperature anomalies are seen over the tropics $\left(0-20^{\circ} \mathrm{S}\right)$, positive temperature anomalies are seen across the middle latitudes $\left(30-55^{\circ} \mathrm{S}\right)$, and negative temperature anomalies are found poleward of $55^{\circ} \mathrm{S}$. The low-level meridional temperature gradient is in turn weakened between 20 and $40^{\circ} \mathrm{S}$, aligning with the negative $300 \mathrm{hPa}$ zonal wind anomalies and reinforcing the positive momentum fluxes seen in the SH and Pacific sectors (Fig. 4.12). The 850 $\mathrm{hPa}$ temperature gradient is strengthened between 45 and $65^{\circ} \mathrm{S}$ in all sectors, aligning with the positive $300 \mathrm{hPa}$ zonal wind anomalies and reinforcing the negative momentum fluxes favoring westerly wind production. 
a) DJF Eastern Pacific Cold Years: $850 \mathrm{hPa}$ Temperature Anomalies
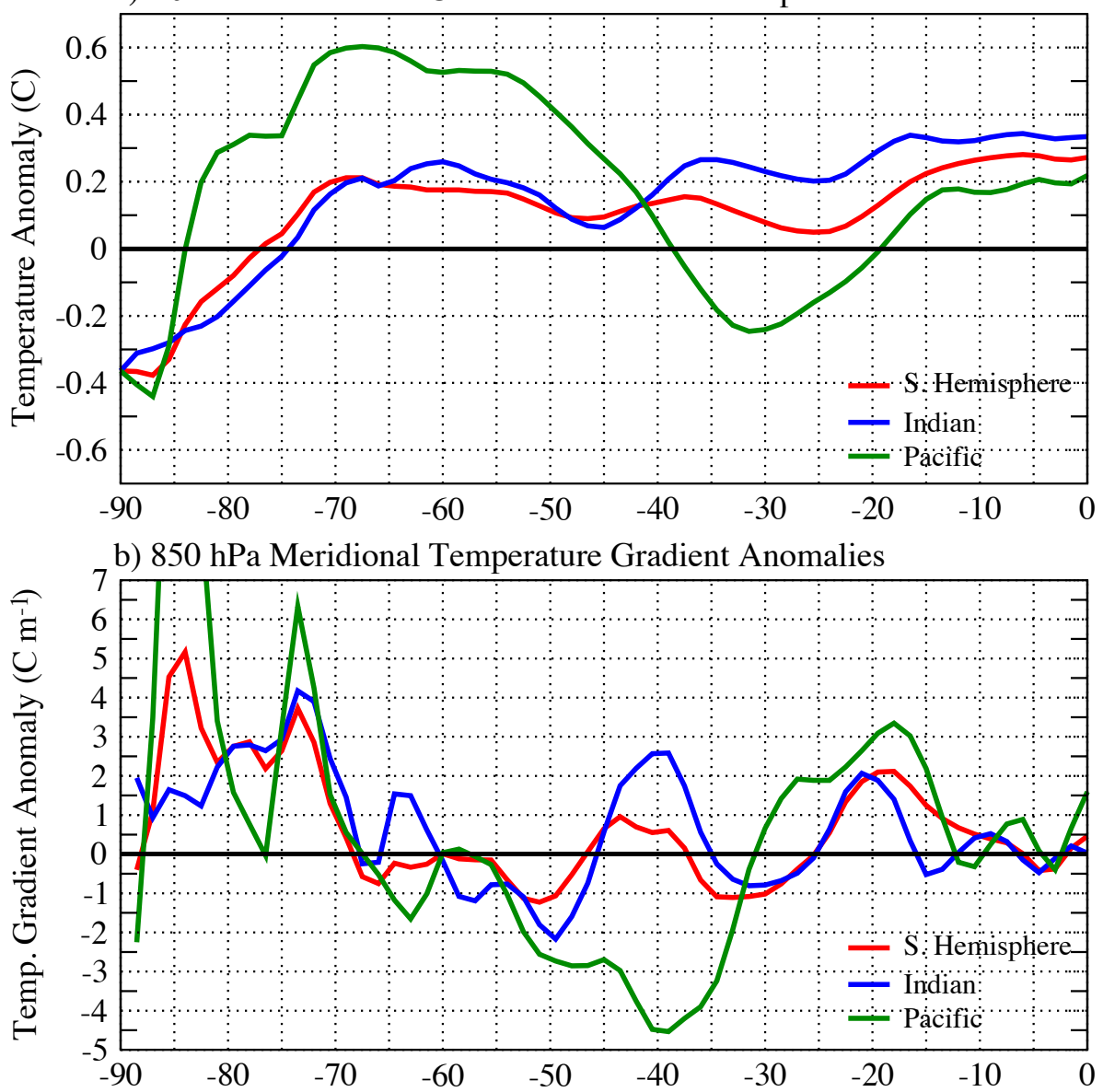

c) $300 \mathrm{hPa}$ Zonal Wind Anomalies

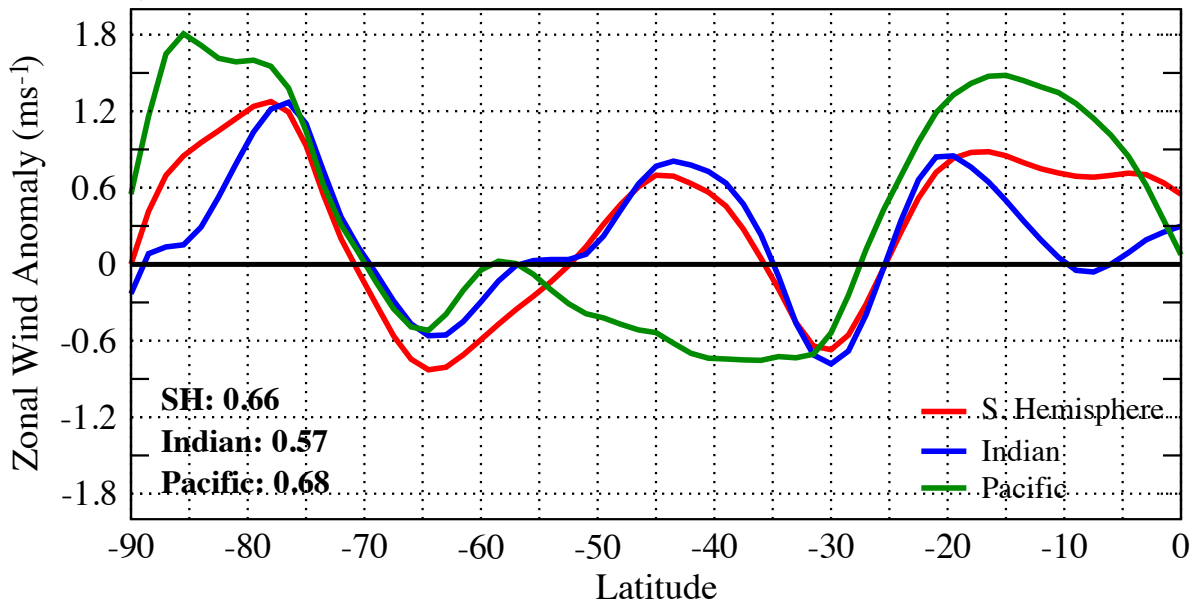

Figure 4.13: Anomaly composite mean for the top six coldest SST years in the eastern tropical Pacific during DJF over 1979-2014 for (a) $850 \mathrm{hPa}$ zonal-mean temperature anomalies $\left({ }^{\circ} \mathrm{C}\right)$, (b) $850 \mathrm{hPa}$ zonal-mean meridional temperature gradient anomalies $\left({ }^{\circ} \mathrm{C} \mathrm{m}^{-1}\right.$; scaled by a factor of $10^{7}$ ), and (c) $300 \mathrm{hPa}$ zonal-mean zonal wind anomalies $\left(\mathrm{ms}^{-1}\right)$. Correlations between $850 \mathrm{hPa}$ zonal-mean meridional temperature gradient anomalies and $300 \mathrm{hPa}$ zonal-mean zonal wind anomalies by sector are shown in bottom left of (c). 
a) MAM Eastern Pacific Cold Years: $850 \mathrm{hPa}$ Temperature Anomalies
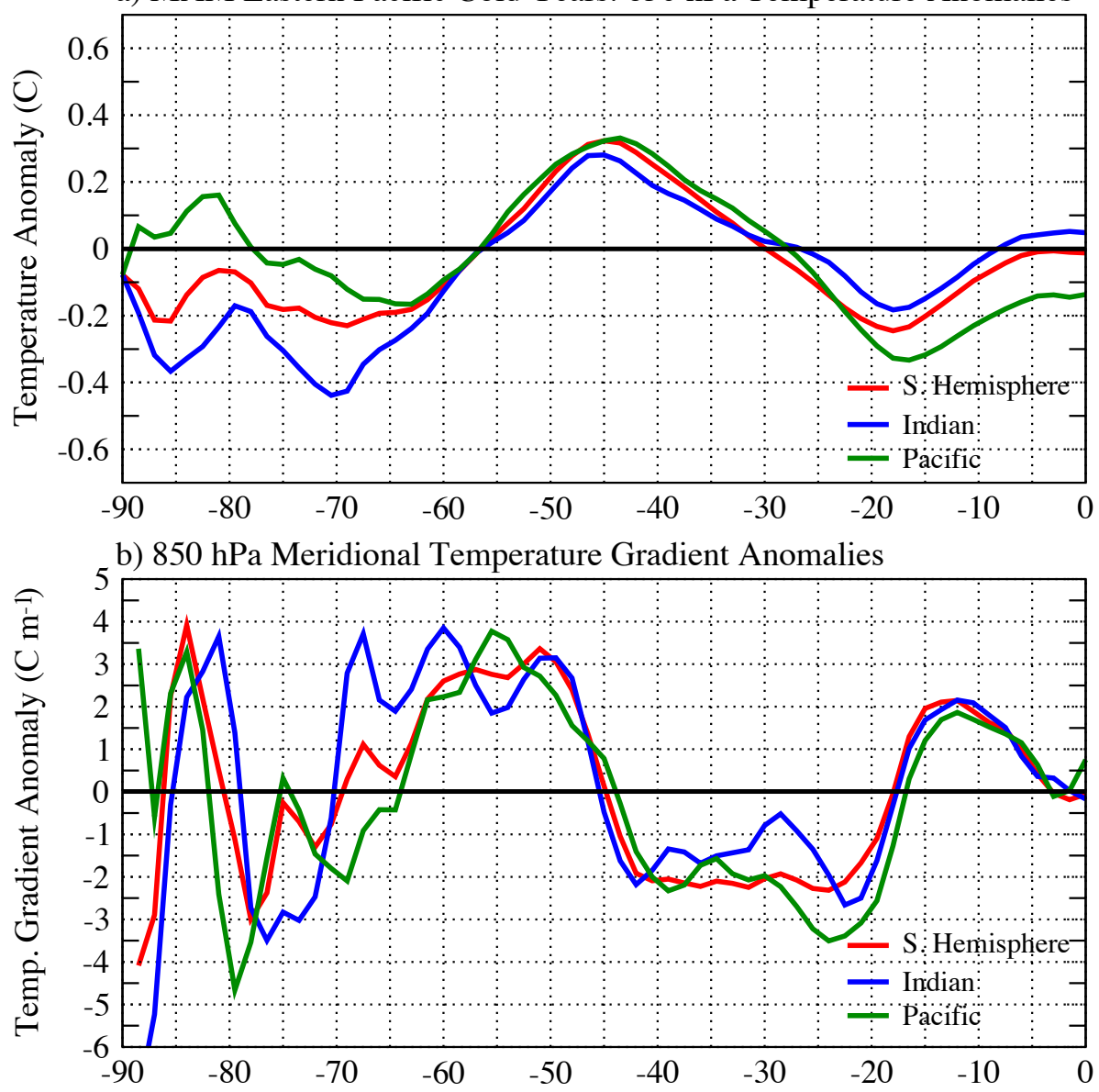

c) $300 \mathrm{hPa}$ Zonal Wind Anomalies

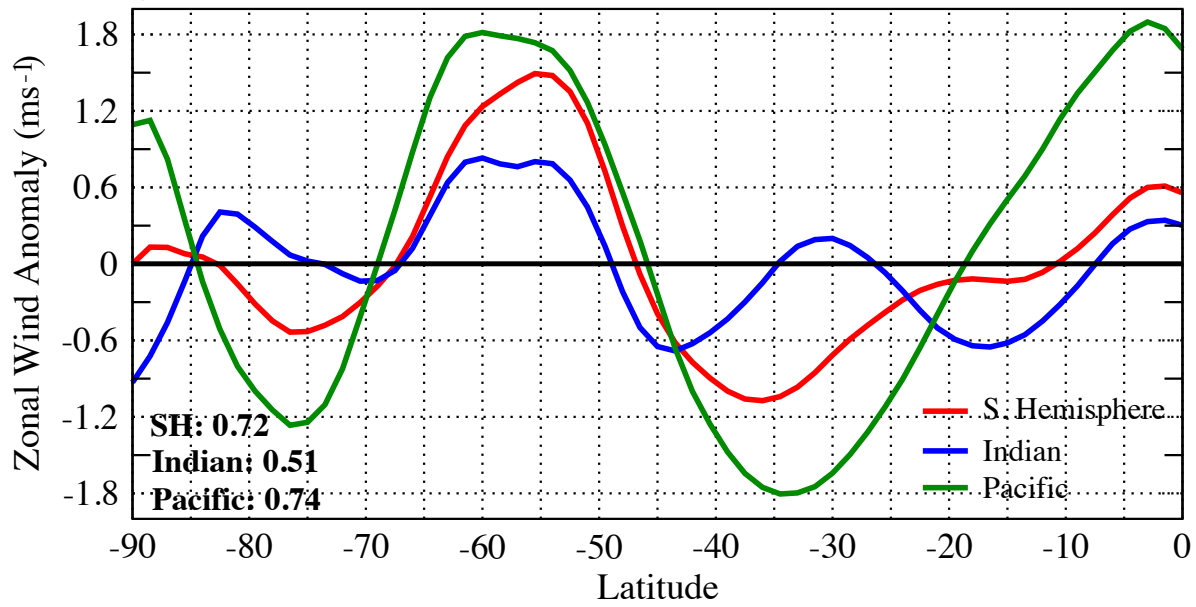

Figure 4.14: As in Fig. 4.13, except for MAM. 


\subsection{Tropical Pacific Relationships with East Antarctic Cooling during Austral Autumn}

\subsubsection{Overview}

This section investigates how recent trends in tropical Pacific SSTs have impacted East Antarctic climate during autumn. Previous studies have identified a ubiquitous cooling around coastal East Antarctica during autumn, which has been linked to a strengthening of the SH westerlies that reduces poleward advection of heat and katabatic winds over the continent. Here it is demonstrated that after 1979, the autumn cooling of coastal East Antarctica is not ubiquitous, and there are regions where cooling has amplified over the past $\sim 30$ years while other regions have shown a weakening or reversal (warming) in the rate of cooling. This pattern of regional cooling, verified by coastal East Antarctic weather stations, is not consistent with a strengthening of the westerlies which would result in a more uniform cooling; instead, the regional cooling is tied to regional circulation changes associated with Rossby wavetrains emanating from the tropical Pacific. These results are unprecedented and indicate that East Antarctic climate is highly sensitive to tropical Pacific climate variability, and that recent cooling of East Antarctica, previously thought to be tied only to a strengthening of the westerlies from spring ozone depletion, is equally related to variability in the tropics. Therefore, future East Antarctic climate change during autumn is dependent not only on a recovering ozone hole, but also on tropical Pacific climate variability, which alters regional patterns of sea ice concentration and thermal advection along the East Antarctic coast. This significantly adds to our understanding of not only the recent East Antarctic cooling trends, particularly why East Antarctica has been cooling while West Antarctica is rapidly warming, but also in a broader context of how the tropics impact Antarctic-wide climate. Specifically, many previous studies have documented how the tropics impact West Antarctica and the Antarctic Peninsula, but little is known about the tropical impact on East Antarctic climate. Here, it is shown that all of Antarctica, including East Antarctica, is sensitive to tropical variability, and the tropics have the potential to amplify or offset climatic changes associated with changes in the westerlies. 


\subsubsection{Seasonal Trends in East Antarctic Surface Temperatures}

Seasonal temperature trends in coastal East Antarctic stations are shown in Table 4.4. Stations are ordered (top to bottom) from Halley eastward to Dumont d'Urville (see Fig. 3.1 for map). Trends are calculated over each station's full period of record (Table 3.1) ending in 2014, and over 1979-2014 to compare with ERA-Interim. During DJF, there are generally no significant temperature trends over the full period of record except for weak cooling at Mawson (significant only at $p<0.10$ ). The rate of cooling increases at every station after 1979 and becomes statistically significant at five of the nine stations. During MAM, most stations exhibit cooling during both periods; however, there is a notable increase in the rate of cooling after 1979 in two separate regions: over western East Antarctica at Novolazarevskaya (hereafter Novo) and Syowa stations, and over eastern East Antarctica at Casey and Dumont d'Urville (hereafter Dumont). Meanwhile, the rate of cooling decreases at Mawson and Davis stations, with weak warming observed after 1979.

Widespread cooling of coastal East Antarctica during both DJF and MAM has generally been attributed to a positive trend in the SAM index and an associated strengthening of the circumpolar westerlies which reduces poleward heat advection toward East Antarctica and weakens katabatic winds over the continent (Thompson and Solomon 2002; Marshall 2007; van den Broeke and van Lipzig 2003). Therefore, the positive SAM trend is associated with widespread cooling across East Antarctica. The regional nature of the increased rate of cooling

after 1979 during MAM and the weak warming in between at Mawson and Davis is inconsistent with a positive SAM trend. The remainder of this study will focus on the regional temperature trends during MAM; nearly all trends during both periods are insignificant during JJA, and the East Antarctic warming during SON is a focus of future work. 
Table 4.4: Seasonal trends and 95\% confidence intervals for Antarctic station temperatures (units are ${ }^{\circ} \mathrm{C}$ decade ${ }^{-1}$ ). Trends are calculated from the start of the record (see Table 3.1 for starting years) ending in 2014, and for 1979-2014. Trends significant at $p<0.10$ are boldface, $p<0.05$ are boldface and underlined, and $p<0.01$ are denoted with an asterisk.

\begin{tabular}{|c|c|c|c|c|c|c|c|c|}
\hline \multirow[b]{2}{*}{ Station } & \multicolumn{2}{|c|}{ DJF } & \multicolumn{2}{|c|}{ MAM } & \multicolumn{2}{|c|}{ JJA } & \multicolumn{2}{|c|}{$\mathrm{SON}$} \\
\hline & full & $1979-2014$ & full & $1979-2014$ & full & $1979-2014$ & full & $1979-2014$ \\
\hline Halley & $-0.03 \pm 0.13$ & $\underline{-0.32} \pm 0.27$ & $\underline{-0.41 \pm 0.31}$ & $-0.37 \pm 0.57$ & $-0.04 \pm 0.33$ & $-0.47 \pm 0.64$ & $0.05 \pm 0.25$ & $0.10 \pm 0.43$ \\
\hline Novo & $0.05 \pm 1.94$ & $\underline{-0.24 \pm 0.24}$ & $0.02 \pm 0.20$ & $\underline{-0.36} \pm 0.33$ & $0.28 \pm 3.92$ & $0.18 \pm 0.53$ & $0.17 \pm 1.77$ & $0.07 \pm 0.33$ \\
\hline Syowa & $-0.01 \pm 0.11$ & $-0.09 \pm 0.22$ & $-0.13 \pm 0.21$ & $\underline{-0.53 \pm 0.42}$ & $0.11 \pm 0.28$ & $-0.07 \pm 0.58$ & $0.02 \pm 0.19$ & $-0.02 \pm 0.38$ \\
\hline Mirny & $-0.02 \pm 0.12$ & $-0.02 \pm 0.28$ & $-0.09 \pm 0.23$ & $-0.17 \pm 0.46$ & $0.16 \pm 0.25$ & $0.03 \pm 0.57$ & $\underline{0.23} \pm \mathbf{0 . 1 8}$ & $\underline{\mathbf{0 . 3 8} \pm 0.34}$ \\
\hline Casey & $-0.07 \pm 0.10$ & $\underline{-0.22} \pm 0.21$ & $-0.01 \pm 0.29$ & $-0.42 \pm 0.53$ & $0.07 \pm 0.31$ & $-0.44 \pm 0.60$ & $0.19 \pm 0.20$ & $0.13 \pm 0.37$ \\
\hline Dumont & $-0.01 \pm 0.10$ & $\underline{-0.24} \pm 0.23$ & $\underline{-0.27} \pm 0.16 *$ & $\underline{-0.40} \pm 0.31$ & $-0.02 \pm 0.24$ & $-0.51 \pm 0.51$ & $0.06 \pm 0.16$ & $-0.24 \pm 0.32$ \\
\hline
\end{tabular}




\subsubsection{Atmospheric Circulation Trends and Their Connection to East Antarctic Cooling and}

\section{Large-Scale Climate Forcing}

Post-1979 trends in MAM circulation and 2-m temperatures are shown in Fig. 4.15a-b, and trends in tropical SSTs and upper-tropospheric velocity potential are shown in Fig. 4.15c-d. Along the western East Antarctic coast (between $\sim 30^{\circ} \mathrm{W}$ and $30^{\circ} \mathrm{E}$ ) near Novo and Syowa, there has been significant increases in westerly / southwesterly winds associated with anticyclonic circulation over the South Atlantic near $\sim 15^{\circ} \mathrm{W}$ and cyclonic circulation near $\sim 60^{\circ} \mathrm{E}$. Farther east (between $\sim 90^{\circ} \mathrm{E}$ and $150^{\circ} \mathrm{E}$ ) near Mirny, Casey, and Dumont, there have been increases in southerly winds near $\sim 90^{\circ} \mathrm{E}$ that become westerly (assuming geostrophic flow) along the coast near Casey and Dumont. The strengthened southerly and westerly winds near Casey and Dumont appear associated with a negative height trend over extreme eastern East Antarctica and the Ross Ice Shelf, and a positive height trend off the southwest coast of Australia.

Trends in ERA-Interim 2-m temperature (Fig. 4.15b) agree well with the observations. The strongest cooling during MAM is regional and located along the eastern and western East Antarctic coast near Novo / Syowa and Casey / Dumont. In between these cooling trends, across the central East Antarctic coast, there are no significant temperature trends, consistent with observed temperature trends at Mawson, Davis, and Mirny.

The regional anticyclonic circulation over the South Atlantic appears part of a wavetrain that follows a great circle across the South Pacific into the South Atlantic, and is consistent with a La Niña-like PSA pattern like the MAM wavetrain described by Ding and Steig (2013). Trends in tropical SSTs and upper-tropospheric velocity potential (Figs. $4.15 \mathrm{c}-\mathrm{d}$ ) indeed show significant positive SST trends and increases in large scale ascent / upper-level divergence (i.e., negative $300 \mathrm{hPa}$ velocity potential trend) over the western tropical Pacific, consistent with a La Niña pattern. Although increasing SSTs are seen over all the tropical basins during MAM, the velocity potential trends suggest the western tropical Pacific warm pool region would be the primary source for a Rossby wavetrain as the increased ascent and associated upper-level divergence here can generate poleward propagating Rossby waves along the sub-tropical jet which develops over Australia during MAM (e.g., Lachlan-Cope and Connolley 2006; Ding et al. 2012b).

Figure 4.16 shows MAM trends in East Antarctic sea ice concentration and meridional thermal advection. Although sea ice concentrations are known to modulate coastal temperatures 

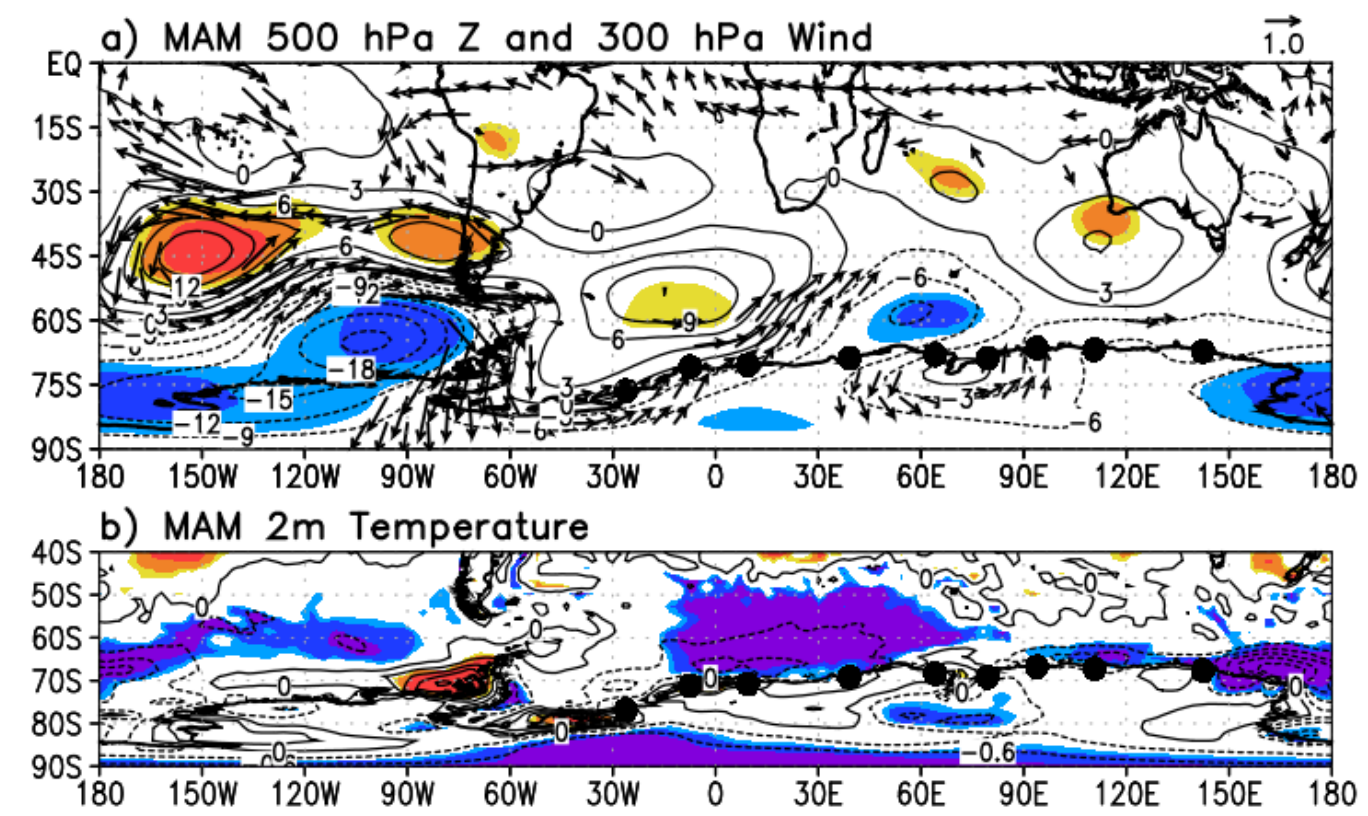

c) MAM NOAA V4 SST

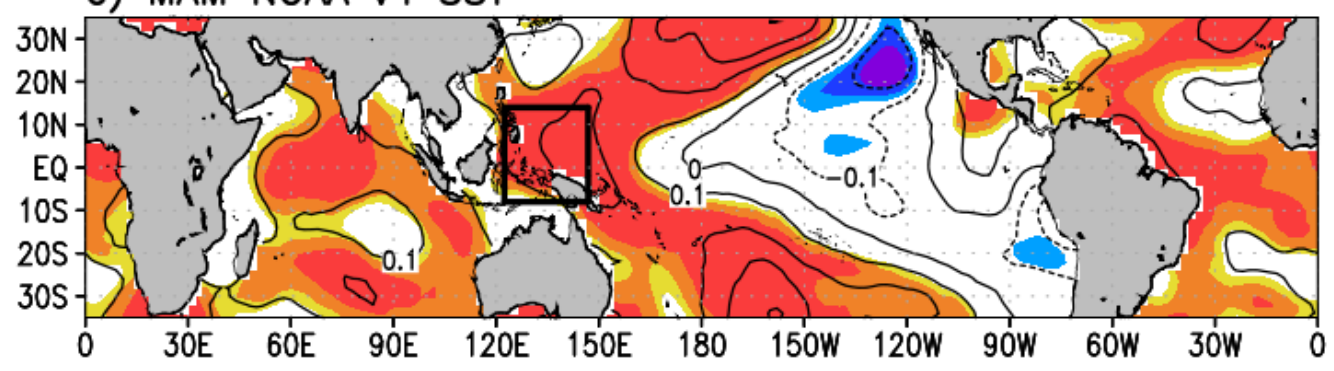

d) MAM $300 \mathrm{hPa}$ Velocity Potential

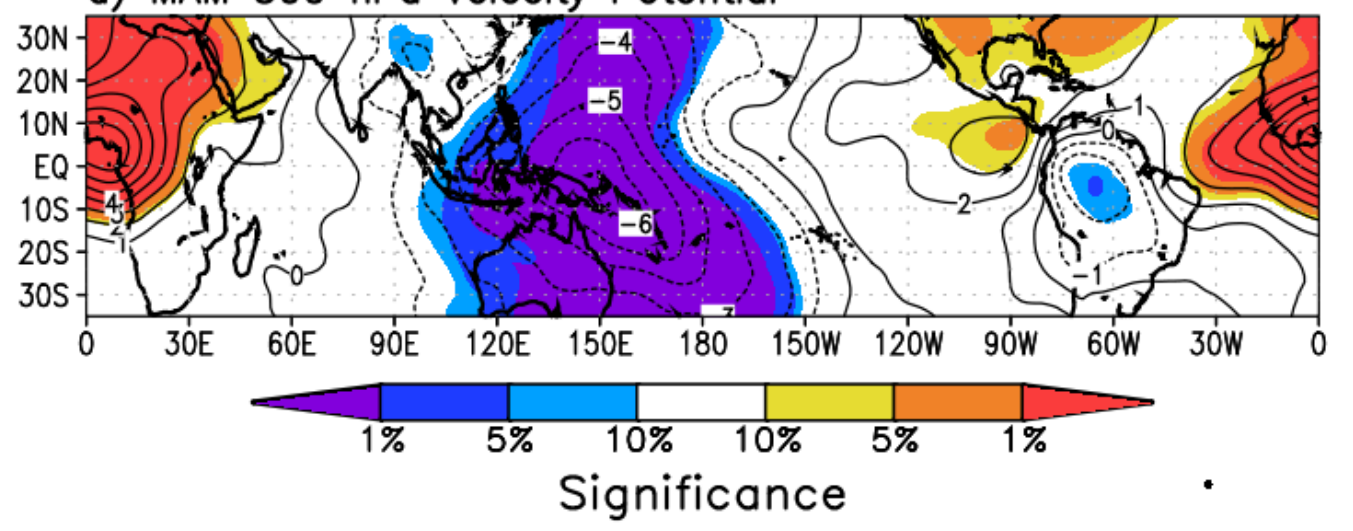

Figure 4.15: MAM linear trend, 1979-2014, in (a) $500 \mathrm{hPa}$ geopotential height and $300 \mathrm{hPa}$ wind, (b) 2-m temperature, (c) tropical SST, and (d) $300 \mathrm{hPa}$ velocity potential. Wind vector trends $\left(\mathrm{ms}^{-1}\right.$ decade $^{-1}$; indicated by reference vector) are shown only if at least one component is significant at $p<0.10$. Contour interval for (a) is $3 \mathrm{~m} \mathrm{decade}^{-1}$, (b) is $0.3^{\circ} \mathrm{C} \mathrm{decade}{ }^{-1}$, (c) is $0.1^{\circ} \mathrm{C}$ decade $^{-1}$, and (d) is $1 \times 10^{5} \mathrm{~m}^{2} \mathrm{~s}^{-1}$ decade $^{-1}$. Shading, from lightest to darkest, indicates trends that are statistically significant at $p<0.10, p<0.05$, and $p<0.01$, respectively, as referenced by the color bar. Station sites are shown as black circles. From left to right, station sites are: Halley, Neumayer, Novolazarevskaya, Syowa, Mawson, Davis, Mirny, Casey, and Dumont d'Urville. 
through sensible and latent heat fluxes, sea ice concentrations exhibit a ubiquitous increase along the entire East Antarctic coast which is not consistent with the regional nature of the temperature trends. Instead, recent changes in thermal advection patterns (Fig. 4.16b) associated with the regional circulation more strongly resemble the regional temperature trends. This includes increases in cold air advection near Novo and Syowa (particularly at Novo) and near Mirny and Casey, and increases in warm air advection near Mawson and Davis. At Dumont, there has not been an increase in cold air advection and therefore the cooling is likely more related to the strengthened westerlies offshore associated with the negative height trend over eastern East Antarctica and the positive height trend southwest of Australia (Fig. 4.15a). Although increasing sea ice concentrations have also likely played a role in the cooling at Dumont, this could still be related to the local circulation changes, including the strengthened westerlies or upstream cold air advection. Regardless, the regional nature of the station temperature changes is more consistent with the thermal advection patterns rather than the increasing sea ice concentrations around the entire East Antarctic coast.

To investigate linear relationships of East Antarctic temperatures with large-scale modes of climate variability, detrended correlations for Novo, Syowa, Casey, and Dumont temperatures with the leading tropical and SH climate modes are given in Table 4.5, while spatial correlations with tropical SSTs and circulation are shown in Fig. 4.17. Consistent with previous studies (e.g., Marshall 2007), all stations are significantly correlated with the SAM index. However, Novo and Syowa also exhibit a significant correlation $(p<0.01)$ with ENSO, while none of the stations are significantly correlated with the Atlantic's ENSO counterpart (represented by the ATL3 region $4^{\circ} \mathrm{S}-2^{\circ} \mathrm{N}, 20^{\circ} \mathrm{W}-0^{\circ}$, which is the region of greatest variance in equatorial Atlantic SSTs; Zebiak 1993). A significant positive correlation is seen for Syowa and equatorial Indian Ocean SSTs. However, the sign of this relationship is inconsistent with the observed equatorial Indian Ocean SST trend (which is positive) and the cooling at Syowa. Therefore, this relationship is likely an autocorrelation associated with ENSO's impact on tropical Indian Ocean SSTs (i.e., La Niña events are associated with negative SST anomalies over the equatorial Indian Ocean; Alexander et al. 2002). Therefore, recent changes in equatorial Indian Ocean SSTs do not appear related to the cooling at Syowa. For Casey and Dumont, no significant correlations exist with any of the tropical climate modes, and interannual temperature variability here is significantly correlated with the SAM index only. 

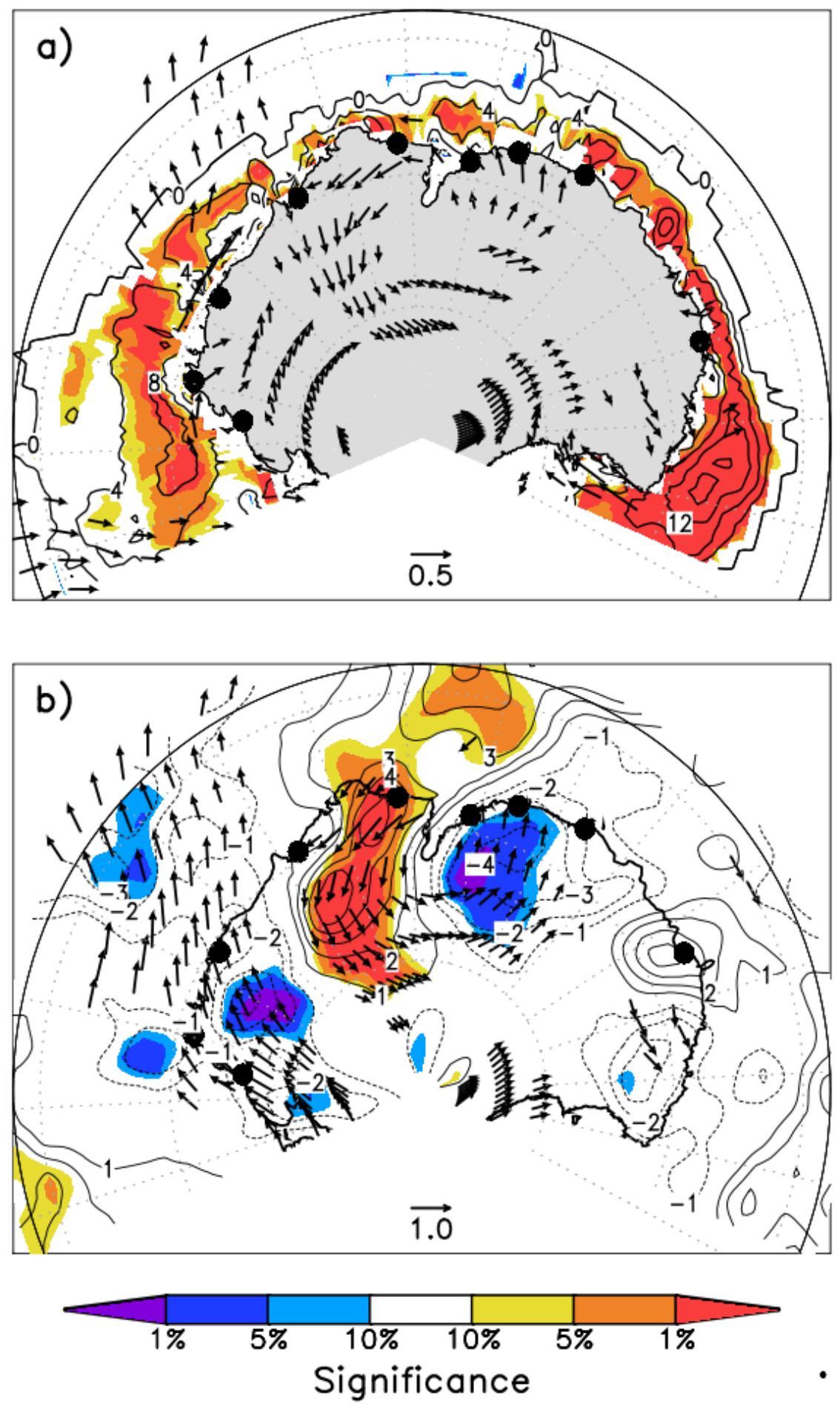

Figure 4.16: MAM linear trend, 1979-2014, in (a) sea ice concentration and 10-m wind, and (b) $500 \mathrm{hPa}$ meridional temperature advection $\left(-v^{\prime} \partial \mathrm{T} / \partial \mathrm{y}\right)$ and $500 \mathrm{hPa}$ wind. Wind vector trends $\left(\mathrm{ms}^{-1}\right.$ decade $^{-1}$; indicated by reference vector) are shown only if at least one component is significant at $p<0.10$. Contour interval for (a) is $4 \%$ decade $^{-1}$ and (b) is $1{ }^{\circ} \mathrm{Cs}^{-1} \mathrm{decade}^{-1}$ (scaled by $10^{6}$ ) with zero contours omitted in (b). Shading indicates statistical significance of trends as in Fig. 4.15. Station sites are plotted as in Fig. 4.15. 
Table 4.5: MAM detrended correlations, 1957-2014 or the start of the record, of coastal East Antarctic station temperatures (those exhibiting an increased rate of cooling after 1979) with the SOI and tropical SSTs in the Niño 3.4 , ATL $3\left(4^{\circ} \mathrm{S}-2^{\circ} \mathrm{N}, 20^{\circ} \mathrm{W}-0^{\circ}\right)$, and equatorial Indian Ocean $\left(6^{\circ} \mathrm{S}-6^{\circ} \mathrm{N}, 60-88^{\circ} \mathrm{E}\right)$ regions, and Marshall (2003) SAM index. Statistical significance of correlations is denoted as in Table 4.4.

\begin{tabular}{|lccccc|}
\hline & SOI & Niño 3.4 & ATL 3 & Indian & SAM \\
\hline Novo & $\underline{\mathbf{- 0 . 4 2 *}}$ & $\underline{\mathbf{0 . 3 5 *}}$ & -0.11 & 0.22 & $\underline{\mathbf{- 0 . 4 7 *}}$ \\
Syowa & $\underline{\mathbf{- 0 . 4 5 *}}$ & $\underline{\mathbf{0 . 3 7 *}}$ & 0.01 & $\underline{\mathbf{0 . 4 4}}$ & $\underline{\mathbf{- 0 . 3 3}}$ \\
Casey & -0.18 & 0.05 & 0.01 & 0.13 & $\underline{\mathbf{- 0 . 4 7 *}}$ \\
Dumont & -0.16 & 0.13 & -0.09 & 0.06 & $\underline{\mathbf{- 0 . 4 7 *}}$ \\
\hline
\end{tabular}

Detrended correlations of MAM Novo-Syowa mean (left column) and Casey-Dumont mean (right column) temperatures with tropical SSTs and circulation are shown in Fig. 4.17. The correlation coefficients are multiplied by -1 to show the correct anomalies associated with cooling at the Antarctic stations (except for the streamfunction field, Fig. 4.17c-d, to show correct sign of the geopotential height in the SH). Novo-Syowa temperatures are significantly correlated with central and western tropical Pacific SSTs, as well as north tropical Indian and tropical North Atlantic SSTs. The Novo-Syowa streamfunction correlations depict a PSA-like wavetrain closely resembling the wavetrain pattern seen in the circulation trends (Fig. 4.15a). There is no strong SAM pattern seen for Novo and Syowa, as correlations over interior Antarctica are weak and insignificant. In contrast, temperature correlations for Casey and Dumont show little to no connection on interannual timescales with tropical SSTs (Fig. 4.17b), while the circulation pattern more strongly resembles a SAM pattern with significant correlations with circulation / geopotential height over interior Antarctica (Fig 4d). However, it will be shown later that tropical relationships do exist with Casey and Dumont, just not on interannual timescales and not with the raw SST field.

Correlations with zonal and meridional winds indicate negative temperature anomalies along both coastal regions are associated with local westerly (positive correlations) and southerly (positive correlations) wind anomalies. The positive zonal wind correlations for Novo and Syowa are regional and statistically significant between $30^{\circ} \mathrm{W}$ and $30^{\circ} \mathrm{E}$ and between 90 and $120^{\circ} \mathrm{E}$ only, while Casey and Dumont slightly resemble more of a SAM pattern with fullhemispheric zonal wind anomalies along $\sim 60^{\circ} \mathrm{S}$. Negative temperature anomalies at both regions are also associated with northerly winds between 60 and $90^{\circ} \mathrm{E}$ (Fig. $4.17 \mathrm{~g}-\mathrm{h}$ ) near Mawson and 


\section{MAM Novo-Syowa Mean Temp}

a) SST Correlation

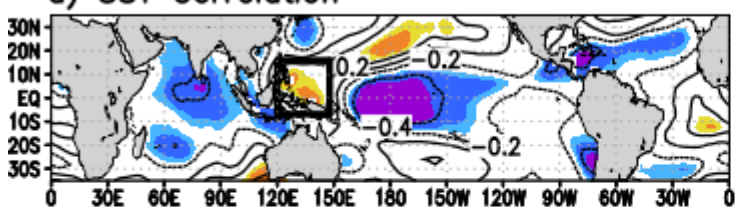

c) $500 \mathrm{hPa}$ Streamfunction
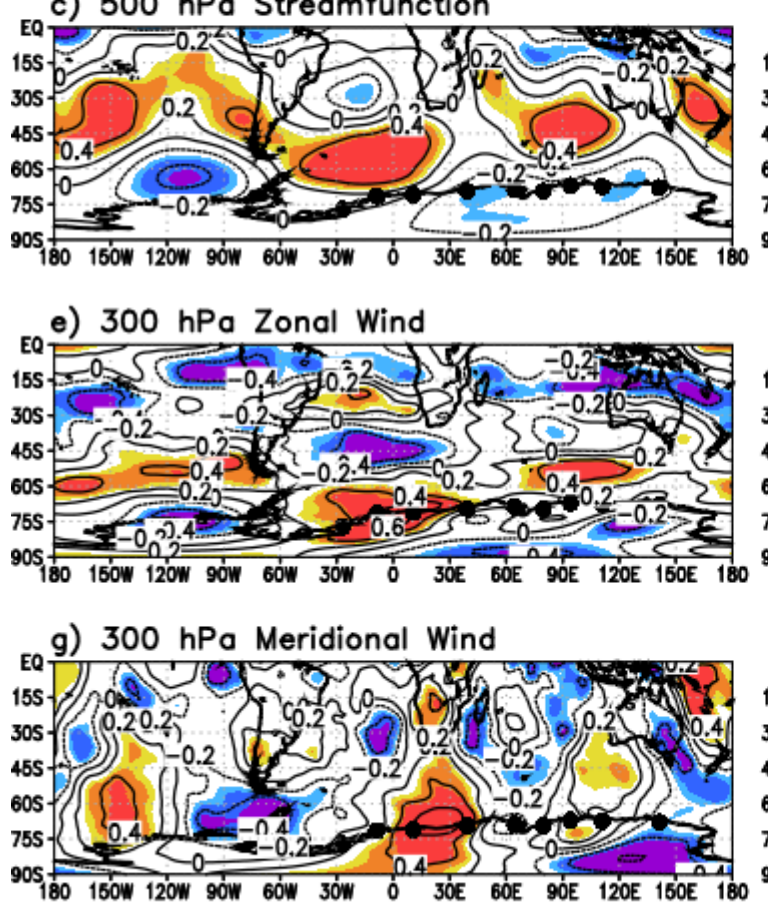

\section{MAM Casey-Dumont Mean Temp}

b) SST Correlation

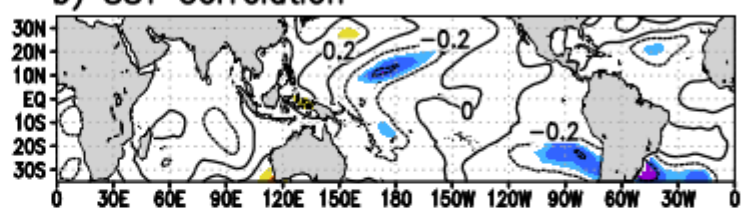

d) $500 \mathrm{hPa}$ Streamfunction
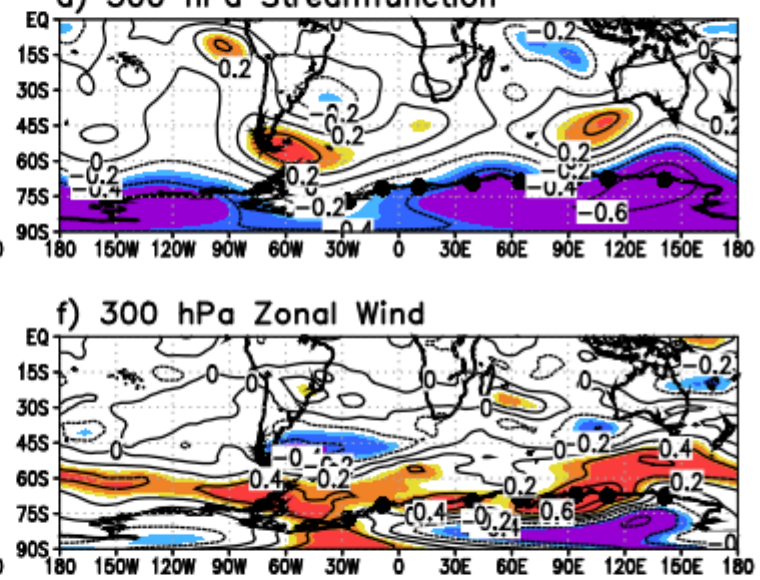

h) $300 \mathrm{hPa}$ Meridional Wind

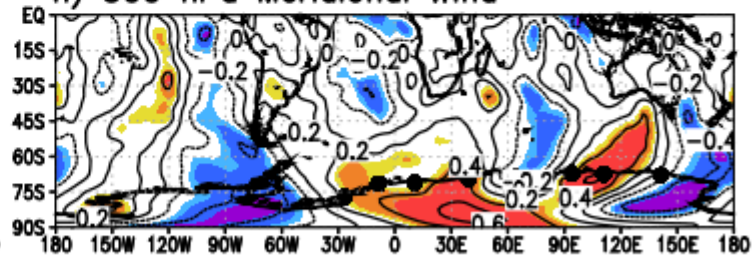

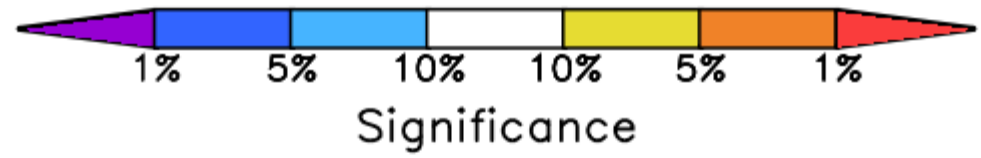

Figure 4.17: MAM detrended correlations, 1979-2014, of Novo-Syowa (left column) and CaseyDumont (right column) mean temperatures with (a-b) tropical SST, (c-d) $500 \mathrm{hPa}$ streamfunction, (e-f) $300 \mathrm{hPa}$ zonal wind, and (g-h) $300 \mathrm{hPa}$ meridional wind. Correlation coefficients are multiplied by -1 except for (c-d) to show correct anomalies associated with negative East Antarctic temperature anomalies. Shading indicates statistical significance of correlations and is drawn as in Figs. 4.15-4.16. Contour interval is 0.2. Station sites are plotted as in Fig. 4.15.

Davis, indicating negative temperature anomalies at Novo-Syowa and Casey-Dumont regions are associated with and consistent with positive temperature anomalies / warming at Mawson and Davis.

The linear circulation and 2-m temperature response associated with recent tropical and SAM-related trends during MAM are estimated next using linear congruency. Linear congruency 
is calculated by regressing the geopotential height and 2-m temperature fields onto the various climate indices and multiplying the regression coefficients by the observed climate index trend. Linear circulation impacts associated with ENSO are investigated using the observed MAM trend in the SOI. Linear impacts associated with warming over the western tropical Pacific SSTs are investigated using the observed MAM western tropical Pacific SST trend in the region $4^{\circ} \mathrm{S}$ $14^{\circ} \mathrm{N}, 122-144^{\circ} \mathrm{E}$ (black box in Figs. $4.15 \mathrm{c}$ and $4.17 \mathrm{a}$ ). This region is used because it is significantly correlated with Novo-Syowa mean temperatures at $p<0.05$ (Fig. 4.17a) and it exhibits a significant positive trend during 1979-2014 (Fig. 4.15c). To investigate west tropical Pacific impacts independent of ENSO (the SOI and western tropical Pacific SST region are correlated at $\mathrm{r}=0.62, p<0.01$ ), a western tropical Pacific residual SST is used by linearly removing the portion of the western tropical Pacific SST variability related to the SOI (Fig. 4.18). The residual index has a zero correlation with the SOI, and therefore is linearly independent of the SOI. SAM-related circulation changes are investigated using the observed MAM trend in the Marshall (2003) SAM index over 1979-2014. The SAM index and SOI are correlated at $\mathrm{r}=0.18, p>0.10$ during MAM, and therefore are only weakly related and primarily

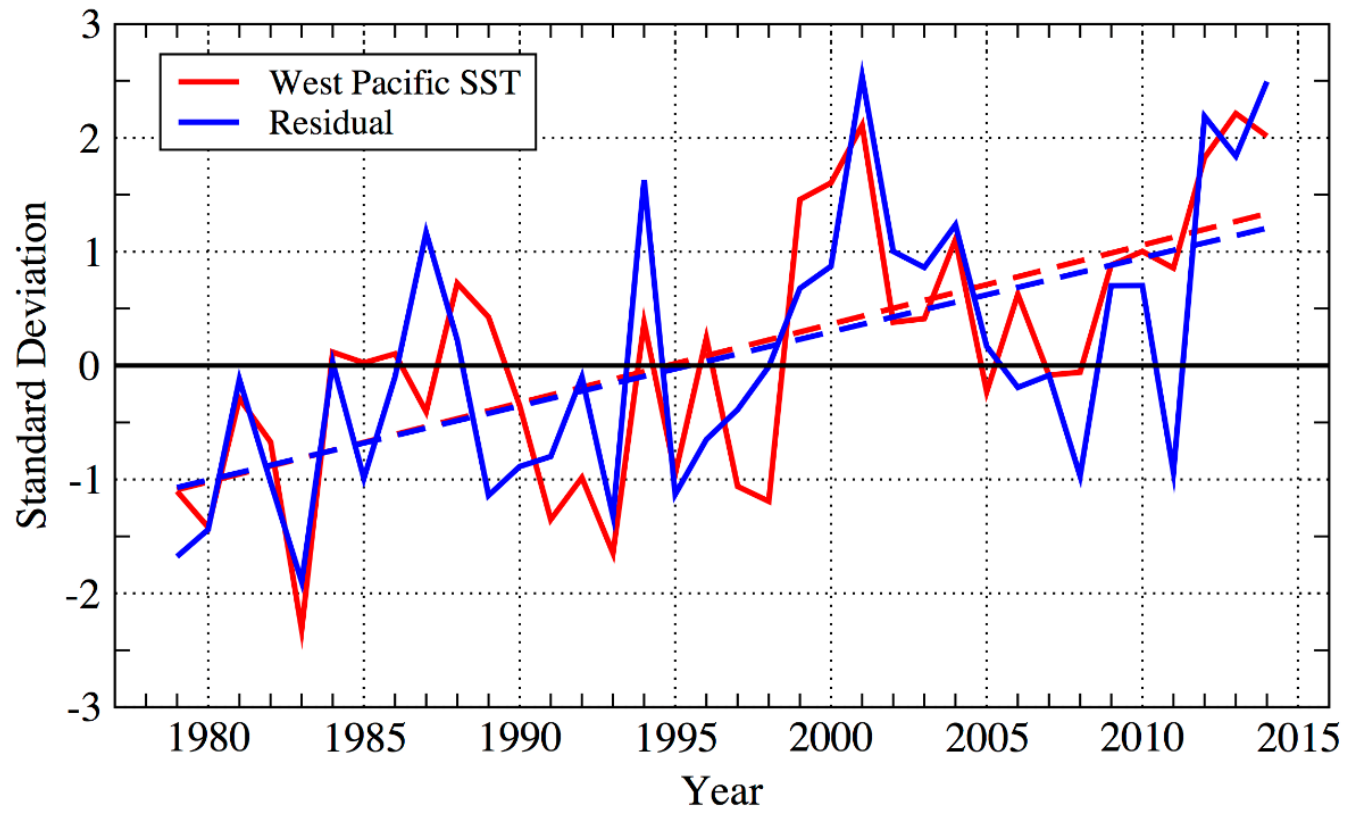

Figure 4.18: Time series of MAM western tropical Pacific SST raw (red) and residual (blue) after removing the SOI. Also plotted are the respective trend lines. 
linearly independent during MAM. All climate index trends are given in Table 4.6. Spatial linear congruency with circulation and East Antarctic temperatures are shown in Figs. 4.19 and 4.20, respectively, and with station temperatures in Table 4.6.

The MAM positive SOI trend is associated with a PSA-like wavetrain over the South Pacific and South Atlantic (Fig. 4.19b) that aligns well with the observed geopotential height trends. The SOI trend is linearly congruent with $60-80 \%$ of the significant South Atlantic positive height trend near $15^{\circ} \mathrm{W}$. The circulation pattern associated with western tropical Pacific residual warming (the portion not related to the SOI) is associated with a weaker and poleward / westward displaced wavetrain with height increases across the central South Pacific, height decreases over the Ross Ice Shelf (40-60\%), and height increases off the east coast of the Antarctic Peninsula. The western tropical Pacific warming is also linearly congruent with 30$60 \%$ of the locally significant height decreases over coastal and interior East Antarctica. The positive SAM index trend is associated with a more zonal circulation pattern and is linearly congruent with $60-80 \%$ or more of the height decreases over interior East Antarctica. However, over the southern Indian Ocean, the spatial pattern of the SAM-related circulation changes does not resemble the regional nature of the circulation trends seen there.

Linear congruency with East Antarctic 2-m temperature is shown in Fig. 4.20, and with station temperatures in Table 4.6. The SOI is linearly congruent with $40-60 \%$ of the significant cooling along the western East Antarctic coast near Novo and Syowa (between $\sim 15$ and $45^{\circ} \mathrm{E}$ ) and offshore between 30 and $60^{\circ} \mathrm{E}$. Western tropical Pacific residual warming is more associated with the cooling farther west along the Greenwich meridian in association with the westward and poleward displaced anticyclone over the Peninsula (Fig. 4.19c), and is also linearly congruent with $40-60 \%$ of the significant cooling along the eastern East Antarctic coast near Casey and Dumont (from $\sim 120^{\circ} \mathrm{E}$ to the dateline). Both the SOI and western tropical Pacific trends are also associated with weak warming between $\sim 60$ and $75^{\circ} \mathrm{E}$ near Mawson and Davis, consistent with Mawson and Davis observed warming. The positive SAM trend is associated with a more uniform cooling of $0.1-0.3^{\circ} \mathrm{C}$ decade $^{-1}$ over interior East Antarctica and is linearly congruent with $60-80 \%$ of the significant cooling near the pole. However, the rate of cooling along the coast associated with the positive SAM trend is weaker and more uniform than that associated with the western tropical Pacific residual, and to a lesser extent, the SOI. 

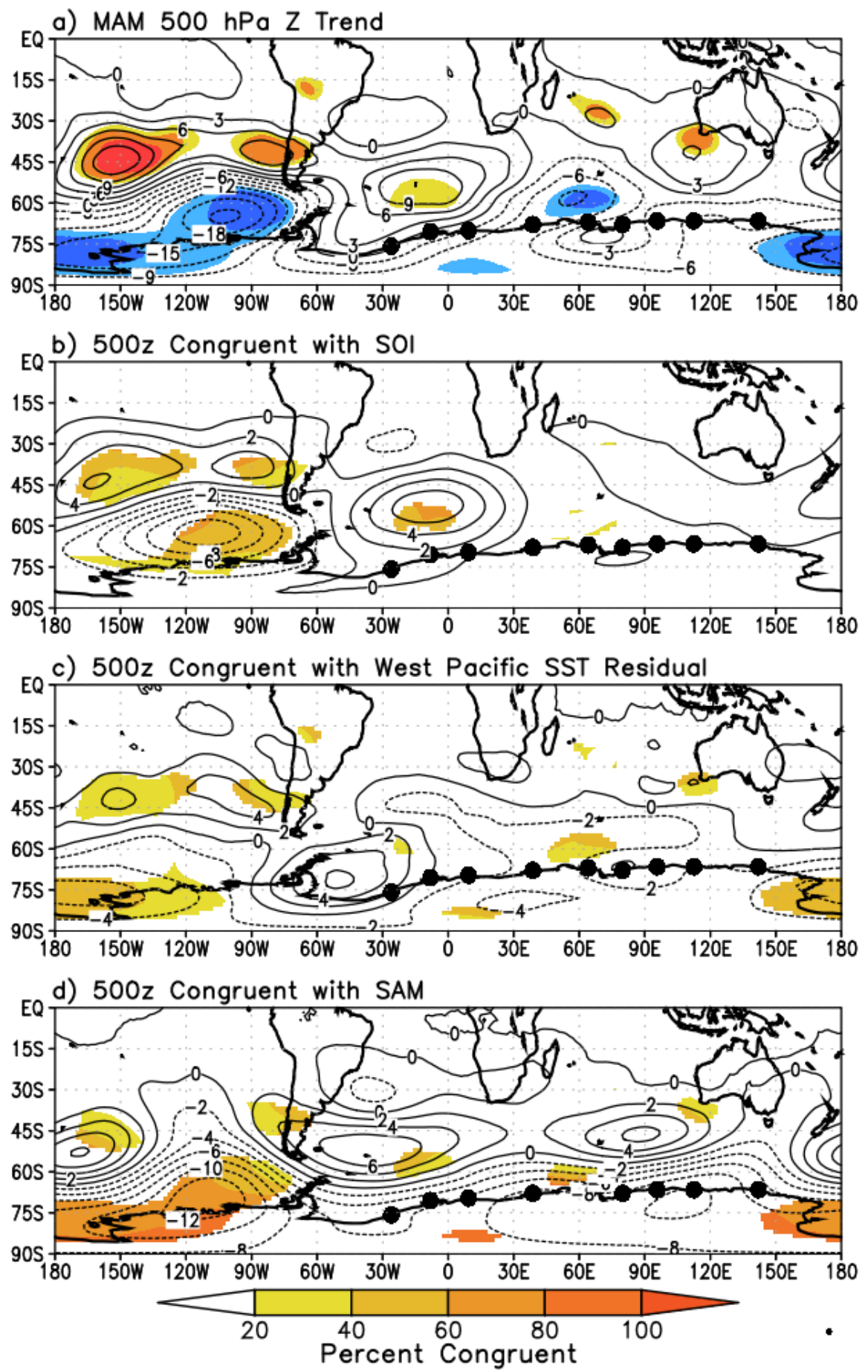

Figure 4.19: (a) Linear trend in MAM $500 \mathrm{hPa}$ geopotential height (and significance), 19792014, as in Fig. 4.15c, and spatial linear congruency with (b) the SOI, (c) the western tropical Pacific residual SST, and (d) the SAM index trends. Contours in (b-d) show the 500 hPa height trend pattern that is associated with the linear trend in the (b) SOI, (c) western tropical Pacific residual SST, and (d) SAM index, while shading in (b-d) indicates the percentage of the $500 \mathrm{hPa}$ height trends that is linearly congruent with the SOI, western tropical Pacific residual SST, and SAM index trends. Shading is drawn only where $500 \mathrm{hPa}$ height trends are significant at $p<0.10$. 
Contour interval for $(\mathrm{b}-\mathrm{d})$ is $2 \mathrm{~m} \mathrm{decade}^{-1}$. Black dots denote the locations of surface observing stations.

a) MAM $2 \mathrm{~m}$ Temperature Trend

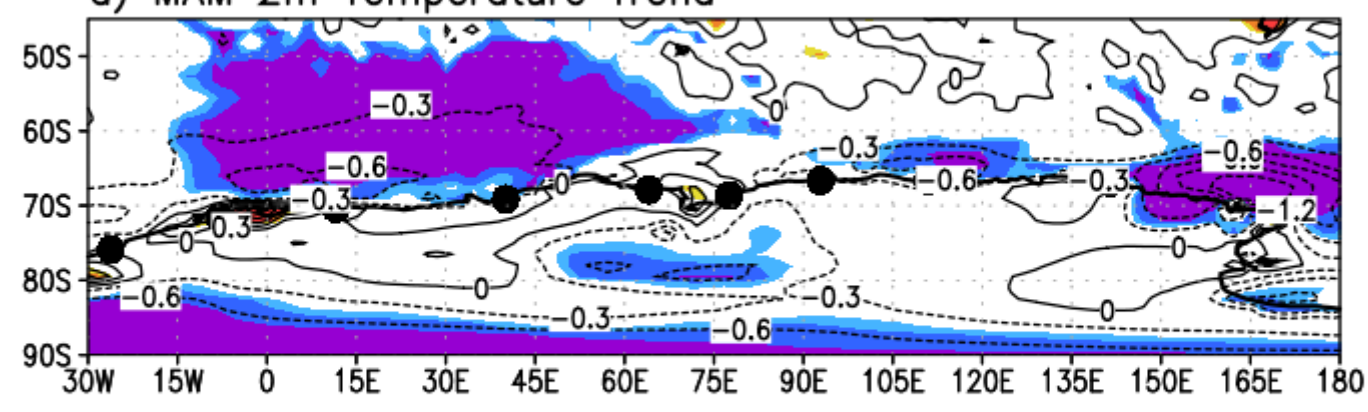

b) $2 \mathrm{~m}$ Temp Congruent with SOI

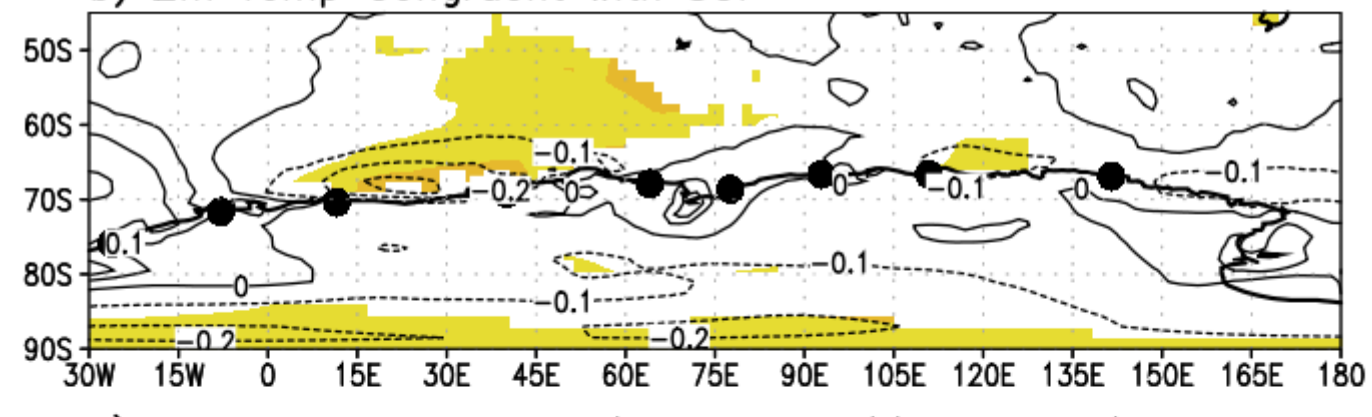

c) $2 \mathrm{~m}$ Temp Congruent with West Pacific SST Residual

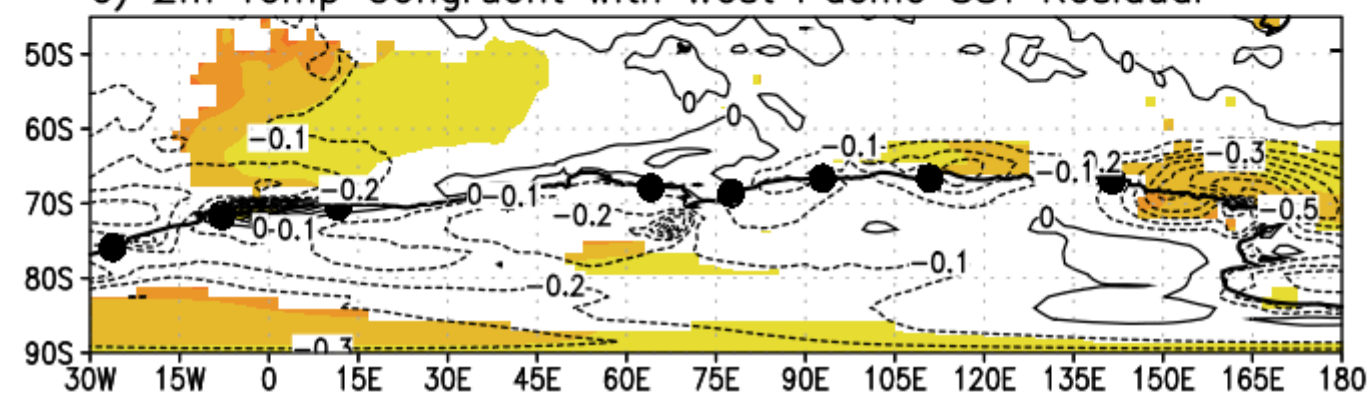

d) $2 \mathrm{~m}$ Temp Congruent with SAM
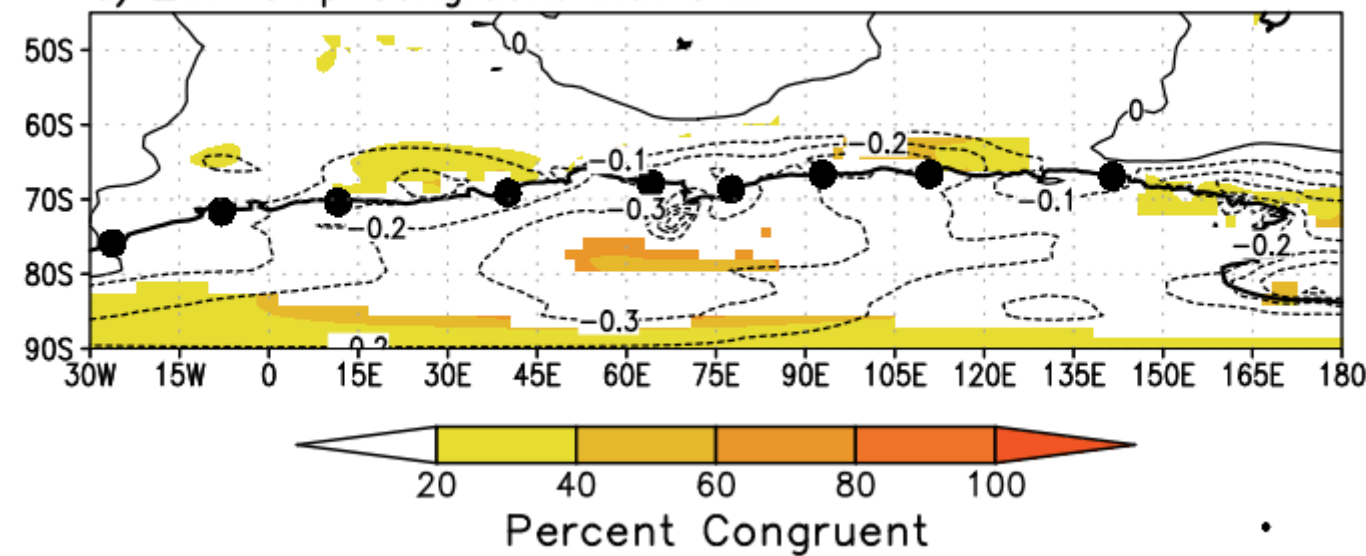

Figure 4.20: As in Fig. 4.19, except for East Antarctic 2-m temperature. Contour interval for (bd) is $0.1^{\circ} \mathrm{C}$ decade $^{-1}$. 
Table 4.6: The 1979-2014 MAM trends and 95\% confidence intervals for East Antarctic station temperatures (as in Table 4.4), the SOI, western tropical Pacific residual SST, and the Marshall (2003) SAM index (units of standardised index decade ${ }^{-1}$ for SOI and SAM index and ${ }^{\circ} \mathrm{C} \mathrm{decade}^{-1}$ for station temperature and SST), and the portion / percentage (units of ${ }^{\circ} \mathrm{C}$ decade $^{-1}$ ) of the station temperature trends that is linearly congruent with the climate index trends. The western tropical Pacific region $\left(4^{\circ} \mathrm{S}-14^{\circ} \mathrm{N}, 122-144^{\circ} \mathrm{E}\right)$ is indicated by a black box in Figs. $4.15 \mathrm{c}$ and $4.17 \mathrm{a}$, and the residual is the SST time series remaining after linearly removing the SOI. Statistical significance of trends is denoted as in Tables 4.4-4.5.

\begin{tabular}{|lcccc|}
\hline & & & West Pacific Residual & \\
& & SOI Trend & SST Trend & SAM Trend \\
& & $\mathbf{0 . 3 4} \pm \mathbf{0 . 3 7}$ & $\underline{\mathbf{0 . 1 2} \pm \mathbf{0 . 0 6}}$ & $\mathbf{0 . 3 1} \pm \mathbf{0 . 3 2}$ \\
\hline \hline \multirow{2}{*}{ Station Temp } & Congruent with & Congruent with & Congruent with \\
Trend & SOI & West Pacific SST & SAM \\
Syowa & $\underline{\mathbf{- 0 . 3 6} \pm \mathbf{0 . 3 3}}$ & $-0.16(44 \%)$ & $-0.16(43 \%)$ & $-0.18(51 \%)$ \\
Mean & $\underline{\mathbf{0 . 5 3} \pm \mathbf{0 . 4 2}}$ & $-0.20(37 \%)$ & $-0.08(16 \%)$ & $-0.18(34 \%)$ \\
\hline Casey & $-\mathbf{- 0 . 4 2 \pm 0 . 3 3}$ & $-0.18(40 \%)$ & $-0.12(27 \%)$ & $-0.18(40 \%)$ \\
Dumont & $\underline{\mathbf{- 0 . 4 0} \pm \mathbf{0 . 3 1}}$ & $-0.07(17 \%)$ & $-0.19(45 \%)$ & $-0.26(64 \%)$ \\
Mean & $\underline{\mathbf{0 . 4 1} \pm \mathbf{0 . 3 9}}$ & $-0.05(13 \%)$ & $-0.24(59 \%)$ & $-0.13(32 \%)$ \\
\hline
\end{tabular}

The SAM-related cooling is consistent with the more zonal circulation response and lacks more regional, meridional circulation anomalies that would locally enhance cooling / warming through thermal advection. Therefore, the positive SAM index trend is primarily associated with cooling over continental Antarctica and more ubiquitous (although weaker) cooling along the coast, while the more regionally enhanced cooling over the Southern Ocean and along the coast near Novo-Syowa and Casey-Dumont are more related to local westerly and southwesterly wind anomalies associated with the tropical climate trends.

Linear congruency with station temperatures confirms the reanalysis-based temperature results. Both the positive SOI trend and positive SAM index trend are linearly congruent with an equal $40 \%$ of the cooling at Novo and Syowa, and the western tropical Pacific residual warming is linearly congruent with more than half of the observed cooling at Casey and Dumont while the positive SAM index trend is linearly congruent with less than half of the Casey-Dumont cooling. The SOI trend shows essentially no relationship to the cooling trends at Casey and Dumont, 
indicating the portion of the western tropical Pacific warming not related to ENSO is more strongly associated with the Casey-Dumont cooling.

\subsubsection{Tropical Pacific Composites and Relationships with East Antarctic Cooling}

Potential mechanisms driving the MAM circulation changes are investigated with composites in Figs. 4.21-4.22. Anomalous forcing for ascent / upper-level divergence over the tropics is examined using SST and $300 \mathrm{hPa}$ velocity potential. Circulation is investigated using $500 \mathrm{hPa}$ streamfunction (multiplied by -1 to show correct sign for geopotential height anomaly in the $\mathrm{SH}$ ), and anomalous Rossby wave propagation is examined using the Eu vector (Trenberth 1986, 1991). The Eu vector is similar to the Eliassen-Palm flux described by Edmon et al. (1980). The zonal component of the $\mathbf{E} \mathbf{u}$ vector is $\frac{1}{2}\left(\overline{v^{* 2}-u^{* 2}}\right)$ and the meridional component is $-\overline{u^{*} v^{*}}$, or the negative of the transient eddy momentum flux. The Eu vector points in the direction of the relative group velocity of propagating Rossby waves, it points opposite the momentum flux, and the divergence of $\mathbf{E u}$ is associated with momentum flux convergence and westerly wind production (Trenberth 1991). Geopotential height and upper-tropospheric wind anomalies are investigated using $500 \mathrm{hPa}$ geopotential height and $300 \mathrm{hPa}$ wind.

Following the linear congruency results, composites for the top six SOI years and top six coldest years at Novo are shown alongside each other in Fig. 4.21, and the top six warmest western tropical Pacific residual years are shown alongside the top six coldest Dumont years in Fig. 4.22. The top six years represent the $85^{\text {th }}$ and $15^{\text {th }}$ percentiles of the distribution (during 1979-2014), the purpose being to show average anomalies associated with exceptional years. Anomaly composites were calculated individually for all four stations and for five and seven years instead of six, and similar results were obtained. However, results for Novo are shown instead of Syowa, and Dumont instead of Casey, because the respective tropical climate index trends explain a larger percentage of the cooling at these stations and the anomalies for these stations are greater in magnitude and more easily distinguishable. The anomalies for Syowa instead of Novo, or Casey instead of Dumont, are nearly identical in sign and location to those presented here, only the magnitude of the anomalies is weaker. The MAM years used for compositing are given in Table 4.7.

For the Novo / SOI composite (Fig. 4.21), both are associated with significant positive SST anomalies over the western tropical Pacific and negative SST anomalies over the central and 
Novo Cold

a) SST Anomaly

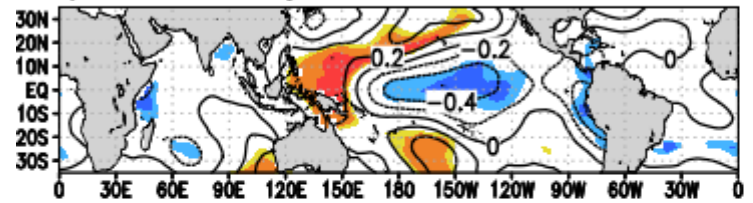

c) $300 \mathrm{hPa}$ Velocity Potential Anomaly

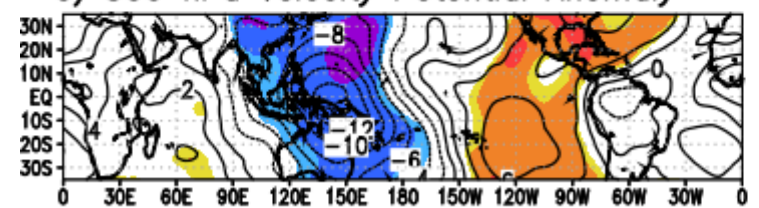

e) 500 Streamfunction / 300 Eu Anomaly

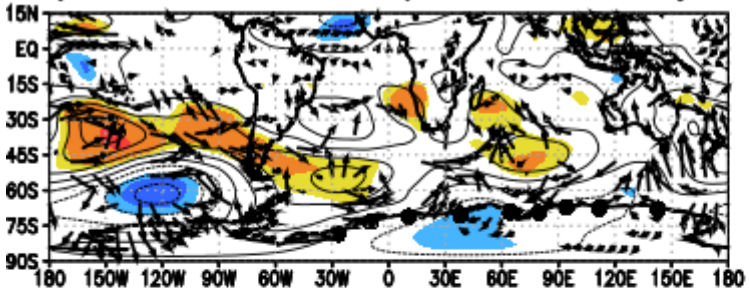

g) $500 \mathrm{Z} / 300$ Wind Anomaly

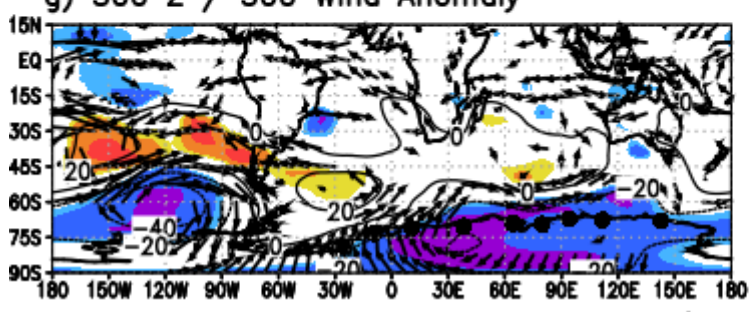

$\overrightarrow{25}$

$$
\overrightarrow{2.5}
$$

$\mathrm{SOI+}$

b) SST Anomaly

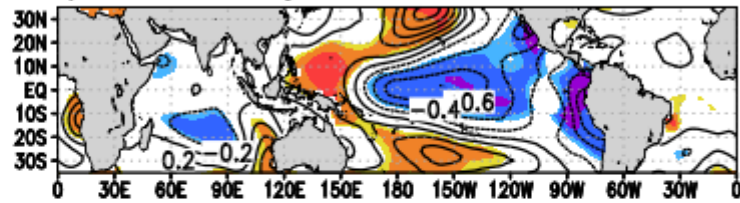

d) $300 \mathrm{hPa}$ Velocity Potential Anomaly

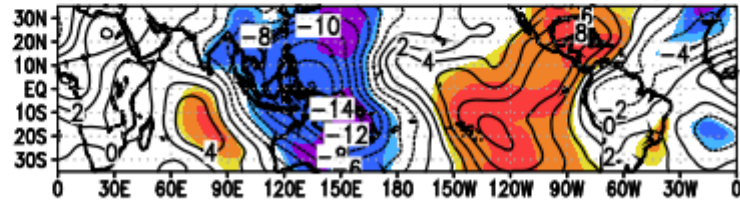

f) 500 Streamfunction / 300 Eu Anomaly

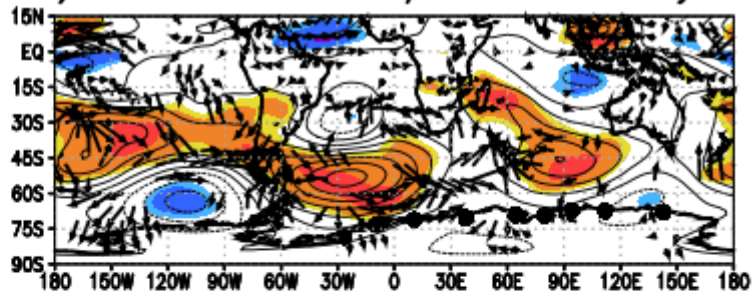

h) $500 \mathrm{Z} / 300$ Wind Anomaly

$\overrightarrow{25}$

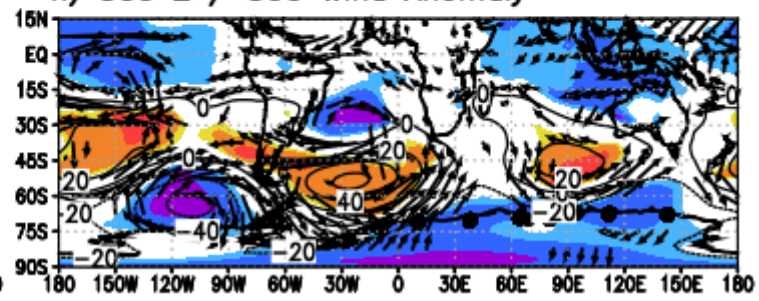

$\overrightarrow{2.5}$

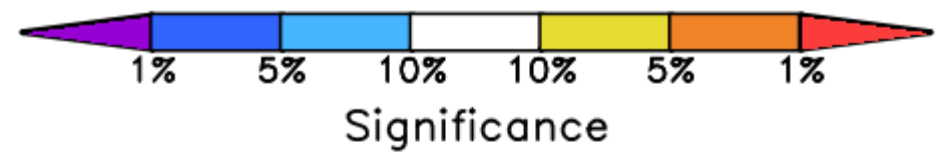

Figure 4.21: MAM anomaly composite mean for the six coldest years at Novo (left column) and the six highest SOI years (right column) during 1979-2014. (a-b) Tropical SST, (c-d) $300 \mathrm{hPa}$ velocity potential, (e-f) $500 \mathrm{hPa}$ streamfunction (multiplied by -1, contour labels omitted) and $300 \mathrm{hPa} \mathbf{E u}$, and (g-h) $500 \mathrm{hPa}$ geopotential height and $300 \mathrm{hPa}$ wind. The MAM years used for compositing are given in Table 4.7. Shading indicates significance of anomalies and is drawn as in Figs. 4.15-4.17. Contour interval for $(\mathrm{a}-\mathrm{b})$ is $0.2^{\circ} \mathrm{C}$, (c-d) is $2 \times 10^{5} \mathrm{~m}^{2} \mathrm{~s}^{-1}$, (e-f) is $1 \times 10^{6} \mathrm{~m}^{2} \mathrm{~s}^{-1}$, and $(\mathrm{g}-\mathrm{h})$ is $20 \mathrm{~m}$. Eu vector and $300 \mathrm{hPa}$ wind vector anomalies are shown only if at least one component is significant at $p<0.10$. 


\section{Dumont Cold}

a) SST Anomaly

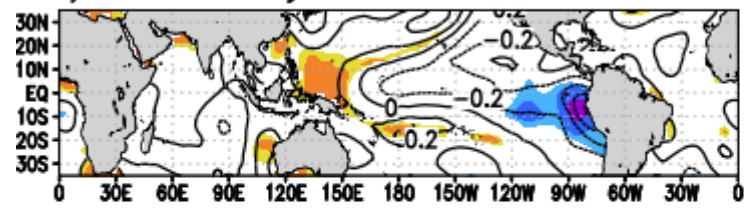

c) $300 \mathrm{hPa}$ Velocity Potential Anomaly

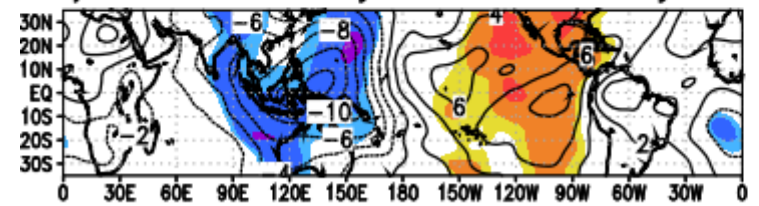

e) 500 Streamfunction / 300 Eu Anomaly
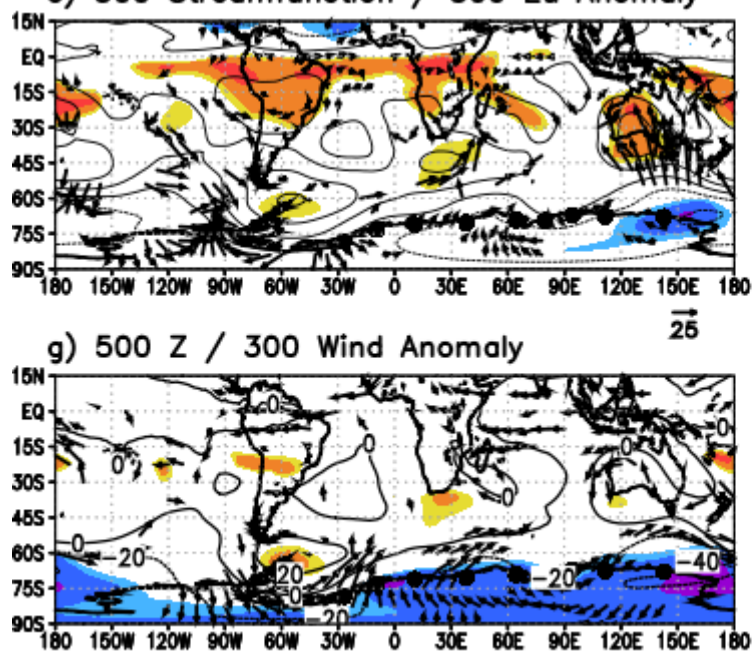

$\overrightarrow{2.5}$
W. Pacific SST Resid Warm

b) SST Anomaly

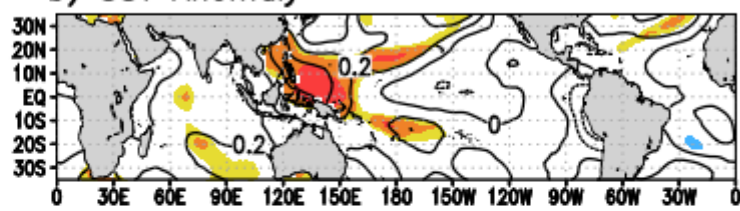

d) $300 \mathrm{hPa}$ Velocity Potential Anomaly

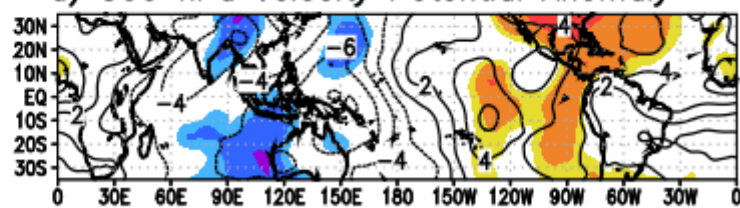

f) 500 Streamfunction / 300 Eu Anomaly

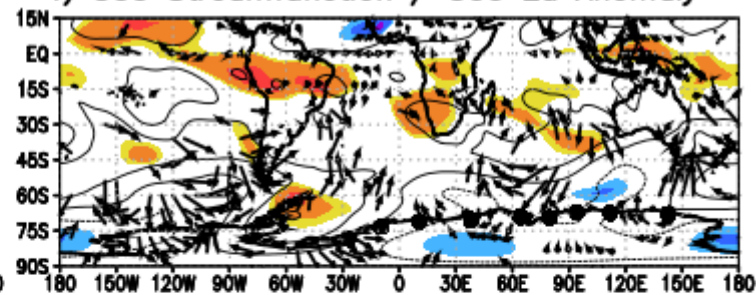

h) $500 \mathrm{Z} / 300$ Wind Anomaly

$\overrightarrow{25}$

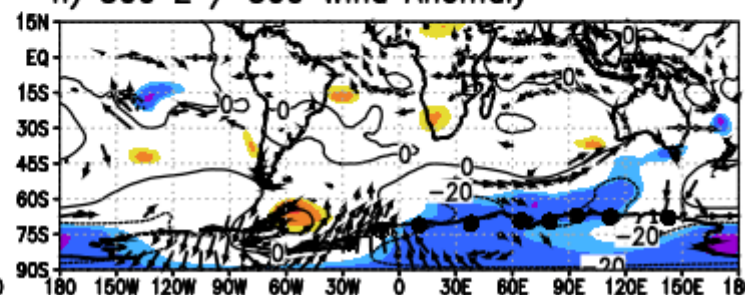

$\overrightarrow{2.5}$

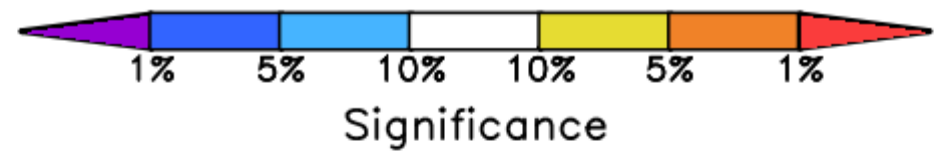

Figure 4.22: As in Fig. 4.21, except for the six coldest MAM years at Dumont (left column) and the six warmest western tropical Pacific residual SST years during MAM (right column). 
Table 4.7: Top six coldest MAM years (rank order; $15^{\text {th }}$ percentile) over 1979-2014 for Novo, Syowa, Casey, and Dumont, and top six highest SOI and warmest western tropical Pacific residual SST years (rank order, $85^{\text {th }}$ percentile). Also given for the station years are the ENSO / SAM phases based on when the climate index (SAM index and either the SOI or Niño 3.4 SST anomaly) is above or below the $70^{\text {th }}$ or $30^{\text {th }}$ percentile, respectively. EN=El Niño (negative SOI or positive Niño 3.4 SST anomaly) and LN=La Niña (positive SOI or negative Niño 3.4 SST anomaly).

\begin{tabular}{|cc|cc|c|}
\hline \multicolumn{2}{|c|}{ Novo } & \multicolumn{2}{|c|}{ Syowa } & SOI \\
\hline \hline$\underline{\text { Year }}$ & $\underline{\text { ENSO-SAM }}$ & $\underline{\text { Year }}$ & $\underline{\text { ENSO-SAM }}$ & $\underline{\text { Year }}$ \\
2000 & LN/SAM+ & 1989 & LN/SAM+ & 2011 \\
1989 & LN/SAM+ & 2000 & LN/SAM+ & 1989 \\
2004 & neutral & 1993 & EN/SAM+ & 1999 \\
2013 & LN/SAM+ & 2012 & LN/SAM+ & 2000 \\
1996 & LN & 1996 & LN & 2013 \\
2012 & LN/SAM+ & 2010 & LN & 2006 \\
\hline & Casey & & Dumont & West Pacific SST \\
\hline \hline Year & ENSO-SAM & $\underline{\text { Year }}$ & $\underline{\text { ENSO-SAM }}$ & $\underline{\text { Year }}$ \\
1999 & LN/SAM+ & 1999 & LN/SAM+ & 2001 \\
$2000 *$ & LN/SAM+ & $1994 *$ & EN & 2014 \\
1995 & EN & $2013 *$ & LN/SAM+ & 2012 \\
$1994 *$ & EN & $2003 *$ & SAM + & 2013 \\
1997 & EN/SAM+ & $200 *^{*}$ & LN/SAM + & 1994 \\
$2014 *$ & neutral & 2005 & EN & 2004 \\
\hline
\end{tabular}

eastern tropical Pacific resembling a La Niña pattern (Fig. 4.21a-b), but without a continuous extension of significant cold equatorial Pacific SSTs eastward to the coast of South America. An anomalous velocity potential couplet is seen over the tropical Pacific for both groups (Fig. 4.21cd), with anomalous ascent in the western tropical Pacific and descent over the eastern tropical Pacific. This represents a strengthened Walker circulation and anomalous upper-level divergence over the western tropical Pacific, both of which are commonly seen during La Niña events.

The $500 \mathrm{hPa}$ streamfunction and $\mathbf{E u}$ anomalies show poleward wave propagation out of the western tropical Pacific into the high-latitude South Pacific and eastward wave propagation through Drake Passage into the high-latitude South Atlantic. Both circulation patterns depict a La Niña-like PSA wavetrain with significant anticyclonic circulation anomalies over the highlatitude South Atlantic. The wavetrain is more pronounced for positive SOI years, but the sign 
and location of circulation anomalies for cold years at Novo are nearly identical to those for positive SOI years. There are anomalous equatorward wave fluxes / poleward momentum fluxes and Eu divergence between $\sim 45-60^{\circ} \mathrm{S}$ near $30^{\circ} \mathrm{W}$ which would locally enhance acceleration of the westerly winds and also favor downstream trough development near $30^{\circ} \mathrm{E}$ where there is equatorward wave fluxes near the coast. Both features would locally strengthen the westerlies, the former through momentum flux convergence, and the latter through strengthening the meridional pressure gradient. A similar wavetrain is seen for $500 \mathrm{hPa}$ geopotential heights with an anomalous anticyclone over the South Atlantic, and both composite groups are associated with significant westerly / southwesterly winds between $30^{\circ} \mathrm{W}$ and $30^{\circ} \mathrm{E}$.

Three of the six years used for the Novo / SOI composite groups overlap (2000, 1989, and 2013). No El Niño events were observed during any of the cold years at Novo, and five of the six coldest years at both Novo and Syowa were La Niña years, further supporting a strong ENSO / La Niña connection to the cooling at Novo and Syowa. Similarly, no negative SAM years occurred during the six coldest years at Novo and Syowa, which also is consistent with the significant correlations with the SAM index and the similar-magnitude linear congruency results for the SOI and SAM trends. However, the two modes clearly represent different circulation patterns, with the SOI associated with local westerly / southwesterly wind anomalies, while the SAM is associated with a more hemispheric-wide strengthening of the westerlies.

The Dumont and western tropical Pacific SST residual composites are shown in Fig. 4.22. Both groups are associated with significant positive SST anomalies and anomalous ascent / upper-level divergence over the western tropical Pacific and a strengthened Walker circulation. The anomalous Walker circulation is like that seen in the Novo / SOI composites, but only two of the six Dumont years overlap with Novo, and only one western tropical Pacific residual year overlaps with the SOI. Therefore, although the SST / velocity potential anomalies are similar, they represent two largely independent patterns. A mix of ENSO phases are seen for the Casey and Dumont composite years, consistent with the weak correlations with ENSO. However, four of the six coldest years at Dumont and three of the six coldest years at Casey had positive western tropical Pacific residual SST anomalies above the $70^{\text {th }}$ percentile, and the remaining two years at Dumont (1999 and 2005) had positive western tropical Pacific residual SST anomalies although below the $70^{\text {th }}$ percentile (not shown). Therefore, no Dumont cold years occurred with negative western tropical Pacific residual SST anomalies. 
In contrast to the Novo / SOI composites, there is not a PSA wavetrain seen in the circulation anomalies. The Dumont composite weakly resembles positive SAM conditions with negative height anomalies over Antarctica, however, the pattern does not depict a robust SAM pattern as there are no significant height anomalies across the middle latitudes and there is not a hemisphere-wide strengthening of the mid-latitude jet. Instead, the circulation pattern reflects a regional ridge-trough pattern oriented meridionally from southwest Australia to the eastern East Antarctic coast and strong poleward momentum fluxes / Eu divergence between $45-60^{\circ} \mathrm{S}$ between $120-155^{\circ} \mathrm{E}$ (Fig. 4.22e). This would produce a strengthening of the westerlies along the coast through a combination of momentum flux convergence a strengthened meridional pressure gradient associated with the height anomalies. Although less marked, the western tropical Pacific composite shows a similar wavetrain with a ridge southwest of Australia and a trough near $60^{\circ} \mathrm{S}$, $120^{\circ} \mathrm{E}$, and poleward momentum fluxes along the coast near $150^{\circ} \mathrm{E}$ (Fig. $4.22 \mathrm{f}$ ). Overall, the regional circulation features across the full SH are nearly identical for the two composites, including poleward wave fluxes across the high-latitude South Pacific, an anticyclone over the northern Antarctic Peninsula, northerly winds over West Antarctica, and a deep trough over the Ross Ice Shelf. As noted previously, the positive western tropical Pacific residual SST trend was linearly congruent with $40-80 \%$ of the observed height decreases over the Ross Ice Shelf (Fig. $4.19 \mathrm{c}-\mathrm{d})$.

To identify potential forcing mechanisms explaining the relationships previously presented, correlations with tropical OLR are shown in Figs. 4.23-4.24. Separate analysis (not shown) identified that Novo and Syowa temperatures are significantly correlated with OLR over the western tropical Pacific warm pool region $\left(115-155^{\circ} \mathrm{E}, 20^{\circ} \mathrm{S}-7.5^{\circ} \mathrm{N}\right)$, while Casey and Dumont temperatures are correlated with OLR on the western and southern edge of the warm pool over the eastern tropical Indian Ocean $\left(90-122.5^{\circ} \mathrm{E}, 15^{\circ} \mathrm{S}-5^{\circ} \mathrm{N}\right)$. This is consistent with the Eu composite analyses, which showed anomalous poleward wave fluxes out of the western tropical Pacific for Novo / positive SOI years, and anomalous poleward wave fluxes west of Australia over the southeast Indian Ocean for warm western tropical Pacific SST years. Western tropical Pacific OLR correlations are shown in Fig. 4.23, and eastern Indian Ocean OLR correlations are shown in Fig. 4.24. All correlations are detrended and multiplied by -1 to show correct height / temperature anomalies associated with anomalous deep convection (negative OLR anomalies). 

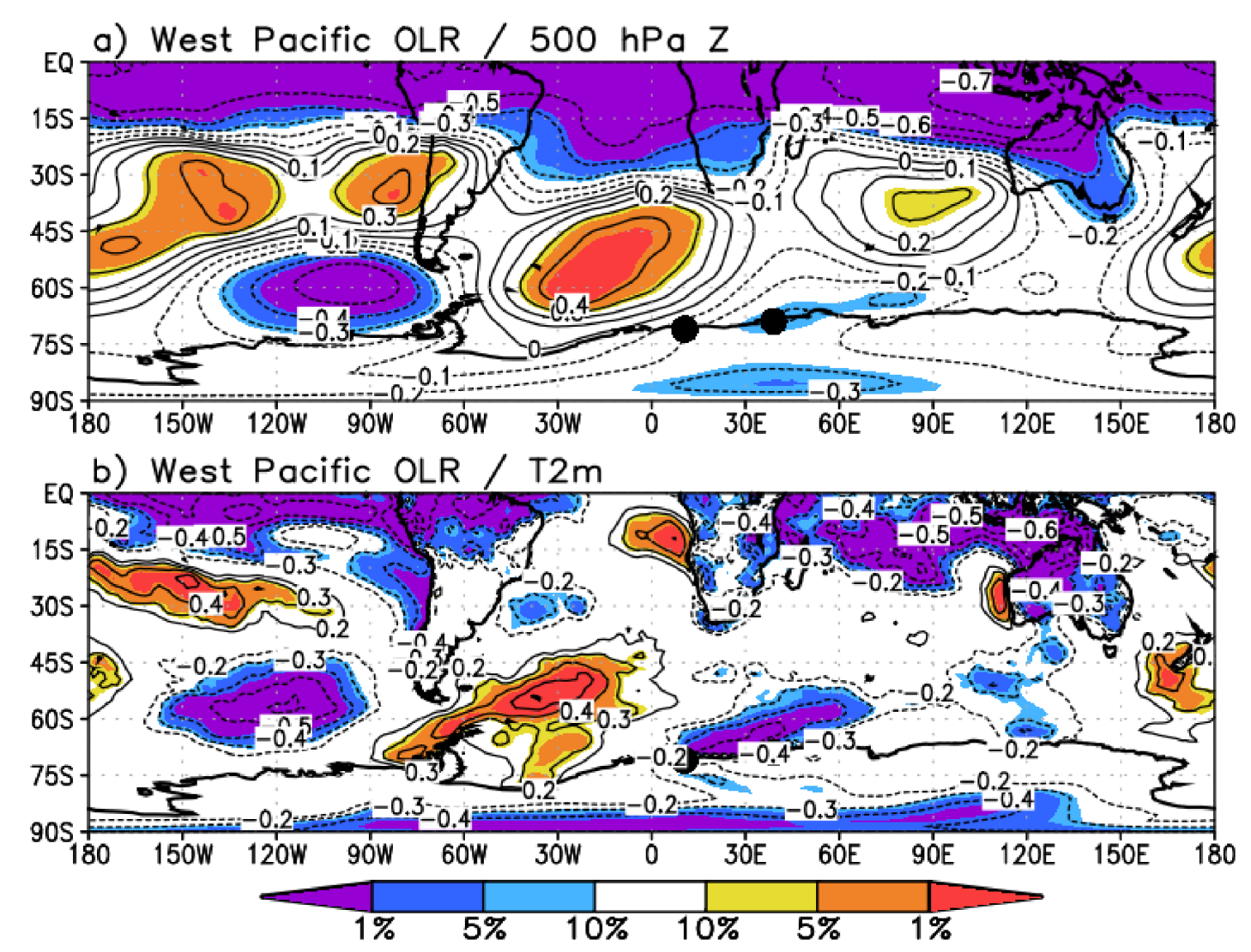

c) West Pacific OLR / Syowa-Novo Temperature

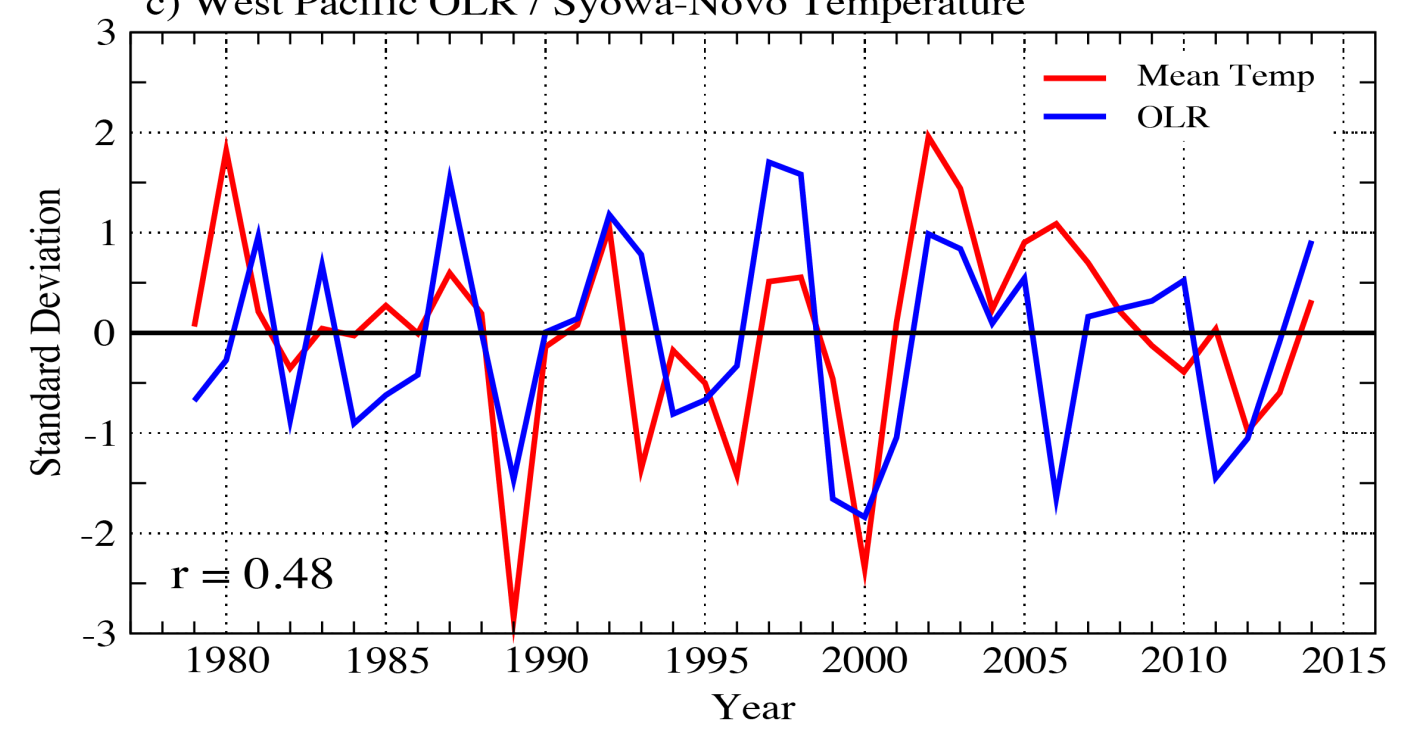

Figure 4.23: MAM detrended correlation, 1979-2014, of western tropical Pacific OLR (115$155^{\circ} \mathrm{E}, 20^{\circ} \mathrm{S}-7.5^{\circ} \mathrm{N}$ ) with (a) $500 \mathrm{hPa}$ geopotential height and (b) 2-m temperature. (c) The detrended, standardised time series of western tropical Pacific OLR and Novo-Syowa mean temperature. The correlation of the two time series is given in the bottom left of (c). Contour interval for (a-b) is 0.1 , and the zero and \pm 0.1 contours are omitted in (b). Shading in (a-b) indicates statistical significance of correlations as in Figs. 4.15-4.17. Only Novo and Syowa station sites are plotted. 
a) East Indian OLR / $500 \mathrm{hPa} \mathrm{Z}$
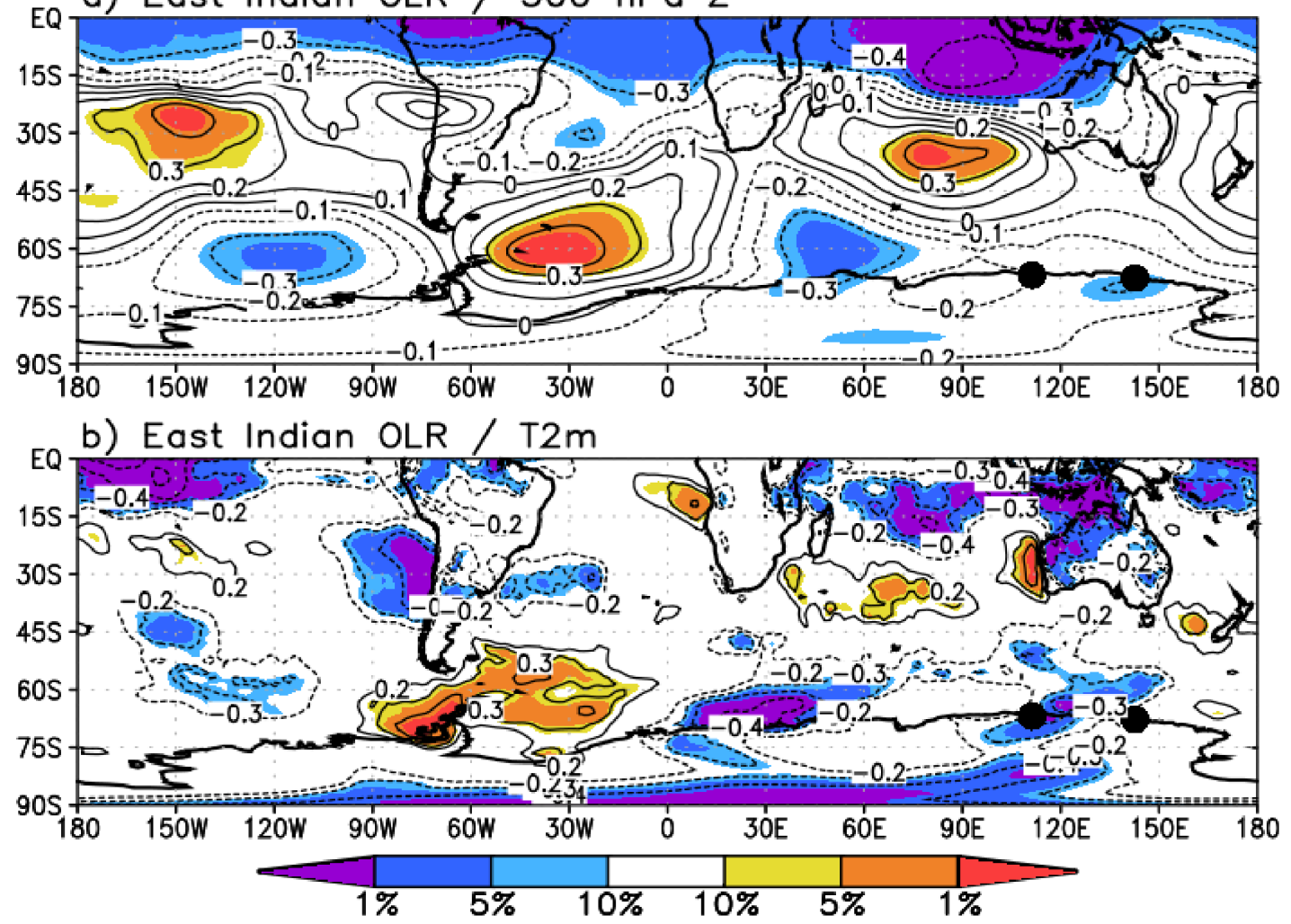

c) East Indian OLR / Casey-Dumont Temperature

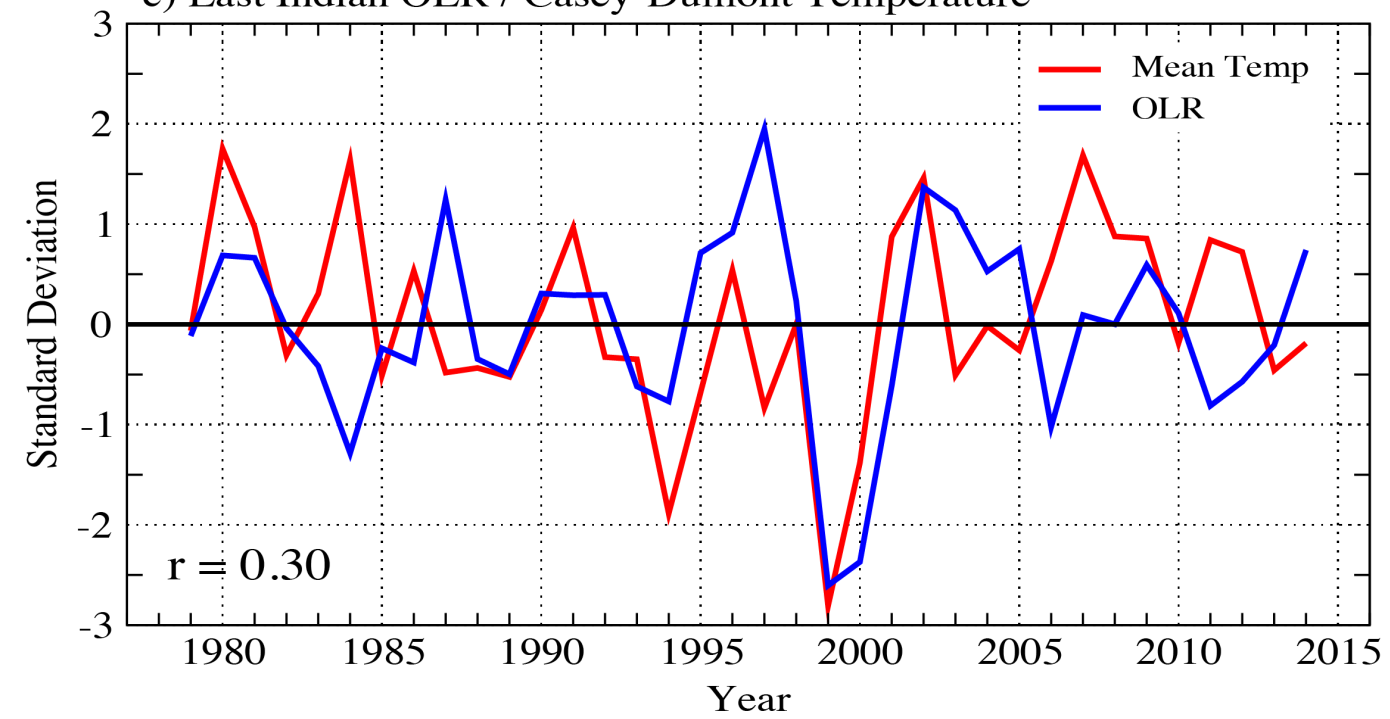

Figure 4.24: As in Fig. 4.23, except for OLR over the eastern Indian Ocean $\left(90-122.5^{\circ} \mathrm{E}, 15^{\circ} \mathrm{S}\right.$ $5^{\circ} \mathrm{N}$ ) and for Casey-Dumont mean temperature. Only Casey and Dumont station sites are plotted. 
Convective activity over the western tropical Pacific warm pool is associated with a PSAlike wavetrain across the South Pacific that terminates over the South Atlantic (Fig. 4.23a), and is significantly correlated with 2-m temperatures along the East Antarctic coast between 0 and $60^{\circ} \mathrm{E}$. The wavetrain is nearly identical to the wavetrain associated with the positive SOI composite. The correlations imply anomalous deep convection over the west Pacific warm pool is associated with positive height anomalies over the high-latitude South Atlantic, which would be associated with anomalous southwesterly winds (assuming geostrophic flow along correlation contour) and negative 2-m temperature anomalies across the Novo and Syowa region (Fig. 4.23b). The detrended correlation between west Pacific warm pool OLR and the Novo-Syowa mean temperature is 0.48 significant at $p<0.01$.

Eastern Indian Ocean OLR (Fig. 4.24) is also associated with a PSA-like wavetrain, which is not surprising given the two OLR boxes slightly overlap. However, the OLR variability over the eastern Indian Ocean, which is slightly westward of the warm pool, is more associated with a positive height anomaly southwest of Australia and negative heights over extreme eastern East Antarctica near Casey and Dumont. From the Dumont composite circulation anomalies (Fig. 4.22e) and the Casey-Dumont correlations with circulation (Fig. 4.17d), this meridionally oriented ridge-trough feature plays an important role at modulating regional temperature across the extreme eastern East Antarctic coast, and it appears to be associated with convective activity on the western edge of the west Pacific warm pool not related to ENSO variability. Correlations between eastern Indian Ocean OLR and 2-m temperatures are as high as 0.40 significant at $p<0.01$ along the coast near $120^{\circ} \mathrm{E}$ (Fig. $4.24 \mathrm{~b}$ ), while the detrended correlation with CaseyDumont mean temperatures is slightly weaker at 0.30 significant at $p<0.10$. 


\subsection{Increased Deep Convection in the SPCZ and Relationship with West Antarctic Warming during Austral Spring}

\subsubsection{Overview}

This section presents results from Clem and Renwick (2015) published in Journal of Climate in September of 2015. It investigates the forcing mechanism responsible for recent regional circulation changes that have caused significant warming of West Antarctica and the Antarctic Peninsula during spring. It is confirmed that the regional circulation changes / West Antarctic warming trends are indeed part of a tropically-forced wavetrain, but it is further shown that the wavetrain is forced specifically by increased deep convection on the poleward side of the SPCZ. Rather than two separate wavetrains, which has been suggested by previous studies, it is a single wavetrain forced in the early part of spring that dramatically changes in structure during mid-tolate spring. In early spring (i.e., September), Rossby waves propagate meridionally along the dateline into the South Pacific. During October, the Rossby wave propagation is steered farther to the east toward the Antarctic Peninsula as the westerlies strengthen over the South Pacific. During November, the convective trends in the SPCZ are weakened and a wavetrain is no longer seen. These results confirm that the tropics play a critical role in the Antarctic climate system during spring, but bring new insight into this role by identifying the SPCZ as a key genesis region for Rossby waves during spring. Therefore, future changes in West Antarctic climate during spring will be closely tied to changes in tropical Pacific climate, but more specifically, changes in the configuration and intensity of deep convection within the SPCZ. This significantly improves our understanding of how West Antarctic climate, which exhibits some of the strongest warming trends on the planet during spring, is linked to the tropics, and how future tropical climate changes may impact this unique region of the planet where the stability of the interior ice sheet is highly sensitive and vulnerable to surface climate changes. 


\subsubsection{SON Seasonal and Monthly Trends}

Figure 4.25 shows the 1979-2014 SON seasonal and monthly linear trends in SH mean sea level pressure (MSLP) and 10-metre (10-m) wind. The SON (Fig. 4.25a) negative pressure trend in the South Pacific is centered at approximately $165^{\circ} \mathrm{W}, 60^{\circ} \mathrm{S}(p<0.05)$ and increasing pressure in the southwest South Atlantic is centered at approximately $30^{\circ} \mathrm{W}, 50^{\circ} \mathrm{S}(p<0.01)$. Accompanying the South Pacific / South Atlantic MSLP trends are significant 10-m wind trends (vectors are only displayed if at least one component is significant at the $p<0.10$ level). Significant positive pressure trends are observed across the eastern tropical and sub-tropical Pacific (between $\sim 5^{\circ} \mathrm{S}-35^{\circ} \mathrm{S}$ ) from $160^{\circ} \mathrm{W}$ to South America. The increasing pressure in the eastern tropical Pacific is associated with significant increases in 10-m easterly winds across the tropical Pacific basin. The MSLP and 10-m wind trends across the tropical Pacific during SON point toward increased La Niña-like conditions after 1979, consistent with the significant positive trend in the SOI noted by Clem and Fogt (2015) during SON over 1979-2012.

From the monthly trends (Fig. 4.25b-d), the lowering of pressure in the South Pacific is strongest and only statistically significant during September (Fig. 4.25b; $p<0.01$ ), and the positive pressure trend is in the southwest South Atlantic is strongest and primarily statistically significant during October (Fig. 4.25c; $p<0.01$ ). Across the eastern tropical Pacific, the positive pressure and easterly 10-m wind trends are strongest and most widespread in September. Lower pressures over the South Pacific during September are much stronger and more widespread than the trends observed in the SON-average, and the cyclonic response in the 10-m wind field is more marked across the South Pacific and along coastal West Antarctica. The lower pressures have led to significant increases in southerly winds across the Southern Ocean south of New Zealand, and significant increases in northerly winds at $\sim 110^{\circ} \mathrm{W}$ that extend to coastal West Antarctica and turn easterly (Fig. 4.25b). During October, the significant negative pressure trend in the South Pacific shifts east toward the Antarctic Peninsula (significant at only $p<0.05$ ), and a positive pressure trend emerges over the South Atlantic significant at $p<0.01$. The anticyclonic response in the 10-m wind field is also stronger and more widespread than that observed in the SON-average, with a significant northerly wind trend across the northern Antarctic Peninsula 
a) SON MSLP ( $\left.\mathrm{hPa} \mathrm{dec}^{-1}\right)$ and $10 \mathrm{~m}$ Wind Trend
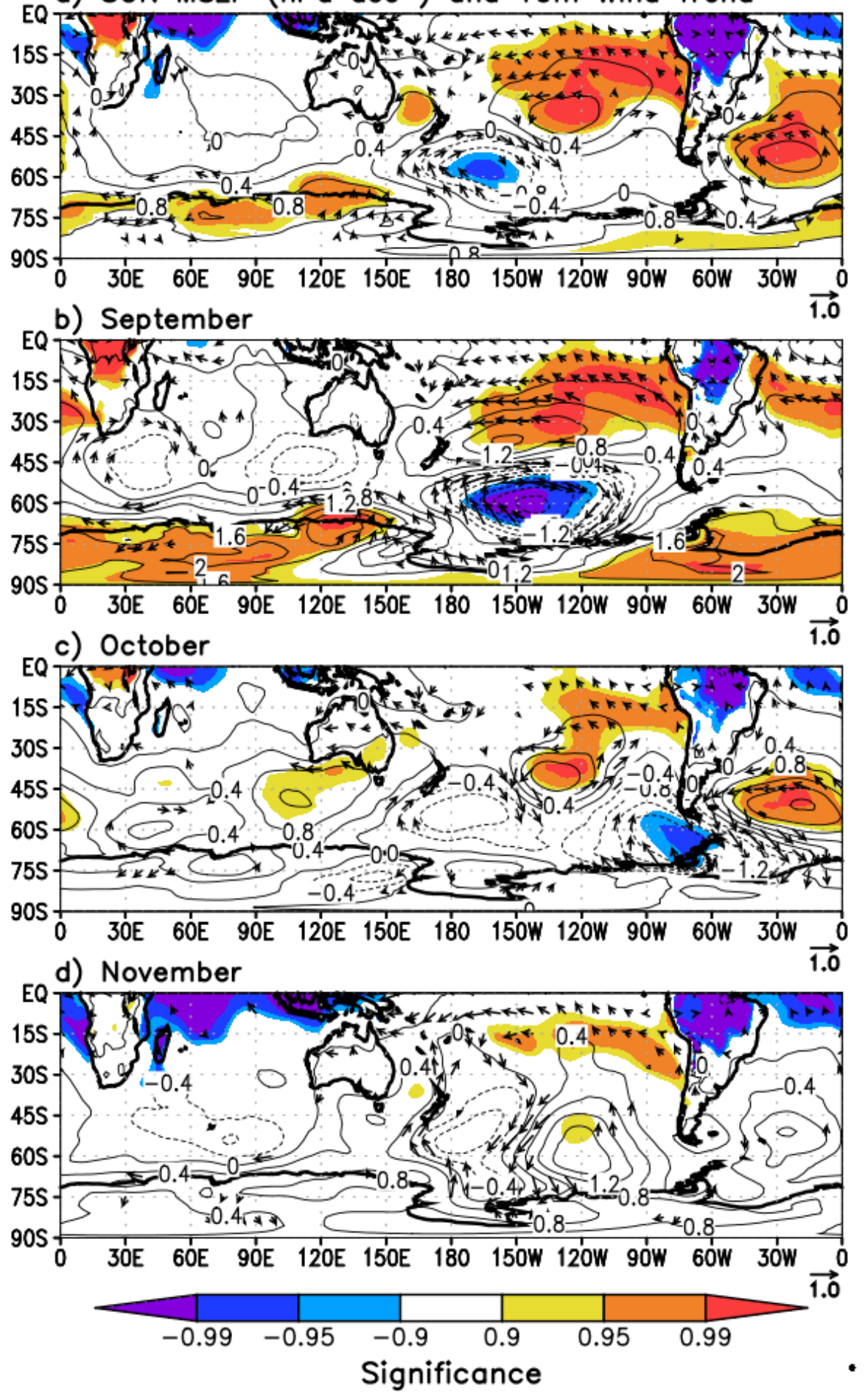

Figure 4.25: 1979-2014 MSLP and 10-m wind trends for a) SON-average, b) September, c) October, and d) November. Shading (from lightest to darkest) indicates trends that are statistically different from zero at $p<0.10, p<0.05$, and $p<0.01$, respectively. Wind trends ( $\mathrm{ms}^{-1}$ decade $^{-1}$; indicated by reference vector) are only displayed if at least one component is significant at $p<0.10$. Contour interval is $0.4 \mathrm{hPa}$ decade $^{-1}$. 


\section{a) SON $2 \mathrm{~m}$ Temp $\left({ }^{\circ} \mathrm{C} \mathrm{dec}^{-1}\right)$ and $10 \mathrm{~m}$ Wind Trend}

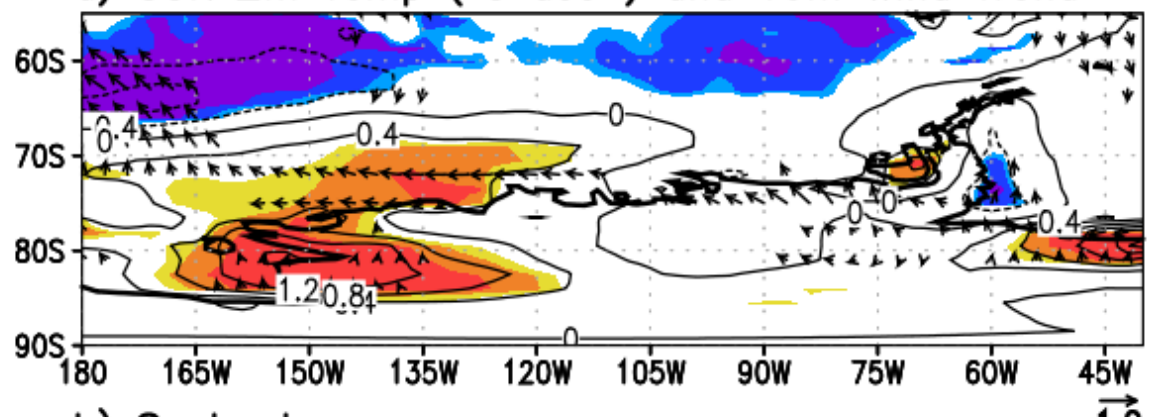

b) September
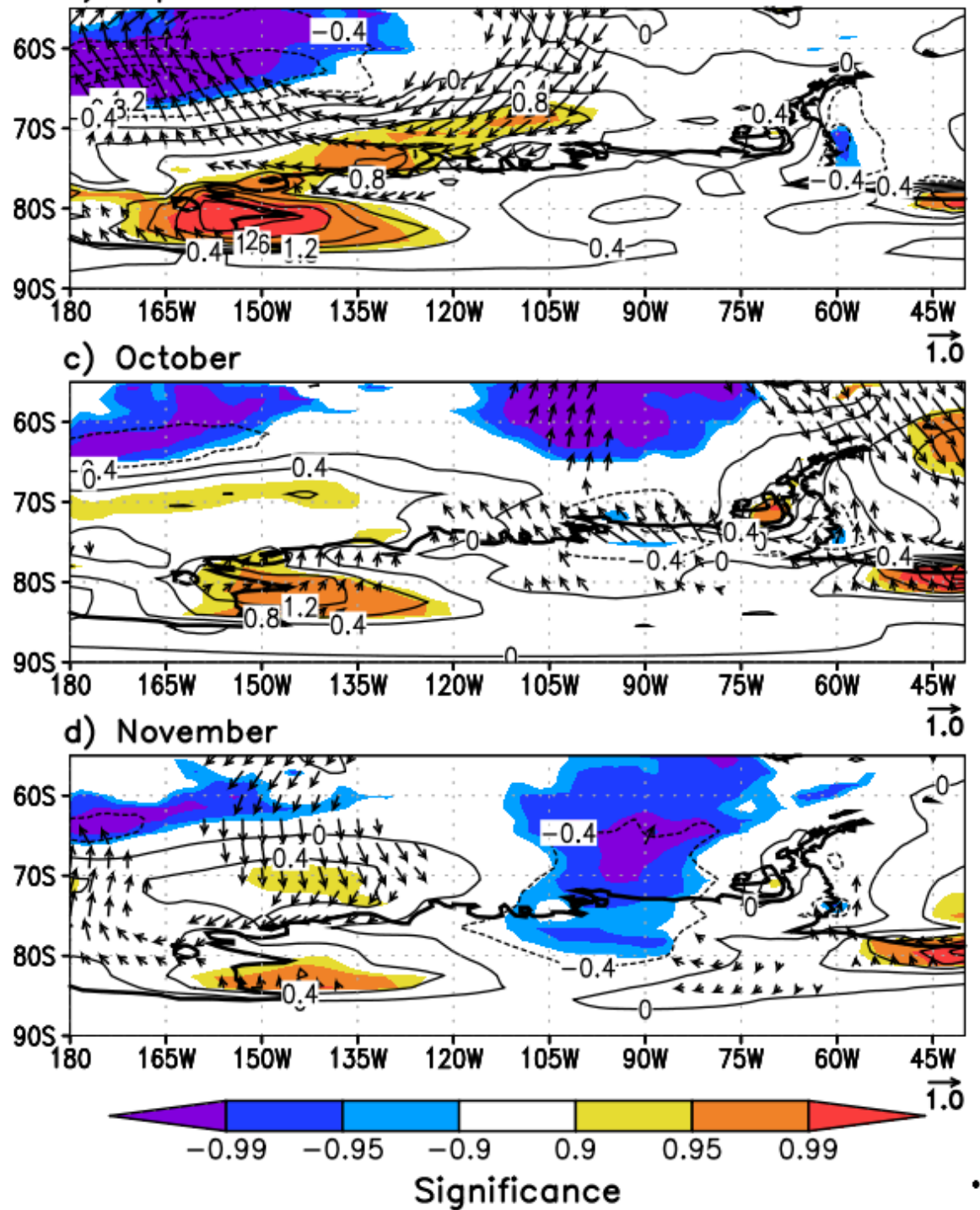

Figure 4.26: As in Fig. 4.25, except for 2-m temperature across the West Antarctic and Antarctic Peninsula region. Contour interval is $0.4^{\circ} \mathrm{C}$ decade $^{-1}$. 
and Weddell Sea. During October, the MSLP trend more strongly resembles a tropically-forced wavetrain reminiscent of the PSA pattern (Mo and Paegle 2001). By November (Fig. 4.26d), the significant pressure trends across the South Pacific and South Atlantic are weakened and primarily no longer significant at $p<0.10$.

Seasonal and monthly 2-metre (2-m) temperature and 10-m wind trends across the West Antarctic and Antarctic Peninsula region are shown in Fig. 4.26. Significant SON warming is seen over western West Antarctica and the western Antarctic Peninsula (Fig. 4.26a), as discussed by Clem and Fogt (2015). The warming trend over western West Antarctica is strongest in September (Fig. 4.26b; more than $2.0^{\circ} \mathrm{C}$ decade $^{-1}$ ), consistent with the offshore pressure decreases and poleward flow toward the continent during September. The northerly and easterly wind trend to West Antarctica does not align exactly with the inland warming across western West Antarctica and the Ross Ice Shelf, however it will be shown later that increases in warm advection to portions of interior West Antarctica are occurring. Over the South Pacific between $\sim 55-70^{\circ} \mathrm{S}$, significant cooling is observed during September, consistent with the increased southerly winds on the western side of the negative pressure trend.

The SON warming along the western Antarctic Peninsula is not observed in the reanalysis during September, but is instead strongest and statistically significant primarily during October. Nearby observations along the western Peninsula (Faraday and Rothera) verify the reanalysis temperature trends near the Peninsula (Table 4.8). At Faraday, significant warming increases from $p<0.10$ in September to $p<0.05$ in October, and warming at Rothera is only statistically significant at $p<0.10$ during October. Consistent with the October warming on the western Peninsula is increased northerly surface winds to the Peninsula arising from the eastward shift in the cyclonic circulation in the South Pacific and the development of positive pressures in the South Atlantic (Fig. 4.25c). As with the West Antarctic warming during September, the significant northerly wind trend to the Peninsula does not align exactly with the localised areas of strongest warming. However, the absence of significant warming or related wind trends here during September, and the development of the warming trend during October when the northerly winds occur suggests that the circulation and temperature trends are closely related across both West Antarctica and the Antarctic Peninsula. 
Table 4.8: September and October temperature trends and 95\% confidence intervals, 1979-2014, for Byrd, Faraday, and Rothera stations (first column, units of ${ }^{\circ} \mathrm{C}$ decade $^{-1}$ ), and portion (second column, in units of ${ }^{\circ} \mathrm{C}$ decade ${ }^{-1}$ ) and percentage (third column) of these temperature trends linearly congruent with September OLR in the $25-32.5^{\circ} \mathrm{S}, 180-165^{\circ} \mathrm{W}$ region. Temperature trends (first column) significant at $p<0.10$ are boldface, and trends significant at $p<0.05$ are boldface and underlined.

\begin{tabular}{|lccc|}
\hline & $\begin{array}{c}\text { Temperature } \\
\text { trend }\end{array}$ & $\begin{array}{c}\text { Congruent with } \\
\text { Sep OLR SPCZ }\end{array}$ & $\begin{array}{c}\text { Percentage } \\
\text { Congruent }\end{array}$ \\
\hline Byrd & $0.97 \pm 1.22$ & 0.60 & $61.9 \%$ \\
Faraday & $\mathbf{0 . 7 9} \pm \mathbf{0 . 8 6}$ & 0.64 & $80.7 \%$ \\
Rothera & $0.66 \pm 0.94$ & 0.65 & $99.5 \%$ \\
& \multicolumn{3}{c}{ October } \\
Byrd & $0.42 \pm 0.81$ & -0.03 & $-6.0 \%$ \\
Faraday & $\mathbf{0 . 7 3} \pm \mathbf{0 . 5 8}$ & 0.40 & $54.1 \%$ \\
Rothera & $\mathbf{0 . 5 9} \pm \mathbf{0 . 6 4}$ & 0.40 & $68.1 \%$ \\
\hline
\end{tabular}

In November (Fig. 4.26d), statistically significant trends in 10-m wind and 2-m temperature continue across the South Pacific, but they are less obviously related to changes in regional atmospheric circulation. The November circulation patterns in Fig. 4.25d show primarily insignificant positive pressure trends in the South Pacific at $\sim 120^{\circ} \mathrm{W}$, and insignificant negative pressure trends at $\sim 170^{\circ} \mathrm{W}$. Their collective influence on the pressure gradient between $\sim 160-120^{\circ} \mathrm{W}$ results in statistically significant increases in northerly flow to western West Antarctica, which appears strongly related to the November warming there (Fig. 4.26d). The November circulation changes are important to understanding the overall SON-averaged warming across western West Antarctica, but they are different than the regional circulation pattern that propagates from west to east across the South Pacific to the South Atlantic during September and October.

To better understand the temperature trends in Fig. 4.26 and the relative role of the regional circulation changes, seasonal and monthly sea ice concentration and thermal advection trends are presented in Figs. 4.27 and 4.28, respectively. Figure 4.27a shows significant SONaverage decreases in sea ice concentration along coastal West Antarctica from approximately $120^{\circ} \mathrm{W}$ toward the dateline. Further offshore, between $60-70^{\circ} \mathrm{S}$ and west of $120^{\circ} \mathrm{W}$, significant increases in sea ice concentration are observed for the SON average. As with the temperature trends, the monthly sea ice concentration trends demonstrate that the SON average is closely tied 
to the changing monthly circulation. In September, the region of significant sea ice decreases along coastal West Antarctica aligns with the increase in northerly and easterly $10-\mathrm{m}$ wind to the West Antarctic coast, and the offshore increases align with the increased southerly flow.

During October (Fig. 4.27c), significant sea ice loss occurs along much of the west coast of the Antarctic Peninsula. The sea ice losses / gains offshore of western West Antarctica persist into October, which may represent memory in the sea ice field from the circulation-driven trends in September (i.e. Ding and Steig 2013; Holland 2014). The continued negative sea ice concentration anomalies along coastal West Antarctica during October may explain why warming continues across western West Antarctica during October (Fig. 4.26c) despite the circulation trends shifting east. During November, localised sea ice decreases continue along the northwestern Peninsula near Faraday and Rothera stations, which again likely reflects the memory in the sea ice field from the trends in October. The significant sea ice increases observed along the outer sea ice edge in October (between $\sim 160-135^{\circ} \mathrm{W}$; more than $15 \%$ decade $^{-1}$ ) weakens slightly during November as do the negative sea ice concentration trends near coastal West Antarctica. Both trends appear to be affected by the increased northerly flow to the region during November, which would push the outer sea ice edge toward the continent and increase sea ice compaction (increase sea ice concentration) along the coast.

Trends in $500 \mathrm{hPa}$ meridional temperature advection and $500 \mathrm{hPa}$ wind are presented in Fig. 4.28. Temperature advection is calculated as the negative of the product of daily ERAInterim $500 \mathrm{hPa}$ transient meridional wind anomalies and the meridional gradient of daily ERAInterim $500 \mathrm{hPa}$ temperatures $\left(-v^{\prime} \partial \mathrm{T} / \partial \mathrm{y}\right)$. Since much of interior West Antarctica's elevation rises through the lower tropospheric pressure levels, temperature advection patterns at the 500 $\mathrm{hPa}$ pressure level are shown to best depict realistic temperature advection at the surface over the continent. Offshore away from the continent, temperature advection patterns at $850 \mathrm{hPa}$ (not shown) yield similar results as those at $500 \mathrm{hPa}$.

The SON-average advection trends (Fig. 4.28a) show that the SON 2-m warming trends across western West Antarctica and the western Antarctic Peninsula (Fig. 4.26a) are closely tied to increased warm advection. In September (Fig. 4.28b), when the lowering of pressure occurs in the South Pacific, increased poleward flow brings increases in warm advection to all of coastal West Antarctica from the western Peninsula to the Ross Ice Shelf. Statistically significant warm 

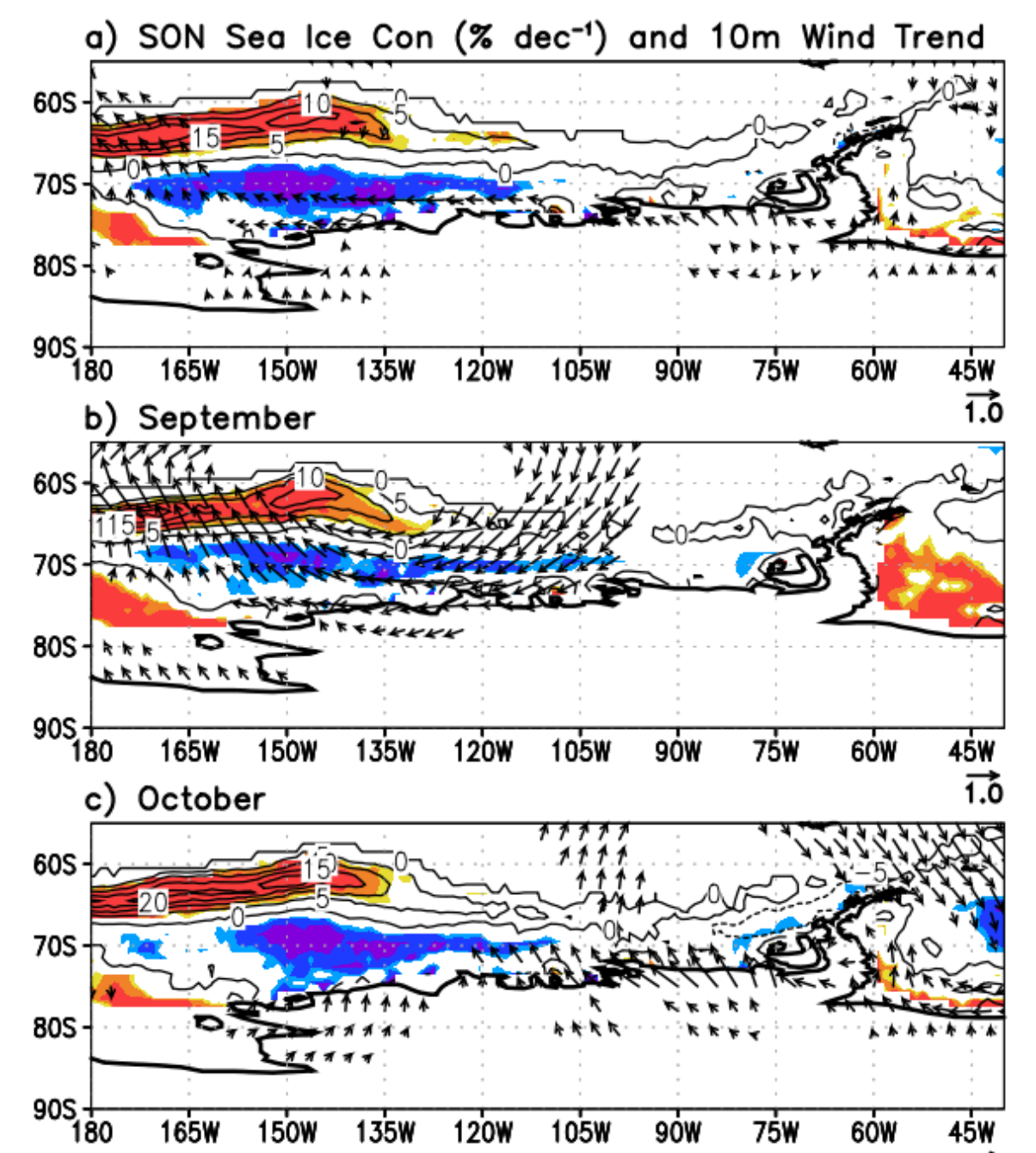

d) November $\overrightarrow{\mathbf{1 . 0}}$

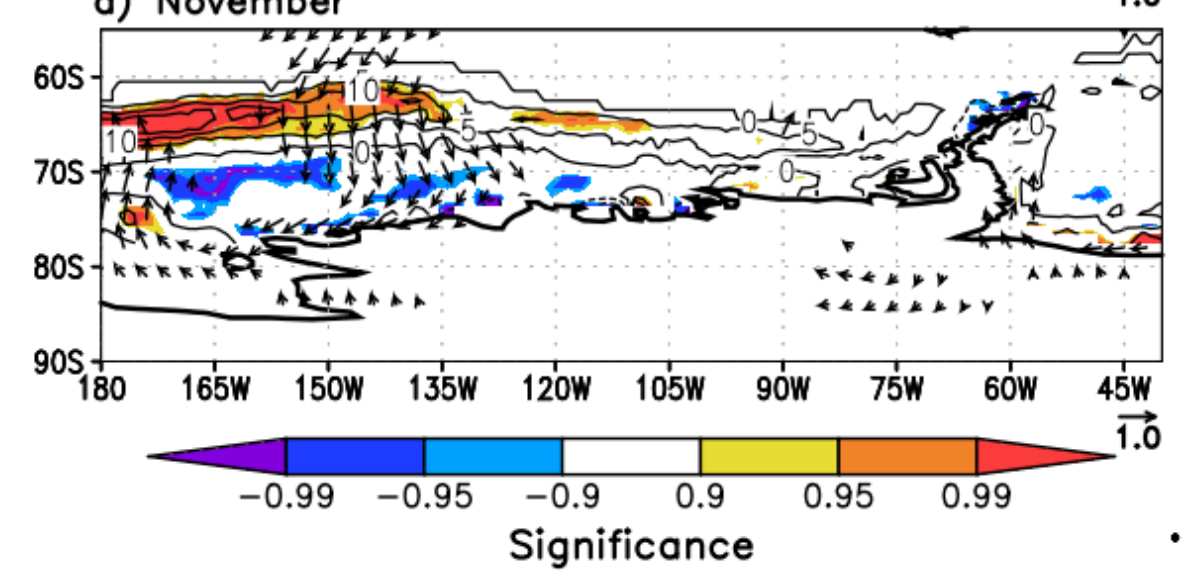

Figure 4.27: As in Figs. 4.25-4.26, except for HadISST sea ice concentrations across the West Antarctic and Antarctic Peninsula region. Contour interval is 5\% decade ${ }^{-1}$. 
a) SON $500 \mathrm{hPa}$ Merid Temp Advection and Wind Trend

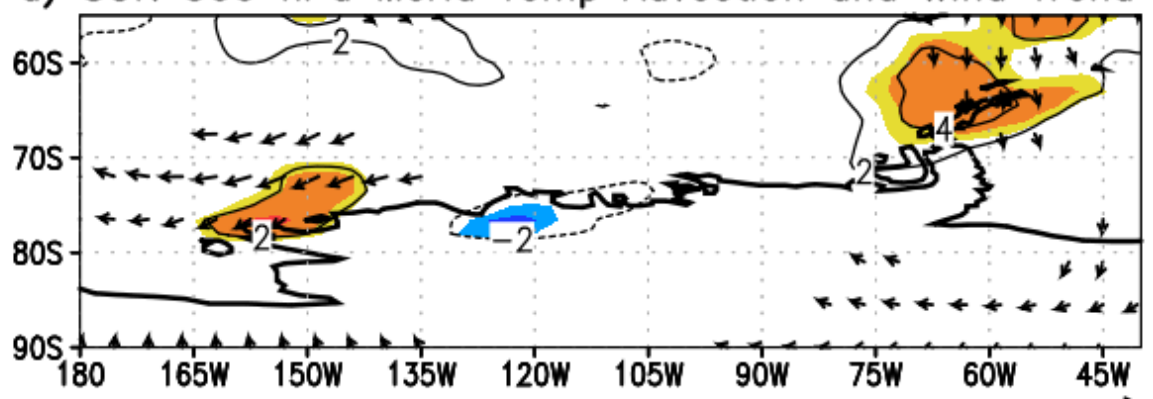

b) September $\overrightarrow{\mathbf{1 . 5}}$
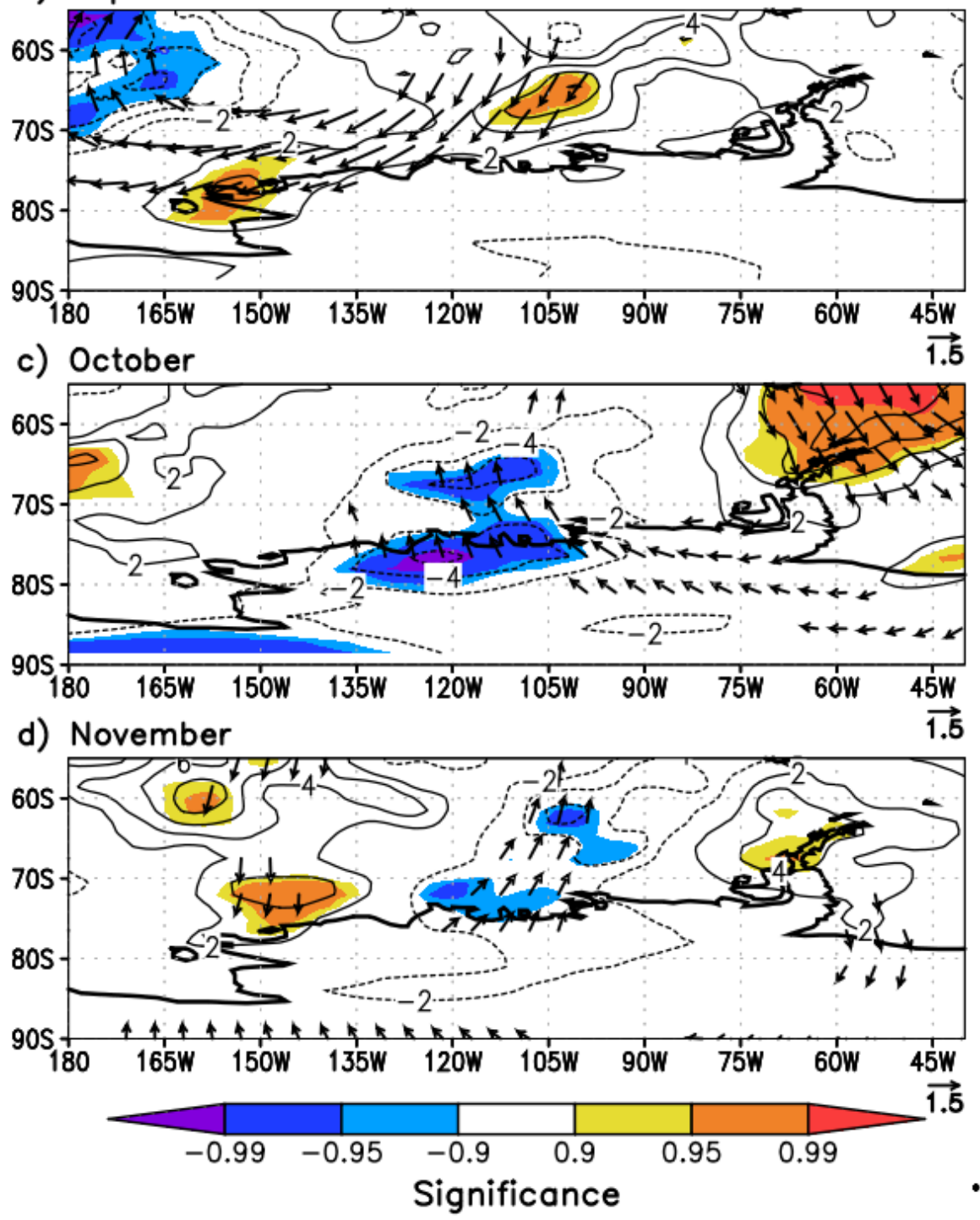

Figure 4.28: As in Figs. 4.25-4.27, except for $500 \mathrm{hPa}$ meridional temperature advection ( $-v^{\prime}$ $\partial \mathrm{T} / \partial \mathrm{y}$ ) and $500 \mathrm{hPa}$ wind (vectors). Contour interval is $2.0^{\circ} \mathrm{C} \mathrm{s}^{-1}$ decade $^{-1}$ (scaled $10^{6}$ ) and zero contours are omitted. 
advection (yellow and orange shading) is located just offshore of West Antarctica centered at $\sim 105^{\circ} \mathrm{W}$, and across the Ross Ice Shelf. Both regions of significant warm advection during September align with significant $500 \mathrm{hPa}$ wind trends, which closely resemble the $10-\mathrm{m}$ wind trends. The increased warm advection across the Ross Ice Shelf also aligns with the significant 2$\mathrm{m}$ warming trends observed there in September (Fig. 4.26b). Significant cold advection is found west of $150^{\circ} \mathrm{W}$ between $55-70^{\circ} \mathrm{S}$, also aligning with the significant $2-\mathrm{m}$ cooling and increases in sea ice concentration (Figs. 4.26b and 4.27b, respectively).

During October, the significant warm advection shifts east to the Peninsula, consistent with the 2-m warming and decreased sea ice concentration along the western Peninsula during October. Significant cold advection is found across portions of inland and coastal central West Antarctica during October (between $135-95^{\circ} \mathrm{W}$ ) as cold, southerly flow develops on the western side of the lowering pressure in the South Pacific. During November, significant warm advection develops again near the Ross Ice Shelf, likely enhancing the warming observed there (Fig. 4.26d), cold advection continues across portions of coastal central West Antarctica, and warm advection continues along the western Antarctic Peninsula. Aside from the warm advection along the western Peninsula during November (which could be related more to the reduced sea ice / open water from the October circulation trends than from November circulation), all regions of significant temperature advection closely follow the circulation trends as they develop west to east across the South Pacific and the South Atlantic during September and October, and the wave three-like pattern that develops in November. The cold advection across central West Antarctica during October and November explains the absence of significant warming across all West Antarctica for the SON-average, and helps explain the regionally distinct nature of the SON warming across West Antarctica and the Peninsula.

The monthly trends in Fig. 4.25b-c suggest that the negative pressure trend in the South Pacific and the positive pressure trend in the South Atlantic may be part of an eastward propagating circulation pattern stemming from the tropical Pacific. The propagation of the September and October circulation trends from the South Pacific to the South Atlantic appears to take approximately two months, starting first in September with a meridionally-oriented pressure dipole across the South Pacific reminiscent of a Rossby wavetrain, and terminating in the South Atlantic in October with a clear tropical component to the circulation. When the pattern first develops in September, it lowers pressures in the high-latitude South Pacific, which forces 
increased northeasterly flow and warm advection / sea ice decreases (Figs. 4.28b and 4.27b, respectively) along the West Antarctic coast. As the pattern propagates eastward, the pressures decrease west of the Peninsula and increase over the South Atlantic, collectively strengthen the northerly flow and warm advection to the Peninsula and reduce sea ice concentrations along the western Peninsula (Figs. 4.28c and 4.27c, respectively). Significant cooling across portions of the Southern Ocean in September and October also follows the increase in cold, southerly flow on the western side of the negative pressure trends.

\subsubsection{September and October Circulation Trends and Linear Relationships with the SPCZ}

Seasonal and monthly trends in tropical Pacific OLR and 10-m wind are presented in Fig. 4.29.

The average location of the SPCZ is drawn as a solid black line, extending from the west Pacific warm pool to $\sim 30^{\circ} \mathrm{S}, 120^{\circ} \mathrm{W}$ (i.e., Trenberth 1991; Vincent 1994). Figure 4.29a shows several statistically significant OLR trends across the tropical Pacific, primarily a reduction in OLR (increase in tropical deep convection) in the western tropical Pacific and along the poleward side of the SPCZ, consistent with increased La Niña-like conditions (Vincent 1994; Folland et al. 2002). The negative OLR trend in the western tropical Pacific and along the SPCZ aligns with significant increases in 10-m wind convergence for all panels in Fig. 4.29, which would encourage upward vertical motion and increases in tropical deep convection along the SPCZ.

The most significant reduction in OLR in the SPCZ region occurs in September (Fig. $4.29 \mathrm{~b}$; centered at $\sim 27.5^{\circ} \mathrm{S}$ between $180-165^{\circ} \mathrm{W}$; denoted with a red box), suggesting a significant increase and a poleward shift of deep convection along the southeastern SPCZ. In October, the negative OLR trend along the SPCZ is located farther west and equatorward nearer the average position of the SPCZ. November sees significant negative OLR trends farther east along the SPCZ, centered at approximately $20^{\circ} \mathrm{S}, 170^{\circ} \mathrm{W}$, also farther equatorward than during September. Since the significant extra-tropical circulation trends occur in September and October, it is hypothesised that they may be linked to the negative OLR trend in September. Not only is the reduction in OLR during September the strongest and of highest statistical significance, but also it is the most anomalous in terms of location as it is farthest poleward in the SPCZ region.

Linear congruency between September OLR averaged over the SPCZ portion trending negative during September $\left(25-32.5^{\circ} \mathrm{S}, 180-165^{\circ} \mathrm{W}\right.$; denoted as a red box in Fig. $\left.4.29 \mathrm{~b}\right)$ and the 
a) SON OLR $\left(\mathrm{Wm}^{-2} \mathrm{dec}^{-1}\right)$ and $10 \mathrm{~m}$ Wind Trend
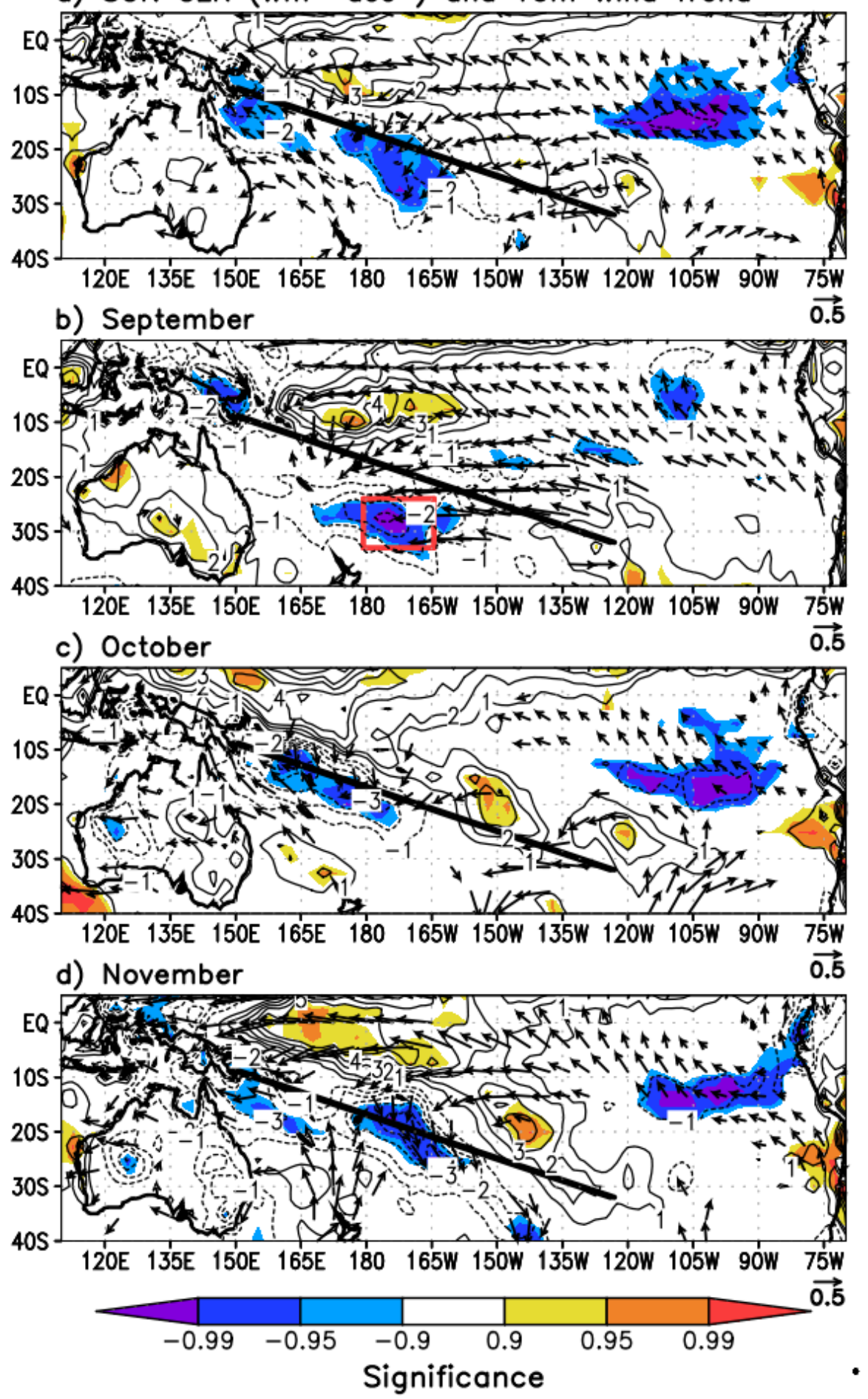

Figure 4.29: As in Figs. 4.25-4.28, except for OLR over the tropical Pacific region. The annualaverage SPCZ region is drawn as a black line in all panels, and the September OLR region used for area-averaging is drawn as a red box in panel b). Contour interval is $1.0 \mathrm{~W} \mathrm{~m}^{-2} \mathrm{decade}^{-1}$, and zero contours are omitted. 
September and October SH MSLP and 2-m temperature trends are presented in Figs. 4.30 and 4.31, respectively. Linear congruency is calculated by regressing the area-averaged September OLR onto the September and October reanalysis data at every grid point. The linear regression coefficients are multiplied by the observed trend in September OLR to yield an expected trend in MSLP and 2-m temperature (contours in Figs. 4.30 and 4.31). The area-averaged September OLR trend over 1979-2014 is $-2.80 \mathrm{~W} \mathrm{~m}^{-2}$ decade $^{-1}$ significant at $p<0.01$. Shading in Figs. 4.30 and 4.31 represents the percentage of the expected trend that is linearly congruent with the observed trends in Fig. 4.25b-c and Fig. 4.26b-c, respectively. Percentage shading is plotted only at grid points where the observed trends are significant at $p<0.10$.

Figure 4.30a shows the reduced September OLR along the SPCZ is associated with a wavetrain across the South Pacific (contours) reminiscent of a PSA pattern. The OLR-related increase in September MSLP across the sub-tropical Pacific is congruent with more than 40-60\% of the statistically significant positive MSLP trends between $15^{\circ} \mathrm{S}-35^{\circ} \mathrm{S}$ from the dateline to coastal South America (shading in Fig. 4.30a; reference Fig. 4.25b). The OLR-related negative MSLP trend over the South Pacific is congruent with $40-60 \%$ or more of the observed negative MSLP trend, and the positive MSLP trend over the southern Weddell Sea is more than $40 \%$ linearly congruent with observed increase in pressure there.

In October (Fig. 4.30b), the lowering of MSLP in the South Pacific (contours) associated with the September OLR shifts east toward the Peninsula and is centered at $\sim 95^{\circ} \mathrm{W}$, consistent with the trends in Fig. 4.25c. OLR-related increases in MSLP over the South Atlantic shift northeast, also consistent with observed October trends. The lowering of pressure west of the Peninsula is congruent with more than $40-60 \%$ of the negative pressure trend and the increases in pressure in the South Atlantic are congruent with $20-60 \%$ of the positive pressure trends there (shading in Fig. 4.30b; reference Fig. 4.25c). The linear congruency analysis supports the hypothesis of a tropically-forced, eastward propagating wavetrain that first influences the South Pacific in September, and the South Atlantic in October. Following these connections, it is plausible that linear relationships exist between the September SPCZ and the September and October 2-m temperature trends. As in Fig. 4.30, linear congruency maps are generated for September and October 2-m temperature trends across West Antarctica and the Antarctic Peninsula (Fig. 4.31). During September, a warming trend of more than $0.6^{\circ} \mathrm{C} \mathrm{decade} e^{-1}$ is expected across western West Antarctica and the Ross Ice Shelf (contours), warming trends of 

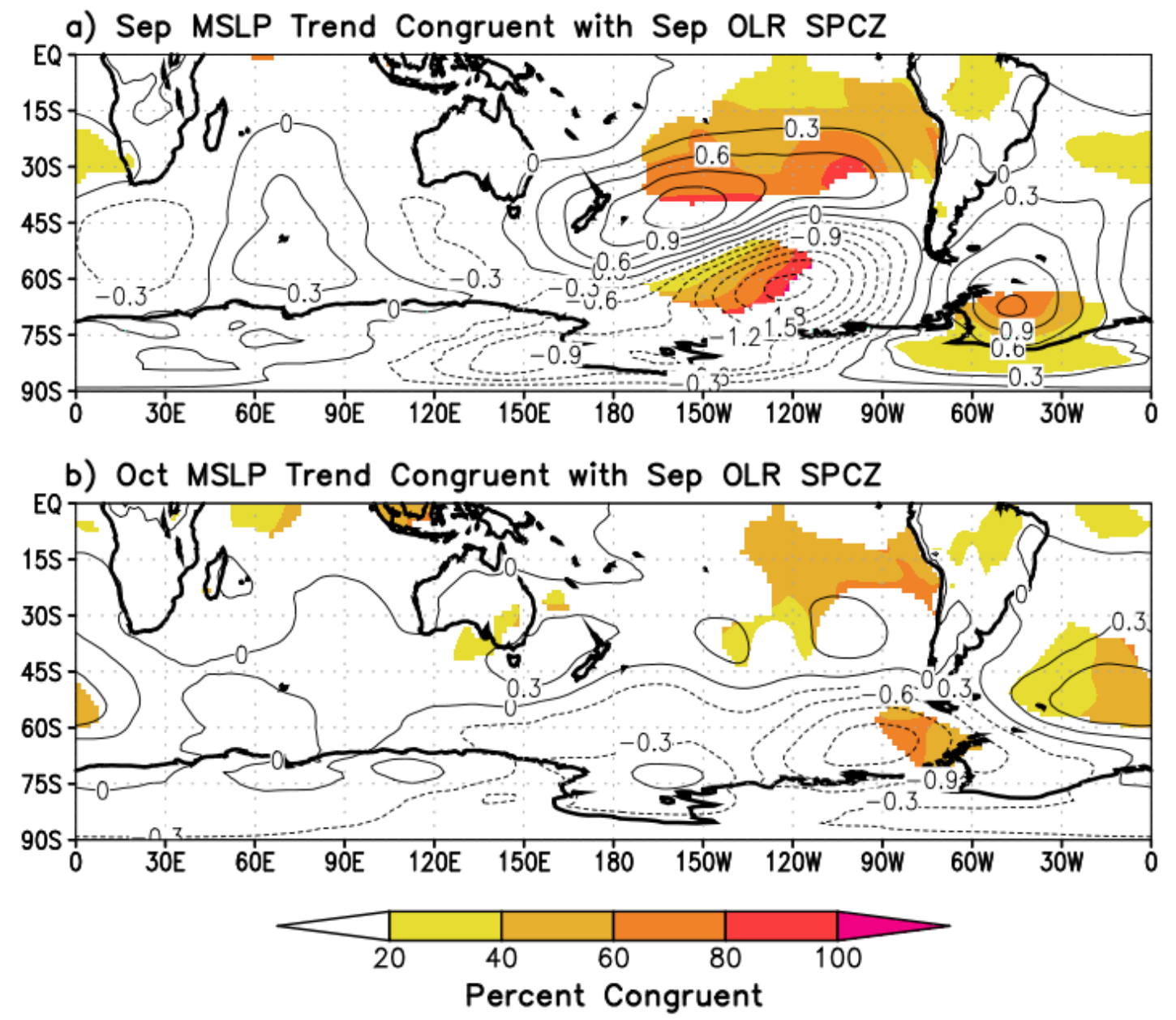

Figure 4.30: Spatial linear congruency of the a) September and b) October MSLP trends with September OLR area-averaged over the $25-32.5^{\circ} \mathrm{S}, 180-165^{\circ} \mathrm{W}$ region (red box in Fig. $4.29 \mathrm{~b}$ ). Contours indicate the MSLP trend that is linearly congruent with the September OLR trend $\left(\mathrm{hPa}\right.$ decade $\left.^{-1}\right)$. Shading indicates the percentage of the statistically significant MSLP trends that is linearly congruent with the September OLR. Shading is only shown where trends are statistically significant at $p<0.10$. Contour interval is $0.3 \mathrm{hPa}$ decade $^{-1}$.

more than $0.4^{\circ} \mathrm{C}$ decade $^{-1}$ along much of coastal West Antarctica and the western Antarctic Peninsula, and cooling trends further offshore across the Southern Ocean between the dateline and $120^{\circ} \mathrm{W}$. The estimated warming over western West Antarctica is linearly congruent with more than $20-40 \%$ of the statistically significant September warming there, and more than 20$40 \%$ of the statistically significant September cooling found across the South Pacific (shading in Fig. 4.31a; compare with Fig. 4.26b).

Turning to October (Fig. 4.31b), OLR-related warming trends of $\sim 0.4^{\circ} \mathrm{C}$ decade $^{-1}$ are estimated along the western Antarctic Peninsula, which is linearly congruent with $40-60 \%$ of the localised statistically significant warming (shading; compare with Fig. 4.26c). A large portion of 
a) Sep $2 m$ Temp Trend Congruent with Sep OLR SPCZ

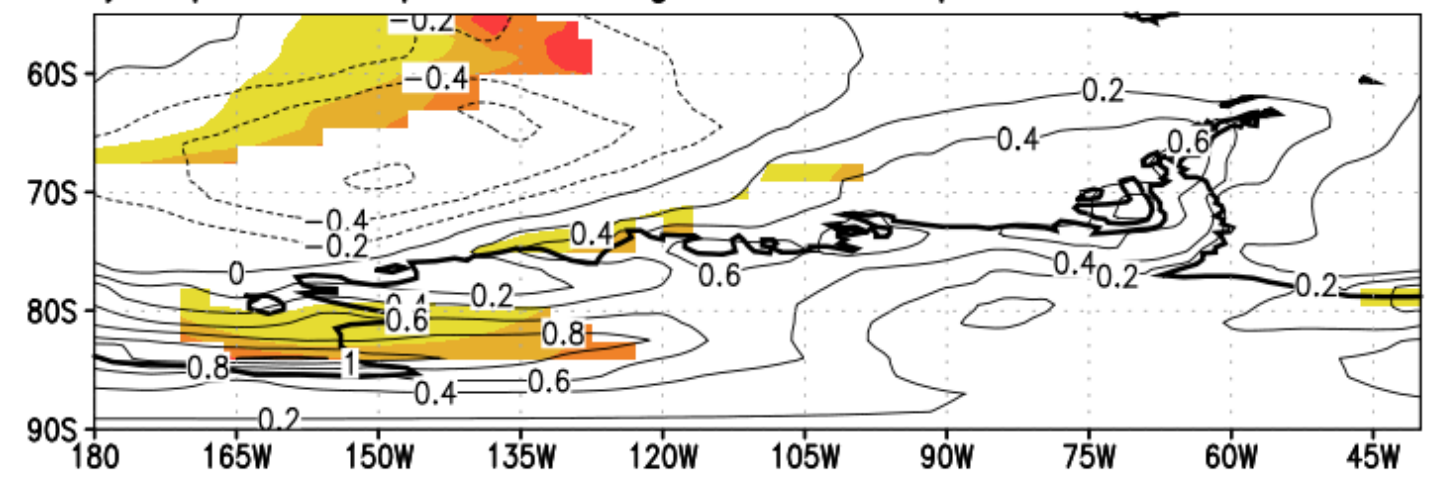

b) Oct $2 \mathrm{~m}$ Temp Trend Congruent with Sep OLR SPCZ

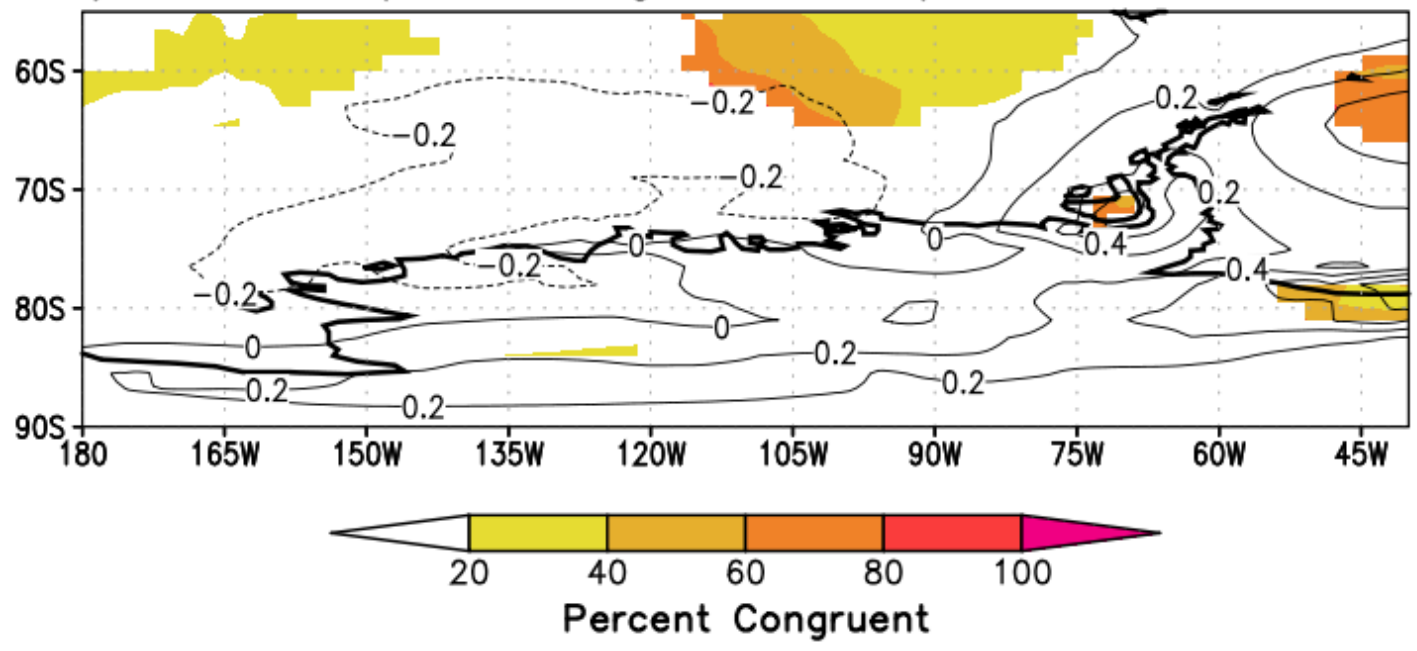

Figure 4.31: As in Fig. 4.30, but for 2-m temperature trends $\left({ }^{\circ} \mathrm{C}\right.$ decade $\left.^{-1}\right)$ across the West Antarctic and Antarctic Peninsula region. Contour interval is $0.2^{\circ} \mathrm{C}$ decade ${ }^{-1}$.

the significant cooling over the South Pacific between $120^{\circ} \mathrm{W}-75^{\circ} \mathrm{W}$ is $20-40 \%$ or more linearly congruent, as is the warming east of the Peninsula over the northern Weddell Sea.

The linear congruency results for ERA-Interim temperature trends in Fig. 4.31 are compared with nearby station observations in Table 4.8. The Byrd temperature trend is not significant at $p<0.10$ in September or October, consistent with ERA-Interim 2-m temperature trends showing the statistically significant warming west of Byrd. However, Byrd exhibits a warming trend during September that is more than twice as strong as in October, consistent with the $500 \mathrm{hPa}$ warm and cold advection across central West Antarctica from September to October, respectively (Fig. 4.28). The observed warming at Byrd during September is more than $60 \%$ linearly congruent with the reduced September OLR in the SPCZ, lending confidence to the results in Fig. 4.31a. For the western Peninsula stations (Faraday and Rothera), more than 80\% 
of the observed warming in September is linearly congruent with the reduced OLR in the SPCZ, and $\sim 50-70 \%$ of the observed warming in October is linearly congruent with the SPCZ. As noted previously, the statistical significance of the warming at Faraday and Rothera increases from September to October, consistent with ERA-Interim 2-m temperature trends / significance.

\subsubsection{Atmospheric Composites and Correlations for September SPCZ OLR}

Relationships between SPCZ OLR in September and the high-latitude circulation and temperature changes are investigated next through composites. Composite anomalies of MSLP and 10-m wind during September and October for the six lowest September OLR years in the $25-32.5^{\circ} \mathrm{S}, 180-165^{\circ} \mathrm{W}$ region during $1979-2014$ are presented in Fig. 4.32. Anomalies are calculated by subtracting the September and October 1981-2010 climatological mean from the six-year average September and October conditions (respectively). The composite anomalies associated with the five lowest OLR years (not shown) are similar to those discussed here using six years, suggesting the results presented here are robust.

In September (Fig. 4.32a), positive MSLP anomalies of up to $4 \mathrm{hPa}(p<0.01)$ are seen over the eastern sub-tropical South Pacific along with increased 10-m easterly flow across the tropical Pacific to the southeastern SPCZ (where the increased convection occurs). A broad negative MSLP anomaly of up to $7 \mathrm{hPa}(p<0.05)$ is observed over the South Pacific, and positive MSLP anomalies are found across the Weddell Sea, both of which are consistent with the September MSLP trends in Fig. 4.25b. The reduced MSLP in the South Pacific is maximised at $\sim 120^{\circ} \mathrm{W}$, but anomalies significant at $p<0.10$ extend westward to $\sim 170^{\circ} \mathrm{W}$, encompassing a large portion of the negative MSLP trend found there during September. The September MSLP anomalies are associated with significant increases in northerly flow across much of coastal and interior West Antarctica.

During October (Fig. 4.32b), a month after the anomalous convection in the SPCZ, the significant circulation anomalies across the South Pacific are weakened and the northerly flow across West Antarctica becomes southerly. The most striking feature during October is that the significant cyclonic circulation anomalies over the South Pacific shift east toward the Peninsula and the anticyclonic circulation anomalies over the South Atlantic shift northeast out of the Weddell Sea, consistent with Fig. 4.25c. The October MSLP anomalies are associated with 
a) September MSLP ( $\mathrm{hPa}$ ) and $10 \mathrm{~m}$ Wind Anomalies

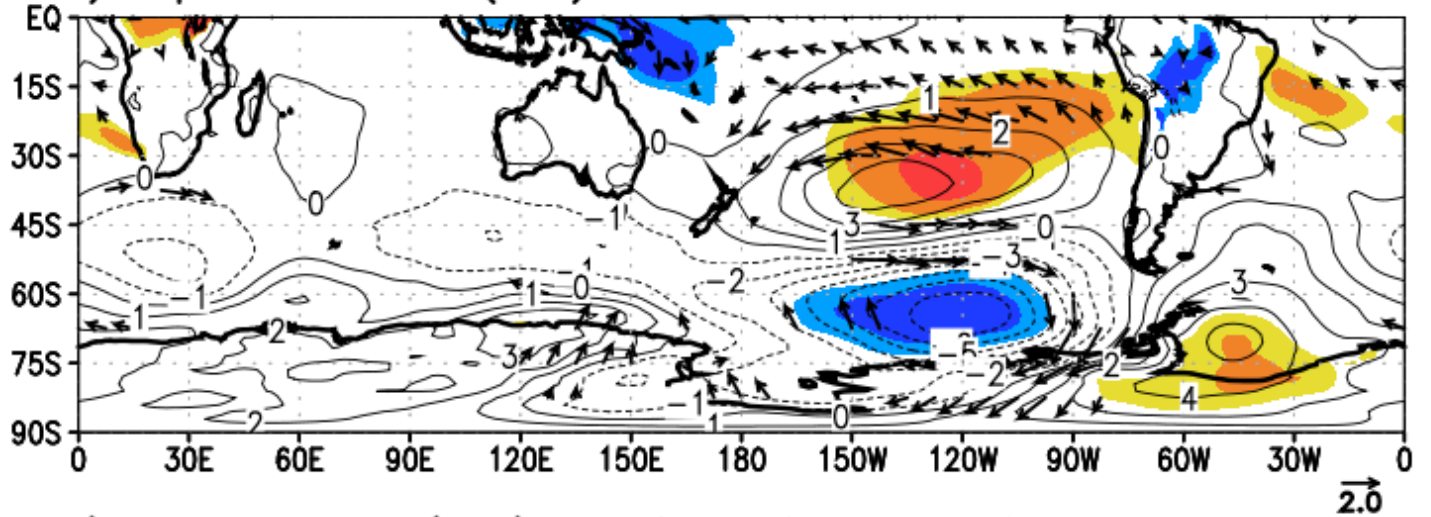

b) October MSLP ( $\mathrm{hPa}$ ) and $10 \mathrm{~m}$ Wind Anomalies

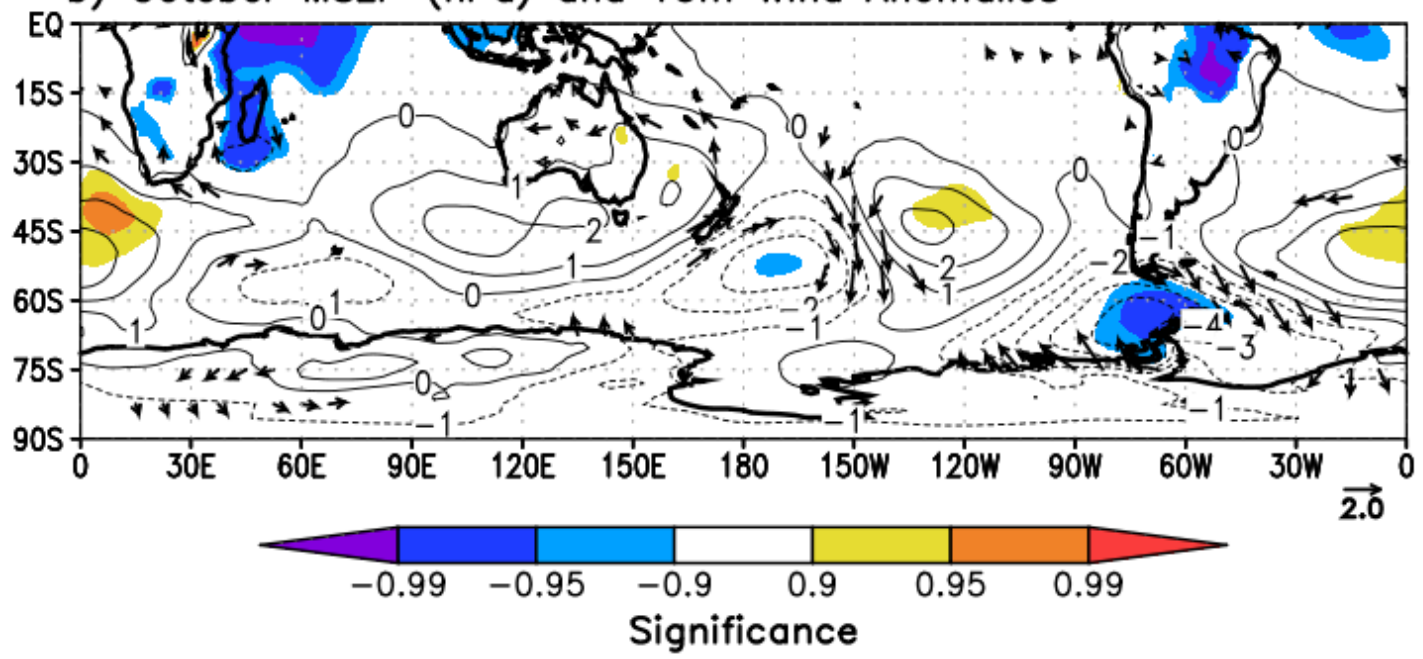

Figure 4.32: Anomaly composite mean for the six years of lowest September OLR averaged over the $25-32.5^{\circ} \mathrm{S}, 180-165^{\circ} \mathrm{W}$ region over the period $1979-2014$. The six years of lowest September OLR used for compositing include: $2007\left(231.5 \mathrm{~W} \mathrm{~m}^{-2}\right), 2008\left(222.1 \mathrm{~W} \mathrm{~m}^{-2}\right), 2009$ $\left(231.6 \mathrm{~W} \mathrm{~m}^{-2}\right), 2010\left(231.9 \mathrm{~W} \mathrm{~m}^{-2}\right), 2012\left(227.6 \mathrm{~W} \mathrm{~m}^{-2}\right)$, and $2014\left(230.4 \mathrm{~W} \mathrm{~m}^{-2}\right)$. The a) September and b) October MSLP and 10-m wind anomalies for the six years are calculated from the respective 1981-2010 September and October climatological means. Shading (from lightest to darkest) indicates MSLP anomalies (hPa) that are statistically different than zero at $p<0.10$, $p<0.05$, and $p<0.01$, respectively, and $10-\mathrm{m}$ wind anomalies $\left(\mathrm{ms}^{-1}\right.$; indicated by reference vector) are only plotted if at least one of the wind components is significant at the $p<0.10$ level. Contour interval is $1.0 \mathrm{hPa}$.

increased northerly flow from the Peninsula eastward across the Weddell Sea, also consistent with the trends.

A final analysis of the relationship between the September SPCZ OLR and extratropical circulation is presented in Fig. 4.33. Here, correlation maps between the detrended September OLR in the SPCZ region and detrended September / October MSLP fields during 1979-2014 are calculated to remove any influence the trends have on the linear relationships in Figs. 4.30-4.31. 
a) Sep OLR SPCZ vs. Sep MSLP Correlation

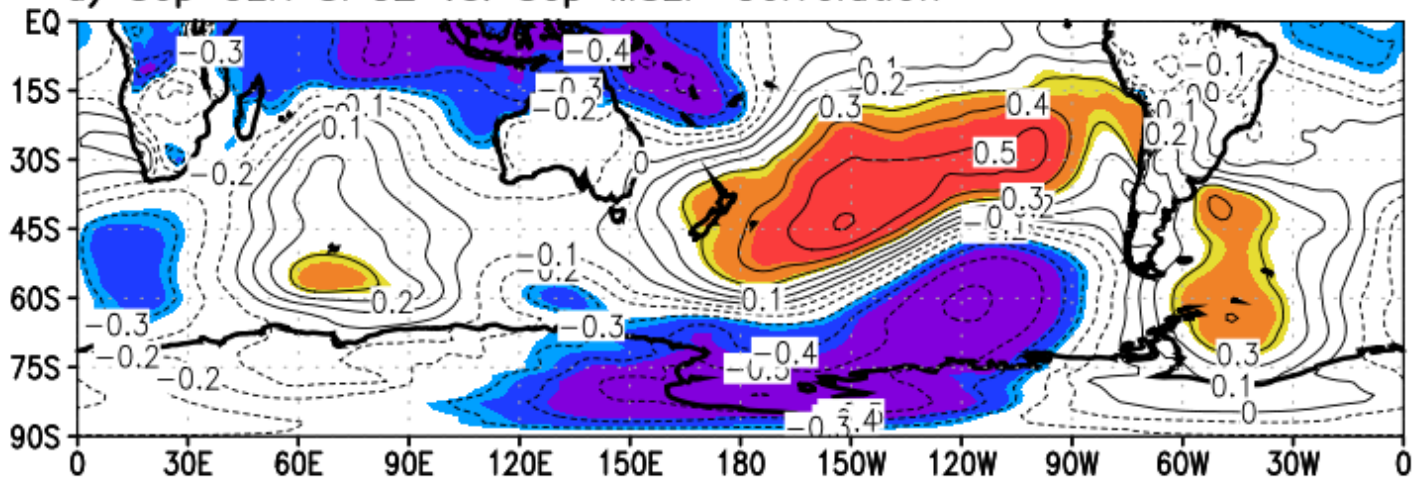

b) Sep OLR SPCZ vs. Oct MSLP Correlation

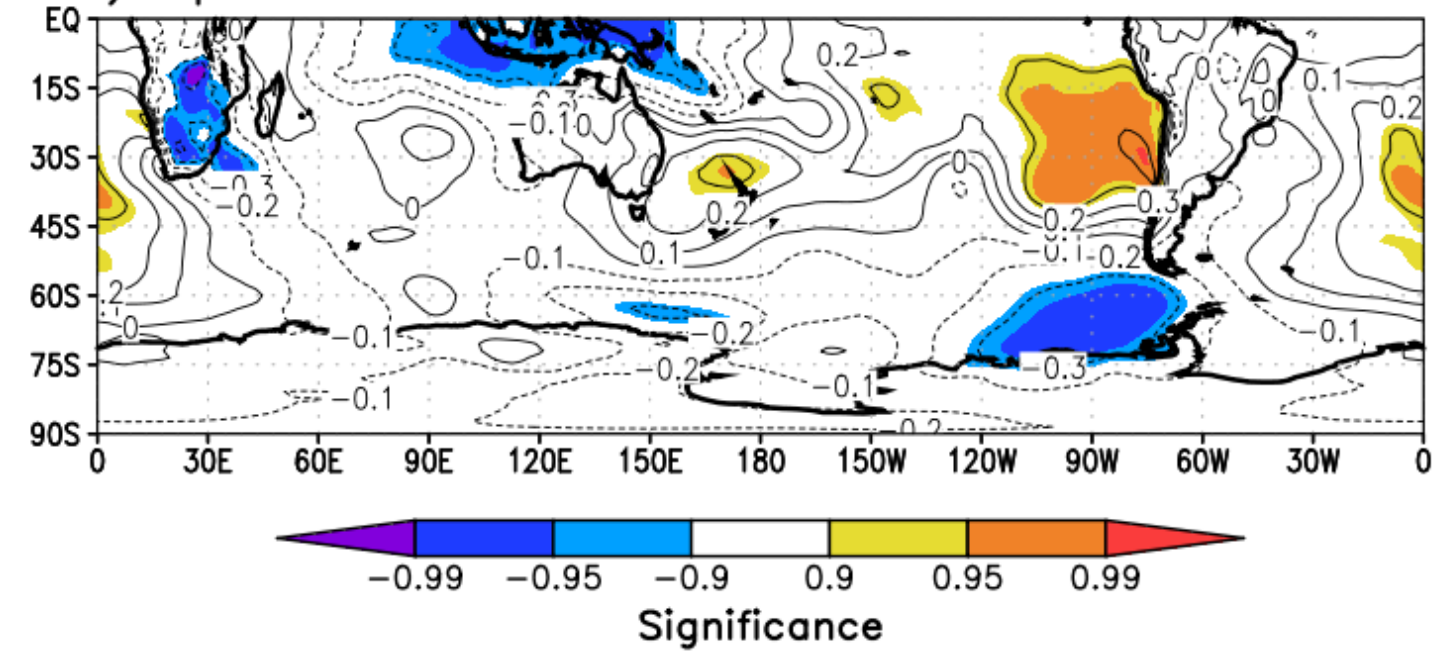

Figure 4.33: Detrended correlation of September OLR with a) September and b) October MSLP. Correlation coefficients (contours) are multiplied by negative one to reflect pressure anomalies associated with anomalous deep convection. Shading (from lightest to darkest) indicates correlation coefficients that are statistically different from zero at $p<0.10, p<0.05$, and $p<0.01$, respectively. Contour interval is 0.1 .

Because the September OLR in the SPCZ region has been trending negative, the correlation coefficients are multiplied by negative one so that the correlation sign represent the appropriate sign of MSLP anomalies. During September (Fig. 4.33a), the detrended response across the SH is characterised by a tropically-forced Rossby wavetrain with significant positive correlations $(p<0.01)$ across the sub-tropical South Pacific, significant negative correlations throughout much of the high-latitude South Pacific $(p<0.01)$, and weaker but still statistically significant positive correlations over the South Atlantic. In October (Fig. 4.33b), the significant negative correlations across the high-latitude South Pacific are located farther east near the Peninsula, and positive correlations (some significant) are found over the South Atlantic. 
Because all trends are removed, Fig. 4.33a implies that interannual variability of September OLR in the $25-32.5^{\circ} \mathrm{S}, 180-165^{\circ} \mathrm{W}$ region is associated with significant same-month pressure anomalies over the South Pacific and the South Atlantic reminiscent of a PSA pattern. Compared to typical same-month correlations between ENSO indices (i.e., the SOI and Niño 3.4 SST anomalies) and pressure fields (not shown), the significant correlations in Fig. 4.33a are more meridionally oriented across the South Pacific and extend farther westward and poleward to encompass more of the Ross Sea and western West Antarctica. In October (Fig. 4.33b), significant linear relationships still exist over the South Pacific and South Atlantic with the preceding month's OLR variability in the SPCZ, but the negative MSLP anomalies in the South Pacific shift east toward the Peninsula, and the positive MSLP anomalies in the South Atlantic shift northeast.

\subsubsection{The SPCZ Teleconnection to the SH}

Finally, a more general investigation of the seasonality of the SPCZ teleconnection and the influence of the position of tropical deep convection is presented. The seasonality of the teleconnection from the region trending negative in September $\left(25-32.5^{\circ} \mathrm{S}, 180-165^{\circ} \mathrm{W}\right.$; red box in Fig. 4.29b) is shown in Fig. 4.34. Detrended, inverted correlation maps (as in Fig. 4.33) between ERA-Interim MSLP and contemporaneous OLR in 'the September region' are provided for all four seasons for the 1979-2013/2014 period (2013 for DJF and 2014 for all other seasons).

In all seasons, an east-west dipole in pressure anomalies / Southern Oscillation feature is observed across the tropical Pacific indicating that ENSO variability strongly modulates OLR variability in the southeastern SPCZ year-round. Increased convection here would be associated with La Niña-like conditions for all seasons, with positive pressure anomalies in the eastern tropical Pacific and negative pressure anomalies in the western tropical Pacific (Vincent 1994; Folland et al. 2002).

The atmospheric response in the extra-tropics is markedly different for each season. In DJF (Fig. 4.34a), a negative pressure anomaly is seen over the Antarctic Peninsula, farther east than typical ENSO-related teleconnections to the South Pacific, and negative pressure anomalies are found over Antarctica resembling SAM positive conditions. This pattern is likely due to the more zonally-symmetric background circulation across the South Pacific during DJF that would steer the tropical signal farther east to the Peninsula, and also the more zonally oriented ENSO 
a) DJF OLR SPCZ Sep Region vs. MSLP Correlation
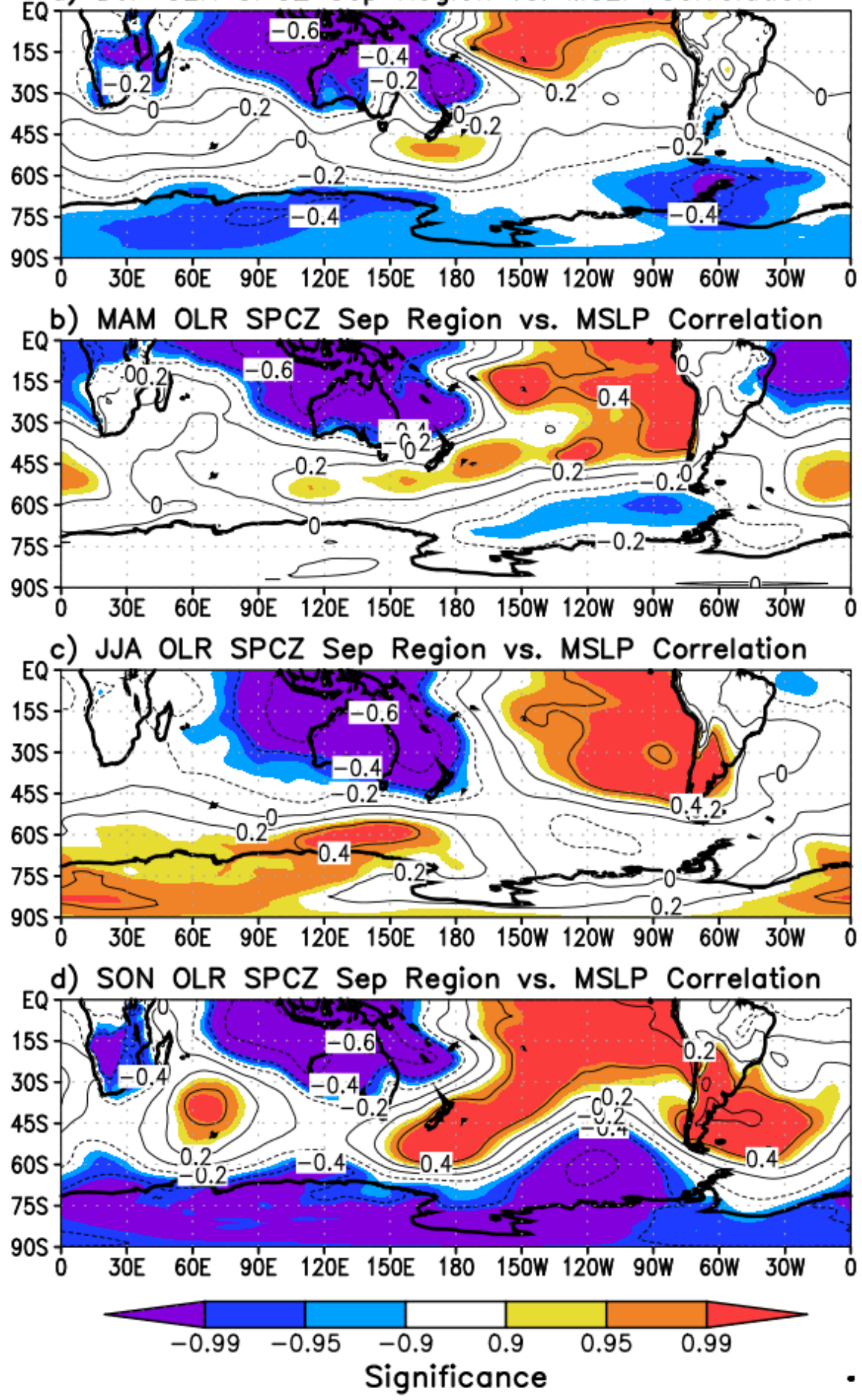

Figure 4.34: Detrended correlation, 1979-2014, of OLR in the September region $\left(25-32.5^{\circ} \mathrm{S}\right.$, $180-165^{\circ} \mathrm{W}$ ) with MSLP for a) DJF, b) MAM, c) JJA, and d) SON. Correlation coefficients and statistical significance are drawn as in Fig. 4.33. Contour interval is 0.2. 

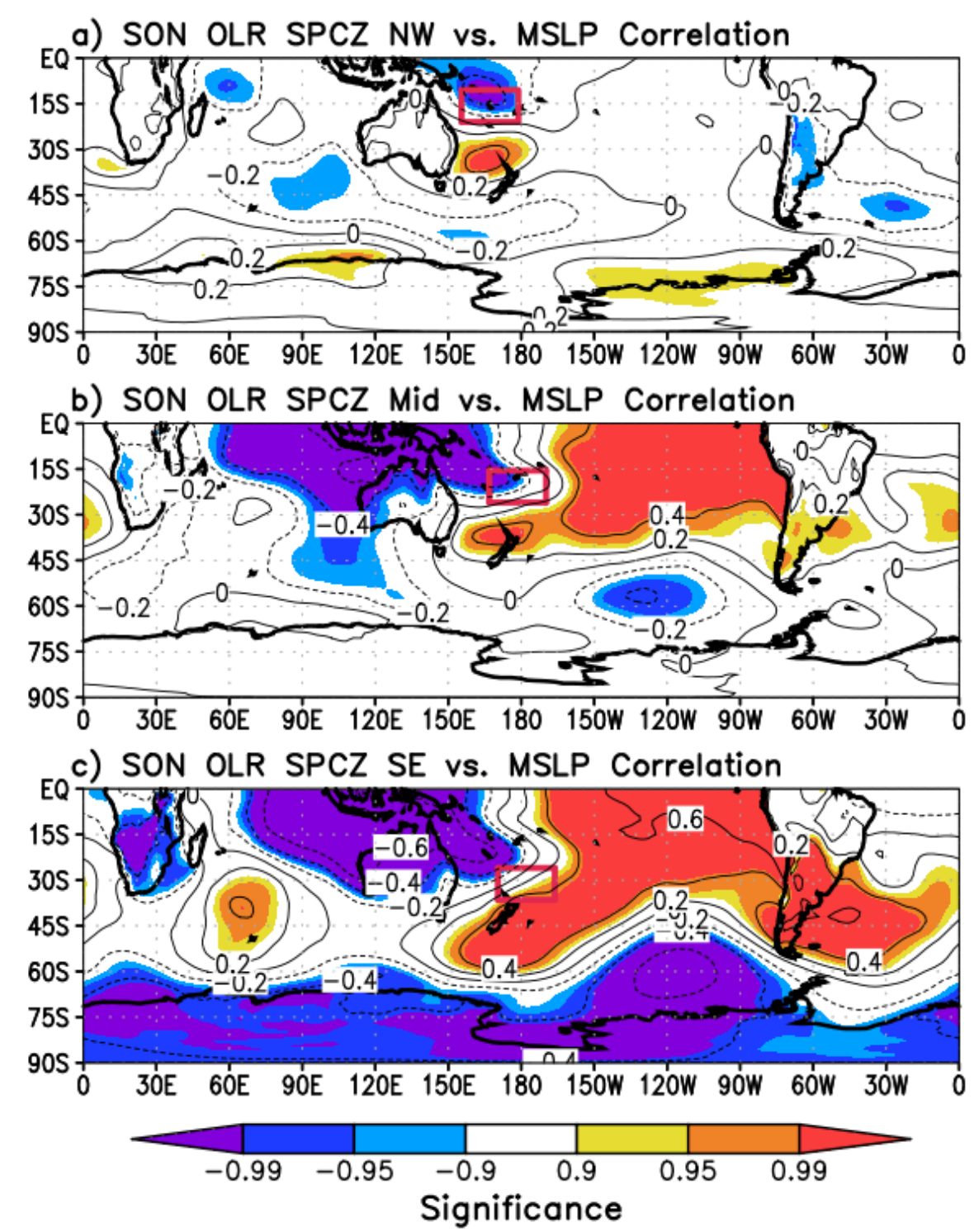

Figure 4.35: Detrended correlation, 1979-2014, of SON OLR in the a) northwest SPCZ region $\left.\left(10-20^{\circ} \mathrm{S}, 155^{\circ} \mathrm{E}-180^{\circ} \mathrm{E}\right), \mathrm{b}\right)$ middle SPCZ region $\left(15-25^{\circ} \mathrm{S}, 165^{\circ} \mathrm{E}-170^{\circ} \mathrm{W}\right)$, and c) southeast SPCZ region $\left(25-35^{\circ} \mathrm{S}, 170^{\circ} \mathrm{E}-165^{\circ} \mathrm{W}\right)$ with SON MSLP. OLR regions used for area-averaging are drawn as a red box in each panel. Correlation coefficients and statistical significance are plotted as in Fig. 4.33-34. Contour interval is 0.2.

response in the SH observed during DJF (Karoly 1989; Seager et al. 2003; L'Heureux and Thompson 2006). The teleconnection to the South Pacific during MAM (Fig. 4.34b) is relatively weak, and it is absent during JJA (Fig. 4.34c). The high-latitude teleconnection during SON (Fig. $4.34 \mathrm{~d}$ ) is the most robust of all seasons, with more than $30 \%$ of the MSLP variability in the South Pacific accounted for by convection in the southeastern SPCZ. A strong SAM component to the circulation is also evident during SON, suggesting SPCZ variability and SAM variability 
are closely tied in SON, consistent with the results of Clem and Fogt (2013). Figure 4.34 demonstrates that SON is the key season for strong South Pacific teleconnections arising from convection along the poleward portion of the SPCZ. Further, compared to DJF and MAM, the SON teleconnection is associated with more regionally distinct MSLP anomalies across the South Pacific and Atlantic.

The SON teleconnection associated with various positions of convection along the SPCZ is presented in Fig. 4.35. Using OLR as a proxy for convection, OLR is area-averaged over the northwest SPCZ near the west Pacific warm pool (NW; $\left.10-20^{\circ} \mathrm{S}, 155^{\circ} \mathrm{E}-180^{\circ} \mathrm{E}\right)$, the middle SPCZ (Middle; $15-25^{\circ} \mathrm{S}, 165^{\circ} \mathrm{E}-170^{\circ} \mathrm{W}$ ), and the southeast SPCZ (SE; 25-35 $\left.\mathrm{S}, 170^{\circ} \mathrm{E}-165^{\circ} \mathrm{W}\right)$. Respective OLR regions used for area-averaging are drawn as a red box.

During anomalous convection along the NW / equatorward portion of the SPCZ during SON (Fig. 4.35a), there is only a local atmospheric response, apparently related to localised ascent / descent associated with the convection, and a South Pacific teleconnection is absent. Additionally, convection on the NW portion does not appear to be linearly related to ENSO activity with the absence of significant correlations across the tropical Pacific. Farther east and poleward along the SPCZ, the South Pacific response to convection become more marked. When anomalous convection occurs in the Middle portion (Fig. 4.35b), a small region of negative pressure anomalies is observed over the South Pacific $(p<0.05)$, and the teleconnection is strongest when the convection occurs farthest poleward in the SE region ( $p<0.01$; Fig. $4.35 \mathrm{c})$. Similar to the teleconnection pattern associated with 'the September region' (Fig. 4.34d), a strong SAM component to the circulation anomalies is also noted.

Figure 4.35 demonstrates that the SPCZ teleconnection to the South Pacific during SON is strongest when the anomalous deep convection is farthest poleward, and Figure 4.34 suggests that the SPCZ teleconnection to the South Pacific / Atlantic is most marked during the SON season. 


\subsection{The Relative Influence of ENSO and SAM on Antarctic Peninsula Climate}

\subsubsection{Overview}

This final section presents results from Clem et al. (2016b) published in Journal of Geophysical Research: Atmospheres in August of 2016. This section investigates how drivers of climate variability vary spatially across the Antarctic Peninsula. Previous studies have shown significant warming of the Peninsula over recent decades, and large ice shelves on the eastern Peninsula have collapsed in response to this warming through surface melting / ponding and resultant hydrofracturing, which has caused significant mass loss throughout the Peninsula. Studies have suggested that the full Peninsula warming is linked to changes in tropical Pacific SSTs, while other studies have showed the tropics only influence the western Peninsula climate during spring. To reconcile these different hypotheses, this section investigates the impact of ENSO and SAM on the western and eastern Peninsula separately. By splitting the Peninsula into its western and eastern sides, significant differences in the impact of ENSO and SAM are noted. During all seasons, the eastern Peninsula is influenced primarily by the SAM and resultant fluctuations in the strength of the westerlies and the intensity / frequency of Föhn wind events. In strong contrast, the western Peninsula is more influenced by ENSO and resultant fluctuations in meridional temperature advection. Meridional temperature advection along the western Peninsula is primarily governed by ENSO variability during winter and spring, while during autumn, variability in the SAM dominates meridional temperature advection along the western Peninsula. These results demonstrate there are significant differences in climate variability between the eastern and western Peninsula, and the two regions need to be examined separately to fully understand how large-scale circulation affects the Peninsula climate. Therefore, these results significantly add to our understanding of the drivers of seasonal to interannual climate variability across the Peninsula. 


\subsubsection{Seasonal and Spatial Influence of ENSO and SAM on Antarctic Peninsula Temperatures}

Seasonal detrended correlations of Antarctic Peninsula temperatures with the SOI, Niño 3.4 SST anomalies, and the Marshall SAM index over 1979-2015 are given in Table 4.9. To investigate the spatial relationship of ENSO and SAM with Peninsula temperatures (following Clem and Fogt (2013)), the average temperature for Faraday-Vernadsky and Rothera stations (hereafter western Peninsula) and Marambio and Esperanza stations (hereafter northeast Peninsula) are analyzed separately from the full five-station average that represents Peninsulawide temperatures (see Fig. 3.1 for all stations and location of western and northeast Peninsula stations). Bellingshausen station, situated on the northern Peninsula, is included only in the "All Peninsula' mean because it lies between the western and northeast Peninsula stations and the local topography is markedly different compared to the western and northeast stations, and therefore has slightly different temperature-wind relationships, as also noted in Clem and Fogt (2013).

During DJF, both the ENSO and SAM index correlations with Peninsula-wide temperatures are weak and insignificant (Table 4.9). The ENSO relationship is near zero for both the western and northeast regions, consistent with Ding and Steig (2013); however, there are significant, opposing relationships between the SAM and western and northeast Peninsula temperatures. Positive SAM conditions are associated with warming on the northeast Peninsula during DJF (consistent with Orr et al. (2008)), but cooling on the western Peninsula. Therefore the weak, insignificant SAM index correlation with Peninsula-wide temperatures during DJF is misleading as significant SAM relationships exist for both the western and northeast Peninsula, but are of opposite sign. The reason for this opposing relationship will be discussed later. During MAM, when Ding and Steig (2013) showed a significant relationship between Peninsula-wide temperatures and tropical Pacific SSTs, there is no significant relationship on interannual timescales between ENSO and Peninsula temperatures except for the western Peninsula; even so these correlations are weak and only significant at $\mathrm{p}<0.10$. Instead, much stronger relationships exist between Peninsula temperatures and the SAM index during MAM. The Peninsula-wide relationship with ENSO becomes stronger during JJA and SON, although the ENSO correlation 
Table 4.9: Seasonal detrended correlations of Antarctic Peninsula temperatures with the SOI, Niño 3.4 SST anomalies, and Marshall (2003) SAM index over 1979-2015. All Peninsula temperatures are the average of the five stations shown in Fig. 3.1: Rothera, Faraday, Bellingshausen, Marambio, and Esperanza. Western Peninsula temperature is the average of Rothera and Faraday, and northeast Peninsula temperature is the average of Esperanza and Marambio. Also given are detrended correlations with ASL magnitude, which is the minimum sea level pressure value in the region $55-75^{\circ} \mathrm{S}, 180-60^{\circ} \mathrm{W}$. Boldface correlations are significant at $\mathrm{p}<0.10$, boldface and underlined correlations are significant at $\mathrm{p}<0.05$, and correlations significant at $\mathrm{p}<0.01$ are denoted with an asterisk.

\begin{tabular}{|c|c|c|c|c|c|c|c|c|c|c|c|c|}
\hline & \multicolumn{3}{|c|}{ DJF } & \multicolumn{3}{|c|}{ MAM } & \multicolumn{3}{|c|}{ JJA } & \multicolumn{3}{|c|}{$\mathrm{SON}$} \\
\hline & $\underline{\mathrm{SOI}}$ & Niño 3.4 & $\underline{\mathrm{SAM}}$ & $\underline{\mathrm{SOI}}$ & Niño 3.4 & $\underline{\text { SAM }}$ & $\underline{\mathrm{SOI}}$ & Niño 3.4 & $\underline{\text { SAM }}$ & $\underline{\mathrm{SOI}}$ & Niño 3.4 & $\underline{\text { SAM }}$ \\
\hline All Peninsula & 0.12 & -0.14 & 0.24 & 0.14 & -0.17 & $\underline{0.67 *}$ & 0.26 & $\underline{-0.43 *}$ & $\underline{0.37}$ & $\underline{0.49 *}$ & $\underline{-0.49 *}$ & $\underline{0.51 *}$ \\
\hline West & -0.01 & -0.07 & -0.31 & 0.33 & -0.31 & $\underline{0.50 *}$ & $\underline{0.39}$ & $\underline{-0.55 *}$ & 0.16 & $\underline{0.59 *}$ & $\underline{-0.59 *}$ & 0.30 \\
\hline Northeast & 0.12 & -0.10 & $\underline{0.45 *}$ & 0.01 & -0.07 & $\underline{0.61 *}$ & 0.12 & -0.28 & $\underline{0.44 *}$ & $\underline{0.33}$ & -0.32 & $\underline{0.56 *}$ \\
\hline ASL & $\underline{-0.35}$ & $\underline{0.35}$ & $\underline{-0.78 *}$ & -0.28 & 0.09 & $\underline{-0.50 *}$ & -0.29 & $\underline{0.33}$ & $\underline{-0.72 *}$ & -0.18 & 0.20 & $\underline{-0.81 *}$ \\
\hline
\end{tabular}

Table 4.10: Seasonal detrended partial correlations over 1979-2015 of Antarctic Peninsula temperatures with the SOI (after removing the SAM index) and the SAM index (after removing the SOI). Also given are detrended partial correlations with ASL magnitude, as in Table 4.9. Statistical significance of partial correlations is denoted as in Table 4.9.

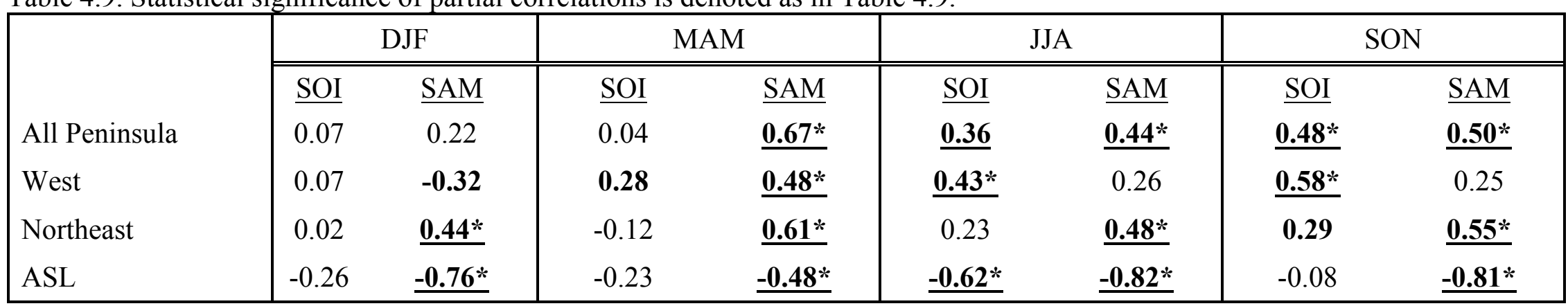


is consistently strongest along the western Peninsula, while the SAM index correlation is strongest with northeast Peninsula temperatures during all seasons.

Partial correlations are given in Table 4.10, calculated after linearly removing the effect of the SAM index upon the SOI, and vice versa. The SOI partial correlation with Peninsula temperatures (and ASL magnitude) during MAM is even weaker after influences of the SAM index are removed, indicating the original ENSO correlations during MAM (Table 4.9), albeit weak, are partially a manifestation of co-variability with the SAM index. Meanwhile, the SAM index partial correlations (after removing the influence of the SOI) are virtually unchanged and all remain significant at $\mathrm{p}<0.01$, further suggesting circulation variability associated with the SAM pattern dominates temporal variability in ASL magnitude and Peninsula temperatures during MAM.

The ENSO / SAM relationship with western and northeast Peninsula temperatures is investigated spatially in Figs. 4.36 and 4.37. Similar to Fig. 4 of Ding and Steig (2013), correlations between Peninsula temperatures and tropical SSTs / $500 \mathrm{hPa}$ geopotential height are shown for all seasons (DJF and MAM shown in Fig. 4.36; JJA and SON shown in Fig. 4.37), however the western (left column) and northeast (right column) Peninsula investigated separately. The findings of Ding and Steig (2013) and results from Table 4.9 for DJF are confirmed with no significant temporal relationship between tropical SSTs and Peninsula temperatures during DJF. This is possibly due to the strong zonal symmetry of the SH circulation during DJF (Karoly 1989) manifested as a climatologically weaker ASL in summer (e.g., Fogt et al. 2012a; Turner et al. 2013b). It may also be related to the climatologically weaker sub-tropical jet over the South Pacific sector, weakening anomalous meridional vorticity gradients and the associated Rossby wave source thereby weakening the connection between tropical deep convection to the high southern latitudes via poleward propagating Rossby waves (e.g., LachlanCope and Connolley 2006).

The regional circulation anomalies for the western Peninsula during DJF (Fig. 4.36a) shows positive pressure anomalies over the Weddell Sea are associated with positive temperature anomalies on the western Peninsula. In contrast, positive temperature anomalies on the northeast Peninsula during DJF (Fig. 4.36b) are associated with positive pressure anomalies north of the Peninsula over the South Atlantic (resembling a positive SAM state). When the positive pressure anomaly east of the Peninsula is located farther poleward over the Weddell Sea, the flow across 
a) DJF West Peninsula SST / $500 z$
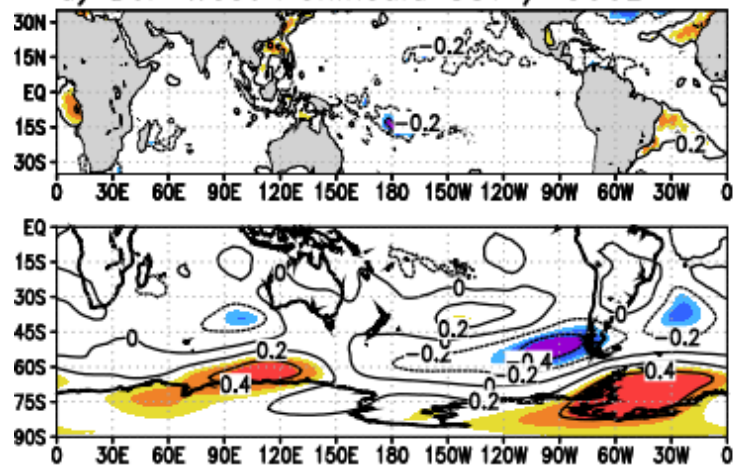

c) MAM West Peninsula SST / $500 z$
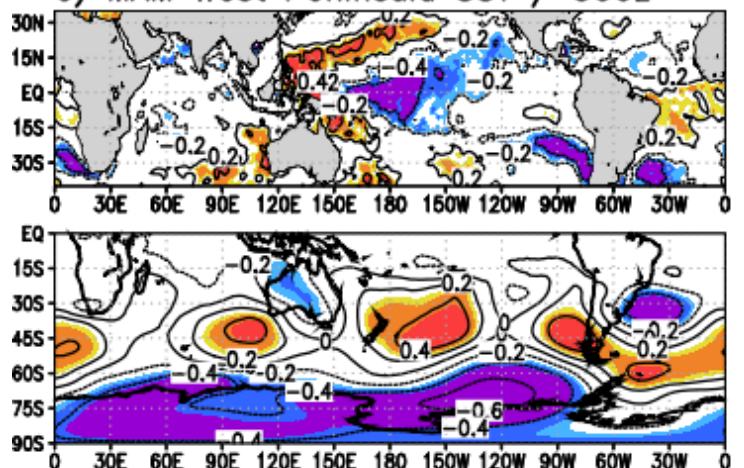

b) DJF NE Peninsula SST / $500 z$
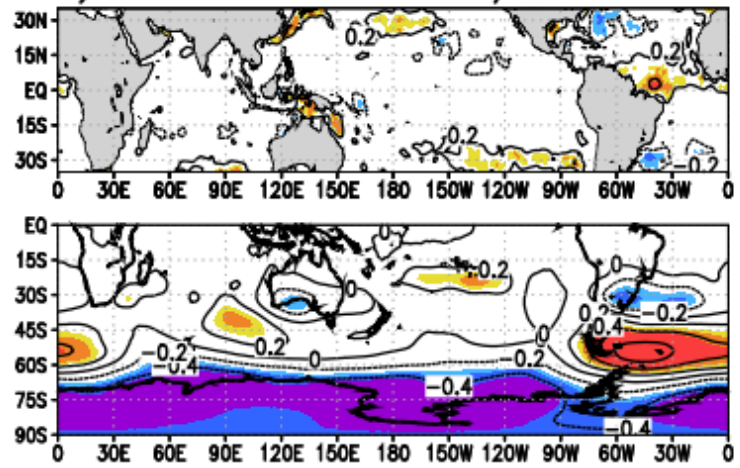

d) MAM NE Peninsula SST / $500 z$
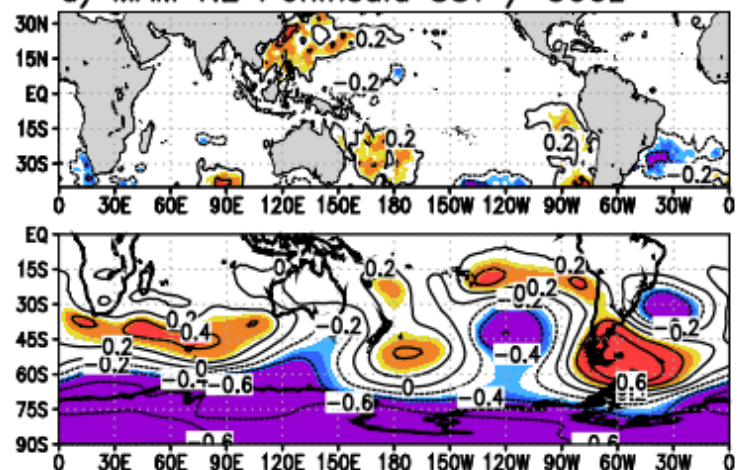

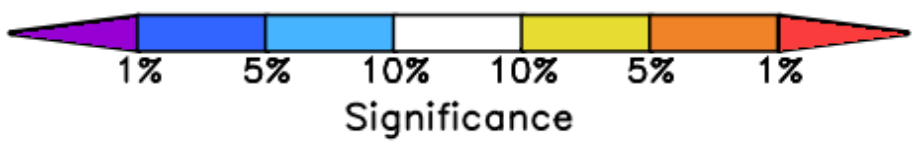

Figure 4.36: Detrended seasonal correlations of western (left column) and northeast (right column) Antarctic Peninsula temperatures with HadISST tropical SST (top panels) and ERAInterim $500 \mathrm{hPa}$ geopotential height (bottom panels) for (a-b) DJF, (c-d) MAM. Correlation coefficients are contoured (contour interval is 0.2 and zero contours are omitted for SST correlations), and statistical significance of correlations at the $\mathrm{p}<0.10, \mathrm{p}<0.05$, and $\mathrm{p}<0.01$ is shaded (indicated by reference color bar at bottom).

the Peninsula would be anomalously northeasterly, which would increase poleward heat transport and warm the western Peninsula. When the positive pressure anomaly is located farther equatorward over the South Atlantic, positive zonal wind anomalies would occur across the Peninsula leading to Föhn effects and adiabatic warming at the northeast Peninsula stations (Orr et al. 2008). It is unclear what the exact influence of the SAM is on the latitudinal position of this regional circulation feature, but there is an indication that positive SAM conditions are associated with a more equatorward positive pressure anomaly over the South Atlantic accompanied with negative pressure anomalies over the Weddell Sea and remaining polar cap, 
a) JJA West Peninsula SST / $500 z$
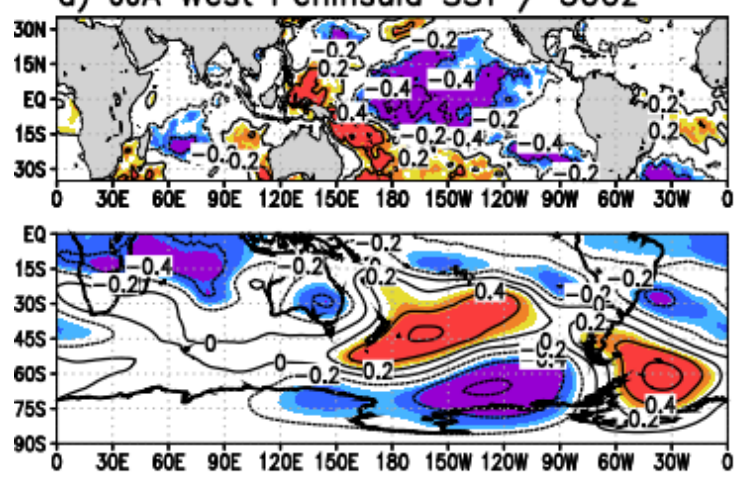

c) SON West Peninsula SST / $500 z$

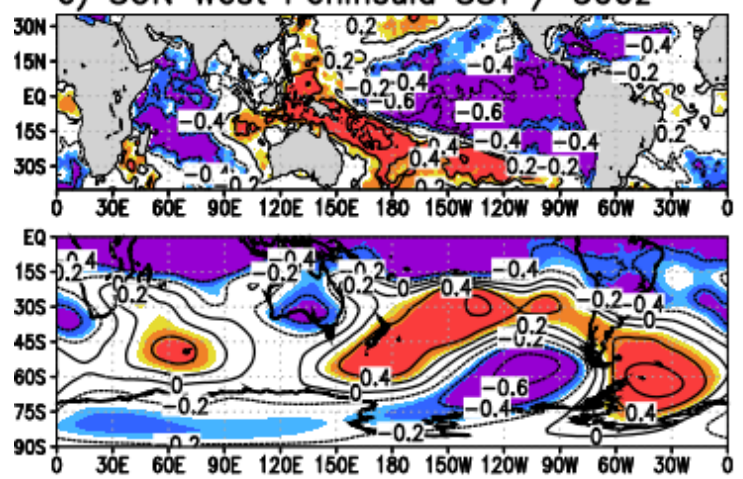

b) JJA NE Peninsula SST / $500 z$
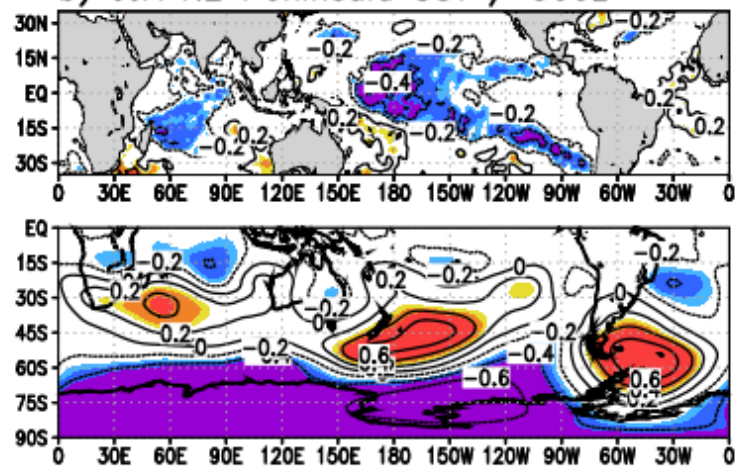

d) SON NE Peninsula SST / $500 z$
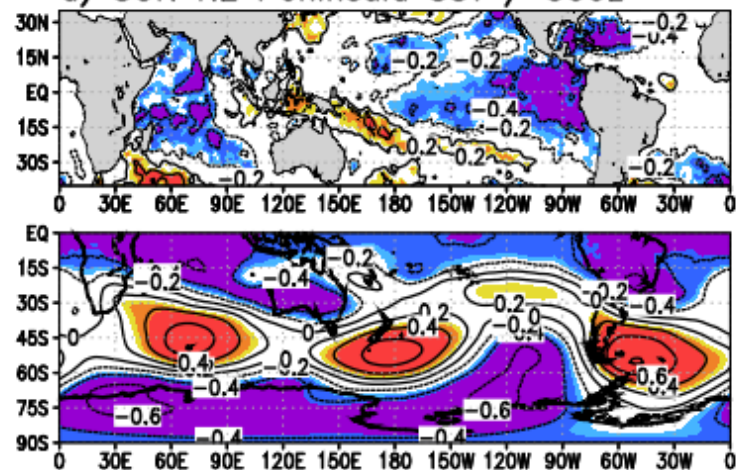

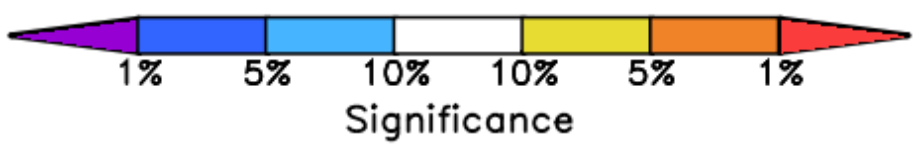

Figure 4.37: As in Fig. 4.36, except for (a-b) JJA and (c-d) SON seasons.

which explains the significant positive correlation between the SAM index and northeast Peninsula stations during DJF.

During MAM, significant tropical Pacific SST correlations are seen for western Peninsula temperatures (Fig. 4.36c), but not for northeast Peninsula temperatures (Fig. 4.36d). A wavetrain following a great circle out of the western tropical Pacific with a deepened ASL is evident for warm western Peninsula temperatures, but positive SAM-like circulation features are also clearly present outside of the tropics. For the northeast Peninsula, a tropically forced wavetrain is much less apparent over the South Pacific (i.e., although the correlation values reflect a ridge-trough pattern, it is not as strongly tied to the tropics), and the circulation anomalies over the South Atlantic and Indian Oceans are primarily zonal and SAM-like. The overall weak connection to the tropics and stronger SAM-like circulation features during MAM is consistent with the partial 
correlations: when local circulation anomalies associated with the SAM are removed, the ENSO correlation with Peninsula temperatures and ASL magnitude becomes much weaker (Table 4.10).

During JJA and SON (Fig. 4.37), stronger, statistically significant correlations with tropical Pacific SSTs are seen for both western and northeast Peninsula temperatures, consistent with Ding and Steig (2013) and correlations seen in Table 4.9. The circulation anomalies for the western Peninsula appear to be comprised almost entirely of a tropically forced wavetrain during JJA and SON (Fig. 4.37a,c), while the circulation anomalies for the northeast Peninsula (Fig. $4.37 \mathrm{~b}$,d) still resemble a SAM pattern but with an embedded tropically forced wavetrain; this pattern in winter and spring reflects the more zonally asymmetric signature that often characterises the SAM in these seasons (Fogt et al. 2012b). Partial correlations with western Peninsula temperatures during JJA and SON confirm a strong tropical connection: after removing the portion of the ENSO correlation related to the SAM, the strength of the ENSO correlation with Peninsula temperatures and ASL magnitude either increases or remains unchanged.

The results presented in Tables 4.9-4.10 and Figs. 4.36-4.37 are consistent with Ding and Steig (2013) in that there is a very weak tropical connection with Peninsula temperatures during DJF while strong tropical connections exist during JJA and SON. However, the correlations demonstrate that large-scale circulation patterns akin to the SAM are more closely related to interannual Peninsula-wide temperature variability than to circulation patterns associated with ENSO, especially during MAM. Additionally, strong SAM features seen during all seasons for the northeast Peninsula may have been overlooked in previous studies. During SON, Clem and Fogt (2013) identified a persistent and significant ENSO relationship with western Peninsula temperatures while the SAM relationship was significant and persistent with northeast Peninsula temperatures. To better understand the relative roles of ENSO and SAM on western versus northeast Peninsula climate during MAM and JJA, anomaly composites for each region are investigated.

A list of the six warmest and six coldest years for both regions is shown in Table 4.10, along with the observed average temperature for the two respective stations and the associated ENSO / SAM phases. The six warmest and coldest years represent the $85^{\text {th }}$ and $15^{\text {th }}$ percentiles of the temperature distribution, respectively, while the ENSO and SAM phases are noted only when 
Table 4.11: Top six warmest and coldest years (rank order; $85^{\text {th }}$ and $15^{\text {th }}$ percentiles, respectively) by season for western and northeast Peninsula temperatures used for compositing in Figs. 4.38-4.40. Also given is the observed average temperature $\left({ }^{\circ} \mathrm{C}\right)$ for each year and the ENSO / SAM phase. Phases are based on when the climate index (SAM index and either the SOI or Niño 3.4 SST) is above or below the $70^{\text {th }}$ or $30^{\text {th }}$ percentile, respectively. EN=El Niño (negative SOI or positive SST anomaly) and LN=La Niña (positive SOI or negative SST anomaly). Neutral implies that both ENSO and SAM were weak (their indices were between the $30^{\text {th }}$ and $70^{\text {th }}$ percentiles).

\begin{tabular}{|c|c|c|c|c|c|c|c|c|c|c|c|}
\hline \multicolumn{6}{|c|}{ DJF } & \multicolumn{6}{|c|}{ MAM } \\
\hline \multicolumn{6}{|c|}{ West Peninsula } & \multicolumn{6}{|c|}{ West Peninsula } \\
\hline \multicolumn{3}{|c|}{ Warm } & \multicolumn{3}{|c|}{ Cold } & \multicolumn{3}{|c|}{ Warm } & \multicolumn{3}{|c|}{ Cold } \\
\hline Year & Temp & ENSO-SAM & Year & Temp & ENSO-SAM & $\underline{\text { Year }}$ & Temp & ENSO-SAM & Year & Temp & ENSO-SAM \\
\hline$\overline{1989}$ & 1.9 & $\overline{E N}$ & $\overline{2013}$ & $\overline{-0.3}$ & neutral & $\overline{1999}$ & $\frac{-0.7}{-0.7}$ & $\overline{\mathrm{LN} / \mathrm{SAM}+}$ & $\overline{1980}$ & $\frac{-6.5}{-1}$ & SAM- \\
\hline 2000 & 1.7 & LN/SAM- & 1980 & -0.2 & neutral & 2001 & -0.8 & neutral & 1979 & -4 & neutral \\
\hline 2002 & 1.5 & EN & 1999 & -0.1 & LN/SAM+ & 1998 & -1.2 & EN/SAM+ & 1992 & -4 & EN/SAM- \\
\hline 2009 & 1.5 & EN/SAM- & 1993 & 0 & SAM+ & 2006 & -1.3 & LN/SAM+ & 2002 & -4 & EN/SAM- \\
\hline 1988 & 1.4 & LN & 2015 & 0 & SAM + & 2013 & -1.4 & LN/SAM+ & 1981 & -3.8 & LN/SAM- \\
\hline 1984 & 1.4 & LN/SAM- & 2014 & 0.1 & SAM + & 2012 & -1.5 & LN/SAM+ & 1991 & -3.5 & EN \\
\hline \multicolumn{6}{|c|}{ Northeast Peninsula } & \multicolumn{6}{|c|}{ Northeast Peninsula } \\
\hline \multicolumn{3}{|c|}{ Warm } & \multicolumn{3}{|c|}{ Cold } & \multicolumn{3}{|c|}{ Warm } & \multicolumn{3}{|c|}{ Cold } \\
\hline Year & $\underline{\text { Temp }}$ & ENSO-SAM & $\underline{\text { Year }}$ & $\underline{\text { Temp }}$ & ENSO-SAM & $\underline{\text { Year }}$ & Temp & ENSO-SAM & Year & $\underline{\text { Temp }}$ & ENSO-SAM \\
\hline$\overline{2001}$ & 1.6 & SAM+ & $\overline{1979}$ & $\overline{-1.7}$ & EN/SAM- & $\overline{1998}$ & -2.8 & $\overline{\mathrm{EN} / \mathrm{SAM}+}$ & $\overline{1990}$ & -12.2 & SAM- \\
\hline 1994 & 1.4 & EN/SAM+ & 2000 & -1.6 & LN/SAM- & 1999 & -3.3 & LN/SAM+ & 1986 & -10.9 & SAM- \\
\hline 1999 & 1 & LN/SAM+ & 2013 & -1.5 & neutral & 2006 & -4.1 & LN/SAM+ & 1991 & -10.9 & EN \\
\hline 2005 & 0.9 & LN/SAM- & 1985 & -1.5 & SAM- & 2000 & -4.7 & LN/SAM+ & 1992 & -10.8 & EN/SAM- \\
\hline 1992 & 0.7 & EN & 2012 & -1.4 & neutral & 2003 & -5.4 & SAM+ & 1987 & -10.7 & EN/SAM- \\
\hline 1995 & 0.7 & LN & 1991 & -1.3 & SAM- & 1997 & -5.4 & EN & 2007 & -10.5 & SAM- \\
\hline
\end{tabular}


Table 4.11 (continued):

\begin{tabular}{|c|c|c|c|c|c|c|c|c|c|c|c|}
\hline \multicolumn{6}{|c|}{ JJA } & \multicolumn{6}{|c|}{$\mathrm{SON}$} \\
\hline \multicolumn{6}{|c|}{ West Peninsula } & \multicolumn{6}{|c|}{ West Peninsula } \\
\hline \multicolumn{3}{|c|}{ Warm } & \multicolumn{3}{|c|}{ Cold } & \multicolumn{3}{|c|}{ Warm } & \multicolumn{3}{|c|}{ Cold } \\
\hline$\underline{\text { Year }}$ & $\underline{\text { Temp }}$ & $\underline{\text { ENSO-SAM }}$ & $\underline{\text { Year }}$ & $\underline{\text { Temp }}$ & $\underline{\text { ENSO-SAM }}$ & Year & Temp & $\underline{\text { ENSO-SAM }}$ & $\underline{\text { Year }}$ & Temp & $\underline{\text { ENSO-SAM }}$ \\
\hline 1989 & -3.5 & LN/SAM+ & 1980 & -16 & neutral & 2010 & -1.8 & LN/SAM+ & 1982 & -7.7 & EN/SAM- \\
\hline 1998 & -3.8 & LN/SAM+ & 1987 & -14 & EN & 2008 & -1.8 & LN/SAM+ & 1987 & -7.5 & EN \\
\hline 1983 & -4.7 & neutral & 2015 & -11.4 & EN/SAM+ & 1989 & -2.6 & neutral & 1980 & -7.3 & SAM- \\
\hline 2010 & -5.5 & LN/SAM+ & 1995 & -11.3 & SAM- & 1985 & -2.6 & LN/SAM+ & 1981 & -7.2 & neutral \\
\hline 2000 & -5.6 & $\mathrm{LN}$ & 1992 & -11.2 & EN/SAM- & 1988 & -3.3 & LN/SAM- & 1986 & -6.8 & EN/SAM+ \\
\hline 2003 & -5.6 & neutral & 2002 & -10.9 & $\mathrm{EN}$ & 2005 & -3.4 & $\mathrm{LN}$ & 2013 & -6.5 & SAM- \\
\hline \multicolumn{6}{|c|}{ Northeast Peninsula } & \multicolumn{6}{|c|}{ Northeast Peninsula } \\
\hline \multicolumn{3}{|c|}{ Warm } & \multicolumn{3}{|c|}{ Cold } & \multicolumn{3}{|c|}{ Warm } & \multicolumn{3}{|c|}{ Cold } \\
\hline$\underline{\text { Year }}$ & $\underline{\text { Temp }}$ & ENSO-SAM & $\underline{\text { Year }}$ & $\underline{\text { Temp }}$ & ENSO-SAM & $\underline{\text { Year }}$ & $\underline{\text { Temp }}$ & $\underline{\text { ENSO-SAM }}$ & $\underline{\text { Year }}$ & $\underline{\text { Temp }}$ & ENSO-SAM \\
\hline 1989 & -6.5 & LN/SAM+ & 2007 & -16.9 & LN/SAM- & 2001 & -2.2 & SAM+ & 1997 & -9.9 & EN/SAM- \\
\hline 2010 & -8.2 & LN/SAM+ & 1980 & -16.6 & neutral & 2008 & -2.5 & LN/SAM+ & 1980 & -8.4 & SAM- \\
\hline 1985 & -9 & LN & 1995 & -16.2 & SAM- & 2010 & -2.8 & LN/SAM+ & 1994 & -8.3 & EN/SAM- \\
\hline 1984 & -9.4 & LN/SAM- & 2009 & -16.1 & EN/SAM- & 2005 & -3.2 & LN & 2014 & -8.3 & $\mathrm{EN}$ \\
\hline 1983 & -9.6 & neutral & 1986 & -15.5 & neutral & 1985 & -3.3 & LN/SAM+ & 2007 & -8.1 & LN/SAM- \\
\hline 2000 & -9.6 & $\mathrm{LN}$ & 2011 & -14.5 & LN/SAM- & 1984 & -3.9 & LN & 2012 & -7.8 & neutral \\
\hline
\end{tabular}


the specific index is above its $70^{\text {th }}$ or below the $30^{\text {th }}$ percentile. During DJF, no western Peninsula warm years occurred during positive SAM conditions, and none of the coldest years occurred with negative SAM conditions. Similarly (but opposite in sign), none of the warmest years for the northeast Peninsula occurred with negative SAM conditions, and none of the coldest years occurred during positive SAM conditions. This further supports the significant yet opposing correlation between the SAM index and Peninsula temperatures during DJF. During SON, consistent with the findings of Clem and Fogt (2013) for the period 1979-2012, no warm northeast Peninsula temperature years occurred during negative SAM conditions, and no warm western Peninsula temperature years occurred during El Niño conditions, and vice-versa. This provides additional evidence confirming the persistent ENSO influence on western Peninsula temperatures and the persistent SAM influence on northeast Peninsula temperatures during SON by expanding the period of analysis to 2015 .

During MAM, there is no consistent ENSO phase associated with warm and cold years for either region of the Peninsula (Table 4.11). The only exception is for cold years on the northeast Peninsula where no La Niña event was observed, but in MAM the ENSO relationship with northeast Peninsula temperatures on interannual timescales is weak and insignificant (Tables 4.9 and 4.10). The SAM phase appears to play a more dominant and consistent role for warm and cold years across both regions of the Peninsula during MAM: the SAM index was never negative during warm years and never positive during cold years across both regions. This is consistent with the significant correlations between the SAM index and all Peninsula temperatures during MAM (Tables 4.9 and 4.10).

Anomaly composites for the six warmest years are plotted only for MAM (Fig. 4.38) and JJA (Fig. 4.39) due to analyses already presented here and in previous studies for DJF and SON (e.g., Ding and Steig (2013) and Clem and Fogt (2013)). Tropical forcing is investigated using $300 \mathrm{hPa}$ velocity potential and $500 \mathrm{hPa}$ streamfunction anomalies (top two rows of Figs. 4.384.39). The extratropical circulation associated with the SAM is investigated using $500 \mathrm{hPa}$ height and $300 \mathrm{hPa}$ wind anomalies (third row of Figs. 4.38-4.39). The local Peninsula low-level circulation is analyzed with $925 \mathrm{hPa}$ meridional temperature advection and wind anomalies (bottom row of Figs. 4.38-4.39). Anomaly composites using five warmest years as well as the top five and six coldest years were analyzed separately but are not shown. Anomalies for five years show similar results, and the cold years show nearly identical but inverse results. 
West Peninsula Warm MAM

a) $300 \mathrm{hPa}$ Velocity Potential

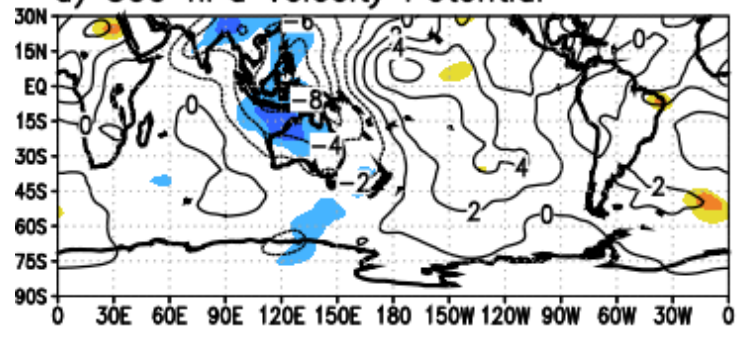

c) $500 \mathrm{hPa}$ Streamfunction

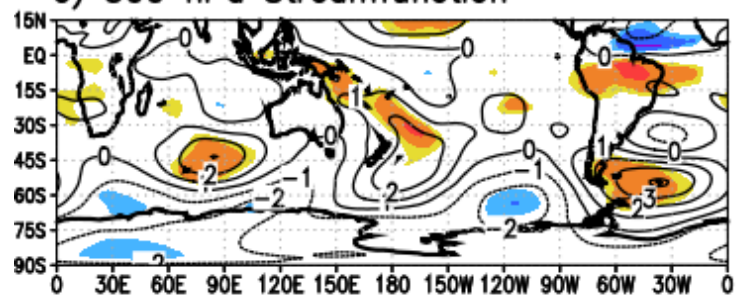

e) $500 \mathrm{hPa} \mathrm{Z} / 300 \mathrm{hPa}$ Wind

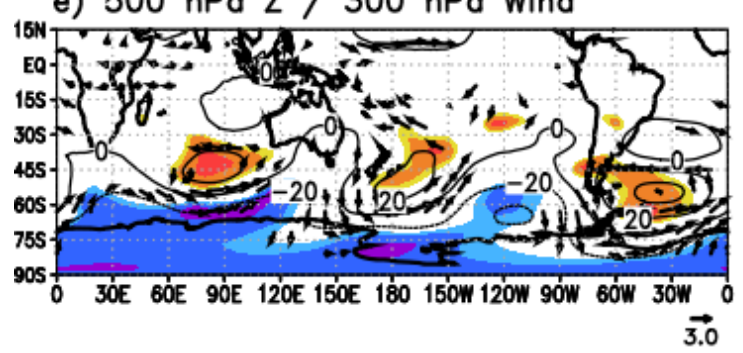

g) $925 \mathrm{hPa}$ Meridional Temp Advection

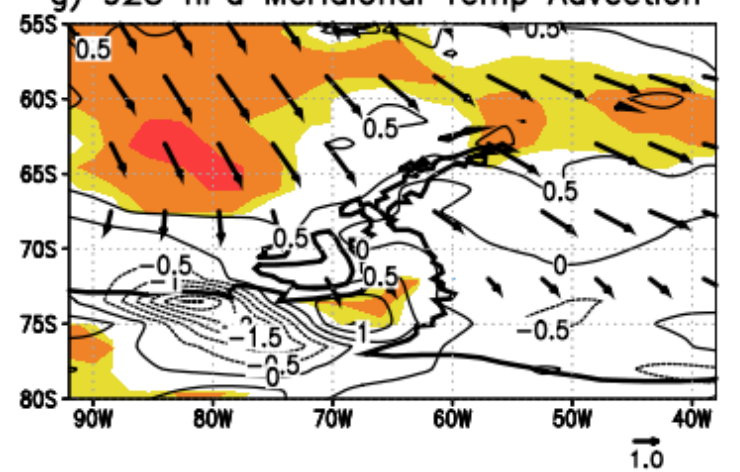

NE Peninsula Warm MAM

b) $300 \mathrm{hPa}$ Velocity Potential

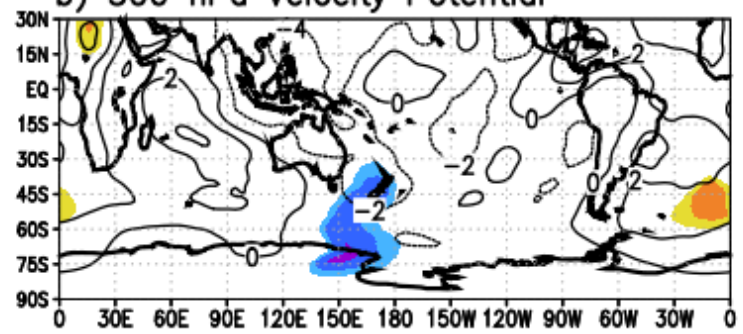

d) $500 \mathrm{hPa}$ Streamfunction

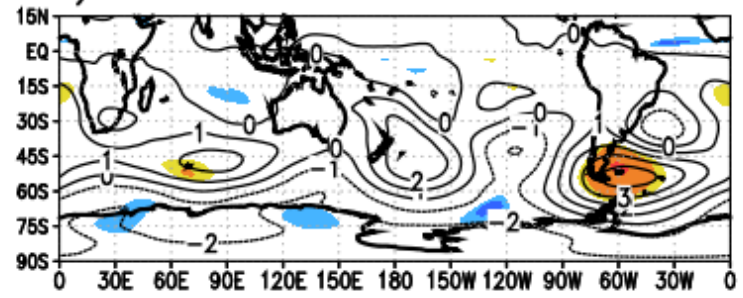

f) $500 \mathrm{hPa} \mathrm{Z} / 300 \mathrm{hPa}$ Wind

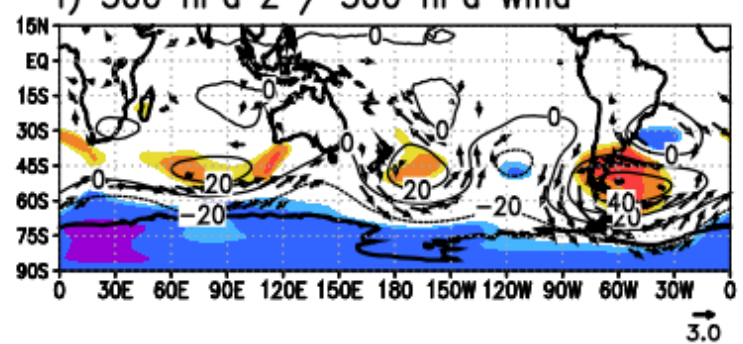

h) $925 \mathrm{hPa}$ Meridional Temp Advection

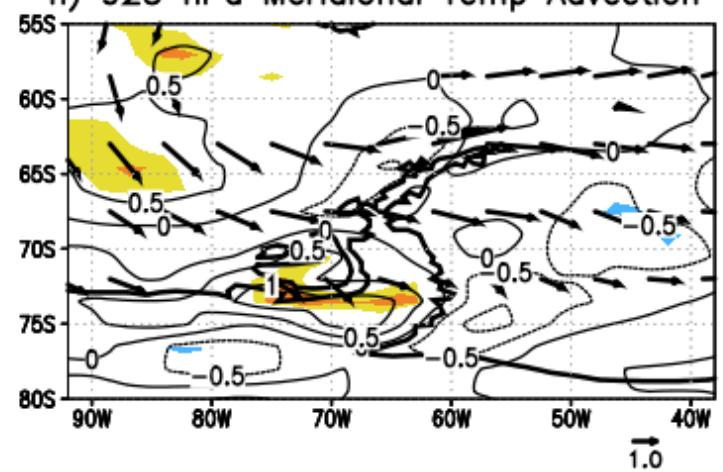

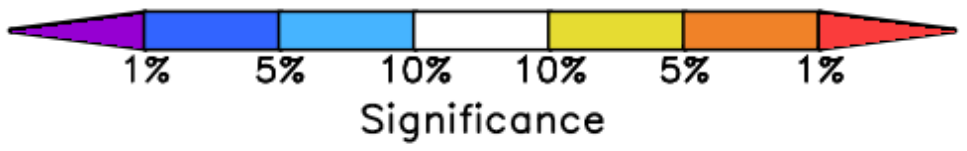

Figure 4.38: Anomaly composite mean for the six warmest years on the western (left column) and northeast (right column) Peninsula during MAM over 1979-2015. (a-b) $300 \mathrm{hPa}$ velocity potential anomalies (contour interval is $2 \times 10^{5} \mathrm{~m}^{2} \mathrm{~s}^{-1}$ ), (c-d) inverted $500 \mathrm{hPa}$ streamfunction anomalies (contour interval is $1 \times 10^{6} \mathrm{~m}^{2} \mathrm{~s}^{-1}$ ), (e-f) $500 \mathrm{hPa}$ geopotential height and $300 \mathrm{hPa}$ wind anomalies (contour interval is 20 metres and wind anomalies are indicated by reference vector in $\mathrm{ms}^{-1}$ ), and (g-h) $925 \mathrm{hPa}$ meridional temperature advection (-v $\left.\partial \mathrm{T} / \partial \mathrm{y}\right)$ and $925 \mathrm{hPa}$ wind anomalies (contour interval is $0.5 \times 10^{5}{ }^{\circ} \mathrm{C} \mathrm{s}^{-1}$ and wind anomalies are indicated by reference 
vector in $\mathrm{ms}^{-1}$ ). Statistical significance of anomalies is shaded as in Figs. 4.36-4.37. Vectors are plotted only if at least one component of the wind anomaly is significant at the $p<0.10$ level.

West Peninsula Warm JJA

a) $300 \mathrm{hPa}$ Velocity Potential

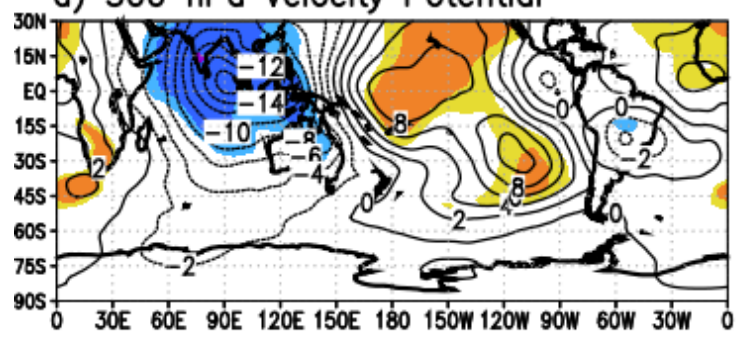

c) $500 \mathrm{hPa}$ Streamfunction

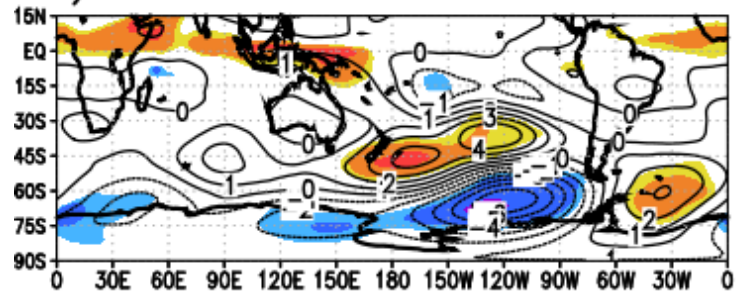

e) $500 \mathrm{hPa} \mathrm{Z} / 300 \mathrm{hPa}$ Wind

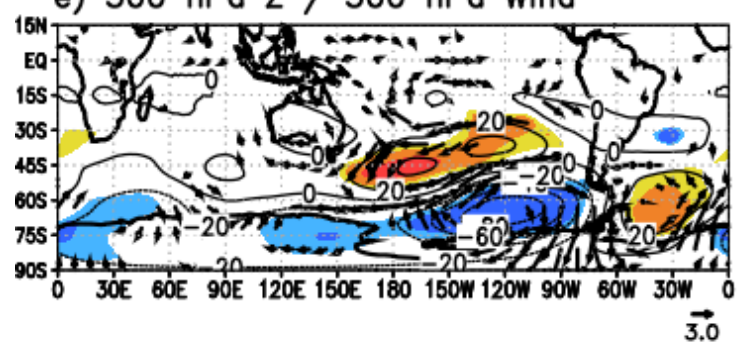

g) $925 \mathrm{hPa}$ Meridional Temp Advection

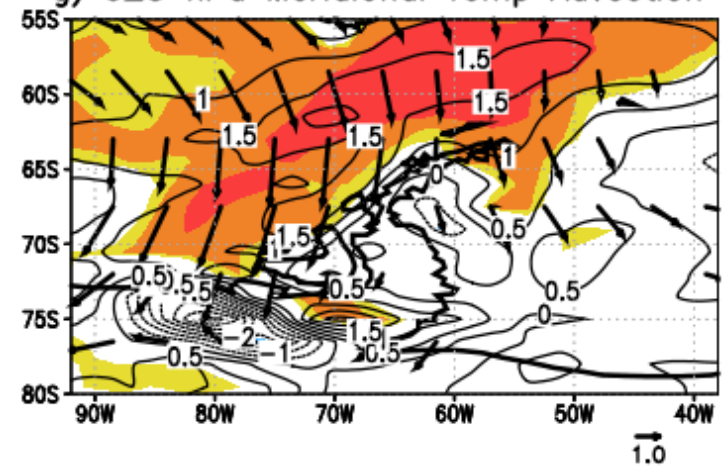

NE Peninsula Warm JJA

b) $300 \mathrm{hPa}$ Velocity Potential

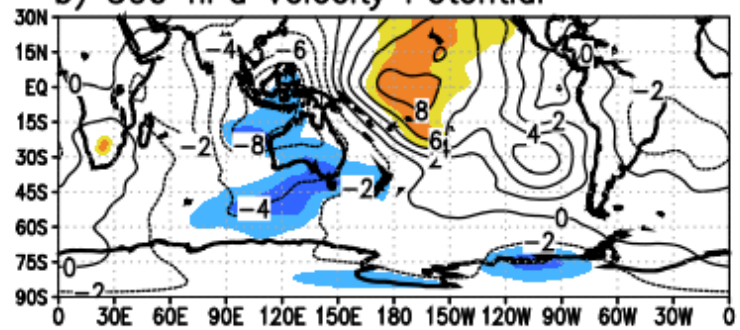

d) $500 \mathrm{hPa}$ Streamfunction

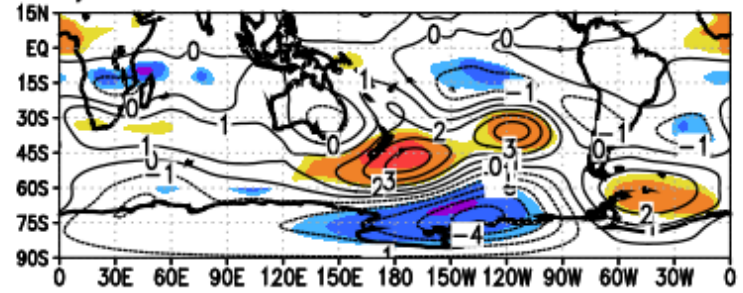

f) $500 \mathrm{hPa} \mathrm{Z} / 300 \mathrm{hPa}$ Wind

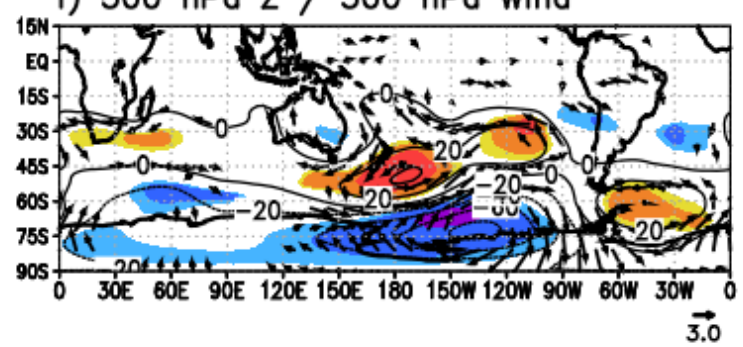

h) $925 \mathrm{hPa}$ Meridional Temp Advection

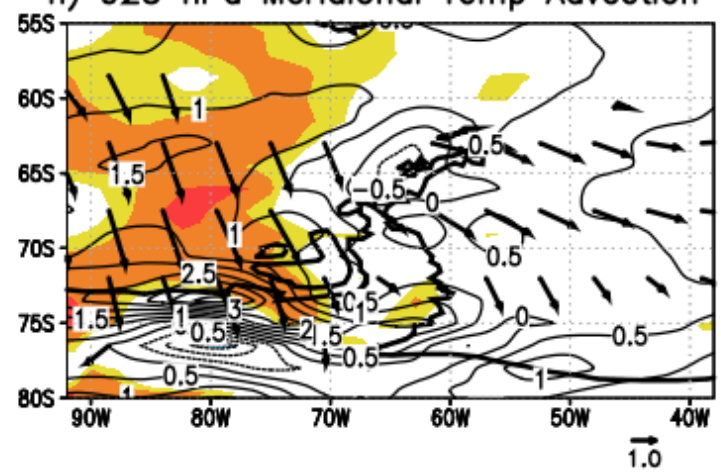

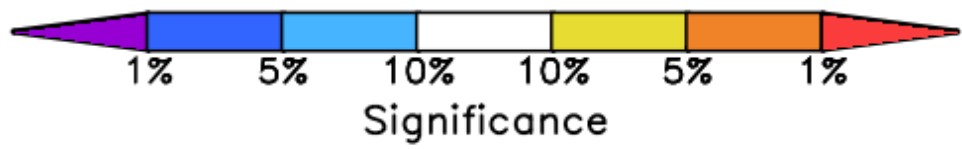

Figure 4.39: As in Fig. 4.38, except for the six warmest years during JJA. 
During MAM (Fig. 4.38) for western Peninsula warm years, a weakly significant zonallyoriented velocity potential couplet is observed over the tropical Pacific indicating a strengthened Walker circulation commonly observed during La Niña events, consistent with the weak ENSO correlations during MAM. For northeast Peninsula warm years, there are no significant velocity potential anomalies over the tropics, indicating average and/or temporally variable tropical forcing. The $500 \mathrm{hPa}$ streamfunction anomalies show a tropically-forced wavetrain across the South Pacific and Atlantic for western Peninsula warm years, like that seen by Ding and Steig (2013), but the circulation anomaly centers, particularly in the vicinity of the ASL, are weak and significant only at $p<0.10$. Very little in the way of a tropically forced wavetrain is seen for northeast Peninsula warm years (Fig. 4.38d). Instead, the $500 \mathrm{hPa}$ height and $300 \mathrm{hPa}$ wind anomalies show more of a positive SAM pattern for both regions, with negative height anomalies poleward of $\sim 60^{\circ} \mathrm{S}$ and positive height anomalies across the middle latitudes. The circulation is marked primarily with meridional wind anomalies for the western Peninsula, including a significantly $(\mathrm{p}<0.05)$ deepened ASL and increased northwesterly flow and warm meridional temperature advection just offshore of the western Peninsula (Fig. 4.38e,g). The northeast Peninsula warm years show similar circulation features, but the deepened ASL is less marked and the $300 \mathrm{hPa}$ wind anomalies are more zonal across the Peninsula and throughout the South Atlantic and Indian Oceans (Fig. 4.38f,h).

The MAM local circulation and meridional temperature advection anomalies for western Peninsula warm years are consistent with previous studies that found meridional wind anomalies to be important for western Peninsula temperatures through modifying local sea ice concentrations and meridional temperature advection (Ding and Steig 2013; Clem and Renwick 2015). The ENSO and SAM correlations and partial correlations (Tables 4.9 and 4.10) show the SAM index has a significant correlation with ASL magnitude during MAM, while the ENSO correlation with the ASL magnitude is weak and insignificant. Therefore, the correlation between the western Peninsula and SAM index during MAM is a reflection of the changes in ASL magnitude associated with phases of the SAM, which changes the meridional flow on the western Peninsula. In contrast, zonal wind anomalies, which are closely tied to the phase of the SAM and its degree of zonal symmetry, are more important for the northeast Peninsula. Therefore, it is the changes in the ASL magnitude (and associated meridional flow) and the degree of zonal flow over the Peninsula (particularly related to the pressure pattern over the 
Atlantic and Indian oceans downstream) that are the key mechanisms driving the significant SAM index correlation with all Peninsula temperatures during MAM.

For JJA (Fig. 4.39), there is a much clearer tropical connection. For both the western and northeast Peninsula warm years, significant velocity potential anomalies are seen across the tropical Pacific with upward motion / upper-level divergence in the western tropical Pacific and subsidence over the central and eastern tropical Pacific. Streamfunction anomalies at $500 \mathrm{hPa}$ show a clear tropically forced wavetrain across the South Pacific that terminates over the South Atlantic. The $500 \mathrm{hPa}$ height and $300 \mathrm{hPa}$ wind anomalies primarily indicate a tropically forced wavetrain (made even clearer in the $500 \mathrm{hPa}$ streamfunction field), but also weak negative height anomalies over Antarctica reflecting a positive SAM phase. A significantly deepened ASL and associated meridional flow and warm meridional temperature advection anomalies to the Peninsula are also seen during JJA (especially for the western Peninsula). However, the northeast Peninsula warmest years are again associated more with positive zonal wind anomalies across the northeast Peninsula and less related to meridional temperature advection anomalies (Fig. 4.39h) as the ASL is displaced farther westward compared to the western Peninsula warm years (compare Figs. 4.39e and 4.39f). The tropical connection is also made clear by the ENSO phases associated with warm years, with no El Niño events observed during warm years at either region during JJA. No La Niña events are observed during cold years on the western Peninsula during JJA indicating ENSO variability dominates both warm and cold years there, while a stronger SAM connection is found for the northeast Peninsula where no positive SAM years are seen during cold years.

\subsubsection{Regional Circulation Characteristics across the Peninsula and their Connection to ENSO and $S A M$}

The regional atmospheric circulation anomalies across the Peninsula (averaged over 64.5$67.5^{\circ} \mathrm{S}$ ) for warm years during all seasons are shown in Fig. 4.40. The years used for compositing are as in Figs. 4.38-4.39 and given in Table 4.11. Nearly identical, inverse sign anomalies are seen for the six coldest years, and the results shown here (using ERA-Interim at $0.75^{\circ}$ latitude-longitude resolution) are qualitatively identical to results using other contemporary reanalysis dataset and ERA-Interim data at coarser resolutions. The meridional wind anomalies are contoured and their significance is shaded. Vectors are comprised of the zonal wind and 
a) DJF West Warm Zonal / Meridional Wind

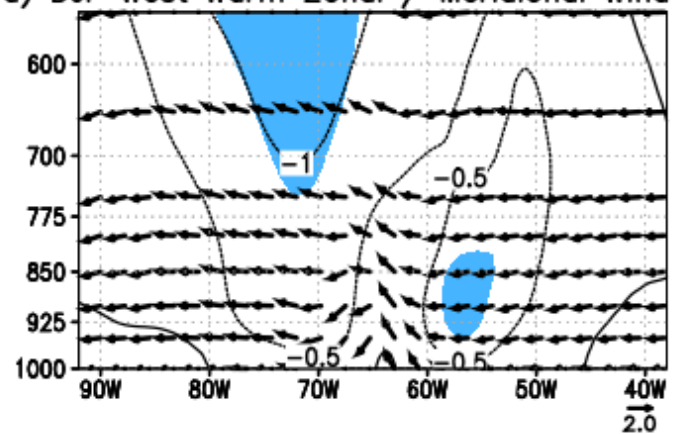

c) MAM West Warm Zonal / Meridional Wind

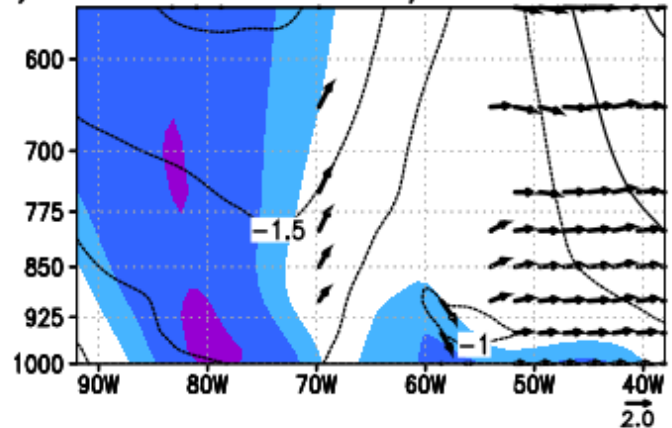

e) JJA West Warm Zonal / Meridional Wind

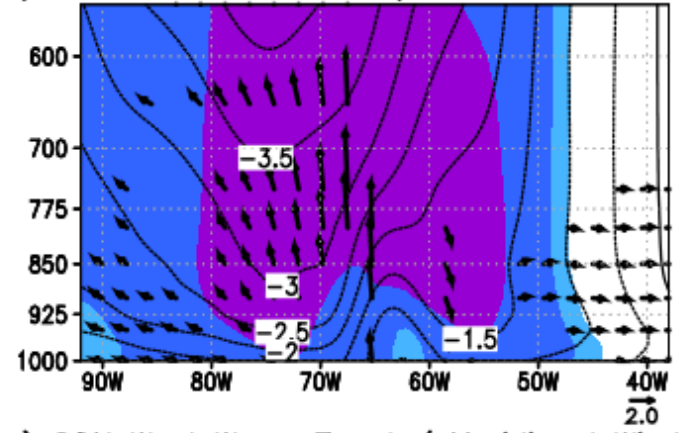

g) SON West Warm Zonal / Meridional Wind

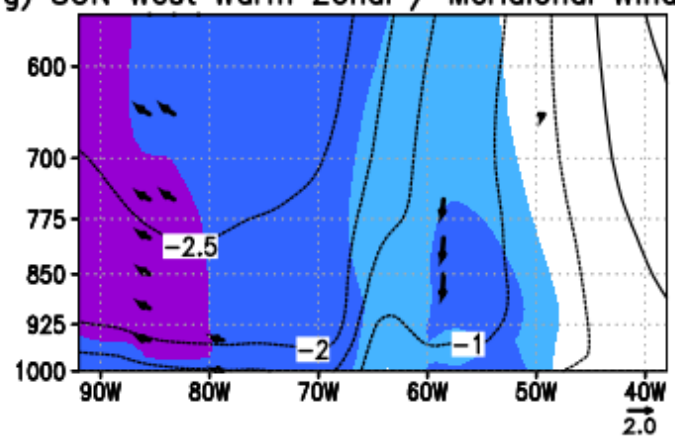

b) DJF NE Warm Zonal / Meridional Wind

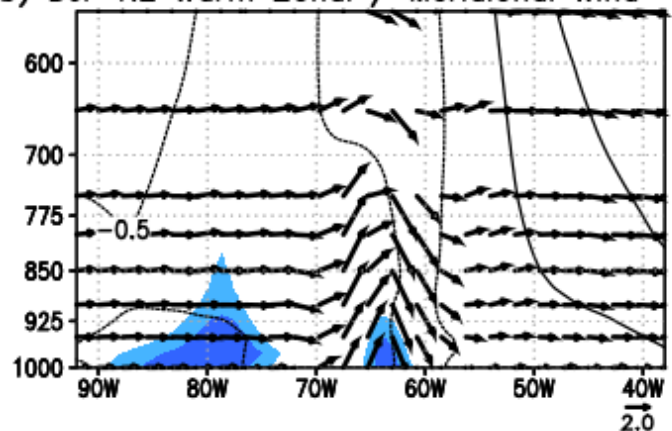

d) MAM NE Warm Zonal / Meridional Wind

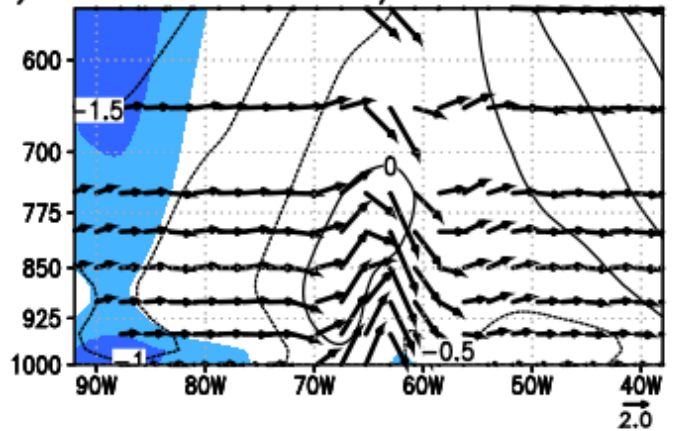

f) JJA NE Warm Zonal / Meridional Wind

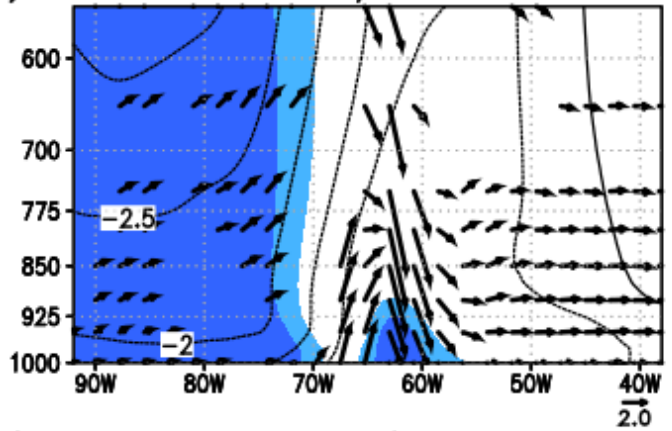

h) SON NE Warm Zonal / Meridional Wind

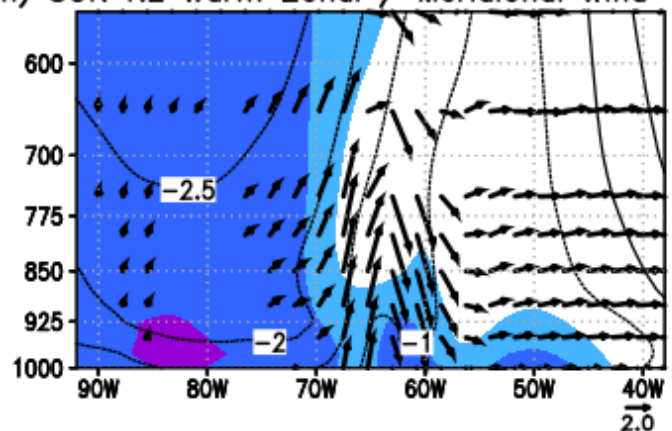

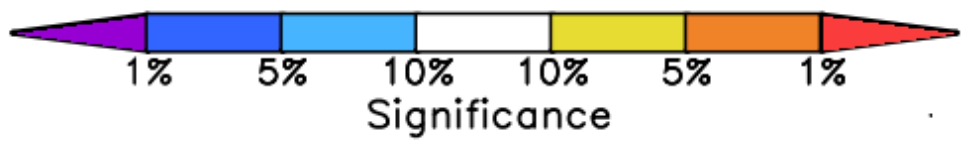

Figure 4.40: Anomaly composite mean of northern Peninsula (meridionally averaged over 64.5$67.5^{\circ} \mathrm{S}$ ) meridional wind (contours) and zonal vertical circulation (vectors) for the six warmest years on the western (left column) and northeast (right column) Peninsula for (a-b) DJF, (c-d) MAM, (e-f) JJA, and (g-h) SON. Contour interval for meridional wind anomalies is $0.5 \mathrm{~ms}^{-1}$, and 
statistical significance of meridional wind anomalies is shaded as in Figs. 4.38-4.39. Vectors are comprised of the zonal wind and omega anomalies (scaled $-10^{2}$ ), and vectors are only plotted if at least component is significant at $p<0.10$. Wind and omega data are from ERA-Interim employed at $0.75^{\circ}$ latitude-longitude resolution. Anomalies and significance are calculated after data are meridionally averaged.

(scaled) vertical velocity anomaly, and only vectors with at least one component significant at $\mathrm{p}<0.10$ are shown.

For northeast Peninsula warm years (Fig. 4.40, right column), significant westerly flow over the steep Peninsula terrain is clearly seen for all seasons. The flow is primarily westerly during DJF and MAM where it reaches the steep coastal mountains on the northern Peninsula, ascends over the mountains, and sharply descends on the lee-side near Esperanza and Marambio stations and across northern portions of the Larsen Ice Shelf. The same orographic process occurs during JJA and SON, but the lower tropospheric flow toward the Peninsula is more northwesterly when taking into account the significant meridional component on the eastern side of the Peninsula (shading). Orr et al. (2008) demonstrated that flow over the Peninsula during DJF leads to warming on the eastern Peninsula through the Föhn effect. This orographic-driven process is clearly tied to warming on the northeast Peninsula during all seasons, even when the flow is northwesterly. For the western Peninsula warm years (left column), meridional flow plays a more important role (meridional wind anomalies are larger in magnitude and generally more significant), and the zonal wind anomalies associated with warm western Peninsula years are too weak to completely cross the Peninsula (there is strong ascent at the coast, but the flow does not cross over to the eastern side).

To identify the relative influence of ENSO and SAM on local winds, partial correlations for the SOI (after removing the SAM index) and SAM index (after removing the SOI) with zonal and meridional winds are plotted in Figs. 4.41 and 4.42, respectively. Winds at $700 \mathrm{hPa}$ are selected for correlation analysis, as Fig. 4.40 shows the spatial pattern of the zonal and meridional wind anomalies to be well represented at $700 \mathrm{hPa}$. However, similar results are obtained at all tropospheric levels ( $10 \mathrm{~m}$ agl up to $300 \mathrm{hPa}$ ) due to the equivalent barotropic nature of the seasonal mean data employed in the correlation maps and composites. The SAM index partial correlation with zonal winds (Fig. 4.41, right column) shows strong, statistically significant $(\mathrm{p}<0.01)$ positive correlations with zonal winds over the northeast Peninsula during all seasons. This relationship is significant across the entire northern two-thirds of the Peninsula 
a) DJF SOI / $700 \mathrm{hPa} \mathrm{U}$ (minus SAM)

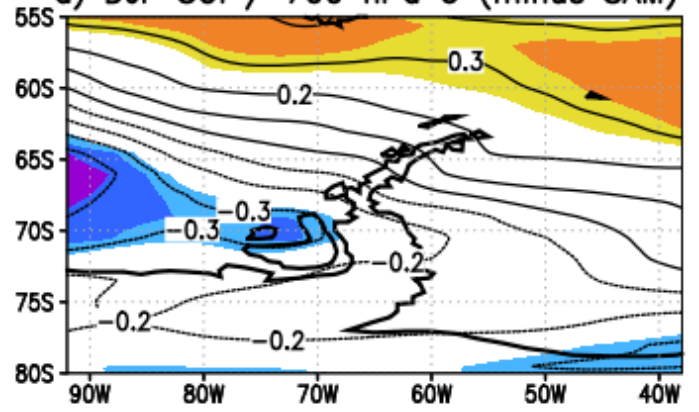

c) MAM SOI / $700 \mathrm{hPa} U$ (minus SAM)

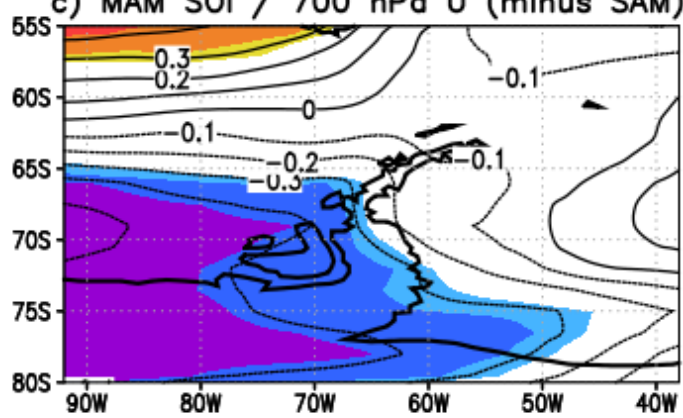

e) JJA SOI / $700 \mathrm{hPa} \mathrm{U}$ (minus SAM)

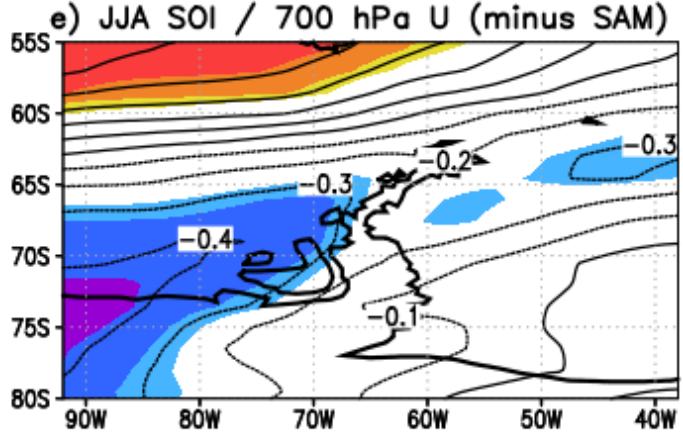

g) SON SOI / $700 \mathrm{hPa} \mathrm{U}$ (minus SAM)
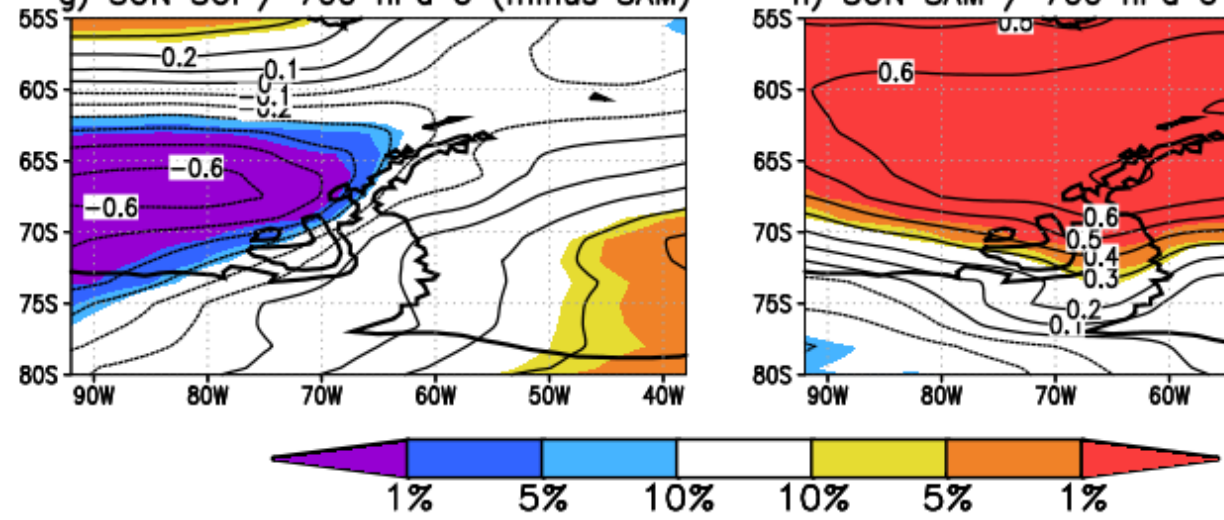

Significance b) DJF SAM / $700 \mathrm{hPa} \mathrm{U}$ (minus SOI)

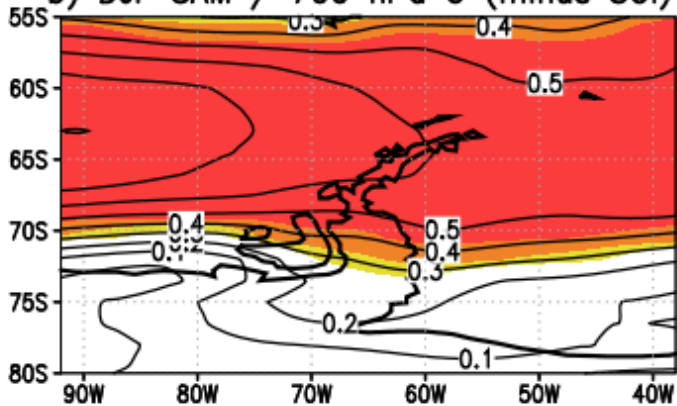

d) MAM SAM / $700 \mathrm{hPa} U$ (minus SOl)
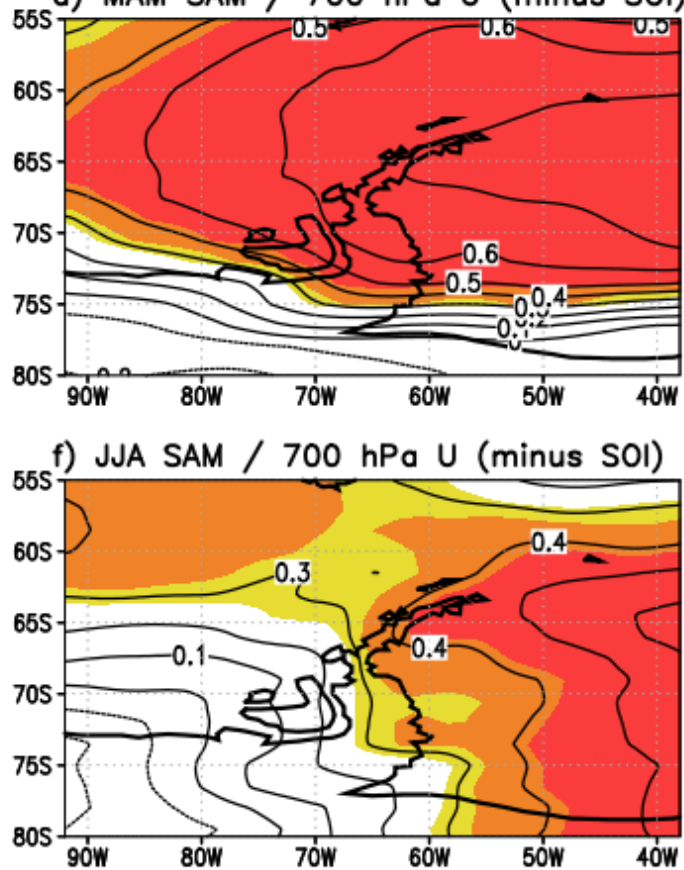

h) SON SAM / $700 \mathrm{hPa} U$ (minus SOl)

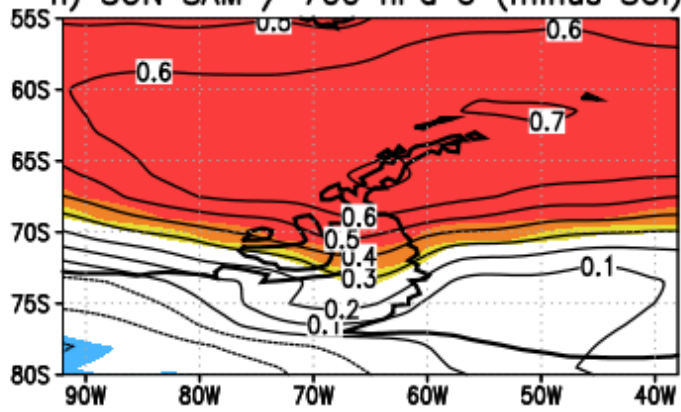

$\quad 1 \%$

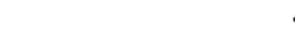

Figure 4.41: Detrended partial correlations of SOI (after removing the SAM index, left column) and SAM index (after removing the SOI, right column) with $700 \mathrm{hPa}$ zonal wind for (a-b) DJF, (c-d) MAM, (e-f) JJA, and (g-h) SON. Contour interval is 0.1 and statistical significance of correlations is plotted as in Figs. 4.36-4.37. 
a) DJF SOI / $700 \mathrm{hPa} \mathrm{V} \mathrm{(minus} \mathrm{SAM)}$

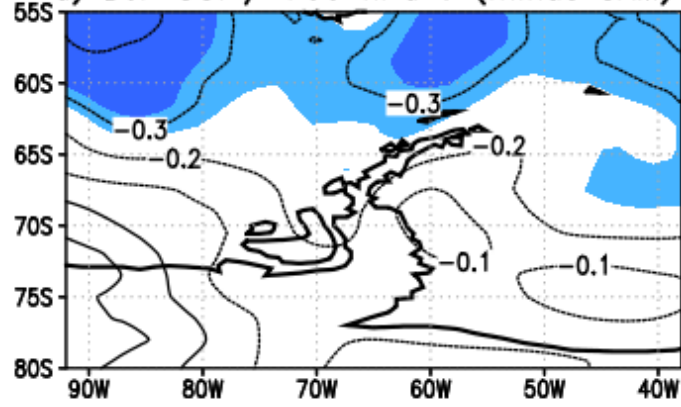

c) MAM SOI / $700 \mathrm{hPa} \mathrm{V} \mathrm{(minus} \mathrm{SAM)}$
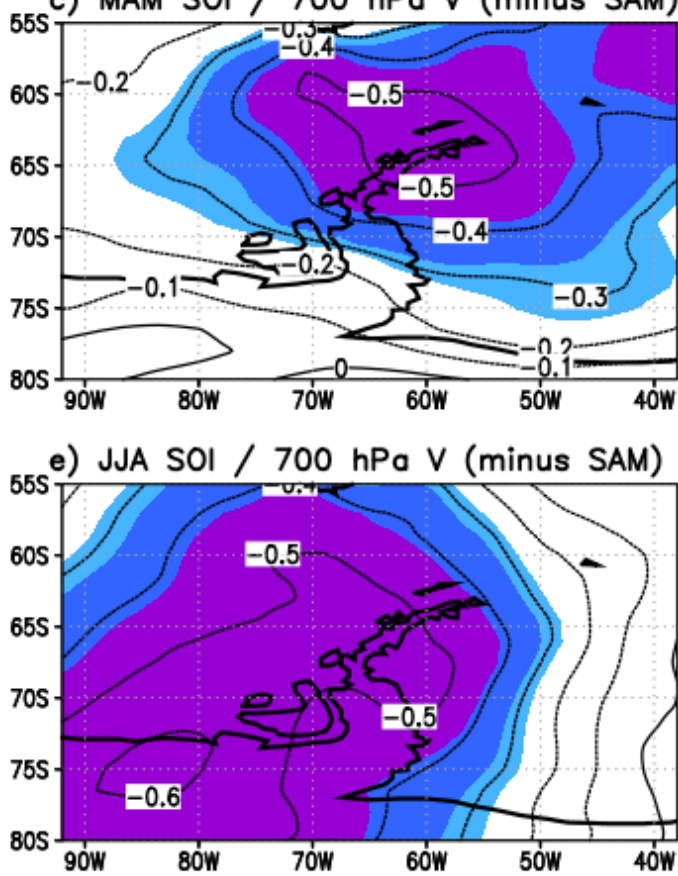

g) SON SOI / $700 \mathrm{hPa} \mathrm{V}$ (minus SAM)

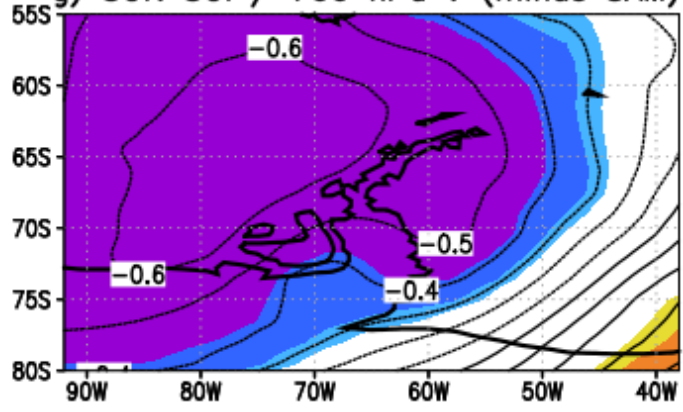

b) DJF SAM / $700 \mathrm{hPa} \mathrm{V} \mathrm{(minus} \mathrm{SOI)}$

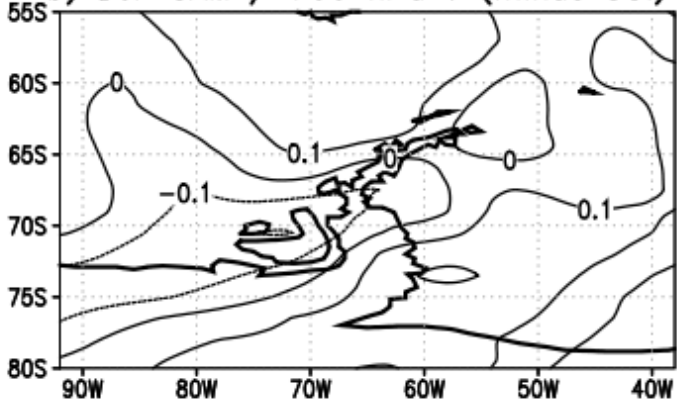

d) MAM SAM / $700 \mathrm{hPa} V$ (minus SOI)
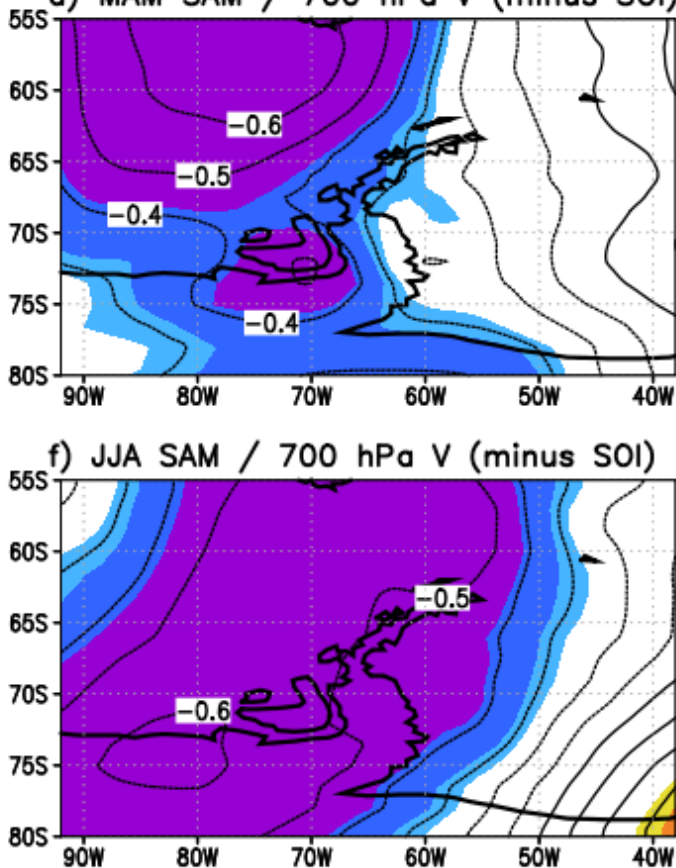

h) SON SAM / $700 \mathrm{hPa} \vee$ (minus SOI)

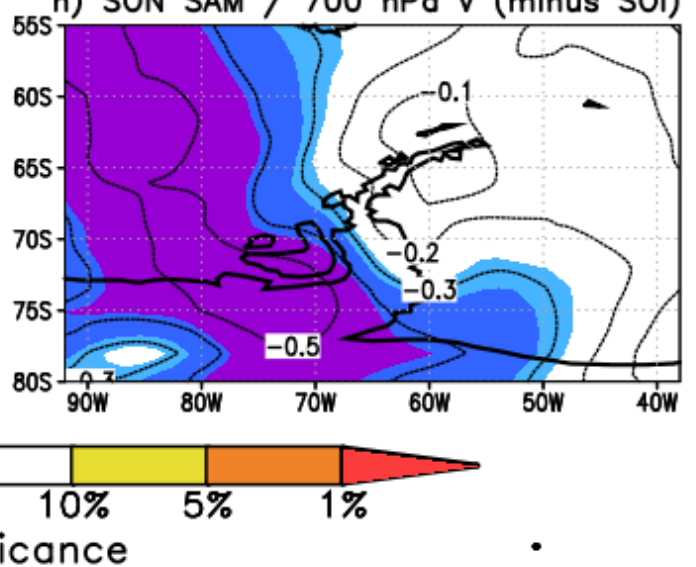

Figure 4.42: As in Fig. 4.41, except for $700 \mathrm{hPa}$ meridional wind. 
during DJF, MAM, and SON, while during JJA a significant correlation is seen only over the northeastern tip of the Peninsula near Esperanza and Marambio stations. In contrast, there is virtually no ENSO relationship with zonal winds over the Peninsula during all seasons; this is true even when the SAM influence is retained for original SOI correlations (not shown). This confirms and further explains the significant SAM index correlation with the northeast Peninsula during all seasons and the comparatively weaker ENSO correlation; northeast Peninsula temperatures are tied to zonal winds traversing the Peninsula, which is dominated by SAM variability.

Partial correlations with 700 hPa meridional winds are shown in Fig. 4.42. Both the SOI and SAM index exhibit weak correlations with meridional winds during DJF likely due to the highly zonal structure of the SH circulation and weakened ASL during summer (Fogt et al. 2012a,b). The SOI is weakly correlated with negative (poleward) meridional wind anomalies off the northern tip of the Peninsula and over portions of the northwest Bellingshausen Sea during DJF, while the SAM index exhibits generally weaker, near zero correlations across the entire Peninsula. The SAM index zero partial correlation line passes between Rothera and FaradayVernadsky, with positive correlations to the north and negative correlations to the south. Despite the correlations being very weak, this likely depicts the split flow described by Orr et al. (2004) associated with westerly flow encountering the Peninsula, and would therefore explain the sign reversal of the SAM index with western Peninsula temperatures during DJF. When the flow over the Bellingshausen Sea toward the Peninsula is primarily zonal (e.g., the flow associated with SAM during DJF), westerly winds may take on a southwesterly component along the northwestern coast as they reach the steep terrain of the Peninsula and the orientation of the northern Peninsula turns easterly. This scenario would lead to a slight cooling at Rothera and Faraday-Vernadsky stations. Any remaining sea ice over the Bellingshausen Sea would also be pushed due eastward toward the west Peninsula coast as opposed to southeastward toward the West Antarctic coast which occurs during other seasons.

Outside of DJF, both the SOI and SAM index show significant, same-sign partial correlations across the Peninsula. The winds over the Peninsula related to ENSO are more purely meridional (e.g., there are no significant partial correlations with zonal winds; El Niño is associated with southerly winds, La Niña is associated with northerly), while the SAM is associated with both meridional and zonal winds outside of DJF (positive SAM is associated 
with northwesterly winds, negative SAM is associated with southeasterly winds). The SOI partial correlation with meridional winds is strongest and most widespread during JJA and SON, consistent with the strengthened correlation with Peninsula temperatures and more robust connection to the tropics seen in the JJA composite. During MAM, the SOI partial correlation is significant over a small region on the northwest Peninsula, while the SAM index partial correlation is strongest offshore of the Peninsula over the Bellingshausen Sea stretching poleward toward the southwestern Peninsula / West Antarctic coast. Although speculative, comparing the spatial patterns of the meridional wind partial correlations during MAM, SAM variability potentially has a greater influence on stunting the equatorward sea ice expansion in the southeastern Bellingshausen Sea during MAM (through its impact on the ASL), while meridional wind variability associated with ENSO may play a greater role at bringing warm, northerly flow to the northwest Peninsula. 


\section{CHAPTER 5: SUMMARY AND CONCLUSIONS}

\subsection{Tropical Pacific Relationships with Recent Trends in the SAM during Austral Summer and Autumn}

Results presented in Chapter 4.1 confirm and extend previous findings (e.g., Zhang et al. 2010; Trenberth et al. 2014) of a statistically significant shift in tropical Pacific SSTs after 1979 with significant cooling in the eastern tropical Pacific and warming across the western tropical Pacific. The SST trends are seen during all seasons, and the significant cooling in the eastern tropical Pacific is primarily off-equatorial and located poleward of all Niño index regions. Therefore cooling in the eastern tropical Pacific is likely a manifestation of SST variability not directly related to ENSO, such as the recent shift of the PDO toward its negative phase (e.g., Meehl et al. 2013) or warming of the equatorial Atlantic which cools eastern tropical Pacific SSTs by intensifying the regional Walker circulation over South America and strengthening the descending branch / surface easterlies over the central and eastern tropical Pacific (Kucharski et al. 2016). The observed cooling in the eastern tropical Pacific is associated with a strengthened Walker circulation / zonal overturning over the tropical Pacific and Indian Oceans during DJF and MAM, and a significant weakening of the South Pacific Hadley cell and STJ during MAM.

During DJF, a significant, hemisphere-wide positive trend in the SAM pattern is noted over 1979-2014 with a significant strengthening of the SH mid-latitude jet (consistent with previous studies). During MAM, a strengthening of the SH mid-latitude jet is also seen, but this strengthening is significant only over the Pacific Ocean. The SH geopotential height trends during MAM resemble more of a Rossby wavetrain over the South Pacific, while outside of the Pacific, the height trends are more regional and zonally asymmetric resembling less of a SAM pattern.

The negative SST trend in the eastern tropical Pacific is linearly congruent with $60-80 \%$ of the observed DJF positive zonal-mean zonal wind trends between 50 and $60^{\circ} \mathrm{S}$, and around half of the MAM positive zonal wind trends between 50 and $60^{\circ} \mathrm{S}$. Detrended partial correlations (after removing the SAM index) indicates about $35 \%$ of the temporal variability in SH zonalmean zonal wind between 50 and $60^{\circ} \mathrm{S}$ is explained by eastern tropical Pacific SSTs, and about $15 \%$ of the variability is explained during MAM. 
During DJF, cold eastern tropical Pacific SST years are associated with anomalous poleward momentum fluxes and a strengthened low-level meridional temperature gradient on the equatorward side of Indian Ocean mid-latitude jet (maximised at $\sim 40^{\circ} \mathrm{S}$ ), which together aid in the production of positive zonal wind anomalies throughout the troposphere between 50 and $60^{\circ} \mathrm{S}$. In contrast, record high positive SAM years during DJF are associated with positive zonal wind anomalies in the stratospheric polar vortex (likely associated with ozone depletion and consistent with previous findings, e.g., Thompson and Solomon 2002; Gillett and Thompson 2003); however, these ozone-related positive SAM events all occurred prior to 2002, and two of the six record high Marshall SAM indices over 1979-2014 that occurred during the past decade (2007 and 2014) were likely reinforced by negative SST anomalies over the eastern tropical Pacific.

During MAM, a stronger connection between the SAM trends and eastern tropical Pacific cooling is noted. The eastern tropical Pacific cold SST years are associated with anomalous poleward momentum fluxes throughout the upper troposphere and a strengthened lower tropospheric meridional temperature gradient across all of the SH middle latitudes (between 45 and $65^{\circ} \mathrm{S}$ ), both of which produce positive zonal wind anomalies between 50 and $60^{\circ} \mathrm{S}$. The positive Marshall SAM index years during MAM again appear linked to stratospheretroposphere coupling, but all of these events occurred prior to 2001 suggesting that the portion of the MAM positive SAM trend forced by ozone depletion was strongest in the earlier part of the period. After 2000, the positive SAM index years during MAM have been weaker than those prior to 2001 and three recent positive SAM years $(2010,2011,2014)$ occurred with strong negative SST anomalies over the eastern tropical Pacific. Most importantly, the zonal wind anomalies associated with positive SAM index years are inconsistent with the MAM zonal wind trends over 1979-2014, while zonal wind anomalies associated with cooling in the eastern tropical Pacific project almost perfectly onto the MAM trends.

Although additional modeling work is needed to confirm the post-2000 tropical forcing of the SAM, observational results presented here indicate circulation anomalies associated with recent eastern tropical Pacific cooling project strongly onto the DJF and MAM positive zonal wind trends between 50 and $60^{\circ} \mathrm{S}$ and likely contributed to the post-2000 positive SAM trend, especially during MAM. It is also found that the observed strengthening of the tropospheric westerlies during DJF is more related to stratospheric ozone depletion than compared to MAM, 
suggesting the impact of ozone depletion on post-2000 SAM trends during MAM may not be robust, and forcing from the tropical Pacific may play a more important role in this season.

\subsection{Tropical Pacific Relationships with East Antarctic Cooling during Austral Autumn}

Results presented in Chapter 4.2 show that during MAM, the rate of cooling along coastal East Antarctica increased in magnitude after 1979 across two distinct regions: between 0 and $40^{\circ} \mathrm{E}$ at Novolazarevskaya and Syowa stations, and between 105 and $150^{\circ} \mathrm{E}$ at Casey and Dumont d'Urville stations. Across the central East Antarctic coast, weak warming occurred at Mawson and Davis stations after 1979. The regional nature of these temperature trends is inconsistent with SAM-related cooling and more so reflects local changes in regional circulation and associated thermal advection patterns. The recent La Niña-like trend (indicated by a positive trend in the SOI) and increasing SSTs over the western tropical Pacific (not related to ENSO) during MAM each are associated with distinct poleward propagating wavetrains emanating out of the western tropical Pacific that are associated with region circulation changes that are consistent with the post-1979 regional East Antarctic cooling.

The La Niña trend is associated with a wavetrain closely resembling the PSA pattern with anticyclonic circulation anomalies over the high-latitude South Atlantic that locally intensifies southwesterly winds and cold air advection across Novolazarevskaya and Syowa. The positive SOI trend is linearly congruent with around $40 \%$ of the post- 1979 cooling at Novolazarevskya and Syowa, which is equal in magnitude to the cooling associated with the positive SAM index trend.

Warming over the western tropical Pacific (not related to ENSO) is associated with a meridional wavetrain that extends from southwest Australia to the eastern East Antarctic coast. It consists of an anomalous ridge over southwest Australia and a downstream trough over eastern East Antarctica and the Ross Ice Shelf. The meridional wavetrain is associated with strong poleward momentum fluxes along the eastern East Antarctic coast that locally strengthen westerly / southwesterly winds and cold air advection near Casey and Dumont. The positive western tropical Pacific residual SST trend is linearly congruent with around $60 \%$ of the post1979 cooling at Casey and Dumont d'Urville, while the positive trend in the SAM index is congruent with only around $50 \%$ of the cooling there. 
The observation-based statistical analysis presented in this study suggests tropical Pacific climate variability has the potential to significantly influence the climate of East Antarctica, in addition to variability in the SAM. However, more work is needed to better understand these relationships. Numerical simulations are needed to confirm the results of this study, and to further investigate how western tropical Pacific climate variability independent of ENSO affects Antarctic climate. Modeling of the MAM La Niña-related and western tropical Pacific SST warming-related forcing is necessary to more fully understand the statistical relationships presented here, and to identify nonlinear relationships. It is not clear whether these coastal East Antarctic temperature changes are a result of anthropogenic climate change or part of natural decadal-scale variability due to the relatively short observational record over the high southern latitudes (Steig et al. 2013; Jones et al. 2016a), but modeling these potential mechanisms can lead to an increased understanding of how East Antarctica's climate may evolve in the coming century in response to tropical decadal variability.

\subsection{SPCZ Relationships with West Antarctic Warming during Austral Spring}

The results presented in Chapter 4.3 show that the regional circulation trends observed across the South Pacific and South Atlantic during SON are not stationary in time. Instead, they are part of a dynamic pattern that develops and dissipates over the two-month period of September to October, propagating eastward across the South Pacific to the South Atlantic. Furthermore, this study finds strong evidence that the primary forcing for these circulation trends is a significant increase in tropical deep convection along the poleward portion of the SPCZ during September, and a resultant Rossby wavetrain that roughly follows a great circle trajectory across the South Pacific to the South Atlantic from September to October. The increase in deep convection along the poleward side of the SPCZ during September appears linked to an increase in surface convergence from significant increases in surface pressure across the eastern half of the tropical Pacific during September, and increases in surface easterly winds that converge along the poleward side of the SPCZ. The increased surface easterlies / surface convergence on the poleward side of the SPCZ is most marked in September, explaining why the increase in convection is strongest in September. 
Consistent with the September and October circulation trends are significant regional trends in 2-m temperatures, sea ice concentration, and meridional temperature advection. The ASL exhibits the most marked deepening during September, which brings increased warm, northeasterly flow to western West Antarctica and the Ross Ice Shelf, and is consistent with around half of the significant warming found there during September. The circulation trends shift east toward the Peninsula during October with increased anticyclonic circulation over the South Atlantic and cyclonic circulation west of the Antarctic Peninsula. The October circulation allows cold, southerly flow to develop over central West Antarctica (explaining the strong regional nature of West Antarctic warming trends, i.e., the absence of warming over central West Antarctica in the SON-average 2-m temperature trends) and brings warm, northerly flow to the western Peninsula that is consistent with around half of the October warming seen there. The circulation trends become much more regional during November with no clear tropical signal; however, significant trends in surface northerly wind is noted in the South Pacific near $150^{\circ} \mathrm{W}$, which appears tied the November warming seen across western West Antarctica in November.

In reality, it is unlikely that Rossby wave forcing and propagation operates perfectly on calendar-month timescales, as is implied in the monthly-based analysis shown here.

Relationships using daily OLR and height fields were also investigated (not shown) and they support the hypotheses presented here and are consistent with previous studies (e.g., Renwick and Revell 1999). The wave propagation is strongest early in spring, and weakens towards the end of spring as the background circulation weakens. The wave response peaked on average around a week after the maximum OLR anomaly in the SPCZ. It was also found that the South Pacific mid-latitude jet strengthens from September to October (as noted by many previous studies), which partly explains why the wavetrain propagates eastward across the South Pacific during these two months.

\subsection{Temporal and Spatial Impacts of ENSO and SAM on Antarctic Peninsula Climate}

Results presented in Chapter 4.4 indicate there is a spatially and seasonally dependent impact of atmospheric circulation changes associated with ENSO and SAM phases on Antarctica Peninsula temperatures. During DJF, the SAM index is significantly correlated with both western and northeast Peninsula temperatures, but the relationship is of opposite sign between the two 
locations (positive SAM conditions are associated with warming on the northeast Peninsula and cooling on the western Peninsula). Therefore, when western and northeast Peninsula temperatures are averaged together, the SAM index correlation appears weak during DJF. The cause for the negative correlation between the SAM index and western Peninsula temperatures during DJF is related to the local circulation across the Peninsula related to SAM variability being largely zonal during DJF, and as westerly winds (associated with positive SAM conditions) encounter the steep Peninsula topography, it splits bringing a slight (cold) southwesterly wind to the northwest Peninsula (consistent with Orr et al. 2004). However, the exact cause is not fully understood, and higher resolution dynamical modeling would be helpful to further understand this relationship during DJF.

During MAM, it is found that circulation changes associated with the SAM explain significantly more of the Peninsula climate variability than tropical forcing associated with ENSO. Although previous studies have shown SST trends in the tropical Pacific are associated with temperature change on the Peninsula during MAM, interannual relationships with tropical Pacific variability are weak, especially across the northeast Peninsula. Much stronger ENSOPeninsula temperature relationships are seen during JJA and SON across both sides of the Peninsula.

As shown in Clem and Fogt (2013) during SON, there is a spatial dependency of the ENSO and SAM impact on Peninsula temperatures. It is found that the ENSO relationship with Peninsula temperatures is strongest on the western Peninsula during all seasons outside of DJF, with the overall strength of the relationship being strongest during JJA and SON. Meanwhile, the northeast Peninsula is significantly correlated with the SAM index during all seasons. The SAMnortheast Peninsula relationship exists year-round due to the SAM impact on zonal winds traversing the northern Peninsula and resultant lee-side Föhn winds on the eastern Peninsula. During all seasons, when the SAM is in its positive phase, positive zonal wind anomalies are observed over the northeast Peninsula which allows winds to flow over the Peninsula resulting in lee-side adiabatic warming over the northeast Peninsula. This zonal flow is more closely tied to the zonal circulation anomalies over the Atlantic and Indian Oceans, which resemble a more zonally symmetric, positive SAM structure (Ding et al. 2012b; Fogt et al. 2012a). The ENSO impact on northeast Peninsula temperatures is significantly weaker during all seasons because ENSO shows no relationship with the zonal component of the wind across the Peninsula; instead, 
ENSO is much more strongly related to meridional circulation and meridional thermal advection associated with variability in the ASL, which primarily affects the western Peninsula.

\subsection{Concluding Remarks and Future Work}

Results presented in this study highlight that the tropics play a critical role in the highlatitude Southern Hemisphere climate system through ubiquitous Rossby wave propagation and poleward momentum fluxes, which significantly affects surface climate variability throughout the Antarctic. During summer and autumn, post-1979 tropical Pacific momentum forcing of the westerly winds has occurred simultaneously with upper-tropospheric thermal forcing from spring ozone depletion to drive a strengthening of the westerlies. Therefore, ozone depletion alone does not fully explain the processes driving the summer and autumn westerly wind increases, and this study highlights that both processes need to be taken into consideration for future projections of the SH westerlies and their associated impact on Antarctic climate as the ozone hole recovers.

This study also finds that the tropics have a profound impact on Antarctic climate through poleward propagation of Rossby waves. During autumn, it is shown that recent cooling of East Antarctica is more consistent with wavetrains emanating from the tropical Pacific rather than a strengthening of the westerlies, the latter of which was previously thought to be the sole driver the East Antarctic cooling. Therefore, this study significantly adds to our understanding of the impact of the tropics on Antarctic-wide climate, as it is shown that regional circulation changes associated with tropically-forced wavetrains have a significant impact on East Antarctic climate as well as West Antarctic climate. This knowledge can be transferred over to climate modelers to improve future projections of East Antarctic climate change as the Antarctic ozone hole recovers, as it is demonstrated here that future tropical variability has the potential to amplify or offset regional climate responses to changes in the westerlies associated with ozone recovery.

During spring, when several studies have shown tropically-forced wavetrains to be associated with the warming of West Antarctica and the Antarctic Peninsula, this study identifies a specific forcing mechanism likely responsible for forcing these wavetrains. Further, it shows that there may not be two separate wavetrains, which has been suggested by previous studies, but instead there is one wavetrain that undergoes dramatic changes in structure from early to late spring. Therefore, this study provides a more comprehensive understanding of the how the 
tropics impact Antarctic climate, especially during spring, by identifying the SPCZ as a key genesis region of poleward propagating Rossby waves. This allows for improved West Antarctic climate projections, including mass balance fluxes induced by surface climate variability, by better understanding the importance of SPCZ-forced teleconnections and their seasonal and monthly variability.

More work is needed to verify many of the findings presented in this study. In particular, model experiments are needed to isolate the impact of the tropics on the $\mathrm{SH}$ atmospheric circulation. Specific future work includes exploring the role of the sub-tropical and mid-latitude jet on Rossby wave propagation from the SPCZ. By isolating the SPCZ and examining how changes only in the strength and position of the Southern Hemisphere jets, surface heating / convective anomalies along the SPCZ will be performed to determine how the structure of the jets mediates the impact of the SPCZ on Antarctic climate. Furthermore, modeling of different tropical basins is needed, particularly during autumn, to confirm the source of Rossby wave propagation, particularly from western Australia, and how that impacts eastern East Antarctica. This study finds that convective variability over the eastern tropical Indian Ocean is likely responsible for the meridional wavetrain to East Antarctica during autumn, but to confirm this, surface heating / convective forcing in this region needs to be simulated and the precise Rossby wave source needs to be identified.

Altogether, this study significantly advances our knowledge on how the tropics impact Antarctica on the large-scale through its impact on the westerlies, on the regional scale through its impact on regional patterns of circulation, thermal advection, and sea ice concentration, and on the local scale through its impact on the local topography of the Antarctic Peninsula. Therefore, future climate variability and change across Antarctica and associated mass fluxes and global sea levels are closely tied to circulation changes associated with the tropical variability. If climate models are to accurately predict future climate changes across the Antarctic and associated sea level rise, they must accurately predict future variability in the tropics and they must accurately depict these important tropical-high-latitude teleconnections. Building off the results of this study by isolating the impact of the tropics through model simulations will allow for significant improvements in global climate and sea level projection, allowing for greater clarity and certainty of what the physical landscape of the planet will look like in the coming decades and centuries and the impact this will have on humankind. 


\section{REFERENCES}

Alexander, M. A., I. Bladé, M. Newman, J. R. Lanzante, N. C. Lau, and J. D. Scott, 2002: The Atmospheric Bridge: The Influence of ENSO Teleconnections on Air-Sea Interaction over the Global Oceans. J. Clim., 15, 2205-2231.

Arblaster, J. M., and G. A. Meehl, 2006: Contributions of External Forcings to Southern Annular Mode Trends. J. Clim., 19, 2896-2905.

Aronson, R. B., and CoAuthors, 2015: No barrier to emergence of bathyal king crabs on the Antarctic shelf. Proc. Natl. Acad. Sci., 112, 42, 12997-13002.

Baines, P. G., and K. Fraedrich, 1989: Topographic effects on the mean tropospheric flow patterns around Antarctica. J. Atmos. Sci., 46, 3401-3415.

Bals-Elsholz, T. M., E. H. Atallah, L. F. Bosart, T. A. Wasula, M. J. Cempa, and A. R. Lupo, 2001: The Wintertime Southern Hemisphere Split Jet: Structure, Variability, and Evolution. J. Clim., 14, 4191-4215.

Barnes, E. A., and D. L. Hartmann, 2010: Dynamical Feedbacks of the Southern Annular Mode in Winter and Summer. J. Atmos. Sci., 67, 2320-2330.

Bjerknes, J., 1969: Atmospheric Teleconnections from the Equatorial Pacific. Mon. Wea. Rev., 97, 163-172.

Bracegirdle, T. J., 2012: Climatology and recent increase of westerly winds over the Amundsen Sea derived from six reanalyses. Int. J. Climatol., 33, 843-851.

Bracegirdle, T. J., and G. J. Marshall, 2012: The reliability of Antarctic tropospheric pressure and temperature in the latest global reanalyses. J. Clim., 25, 7138-7146.

Bromwich, D. H., J. P. Nicolas, A. J. Monaghan, M. A. Lazzara, L. M. Keller, G. A. Weidner, and A. B. Wilson, 2013: Central West Antarctica among the most rapidly warming regions on Earth. Nat. Geosci., 6, 139-145.

Bromwich, D. H., J. P. Nicolas, and A. J. Monaghan, 2011: An assessment of precipitation changes over Antarctica and the Southern Ocean since 1989 in contemporary global reanalyses. J. Clim., 24, 4189-4209.

Bromwich, D. H., and R. L. Fogt, 2004: Strong trends in the skill of the ERA-40 and NCEPNCAR reanalyses in the high and middle latitudes of the Southern Hemisphere, 19582001. J. Clim., 17, 4603-4619.

Chapman, W. L., and J. E. Walsh, 2007: A Synthesis of Antarctic Temperatures. J. Clim., 20, 4096-4117. 
Chen, D., T. Lian, C. Fu, M. A. Cane, T. Tang, R. Murtugudde, X. Song, Q. Wu, and L. Zhou, 2015: Strong influence of westerly wind bursts on El Niño diversity. Nature Geosci., 8 , 339-345.

Clem, K. R., J. A. Renwick, and J. McGregor: 2016a: Relationship between eastern tropical Pacific cooling and recent trends in the Southern Hemisphere zonal-mean circulation. Clim. Dyn., DOI 10.1007/s00382-016-3329-7.

Clem, K. R., J. A. Renwick, J. McGregor, and R. L. Fogt, 2016b: The Relative Influence of ENSO and SAM on Antarctic Peninsula Climate. J. Geophs. Res. Atmos., 121, $9324-$ 9341.

Clem, K. R., and J. A. Renwick, 2015: Austral Spring Southern Hemisphere Circulation and Temperature Changes and Links to the SPCZ. J. Clim., 28, 7371-7384.

Clem, K. R., and R. L. Fogt, 2015: South Pacific circulation changes and their connection to the tropics and regional Antarctic warming in austral spring, 1979-2012. J. Geophys. Res. Atmos., 120, doi:10.1002/2014JD022940.

Clem, K. R., and R. L. Fogt, 2013: Varying roles of ENSO and SAM on the Antarctic Peninsula climate in austral spring. J. Geophys. Res., 118, doi:10.1002/jgrd.50860.

Codron, F., 2005: Relation between Annular Modes and the Mean State: Southern Hemisphere Summer. J. Clim., 18, 320-330.

Cohen J., and P. Cohen, 1983: Applied Multiple Regression/Correlation Analysis for the Behavioral Sciences. Taylor \& Francis, 545 pp.

DeConto, R. M., and D. Pollard, 2016: Contribution of Antarctica to past and future sea-level rise. Nature, 531, 591-597, doi:10.1038/nature17145.

Dee, D. P., et al., 2011: The ERA-Interim reanalysis: configuration and performance of the data assimilation system. Q. J. R. Meteorol. Soc., 137, 553-597.

Ding, Q., and E. J. Steig, 2013: Temperature change on the Antarctic Peninsula linked to the Tropical Pacific. J. Clim., 26, 7570-7585.

Ding, H., N. S. Keenlyside, and M. Latif, 2012a: Impact of the Equatorial Atlantic on the El Niño Southern Oscillation. Clim. Dyn., 38, 1965-1972.

Ding, Q., E. J. Steig, D. S. Battisti, and J. M. Wallace, 2012b: Influence of the Tropics on the Southern Annular Mode. J. Clim., 25, 6330-6348.

Ding, Q., E. J. Steig, D. S. Battisti, and M. Küttel, 2011: Winter warming in West Antarctica caused by central tropical Pacific warming. Nat. Geosci., 4, 398-403. 
Edmon, H. J., B. J. Hoskins, and M. E. McIntyre, 1980: Eliassen-Palm Cross Sections for the Troposphere. J. Atmos. Sci., 37, 2600-2616.

England, M. H., S. McGregor, P. Spence, G. A. Meehl, A. Timmermann, W. Cai, A. Sen Gupta, M. J. McPhaden, A. Purich, and A. Santoso, 2014: Recent intensification of wind-driven circulation in the Pacific and the ongoing warming hiatus. Nature Clim. Change, 4, 222227.

Fahnestock, M. A., W. Abdalati, and C. A. Shuman, 2002: Long melt seasons on ice shelves of the Antarctic Peninsula: an analysis using satellite-based microwave emission measurements. Ann. Glaciol., 34, 127-133.

Farman, J. C., B. G. Gardiner, and J. D. Shanklin, 1985: Large losses of total ozone in Antarctica reveal seasonal ClOx/NOx interaction. Nature, 315, 207-210.

Feldstein, S. B., 1998: An observational study of the intraseasonal poleward propagation of zonal mean flow anomalies. J. Atmos. Sci., 55, 2516-2529.

Fogt, R. L., J. M. Jones, and J. Renwick, 2012a: Seasonal zonal asymmetries in the Southern Annular Mode and their impact on regional temperature anomalies. J. Clim., 25, 62536270 .

Fogt, R. L., A. J. Wovrosh, R. A. Langen, and I. Simmonds, 2012b: The characteristic variability and connection to the underlying synoptic activity of the Amundsen-Bellingshausen Seas Low. J. Geophys. Res., 117, D07111, doi:10.1029/2011JD017337.

Fogt, R. L., D. H. Bromwich, and K. M. Hines, 2011: Understanding the SAM influence on the South Pacific ENSO teleconnection. Clim. Dyn., 36, 1555-1576.

Fogt R. L., and D. H. Bromwich, 2006: Decadal variability of the ENSO teleconnection to the high latitude South Pacific governed by coupling with the Southern Annular Mode. $J$. Clim., 19, 979-997.

Folland, C. K., J. A. Renwick, M. J. Salinger, and A. B. Mullan, 2002: Relative influences of the Interdecadal Pacific Oscillation and ENSO on the South Pacific Convergence Zone. Geophys. Res. Lett., 29, doi:10.1029/2001GL014201.

Fyfe, J. C., and D. J. Lorenz, 2005: Characterizing Midlatitude Jet Variability: Lessons from a Simple GCM. J. Clim., 18, 3400-3404.

Garreaud, R., and D. S. Battisti, 1999: Interannual (ENSO) and interdecadal (ENSO-like) variability in the Southern Hemisphere tropospheric circulation. J. Clim., 12, 2113-2123.

Ghil, M., and K. Mo, 1991: Intraseasonal oscillations in the global atmosphere. Part II: Southern Hemisphere. J. Atmos. Sci., 48, 780-790. 
Gillett, N. P., and D. W. J. Thompson, 2003: Simulation of recent Southern Hemisphere climate change. Science, 302, 273-275.

Gong, T., S. B. Feldstein, and D. Luo, 2013: A simple GCM study on the relationship between ENSO and the Southern Annular Mode. J. Atmos. Sci., 70, 1821-1832.

Gong, T., S. B. Feldstein, and D. Luo, 2010: The impact of ENSO on wave breaking and southern annular mode events. J. Atmos. Sci., 67, 2854-2870.

Held, I. M., S. W. Lyons, and S. Nigam, 1989: Transients and the extratropical response to El Niño. J. Atmos. Sci., 46, 163-174.

Holland, P. R., 2014: The seasonality of Antarctic sea ice trends. Geophys. Res. Lett., doi: $10.1002 / 2014 \mathrm{~g} 1060172$.

Holland, P. R., and R. Kwok, 2012: Wind-driven trends in Antarctic sea-ice drift. Nat. Geosci., 5, 872-875.

Hosking, J. S., A. Orr, G. J. Marshall, J. Turner, and T. Phillips, 2013: The influence of the Amundsen-Bellingshausen Seas Low on the climate of West Antarctica and its representation in coupled climate model simulations. J. Clim., 17, 6633-6648.

Hoskins, B. J., and K. I. Hodges, 2005: A New Perspective on Southern Hemisphere Storm Tracks. J. Clim., 18, 4108-4129.

Hoskins, B. J., and D. J. Karoly, 1981: The steady linear response of a spherical atmosphere to thermal and orographic forcing. J. Atmos. Sci., 38, 1179-1196.

Huang, B., V. F. Banzon, E. Freeman, J. Lawrimore, W. Liu, T. C. Peterson, T. M. Smith, P. W. Thorne, S. D. Woodruff, and H-M. Zhang, 2014: Extended Reconstructed Sea Surface Temperature Version 4 (ERSST.v4). Part I: Upgrades and Intercomparisons. J. Clim., 28, 911-930.

Joughin, I., B. E. Smith, and B. Medley, 2014: Marine Ice Sheet Collapse Potentially Under Way for the Thwaites Glacier Basin, West Antarctica. Science, 344, 735-738.

Joughin, I., E. Rignot, C. E. Rosanova, B. K. Lucchitta, and J. Bohlander, 2003: Timing of Recent Accelerations of Pine Island Glacier, Antarctica. Geophys. Res. Lett., 30, 1706, doi:10.1029/2003GL017609.

Jones, J. M, and CoAuthors, 2016a: Assessing recent trends in high-latitude Southern Hemisphere surface climate. Nature Clim. Change, 6, 917-926.

Jones, R. W., I. A. Renfrew, A. Orr, B. G. M. Webber, D. M. Holland, and M. A. Lazzara, 2016b: Evaluation of four global reanalysis products using in-situ observations in the 
Amundsen Sea Embayment, Antarctica: Amundsen Sea reanalyses evaluation. $J$. Geophys. Res. Atmos., 121, doi:10.1002/2015JD024680.

Jones, J. M., R. L. Fogt, M. Widmann, G. J. Marshall, P. D. Jones, and M. Visbeck, 2009: Historical SAM Variability. Part I: Century-Length Seasonal Reconstructions. J. Clim., 22, 5319-5345.

Kalnay, E., et al., 1996: The NCEP-NCAR 40-year reanalysis project. Bull. Am. Meteorol. Soc., 77, 437-471.

Karoly, D. J., 1989: Southern Hemisphere circulation features associated with El Niño-Southern Oscillation events. J. Clim., 2, 1239-1252.

Kidson, J. W., 1999: Principal Modes of Southern Hemisphere Low-Frequency Variability Obtained from NCEP-NCAR Reanalyses. J. Clim., 12, 2808-2830.

Kidson J. W., 1988: Interannual variations in the Southern Hemisphere circulation. J. Clim., 1, $1177-1198$.

Kiladis, G. N., H. von Storch, and H. van Loon, 1989: Origin of the South Pacific Convergence Zone. J. Clim., 2, 1185-1195.

King, J. C., 1994: Recent Climate Variability in the Vicinity of the Antarctic Peninsula. Int. J. Climatol., 14, 357-369.

Kobayashi, S., and CoAuthors, 2015: The JRA-55 reanalysis: General specifications and basic characteristics. J. Meteorol. Soc. Jpn., 93, doi:10.2151/jmsj.2015-001.

Kosaka, Y., and S.-P. Xie, 2013: Recent global-warming hiatus tied to equatorial Pacific surface cooling. Nature, 501, 403-407.

Kucharski, F., A. Parvin, B. Rodriguez-Fonseca, R. Farneti, M. Martin-Rey, I. Polo, E. Mohino, T. Losada, and C. R. Mechoso, 2016: The Teleconnection of the Tropical Atlantic to Indo-Pacific Sea Surface Temperatures on Inter-Annual to Centennial Time Scales: A Review of Recent Findings. Atmosphere, doi:10.3390/atmos7020029.

Kucharski, F., I.-S. Kang, R. Farneti, and L. Feudale, 2011: Tropical Pacific response to $20^{\text {th }}$ century Atlantic warming. Geophys. Res. Lett., 38, doi:10.1029/2010GL046248.

Kwok, R., and J. Comiso, 2002: Spatial patterns of variability in Antarctic surface temperature: Connections to the Southern Hemisphere Annular Mode and the Southern Oscillation. Geophys. Res. Lett., 29, doi:10.1029/2002GL015415.

L'Heureux, M. L., and D. W. J. Thompson, 2006: Observed relationships between the El-Niño / Southern Oscillation and the extratropical zonal-mean circulation. J. Clim., 19, 276-287. 
Lachlan-Cope, T. A., and W. Connolley, 2006: Teleconnections between the tropical Pacific and the Amundsen-Bellingshausens Sea: Role of the El Niño/Southern Oscillation. $J$. Geophys. Res., 111, doi:10.1029/2005JD006386.

Lachlan-Cope, T. A., W. Connolley, and J. Turner, 2001: The role of the non-axisymmetric antarctic orography in forcing the observed pattern of variability of the Antarctic climate. Geophys. Res. Lett., 28, doi:10.1029/2001GL013465.

Landschützer, P, and CoAuthors, 2015: The reinvigoration of the Southern Ocean carbon sink. Science, 349, 1221-1224.

Lau, K.-M., and S. Yang, 2002: Walker Circulation. Elsevier Science, 6.

Lau, K.-M., P.-J. Sheu, and I.-S. Kang, 1994: Multiscale low-frequency circulation modes in the global atmosphere. J. Atmos. Sci., 51, 1169-1193.

Lefebvre, W., H. Goosse, R. Timmermann, and T. Fichefet, 2004: Influence of the Southern Annular Mode on the sea ice-ocean system. J. Geophys. Res., 109, C09005, doi:10.1029/2004JC002403.

Li, X., S.-P. Xie, S. T. Gille, and C. Yoo, 2015: Atlantic-induced pan-tropical climate change over the past three decades. Nature Clim. Change, 6, 275-279.

Li, X., D. M. Holland, E. P. Gerber, and C. Yoo, 2014: Impacts of the north and tropical Atlantic Ocean on the Antarctic Peninsula and sea ice. Nature, 505, 538-542.

Liebmann, B., and C. A. Smith, 1996: Description of a Complete (Interpolated) Outgoing Longwave Radiation Dataset. Bull. Amer. Meteorol. Soc., 77, 1275-1277.

Limpasuvan, V., and D. L. Hartmann, 1999: Eddies and the annular modes of climate variability. Geophys. Res. Lett., 26, 3133-3136.

Liu, W., B. Huang, P. W. Thorne, V. F. Banzon, H-M. Zhang, E. Freeman, J. Lawrimore, T. C. Peterson, T. M. Smith, and S. D. Woodruff, 2014: Extended Reconstructed Sea Surface Temperature Version 4 (ERSST.v4): Part II. Parametric and Structural Uncertainty Estimations. J. Clim., 28, 931-951.

Lorenz, D. J., and D. L. Hartmann, 2001: Eddy-Zonal Flow Feedback in the Southern Hemisphere. J. Atmos. Sci., 58, 3312-3327.

Mantua, N. J., and S. R. Hare, 2002: The Pacific decadal oscillation. J. Oceanography, 58, 2544.

Mantua, N. J., S. R. Hare, Y. Zhang, J. M. Wallace, and R. C. Francis, 1997: A Pacific interdecadal climate oscillation with impacts on salmon production. Bull. Amer. Meteorol. Soc., 78, 1069-1079. 
Marshall, G. J., and D. W. J. Thompson, 2016: The signatures of large-scale patterns of atmospheric variability in Antarctic surface temperatures. J. Geophys. Res. Atmos., 121, 3276-3289.

Marshall, G. J., 2007: Half-century seasonal relationships between the Southern Annular Mode and Antarctic temperatures. Int. J. Climatol., 27, 373-383.

Marshall, G. J., A. Orr, N. P. M. van Lipzig, and J. C. King, 2006: The impact of a changing Southern Hemisphere Annular Mode on Antarctic Peninsula summer temperatures. $J$. Clim., 19, 5388-5404.

Marshall, G. J., P. A. Stott, J. Turner, W. M. Connolley, J. C. King, and T. A. Lachlan-Cope, 2004: Causes of exceptional atmospheric circulation changes in the Southern Hemisphere. Geophys. Res. Lett., 31, L14205, doi:10.1029/2004GL019952.

Marshall, G. J., 2003: Trends in the Southern Annular Mode from observations and reanalyses. $J$. Clim., 16, 4134-4143.

McGregor, S., A. Timmermann, M. F. Stuecker, M. H. England, M. Merrifield, F. F. Jin, and Y. Chikamoto, 2014: Recent Walker circulation strengthening and Pacific cooling amplified by Atlantic warming. Nature Clim. Change, doi:10.1038/NCLIMATE2330.

Meehl G. A., A. Hu, J. M. Arblaster, J. Y. Fasullo, and K. E. Trenberth, 2013: Externally forced and internally generated decadal climate variability associated with the Interdecadal Pacific Oscillation. J. Clim., 26, 7298-7310.

Meredith, M. P., and J. C. King, 2005: Rapid climate change in the ocean west of the Antarctic Peninsula during the second half of the 20th century. Geophys. Res. Lett., 32, doi:10.1029/2005GL024042.

Miller, R. L., G. A. Schmidt, and D. T. Shindell, 2006: Forced annular variations in the 20th century Intergovernmental Panel on Climate Change Fourth Assessment Report models. J. Geophys. Res., 111, D18101, doi:10.1029/2005JD006323.

Mo, K. C., and W. Higgins, 1998: The Pacific-South American modes and tropical convection during the Southern Hemisphere winter. Mon. Wea. Rev., 126, 1581-1596.

Mo, K.C., and J. N. Paegle, 2001: The Pacific-South American modes and their downstream effects. Int. J. Climatol., 21, 1211-1229.

Monaghan, A. J., D. H. Bromwich, W. Chapman, and J. C. Comiso, 2008: Recent variability and trends of Antarctic near-surface temperature. J. Geophys. Res., 113, D04105, doi:10.1029/2007JD009094. 
Nakamura, H., and A. Shimpo, 2004: Seasonal Variations in the Southern Hemisphere Storm Tracks and Jet Streams as Revealed in a Reanalysis Dataset. J. Clim., 17, 1828-1844.

Nicolas, J. P., and D. H. Bromwich, 2014: New Reconstruction of Antarctic Near-Surface Temperatures: Multidecadal Trends and Reliability of Global Reanalyses. J. Clim., 27, doi:10.1175/JCLI-D-13-00733.1, 8070-8093.

Nicolas, J. P., and D. H. Bromwich, 2011: Climate of West Antarctica and Influence of Marine Air Intrusions. J. Clim., 24, 49-67.

O’Donnell, R., N. Lewis, S. McIntyre, J. Condon, 2011: Improved Methods for PCA-Based Reconstructions: Case Study Using the Steig et al. (2009) Antarctic Temperature Reconstruction. J. Clim., 24, 2099-2115.

Oort, A. H., and J. J. Yienger, 1996: Observed interannual variability in the Hadley circulation and its connection to ENSO. J. Clim., 9, 2751-2767.

Orr, A., G. J. Marshall, J. C. R. Hunt, J. Sommeria, C. G. Wang, N. P. M. van Lipzig, D. Cresswell, and J. C. King, 2008: Characteristics of Summer Airflow over the Antarctic Peninsula in Response to Recent Strengthening of Westerly Circumpolar Winds. $J$. Atmos. Sci., 65, 1396-1413.

Orr, A., D. Cresswell, G. J. Marshall, J. C. R. Hunt, J. Sommeria, C. G. Wang, and M. Light, 2004: A "low-level" explanation for the recent large warming trend over the western Antarctic Peninsula involving blocked winds and changes in zonal circulation. Geophys. Res. Lett., 31, L06204, doi:10.1029/2003GL019160.

Peixoto J. P., and A. H. Oort, 1992: Physics of Climate. American Institute of Physics, 520 pp.

Polvani, L. M., D. W. Waugh, G. J. P. Correa, and S. W. Son, 2011: Stratospheric Ozone Depletion: The Main Driver of Twentieth-Century Atmospheric Circulation Changes in the Southern Hemisphere. J. Clim., 24, 795-812.

Pritchard, H. D., S. R. M. Ligtenberg, H. A. Fricker, D. G. Vaughan, M. R. van den Broeke, and L. Padman, 2012: Antarctic ice-sheet loss driven by basal melting of ice shelves. Nature, 484, 502-505, doi:10.1038/nature10968.

Pritchard, H. D., R. J. Arthern, D. G. Vaughan, and L. A. Edwards, 2009: Extensive dynamic thinning on the margins of the Greenland and Antarctic ice sheets. Nature, 461, 971-975.

Purich, A., M. H. England, W. Cai, Y. Chikamoto, A. Timmermann, J. C. Fyfe, L. Frankcombe, G. A. Meehl, and J. M. Arblaster, 2016: Tropical Pacific SSTs Drivers of Recent Antarctic Sea Ice Trends. J. Clim., 29, 8931-8948.

Raphael, M. N., G. J. Marshall, J. Turner, R. L. Fogt, D. Schneider, D. A. Dixon, J. S. Hosking, J. M. Jones, and W. R. Hobbs, 2016: The Amundsen Sea Low: Variability, Change, and 
Impact on Antarctic Climate. Bull. Amer. Meteor. Soc., 111-121, DOI:10.1175/BAMS-D14-00018.1.

Rayner, N. A., D. E. Parker, E. B. Horton, C. K. Folland, L. V. Alexander, D. P. Rowell, E. C. Kent, and A. Kaplan, 2003: Global analyses of sea surface temperature, sea ice, and night marine air temperature since the late nineteenth century. J. Geophys. Res., 108, doi:10.1029/2002JD002670.

Renwick, J. A., and M. J. Revell, 1999: Blocking over the South Pacific and Rossby wave propagation. Mon. Wea. Rev., 127, 2233-2247.

Rienecker, M. M., and CoAuthors, 2011: MERRA: NASA's Modern-Era Retrospective Analysis for Research and Applications. J. Clim., 24, 3624-3648.

Rignot, E., S. Jacobs, J. Mouginot, and B. Scheuchl, 2013: Ice-Shelf Melting Around Antarctica. Science, 341, 266-270.

Rignot, E., J. L. Bamber, M. R. van den Broeke, C. Davis, Y. Li, W. J. van de Berg, and E. van Meijgaard, 2008: Recent Antarctic ice mass loss from radar interferometry and regional climate modeling. Nat. Geosci., 1, 106-110.

Rignot, E., 2006: Changes in ice dynamics and mass balance of the Antarctic ice sheet. Phil. Trans. R. Soc. A, 364, 1637-1655.

Rignot, E., G. Casassa, P. Gogineni, W. Krabill, A. Rivera, and R. Thomas, 2004: Accelerated ice discharge from the Antarctic Peninsula following the collapse of Larsen B ice shelf. Geophs. Res. Lett., 31, L18401, doi:10.1029/2004GL020697.

Rogers, J. C., and H. van Loon, 1982: Spatial variability of sea level pressure and 500mb height anomalies over the Southern Hemisphere. Mon. Wea. Rev., 110, 1375-1392.

Rott, H., W. Rack, R. Skvarca, H. De Angelis, 2002: Northern Larsen Ice Shelf, Antarctica: further retreat after collapse. Ann. Glaciol., 34, 277-282.

Saha, S., and CoAuthors, 2010: The NCEP climate forecast system reanalysis. Bull. Am. Meteorol. Soc., 91, 1015-1057, doi:10.1175/2010BAMS3001.1.

Scambos, T. A., C. Hulbe, M. Fahnestock, J. Bohlander, 2000: The link between climate warming and break-up of ice shelves in the Antarctic Peninsula. J. Glaciol., 46, 154, 516530 .

Scambos, T. A., J. A. Bohlander, C. A. Shuman, and P. Skvarca, 2004: Glacier acceleration and thinning after ice shelf collapse in the Larsen B embayment, Antarctica. Geophys. Res. Lett., 31, L18402, doi:10.1029/2004GL020670. 
Schneider, D., C. Deser, and T. Fan, 2015: Comparing the impacts of tropical SST variability and polar strospheric ozone loss on the Southern Ocean westerly winds. J. Clim., 28, 9350-9372.

Seager, R., N. Harnik, Y. Kushnir, W. Robinson, and J. Miller, 2003: Mechanisms of Hemispherically Symmetric Climate Variability. J. Clim., 16, 2960-2978.

Schneider, D. P., C. Deser, and Y. Okumura, 2012: An assessment and interpretation of the observed warming of West Antarctica in the austral spring. Clim. Dyn., 38, 323-347.

Shepherd, A., and Coauthors, 2012: A Reconciled Estimate of Ice-Sheet Mass Balance. Science, 338, $1183-1189$.

Shepherd, A., and D. Wingham, 2007: Recent Sea-Level Contributions of the Antarctic and Greenland Ice Sheets. Science, 315, 1529-1532.

Shepherd, A., D. Wingham, and E. Rignot, 2004: Warm ocean is eroding West Antarctic Ice Sheet. Geophys. Res. Lett., 31, L23402, doi:10.1029/2004GL021106.

Shepherd, A., D. J. Wingham, J. A. D. Mansley, and H. F. J. Corr, 2001: Inland Thinning of Pine Island Glacier, West Antarctica. Science, 291, 862-864.

Simmonds, I., K. Keay, and E-P Lim, 2003: Synoptic activity in the Seas around Antarctica. Mon. Wea. Rev., 131, 272-288.

Simpkins, G. R., S. McGregor, A. S. Taschetto, L. M. Ciasto, and M. H. England, 2014: Tropical Connections to Climatic Change in the Extratropical Southern Hemisphere: The Role of Atlantic SST Trends. J. Clim., 27, 4923-4936.

Skvarca, P., W. Rack, H. Rott, T. Ibarzábal y Donángelo, 1998: Evidence of recent climatic warming on the eastern Antarctic Peninsula. Ann. Glaciol., 27, 628-632.

Solomon, S., D. J. Ivy, D. Kinnison, M. J. Mills, R. R. Neely III, and A. Schmidt, 2016: Emergence of healing in the Antarctic ozone layer. Science, DOI: 10.1126/science.aae0061.

Son, S. W., and Coauthors, 2010: Impact of stratospheric ozone on Southern Hemisphere circulation change: A multimodel assessment. J. Geophys. Res. Atmos., 115, doi:10.1029/2010JD014271.

Stammerjohn, S. E., R. Massom, D. Rind, and D. Martinson, 2012: Regions of rapid sea ice change: An inter-hemispheric comparison. Geophys. Res. Lett., 39, doi:10.1029/2012GL050874.

Stammerjohn, S. E., D. G. Martinson, R. C. Smith, X. Yuan, and D. Rind, 2008: Trends in Antarctic annual sea ice retreat and advance and their relation to El Niño 
Southern Oscillation and Southern Annular Mode variability. J. Geophys. Res., 113, C03S90, doi:10.1029/2007JC004269.

Steig, E. J., Q. Ding, D. S. Battisti, and A. Jenkins, 2012: Tropical forcing of Circumpolar Deep Water Inflow and outlet glacier thinning in the Amundsen Sea Embayment, West Antarctica. Ann. Glaciol., 53, 19-28.

Steig, E. J., D. P. Schneider, S. D. Rutherford, M. E. Mann, J. C. Comiso, and D. T. Shindell, 2009: Warming of the Antarctic ice-sheet surface since the 1957 International Geophysical Year. Nature, 457, 459-462.

Swart N. C., J. C. Fyfe, N. Gillett, and G. J. Marshall, 2015: Comparing trends in the Southern Annular Mode and Surface Westerly Jet. J. Clim., 28, 8840-8859.

Szeredi, I., and D. J. Karoly, 1987: Horizontal structure of monthly fluctuations of the Southern Hemisphere troposphere from station data. Australian Met. Mag., 35, 119-129.

Thomas, R. and Coauthors, 2004: Accelerated Sea-Level Rise from West Antarctica. Science, 306, 255-258.

Thompson, D. W. J., and S. Solomon, 2002: Interpretation of recent Southern Hemisphere climate change. Science, 296, 895-899.

Thompson, D. W. J., and J. M. Wallace, 2000: Annular modes in the extratropical circulation. Part I: Month-to-month variability. J. Clim., 13, 1000-1016.

Thompson, D. W. J., J. M. Wallace, and G. C. Hegerl, 2000: Annular modes in the extratropical circulation. Part II: Trends. J. Clim., 13, 1018-1036.

Trenberth, K. E., J. T. Fasullo, G. Branstator, and A. S. Phillips, 2014: Seasonal aspects of the recent pause in surface warming. Nature Clim. Change, doi:10.1038/NCLIMATE2341.

Trenberth, K. E., and J. T. Fasullo, 2013: An apparent hiatus in global warming? Earth's Future, doi:10.1002/2013EF000165, 19-32.

Trenberth, K. E., G. W. Branstator, D. J. Karoly, A. Kumar, N.-C. Lau, and C. Ropelewski, 1998: Progress during TOGA in understanding and modeling global teleconnections associated with tropical sea surface temperatures. J. Geophys. Res., 103, 14291-14324.

Trenberth, K. E., 1997: The Definition of El Niño. Bull. Amer. Meteor. Soc., 78, 2771-2777.

Trenberth, K. E., 1991: Storm Tracks in the Southern Hemisphere. J. Atmos. Sci., 48, 2159-2178.

Trenberth, K. E., 1986: An Assessment of the Impact of Transient Eddies on the Zonal Flow during a Blocking Episode Using Localized Eliassen-Palm Flux Diagnostics. J. Atmos. Sci., 43, 2070-2087. 
Trivelpiece, W. Z., J. T. Hinke, A. K. Miller, C. S. Reiss, S. G. Trivelpiece, and G. M. Watters, 2011: Variability in krill biomass links harvesting and climate warming to penguin population changes in Antarctica. Proc. Natl. Acad. Sci., 108, 18, 7625-7628.

Turner, J., H. Lu, I. White, J. C. King, T. Phillips, J. S. Hosking, T. J. Bracegirdle, G. J. Marshall, R. Mulvaney, and P. Deb, 2016: Absence of $21^{\text {st }}$ century warming on Antarctic Peninsula consistent with natural variability. Nature, 535, 411-415.

Turner, J., T. Phillips, J. S. Hosking, G. J. Marshall, and A. Orr, 2013a: The Amundsen Sea low. Int. J. Climatol., doi:10.1002/joc.3558.

Turner, J., T. Maksym, T. Phillips, G. J. Marshall, and M. P. Meredith, 2013b: The impacts of changes in sea ice advance on the large winter warming on the western Antarctic Peninsula. Int. J. Climatol., 33, 852-861.

Turner, J., S. Colwell, G. Marshall, T. Lachlan-Cope, A. Carleton, P. Jones, V. Lagun, P. Reid, and S. Iagovkina, 2005: Antarctic climate change during the last 50 years. Int. J. Climatol., 25, 279-294.

Turner, J., 2004: Review: The El Niño-Southern Oscillation and Antarctica. Int. J. Climatol., 24, $1-31$.

Turner, J., S. R. Colwell, G. J. Marshall, T. A. Lachlan-Cope, A. M. Carleton, P. D. Jones, P. A. Reid, and S. Iagovkina, 2004: The SCAR READER project: Toward a high-quality database of mean Antarctic meteorological observations. J. Clim., 17, 2890-2898.

Uotila, P., T. Vihma, A. Pezza, I. Simmonds, K. Keay, and A. Lynch, 2011: Relationships between Antarctic cyclones and surface conditions as derived from high-resolution numerical weather prediction data. J. Geophys. Res., 116, doi:10.1029/2010JD015358.

Uotila, P., A. Lynch, A. Pezza, K. Keay, and J. Cassano, 2009: A comparison of low pressure system statistics derived from a high resolution NWP output and three reanalysis products over the Southern Ocean. J. Geophys. Res., 114, doi:10.1029/2008JD011583.

van den Broeke, M. R., and N. P. M. van Lipzig, 2003: Factors Controlling the Near-Surface Wind Field in Antarctica. Mon. Wea. Rev., 131, 733-743.

Vaughan, D. G., G. J. Marshall, W. M. Connolley, C. Parkinson, R. Mulvaney, D. A. Hodgson, J. C. King, C. J. Pudsey, and J. Turner, 2003: Recent Rapid Regional Climate Warming on the Antarctic Peninsula. Clim. Change, 60, 243-274.

Verbickas, S., 1998: Westerly wind bursts in the tropical Pacific. Weather, 53, 282-284.

Vincent, D. G., 1994: The South Pacific Convergence Zone (SPCZ): A Review. Mon. Wea. Rev., 122, 1949-1970. 
Vincent, E. M, M. Lengaigne, C. E. Menkes, N. C. Jourdain, P. Marchesiello, and G. Madec, 2011: Interannual variability of the South Pacific Convergence Zone and implications for tropical cyclone genesis. Clim. Dyn., 36, 1881-1896, doi:10.1007/ s0038200907163.

Walker, G. T., and E. W. Bliss, 1932: World weather V. Mem. Roy. Meteor. Soc., 4, 53-84.

Walker, G. T., and E. W. Bliss, 1937: World weather VI. Mem. Roy. Meteor. Soc., 4, 119-139.

Wallace, J.M., and D.S. Gutzler, 1981: Teleconnection in the geopotential height field during the Northern Hemisphere winter. Mon. Wea. Rev., 109, 784-812.

Walsh, K. J. E., I. Simmonds, and M. Collier, 2000: Sigma-coordinate calculation of topographically forced baroclinicity around Antarctica. Dyn. Atmos. Oceans, 33, doi:10.1016/S0377-0265(00)00054-3.

Widlansky, M., P. Webster, and C. Hoyos, 2011: On the location and orientation of the South Pacific Convergence Zone. Clim. Dyn., 36, doi: 10.1007/s00382-010-0871-6, 561-578.

Wingham, D. J., D. Wallis, and A. Shepherd, 2009: Spatial and temporal evolution of Pine Island Glacier thinning, 1995-2006. Geophys. Res. Lett., 36, doi:10.1029/2009GL039126.

World Meteorological Organization/United Nations Environment Programme (WMO/UNEP), Scientific Assessment of Ozone Depletion, 2014: Global Ozone Research and Monitoring Project Report No. 55, WMO, 2014.

World Meteorological Organization (WMO), 2011: Guide to Climatological Practices. WMONo. 100.

Xie, S. P., C. Deser, G. A. Vecchi, J. Ma, H. Y. Teng, and A. T. Wittenberg, 2010: Global warming pattern formation: Sea surface temperature and rainfall. J. Clim., 23, 966-986, doi:10.1175/2009JCLI3329.1.

Zebiak, S. E., 1993: Air-Sea Interaction in the Equatorial Atlantic Region. J. Clim., 6, 15671586.

Zhang W., J. Li, X. Zhao, 2010: Sea surface temperature cooling mode in the Pacific cold tongue. J. Geophys. Res., 115, doi:10.1029/2010JC006501.

Zhang, Y., J. M. Wallace, and D. S. Battisti, 1997: ENSO-like interdecadal variability: 1900-93. J. Clim., 10, 1004-1020. 